This report was prepared as an account of work sponsored by an agency of the United States Government. Nejther the United States Government nor any agency thereof, nor any of their employees, makes any warranty, express or implied, or assumes any legal liability or responstbility for the accuracy, completeness, or usefulness of any information, apparatus, product, or process disclosed, or represents that its use would not infringe privately owned rights. Reference herein to any specific commercial product, process, or service by trade name, trademark, manufacturer, or otherwise does not necessarily constitute or imply its endorsement, recommendation, or favoring by the United States Government or any agency thereof. The views and opinions of authors expressed herein do not necessarily state or reflect those of the United States Government or any agency thereof.

\title{
CONCEPT DESCRIPTION REPORT REFERENCE MODULAR HIGH TEMPERATURE GAS-COOLED REACTOR PLANT
}

\section{UTHORS/CONTRACTORS}

IECHTEL NATIONAL, INC. :OMBUSTION ENGINEERING, INC.

- $A$ A TECHNOLOGIES, INC. IAS-COOLED REACTOR ASSOCIATES IENERAL ELECTRIC CO.

ITONE \& WEBSTER ENGINEERING CORP.

ISSUED BY: BECHTEL NATIONAL, INC.

UNDER SUBCONTRACT TO GAS-COOLED REACTOR ASSOCIATES, FOR THE DEPARTMENT OF ENERGY CONTRACT DE-AC03-78SF02034 


\section{DISCLAIMER}

This report was prepared as an account of work sponsored by an agency of the United States Government. Neither the United States Government nor any agency Thereof, nor any of their employees, makes any warranty, express or implied, or assumes any legal liability or responsibility for the accuracy, completeness, or usefulness of any information, apparatus, product, or process disclosed, or represents that its use would not infringe privately owned rights. Reference herein to any specific commercial product, process, or service by trade name, trademark, manufacturer, or otherwise does not necessarily constitute or imply its endorsement, recommendation, or favoring by the United States Government or any agency thereof. The views and opinions of authors expressed herein do not necessarily state or reflect those of the United States Government or any agency thereof. 


\section{DISCLAIMER}

Portions of this document may be illegible in electronic image products. Images are produced from the best available original document. 


\title{
CONCEPT DESCRIPTION REPORT
}

\author{
MODULAR HTGR PLANT
}

Issued By:

Bechtel National, Inc.

50 Beale Street/P.O. Box 3965

San Francisco, CA 94119

October, 1986 


\section{PREFACE}

This report provides a sumary description of the Modular High Temperature Gas-Cooled Reactor (MHTGR) concept and interim results of assessments of costs, safety, constructibility, operability, maintainability, and availability. Conceptual design of this concept was initiated in October 1985 and is scheduled for completion in 1987. Participating industrial contractors are Bechtel National, Inc. (BNI), Stone \& Webster Engineering Corporation (SWEC), GA Technologies, Inc. (GA), General Electric $C_{0}$. (GE), and Combustion Engineering, Inc. (C-E). Utility requirements, design review, and $A E$ contract management are provided by Gas-Cooled Reactor Associates (GCRA). The work is funded by the United States Department of Energy (DOE). 
$$
\text { . }
$$ 
1 EXECUTIVE SUMMARY

$$
1-1
$$

1. 1 Program Objectives 1-1

1.2 Design Approach 1-3

1.3 Design Status $1-7$

1.4 Standard MHTGR Concept Description 1-9

1.4.1 Plant Description $1-9$

1.4.2 Reactor Safety $1-15$

$\begin{array}{ll}1.4 .3 & \text { Plant Economics } \\ & 1-16\end{array}$

2 OVERALL PLANT DESCRIPTION 2-1

2.1 Site Characteristics 2-1

2.2 Nuclear Island 2-1

2.3 Energy Conversion Area $2-13$

3 PLANT TECHNICAL DESCRIPTION 3-1

3.1 Reactor System 3-1

3.1.1 Reactor Core Subsystem 3-1

3.1.2 Neutron Control Subsystem 3-8

3.1.3 Reactor Internals 3-14

$\begin{array}{ll}3.2 \text { Vessel System 3-27 } & 3.45\end{array}$

3.3 Heat Transport System 3-33

3.3.1 Steam Generator 3-33

3.3.2 Main Circulator 3-42

3.4 Shutdown Cooling System 3-49

3.4.1 Shutdown Cooling Heat Exchanger (SCHE) 3-50

3.4.2 Shutdown Cooling Circulator 3-50

3.4.3 Shutdown Cooling Water 3-59

3.5 Reactor Cavity Cooling System 3-60

3.6 Reactor Service Systems 3-68

3.6.1 Helium Purification 3-68

3.6.2 Radioactive Waste Processing 3-70

3.6.3 Reactor Plant Cooling Water $3-72$

3.6.4 Reactor Service Equipment and Storage Wells 3-73

3.6.5 Helium Storage and Transfer 3-75 
CONTENTS (Cont'd)

3.6.6 Liquid Nitrogen $3-76$

3.6.7 Nuclear Island HVAC 3-76

$\begin{array}{ll}\text { 3.6.8 Other Reactor Service Systems 3-77 } & \text { 3-76 }\end{array}$

3.7 Fuel Handling, Storage, and Shipping System 3-78

3.7.1 Core Refueling 3-78

3.7.2 Site Fuel Handling 3-84

3.7.3 Spent Fuel cooling 3-89

3.8 Turbine Plant Systems 3-92

3.8.1 Turbine-Generator and Accessories 3-94

3.8.2 Feedwater and Condensate Systems 3-94

3.8.3 Main Steam and Turbine Bypass Systems 3-95

3.8.4 Startup and Shutdown System 3-95

3.8.5 Steam and Water Dump System 3-96

3.8.6 Turbine Plant Cooling Water System 3-97

3.8.7 Heat Rejection System 3-97

3.8.8 Other Turbine Plant Systems 3-98

3.9 Plant Electrical System 3-102.

3.9.1 Non-Class IE AC Distribution System 3-102

3.9.2 Non-Class IE DC Power System 3-105

3.9.3 Class 1E Uninterruptable Power Supply (UPS) System 3-105

3.9.4 Class IE DC Power System 3-105

3.9.5 Other Electrical Systems 3-105

3.10 Mechanical Services 3-107

3. 11 Plant Protection and Instrumentation System 3-109

3.11.1 Investment Protection Subsystem 3-109

3.11.2 Safety Protection Subsystem 3-111

3.11.3 Special Nuclear Area Instrumentation 3-112

3.11.4 Plant Protection and Instrumentation System Ha rdware 3-112

3.12 Plant Control, Data, and Instrumentation System 3-114

3.12.1 Plant Supervisory Control Subsystem 3-114

3.12.2 Reactor Module Control Subsystem 3-124

3.12.3 Balance of Plant Control System 3-130

3.12.4 Data Management Subsystem 3-132

3.12.5 Plant Operations Support Subsystem 3-134

3.13 Miscellaneous Control and Instrumentation Group 3-135

3. 14 Plant Building and St ructures 3-137

3.14.1 Reactor Building 3-137 
CONTENTS (Cont'd)

Section

3.14.2 Reactor Auxiliary Building 3-147

3.14.3 Reactor Service Building

$3-148$

3.14.4 Personnel Service Building

3.14.5 Radioactive Waste Management Building

3-151

3.14.6 Turbine Building

3.14.7 Operations Center

$3-151$

3-157

3.14.8 Other Buildings and Structures 3-164

4 COMMERCIAL PLANT SCHEDULE 4-1

4. 1 Schedule Development 4-1

4.2 Construction Sequence 4-5

4.2.1 Nuclear Is land 4-5

4.2.2 Energy Conversion Area 4-7

4.2.3 Miscellaneous Facilities 4-7

4.3 Construction Duration and Critical Path Analysis 4-8

4.3.1 Key Milestones 4-8

4.3.2 Critical Path Analysis - 4-8

4.4 Schedule Achievement 4-10

5 ECONOMIC ANALYSIS $5-1$

5. 1 Plant Capital Cost 5-1

5.1.1 Estimating Basis and Approach for Direct Cost 5-1

5.1.2 Estimating Basis and Approach for Indirect Cost 5-3

5.1.3 Total Capital Cost 5-9

5.2 Fuel Cycle Costs 5-17

5.2.1 Economic Assumptions $\quad 5-17$

5.2.2 Fuel Cycle cost Summary 5-21

5.3 Operations and Maintenance Cost Estimation 5-25

5.3.1 Overall Staffing Estimate 5-25

5.3.2 O\&M Cost Estimate 5-27

5.4 Busbar Generation costs 5-33

5.5 Comparison with Alternatives 5-37

6 PLANT MAINTAINABILITY AND AVAILABILITY ASSESSMENT

6.1 Plant Scheduled Outage Assessment 6-1

6.2 Plant Forced Outage Assessment 6-3 
CONTENTS (Cont'd)

Section

Page

7 CONSTRUCTIBILITY, FABRICABILITY, AND PREASSEMBLY ASSESSMENT

$7-1$

8 SAFETY APPROACH AND ASSESSMENT $\quad 8-1$

8. 1 Overall Approach to Safety and Licensing 8-1

8.1.1 Philosophy 8-1

8.1.2 Licensing Approach 8-3

8.2 Seismic Assessment 8-5.

8.3 Safety Assessment 8-8

8.3.1 Control Heat Generation Events 8-9

8.3.2 Remove Core Heat Events 8-10

8.3.3 Control Chemical Attack Events 8-13

8.3.4 Assesșment Summary 8-12

8.4 Probabalistic Risk Assessment 8-15

8.4.1 Quantification of Risk 8-18

8.4.2 Comparison with PAG Dose Limits 8-19

8.4.3 Comparison with Goals for the Operations of
Nuclear Power Plants

REFERENCE S 
1-1 Four-Module MHTGR Plant 1-11

1-2 Reactor Module 1-13

1-3 TRISO-Coated Fuel Particle Cross-Section 1-17

1-4 Fuel Components 1-19

2-1 Plot Plan 2-3

2-2 Safety of Modular HTGR with Annular Prismatic Core 2-7

2-3 Modular HTGR with Annular Prismatic Core 2-y

2-4 Simplified Flow Diagram -- Plant Power Generation 2-12

2-5 Passive Air-Cooled RCCS 2-14

3-1 Reactor System -- Elevation View 3-2

3-2 Reactor Plan View 3-3

3-3 Standard Fuel Element 3-4

3-4 Outer Neutron Control Assembly 3-10

3-5. Inner Neutron Control Assembly 3-11

3-6 Control Assemblies Installed in Vessel 3-12

3-7 Ex-vessel Detectors and Locations 3-13

3-8 Reactor Core and Internals Arrangement -- 3-15

3-9 Reactor Core and Internals Arrangement -- 3-17

3-10 Core Lateral Restraint St ructure -- Elevation View 3-18

3-11 Core Lateral Restraint Structure -- Plan View 3-19

3-12 Core Support Floor Grid 3-21

3-13 Upper Plenum Thermal Protection Structure --

3-14 Cross Duct to Steam Generator 3-25

3-15 Reactor Vessel Arrangement 3-29

3-16 Steam Generator Vessel Arrangement 3-31

3-17 Crossduct Arrangement 3-32

3-18 Heat Transport System Arrangement 3-34

3-19 Steam Generator Configuration 3-35

3-20 Steam Generator 3-37 


\section{ILLUSTRATIONS (Cont'd)}

\begin{tabular}{|c|c|c|}
\hline Figure & & Page \\
\hline $3-21$ & Main Circulator Configuration & $3-43$ \\
\hline $3-22$ & Main Circulator & $3-45$ \\
\hline $3-23$ & Shutdown Cooling System Configuration & $3-51$ \\
\hline $3-24$ & Shutdown Cooling Heat Exchanger Configuration & $3-52$ \\
\hline $3-25$ & Shutdown Circulator and Heat Exchanger & $3-53$ \\
\hline $3-26$ & Shutdown Cooling Circulator Configuration & $3-57$ \\
\hline $3-27$ & Passive Decay Heat Removal & $3-61$ \\
\hline $3-28$ & Air RCCS Ductwork Isometric & $3-62$ \\
\hline $3-29$ & $\begin{array}{l}\text { Air Cooling Panel Conceptual Design -- } \\
\text { Plan and Sections }\end{array}$ & $3-64$ \\
\hline $3-30$ & Air Cooling Panel Conceptual Design -- Details & $3-65$ \\
\hline $3-31$ & Helium Purification System Flow Schematic & $3-69$ \\
\hline $3-32$ & Location of Fuel Handling Equipment & $3-79$ \\
\hline $3-33$ & In-vessel Fuel Handling Operations & $3-80$ \\
\hline $3-34$ & Spent Fuel Storage Facility & $3-81$ \\
\hline $3-35$ & Fuel Element Construction for Handling & $3-82$ \\
\hline $3-36$ & $\begin{array}{l}\text { Arrangement of Refueling Penetrations and } \\
\text { Equipment }\end{array}$ & $3-83$ \\
\hline $3-37$ & Site Fuel Handling Operations Block Diagram & $3-87$ \\
\hline $3-38$ & Spent Fuel Cooling Flow Diagram & $3-91$ \\
\hline $3-39$ & Turbine Cycle Heat Balance Diagram & $3-93$ \\
\hline $3-40$ & Overall Plant Cooling Water Scheme & $3-99$ \\
\hline $3-41$ & Main Station One Line & $3-103$ \\
\hline $3-42$ & Protection System Data Buses & $3-113$ \\
\hline $3-43$ & PCDIS Integrated Control Overview & $3-115$ \\
\hline $3-44$ & $\begin{array}{l}\text { MHTGR Plant Process Control and Interface } \\
\text { Configuration }\end{array}$ & $3-116$ \\
\hline $3-45$ & Single Control Room Arrangement & $3-119$ \\
\hline $3-46$ & Function Configuration of PSCS Computers & $3-121$ \\
\hline $3-47$ & Functional Configuration of Operator Workstation & $3-123$ \\
\hline $3-48$ & Reactor Module Control Functions & $3-127$ \\
\hline $3-49$ & $\begin{array}{l}\text { Conceptual Reactor Module Control Subsystem } \\
\text { Architecture }\end{array}$ & $3-129$ \\
\hline
\end{tabular}




\section{ILLUSTRATIONS (Cont'd)}

Figure

Page

3-50 Nuclear Island Key Plan 3-138

3-51 Isometric View through Reactor Building 3-139

3-52 Nuclear Is land Arrangement Plan and Isometric 3-140

3-53 Nuclear Island Arrangement Plan and Isometric 3-141

3-54 Nuclear Is land Arrangement Plan and Isometric 3-142

3-55 Nuclear Island Arrangement Plan and Isometric 3-143

3-56 Nuclear Is land Arrangement Plan and Isometric 3-144

3-57 Nuclear Island Arrangement Plan and Isometric 3-145

3-58 General Arrangement, Radioactive Waste Management Bldg. -- Plan

3-153

3-59 General Arrangement, Radioactive Waste Management BIdg. -- Section

3-155

3-60 General Arrangement, Turbine Building -- Section 3-1by

3-61 General Arrangement, Turbine Building -- Section 3-161

3-62 General Arrangement, Operations Center -- Plan 3-165

3-63 General Arrangement, Operations Center -- Plan 3-167

4-1 Summary Project Schedule 4-3

5-1 Cash Flow Curve 5-10

5-2 Uranium Price Projections 5-19

5-3 Enrichment Price Projections 5-20

5-4 Summary Methodology Maintenance and Surveillance Staffing Matrix

$5-27$

8-1 Standard MHTGR Design and Licensing Approach 8-4

8-2 Core Power During Control Rod Withdrawal Without HTS and SCS cooling

8-3 Maximum and Average Core Temperatures During a Depressurized Conduction Cooldown with Primary Coolant Leak

8-4 Cumulative Frequency for Whole Body Dose From Al1 Release Categories

8-5 Cumulative Frequency for Thyroid Dose From A1l Release Categories 
$$
\text { . }
$$ 
TABLES

Table

1-1 Summary of Utility/User Requirements 1-4

1-2 Summary of Top-Level Regulatory Criteria 1-5

2-1 Reactor Module Design Parameters 2-11

2-2 Overall Plant Heat Balance 2-15

3-1 Reactor Vessel and Steam Generator Vessel Data 3-28

3-2 Steam Generator Data 3-39

3-3 Major Features of Main Circulator 3-48

3-4 Shutdown Cooling System Data 3-55

3-5 Major Features of Shutdown Cooling Circulator 3-58

3-6 Summary of RCCS Performance 3-67

3-7 Plant Protection and Instrumentation System 3-110

5-1 EEDB Code of Accounts 5-2

5-2 Discipline Craft/Crew Wage Rates 5-4

5-3 Cost of Major Materials -- Bulks 5-5

5-4 Unit Man-Hour Installation Rates -- Bulks 5-6

5-5 Indirect Rates. 5-8

5-6 Financial Parameters 5-12

5-7 Plant Total Capital Cost Estimate 5-13

5-8 MHTGR Plant Cost Estimate j-14

5-9 Reactor Plant Equipment Price Estimates 5-16

5-10 Fuel Cycle Cost Economic Assumptions 5-22

5-11 MHTGR Fresh Fuel Fabrication Unit Prices 5-23

5-12 30-Year Levelized Fuel Cycle Costs 5-24

5-13 Estimated On-Site Staffing 5-26

5-14 Estimated Total Annual Non-Fuel Operation and Maintenance Costs 5-29

5-15 Fixed Charge Rate Parameters 5-34

5-16 Levelized Busbar Generation Cost 5-35

5-17 $560 \mathrm{MW}($ e) Coal Plant 5-38

5-18 MHTGR Plant vs. Coal Plant 5-39

7-1 Reference Manufacturing Approach 7-3

7-2 Reference Construction Approach 7-5 
$$
\text { . }
$$ 


\section{ACRONYMS AND ABBREVIATIONS}

administrative and general

American Concrete Institute

AFUDC

allowance for funds used during construction auxiliary service cask anticipated transient without scram Bechtel National, Inc. balance-of-plant

$E A B$

ECA

EEDB

EES

EFPY

EIA data management system

EOF Department of Energy

EOL

EPA exclusion area boundary

FHEP energy conversion area

FOAK

Energy Economic Data Base economizer-evaporator-superheater effective full power years Energy Information Administration emergency operations facility end of life Environmental Protection Agency fuel handling equipment positioner First-of-a-Kind 
ACRONYMS AND ABBREVIATIONS (Cont'd)

$\begin{array}{ll}\text { FRS } & \text { floor response spectra } \\ \text { FSIF } & \text { fuel sealing and inspection facility } \\ \text { FSP } & \text { fuel storage pool } \\ \text { FSSE } & \text { fuel shipping subsystem equipment } \\ \text { FSV } & \text { Fort St. Vrain } \\ \text { FTC } & \text { fuel transfer cask } \\ \text { FY } & \text { fiscal year } \\ \text { GA } & \text { GA Technologies, Inc. } \\ \text { GCRA } & \text { Gas-Cooled Reactor Associates } \\ \text { GCSS } & \text { Graphite Core Support Structure } \\ \text { GE } & \text { General Electric Company } \\ \text { HEPA } & \text { high-efficiency particulate air } \\ \text { HP } & \text { high pressure } \\ \text { HPS } & \text { helium purification system } \\ \text { HSF } & \text { hot service facility } \\ \text { HTGR } & \text { high-temperature gas-cooled reactor } \\ \text { HTS } & \text { heat transport system } \\ \text { HVAC } & \text { heating, ventilating, and air conditioning } \\ \text { IA } & \text { integrated approach } \\ \text { I\&C } & \text { instrumentation and controls } \\ \text { ID } & \text { inside diameter } \\ \text { IEEE } & \text { Institute of Electrical and Electronic Engineers } \\ \text { IFMU } & \text { in-vessel flux mapping units } \\ \text { INCA } & \text { inner neutron control assemblies } \\ \text { IP } & \text { intermediate pressure } \\ \text { ISI } & \text { in-service inspection } \\ \text { LAL } & \text { load-apportioning logic } \\ \text { LCO } & \text { limiting conditions for operation } \\ \text { LEU } & \text { low-enriched uranium } \\ \text { LEU/Th } & \text { low-enriched uranium/thorium } \\ \text { low pressure } \\ \text { low-temperature absorbers }\end{array}$




\section{ACRONYMS AND ABBREVIATIONS (Cont'd)}

\begin{tabular}{|c|c|}
\hline MCR & main control room \\
\hline MCS & main circulator subsystem \\
\hline MCSS & metallic core support structure \\
\hline MHTGR & Modular High-Temperature Gas-Cooled Reactor \\
\hline NCSS & Neutron Control Subsystem \\
\hline NDTT & nil-ductility transition temperature \\
\hline NECDB & nuclear energy cost data base \\
\hline NI & nuclear island \\
\hline NICWB & nuclear island cooling water building \\
\hline NOAK & Nth-of $-a-K$ ind \\
\hline NRC & Nuclear Regulatory Commission \\
\hline O\&M & operating and maintenance \\
\hline$O B E$ & operating basis earthquake \\
\hline OD & outside diameter \\
\hline ONCA & outer neutron control assemblies \\
\hline OPDS & Overall Plant Design Specification \\
\hline ORNL & Oak Ridge National Laboratory \\
\hline PAG & Protective Action Guideline \\
\hline PCDIS & plant control, data, and instrumentation system \\
\hline PID & proportional-integral-derivative (control function) \\
\hline POS & plant operations support (system) \\
\hline PPIS & plant protection and instrumentation system \\
\hline PRA & probabalistic risk assessment \\
\hline PSB & personnel service building \\
\hline PSCS & plant supervisory control system \\
\hline PSID & preliminary safety information document \\
\hline PSR & Permanent side reflector \\
\hline RAB & reactor auxiliary building \\
\hline$R B$ & reactor building \\
\hline $\operatorname{RCCS}$ & reactor cavity cooling system \\
\hline RPCWS & reactor plant cooling water subsystem \\
\hline RS & reactor system \\
\hline RSB & reactor service building \\
\hline RSS & reserve shutdown system \\
\hline RWMB & radioactive waste management building \\
\hline
\end{tabular}




\section{ACRONYMS AND ABBREVIATIONS (Cont'd)}

SBS

$\operatorname{SCC}$

SCCS

SCHE

SCHES

$\operatorname{SCS}$

SCWS

SDA

SDD

SFCS

SFHS

SG

SGS

SLSV

SMS

SPDS

SPL

SRDC

SSC

$\operatorname{SSDD}$

SSE

SU/SD

SV

SWE C

TB

TEFRA.

TFSF

TG

$\operatorname{Th} \mathrm{O}_{2}$

UPC

UPTPS

UPS

VS side-by-side (configuration)

shutdown cooling circulator

shutdown cooling circulator subsystem

shutdown cooling heat exchanger

shutdown cooling heat exchanger subsystem

shutdown cooling system

shutdown cooling water system

startup detector assemblies

system design description

spent fuel cooling subsystem

site fuel handling subsystem

steam generator

steam generator subsystem

shutdown loop shutoff valve

seismic monitoring system

safety parameter display system

sound pressure level

safety-related design condition

structures, systems, and components

Subsystem design description

safe shutdown earthquake

startup and shutdown system

steel vessel

Stone \& Webster Engineering Corporation

turbine building

Tax Equity and Fiscal Responsibility Act

temporary fuel storage facility

turbine generator

thorium oxide

Utility Power Corporation

Upper plenum thermal protection structure

uninterruptable power supply

vessel system (reactor and steam generator) 
SECTION 1

\section{EXECUTIVE SUMMARY}

\subsection{PROGRAM OBJECTIVE}

The objective of the High Temperature Gas-Cooled Reactor (HTGR) program is the development of a safe, economic nuclear power option for the nation's electrical generation needs by the turn of the century. The reference concept (Reference 1-1) selected to meet this objective is a modular HTGR (MHTGR) plant composed of four 350 MWt prismatic core reactor modules, coupled to two turbine generator sets producing a net electrical output of $538 \mathrm{MW}(\mathrm{e})$.

The achievement of this "objective is envisioned to include four major elements :

1. Development of a reference plant design and certification of this design by the Nuclear Regulatory Commission.

2. Completion of a technology program as necessary to support the reference plant design.

3. Construction and operation of a demonstration plant which verifies the key performance, operations, maintenance, safety and cost aspects of a single module.

4. Construction and successful one-step licensing of a first multi-module commercial plant.

This report provides a summary of the progress to date in accomplishing the first element above, namely a description of the Reference MHTGR design and a 
summary of assessments completed in FY 1986 in the areas of safety, constructability, and cost of the current design. The reference design described in this report is extracted from information contained in controlled design documentation, i.e., Overall Plant Design Specifications (OPDS), Reference 1-2, Utility/User Requirements, Reference 1-3, and System Design Descriptions (SDDs), and is consistent with the Preliminary Safety Information Document (PSID, Reference 1-4) submitted to the NRC. 


\subsection{DESIGN APPROACH}

MHTGR Plant design and development are directed towards producing safe, economic power. The four goals identified to guide work toward this objective are:

Goal 1 - Maintain Plant Operation

Goal 2 - Maintain Plant Protection

Goal 3 - Maintain Control of Radionuclide Release

Goal 4 - Maintain Emergency Preparedness

The plant configuration and features are established within the framework of these goals in accordance with Utility/User Requirements and the Top-Level Regulatory Criteria.

The Utility/User Requirements are intended to provide a basis for HTGR development responsive to the needs of the electric generation market as perceived by the end user. Table 1-I provides a sumary of the key Utility/ User Requirements; the complete listing of requirements may be found in Reference 1-3.

The Top-Level Regulatory Criteria for the MHTGR are current regulatory requirements and policy statements which are: (1) direct statements of acceptable health and safety consequences or risks to individuals or the public; (2) independent of reactor type and site; and (3) are quantifiable. Table 1-2 provides a sumary of the Top-Level Regulatory Criteria selected for the MHTGR; the complete listing of requirements may be found in Reference 1-5.

The technical management methodology used to direct the development of the MHTGR design is called the Integrated Approach (Reference 1-6). It is the systematic process of developing the functions, requirements, and design selections in accordance with the Top-Level Regulatory Criteria and the 
Table 1-1

SUMMARY OF UTILITY/USER REQUIREMENTS

Requirement Type

Licensing Objective

Safety

Investment Protection

Availability

Performance

Site Parameters

Fue1 Cycle

Economics
Requirement

NRC Certification of Standardized NI

No sheltering or evacuation of public required

Plant personnel exposures less than 100 man-rem per year

Exceedance of safety-related design conditions less than $10^{-5}$ per reactor year

Equivalent availability greater than 80 percent

Scheduled outages less than ten percent

Long outages (greater than six months) less than one percent

Nominal output of 550 MWe

Plant service life of 40 years

Envelope 85 percent of prospective sites

Exclusion Area boundary of $425 \mathrm{~m}$

Seismic ground acceleration of $.3 \mathrm{~g} \mathrm{SSE} / .15 \mathrm{~g} O B E$

Less than 20 percent enrichnent

Once-through throwaway fuel management

Levelized busbar cost ten percent better than coal alternative

Installed capital cost less than $\$ 2,000 / \mathrm{KW}$ (1986 dollars) 
Table 1-2

SUMMARY OF TOP-LEVEL REGULATORY CRITERIA

Criteria Type

Public Risk

Dose Limits, Normal Operation

Dose Limits for Anticipated

Operational Occurrences

Dose Limits for Accidents

Dose Limits Triggering off-site Sheltering or Evacuation

\section{Criteria}

Risk of prompt fatality less than one-tenth of one percent of the sum of prompt fatality risks resulting from other causes

Risk of cancer fatalities less than onetenth of one percent of the sum of cancer fatality risks resulting from other causes

10 CFR 20 Limits

- less than 0.5 rem whole body/year

- less than 0.002 rem in any one hour

- less than 0.1 rem in any seven consecutive days.

10 CFR 50 Appendix I Limits

- dose from liquid pathway less than 0.003 rem whole body or 0.010 rem any organ.

- dose from gaseous pathway less than 0.005 rem whole body or 0.015 rem any organ.

- dose from particulates less than 0.015 rem any organ.

40 CFR 190 Limits

- Whole body annual dose from entire fuel cycle less than 0.025 rem whole body, less than 0.075 rem thy roid, or

- less than 0.025 rem any organ.

10 CFR 50 Appendix I doses on an expected value basis

10 CFR 100 Guidelines

- less than 25 rem whole body

- less than 300 rem thy roid

EPA 520 Guidelines

- less than 1 rem whole body

- less than 5 rem thy roid 
Utility/User Requirements towards the objective of safe, economic power.

An essential feature of the Integrated Approach is functional analysis (Reference 1-7), which is a process of ordering hierarchical plant functions. The evolving design is guided with other analytical methodologies which include probabilistic risk assessments, reliability evaluations, and economic comparisons. The Reference MHTGR Plant design which resulted from this approach is described in the following sections. 


\subsection{DESIGN STATUS}

The particular design features of the MHTGR have been arrived at after evaluating alternative concepts and conducting a series of trade studies (Reference 1-8) beginning in early 1984. Major features studied over this period have been:

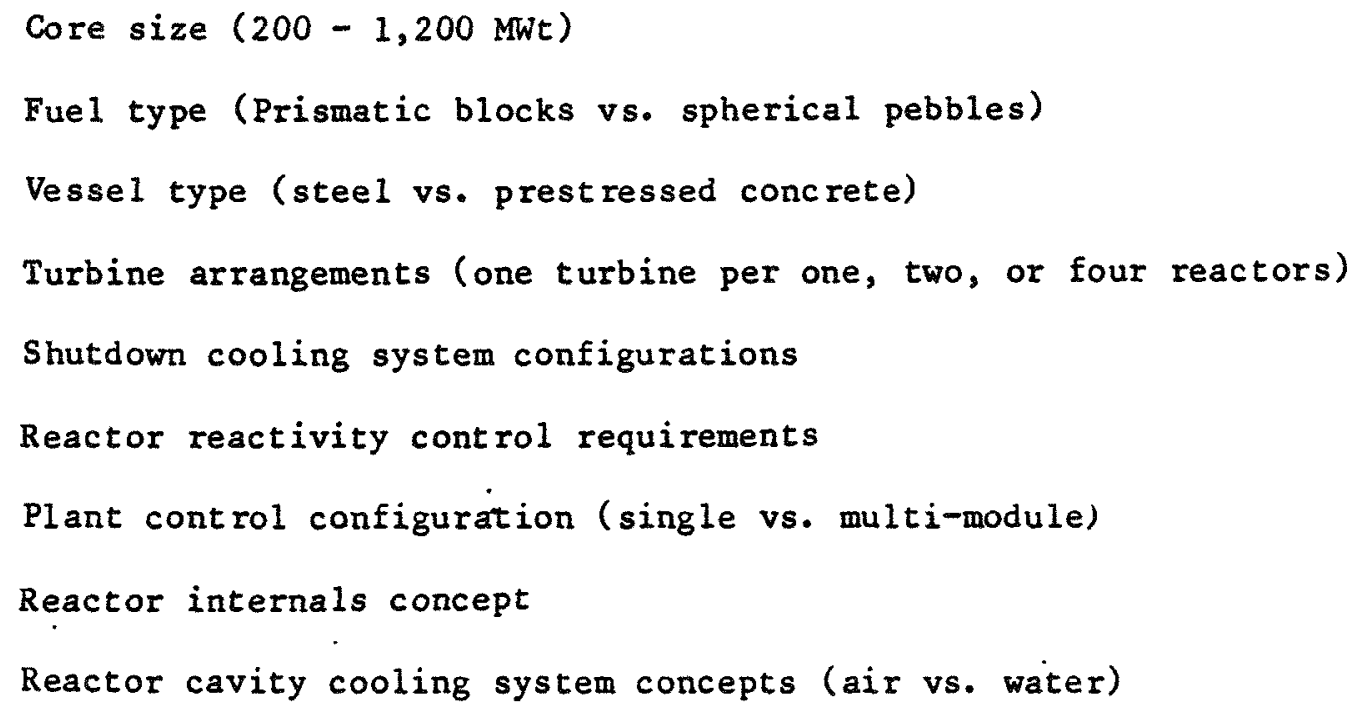

In August 1985, after completing the majority of the above major feature trade studies, the concept described herein was selected as the reference concept for further development in FY 1986. During FY 1986, the conceptual design has advanced and been documented in a series of System Design Descriptions (SDDs), Subsystem Design Descriptions (SSDDs) and Buildings and Structures Design Descriptions (BSDDs). The plant has been partitioned into 77 process systems and 16 buildings. Conceptual design documentation has been initiated for eighty percent of the systems and fifty percent of the buildings. The remainder are conventional systems or structures which may be adequately characterized in technical and economic terms from comercial experience.

A major objective of the FY 1986 program was the preparation of a Preliminary Safety Information Document (PSID) for submittal to the Nuclear Regulatory Commission (NRC). It is planned that the NRC will review the PSID in FY 1987 
and then issue a statement as to the licensability of the Reference MHTGR Plant.

At this point, conceptual design work is about one-half done, with roughly ten percent of reactor engineering completed and five percent of the balance of the plant design work finished. Key work remaining in the conceptual design phase includes some optimization of power conversion parameters, development of process and instrumentation diagrams to support hardware selection and building layout in ancillary areas, completion of assessments (including a detailed cost estimate) to verify that user requirements are satisfied, and completion of the NRC review of the PSID. Completion of conceptual design is tentatively scheduled for October, 1987. No technical feasibility issues have been identified that would have a major effect on the configuration or systems in the Reference MHTGR. 


\subsection{STANDARD MHTGR CONCEPT DESCRIPTION}

\subsubsection{Plant Description}

Four reactor modules and two turbine-generator sets are used in this design to achieve the $538 \mathrm{MW}(e)$ plant rating. The overall plant arrangement is illustrated in Figure 1-1. Each reactor module is housed in a vertical cylindrical concrete enclosure that is fully embedded in the earth. The Nuclear Island (NI) portion of the plant, consisting of four reactor enclosures (silos) and adjacent structures that house fuel handling, helium processing, and other essential reactor service systems, is kept to a minimum size and complexity. All four reactors and the turbine plant are operated from a common control room.

Each $350 \mathrm{MW}(t)$ reactor module shown in Figure 1-2 consists of two vertical steel vessels -- a reactor vessel and a steam generator vessel -- in a sideby-side configuration and connected by a short coaxial crossduct. The core, reflector, core support structure, and core restraint devices are installed in the reactor vessel. The reactor is graphite-moderated, helium-cooled, and uses prismatic fuel elements in the form of hexagonal blocks. The active core occupies an annular region surrounded by inner and outer graphite reflector elements. Gravity-assisted control rod mechanisms operate control rods in the inner and outer reflector elements. A reserve shutdown system also operates in the innermost region of the active core.

A vertical helical-coil steam generator is located in the steam generator vessel. The main helium circulator is mounted vertically on top of the same vessel. The steam generator vessel is connected to the reactor vessel below the core by a coaxial crossduct.

A shutdown cooling system (SCS) heat exchanger and circulator are located at the bottom of the reactor vessel. In the event that main loop cooling is lost, the SCS provides cooling to ensure investment protection of primary system components and to facilitate maintenance of the steam generator and main circulator. 



\section{FOUR-MODULE MHTGR POWER PLANT}

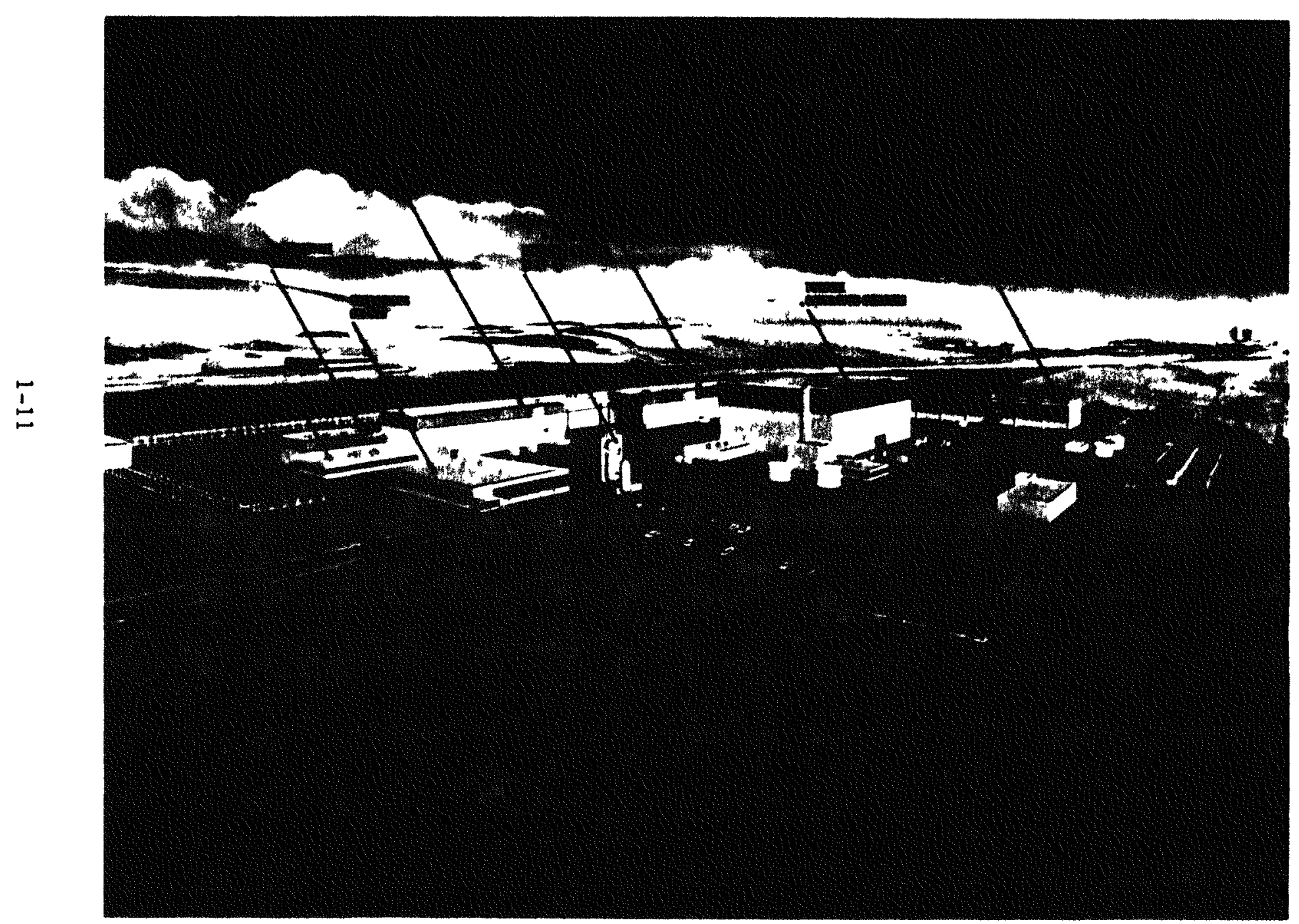

Nigure 1-1 
REACTOR MODULE

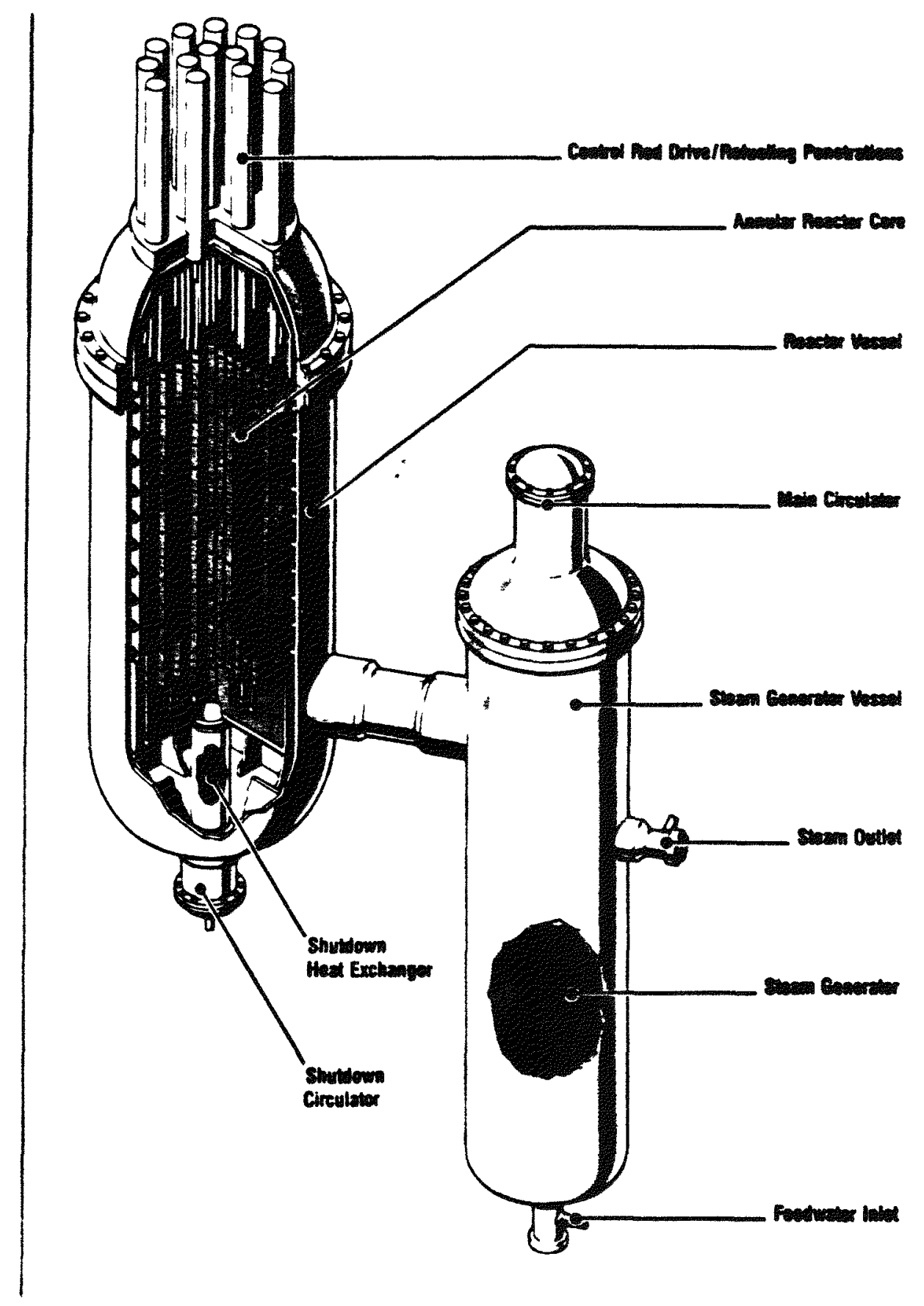

Figure 1-2 


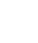




\subsubsection{Reactor Safety}

A potential source of severe accidents in reactor plants is the failure to remove decay heat. Demonstrating that decay heat can be rejected with the reliability demanded by the $\mathrm{NRC}$ has proven to be $a$ major expense to the industry. A significant feature of the Reference MHTGR design is its capability for passively rejecting decay heat from the reactor. In the unlikely event that both the normal and shutdown cooling systems are unavailable, decay heat is rejected by radiation, conduction, and natural convection through the reactor vessel wall to the reactor cavity. This heat is then removed from the reactor cavity by the natural circulation of outside air through enclosed panels on the cavity walls. The fuel temperatures that occur during an extended heatup and cooldown in the passive mode are below the temperatures that would cause significant fuel damage and release of fission products to the primary system.

Operator error is another potential source of severe accidents. A characteristic of the MHTGR Plant is its benign response, which combined with passive decay heat rejection, simplifies operator response and provides for long time intervals for deliberate actions before equipment is damaged. These attributes stem from the following inherent features:

- HELIUM COOLANT -- The use of an inert, single phase coolant eliminates the possibility of a loss-of-coolant event. In contrast to water reactors, pressure measurements are certain, pump cavitation cannot occur and no chemical reaction between the coolant, cladding or fuel is possible.

- GRAPHITE CORE - The high heat capacity and low power density of the core result in a very slow and predictable temperature transients. In addition, the strength of graphite increases with temperature up to levels well above those associated with licensing basis events. 
- CERAMIC FUEL PARTICLES - The primary fission product barrier in the MHTGR is the three ceramic coatings surrounding the fuel kernels. See Figures $1-3$ and 1-4. Test's have shown that coating integrity is sustained to fuel temperatures in excess of $1,760^{\circ} \mathrm{C}\left(3,200^{\circ} \mathrm{F}\right)$.

The retention of fission products within fuel particle coatings over the spectrum of licensing basis events, which include events that expose the particles to extreme thermal and chemical (air or water) environments, is the approach taken to design for reactor safety. The design assures fission product retention by passive means and without operator action. Calculated radiation releases at the plant boundary for licensing basis events are less than the EPA Protective Action Guidelines for which public sheltering is recommended. Accordingly, there is no technical reason to involve the public in emergency planning. MHTGR safety is addressed more completely in Section 8 .

\subsubsection{Plant Economics}

The attributes described in the preceding sections permit simplification and reduced risk of cost overruns. As noted in Section 1.1, an integral part of the deployment plan for the MHTGR is the consolidation of the User/Vendor/ Regulatory infrastructure through a demonstration plant. Economic benefits and stabilization are projected as a result of:

- Design certification of a Standard Nuclear Island via a demonstration plant

- Separation of the Standard Nuclear Island from the Energy Conversion Area to permit maximum use of conventional construction practices and standards 


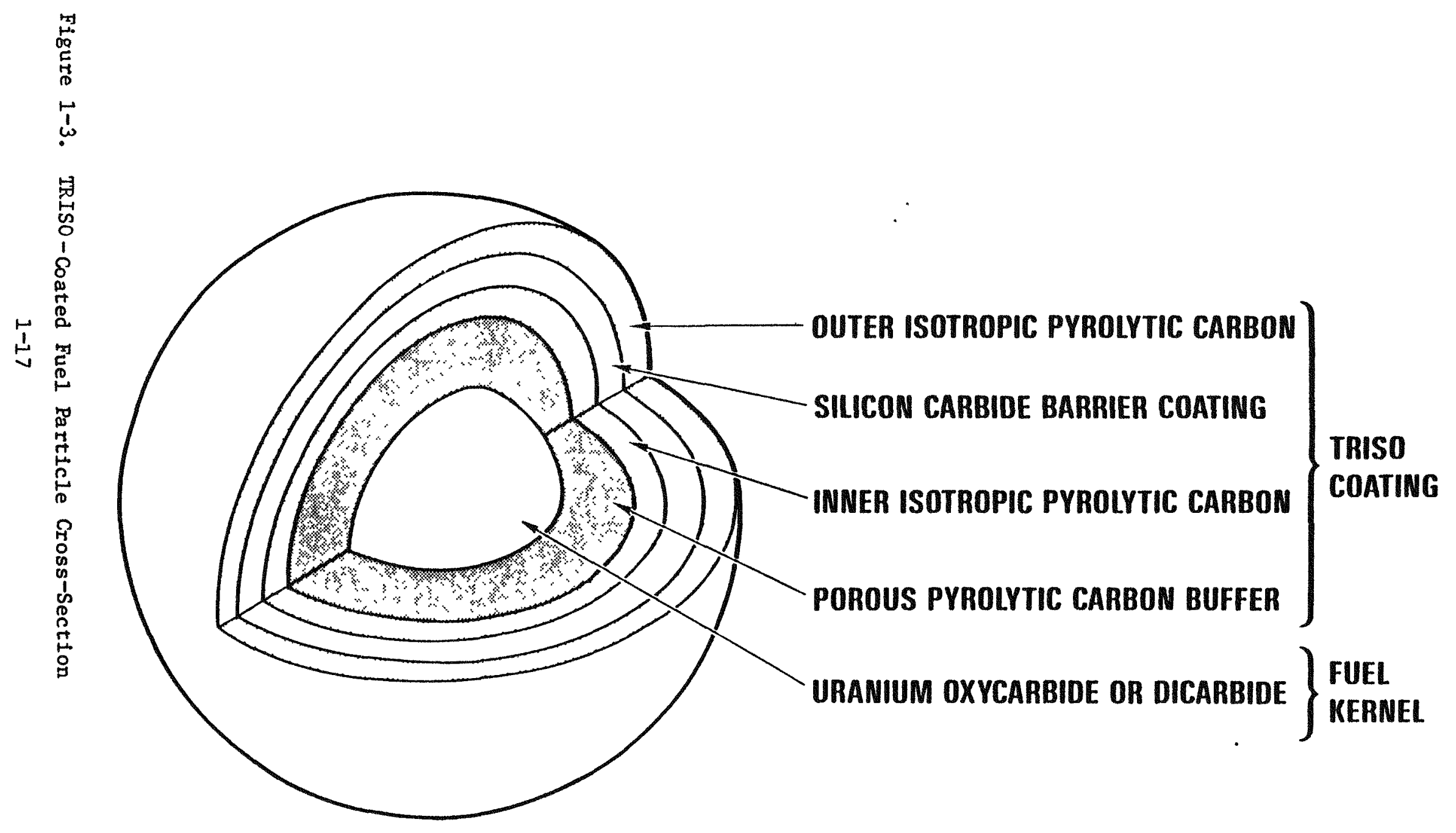



FUEL COMPONENTS

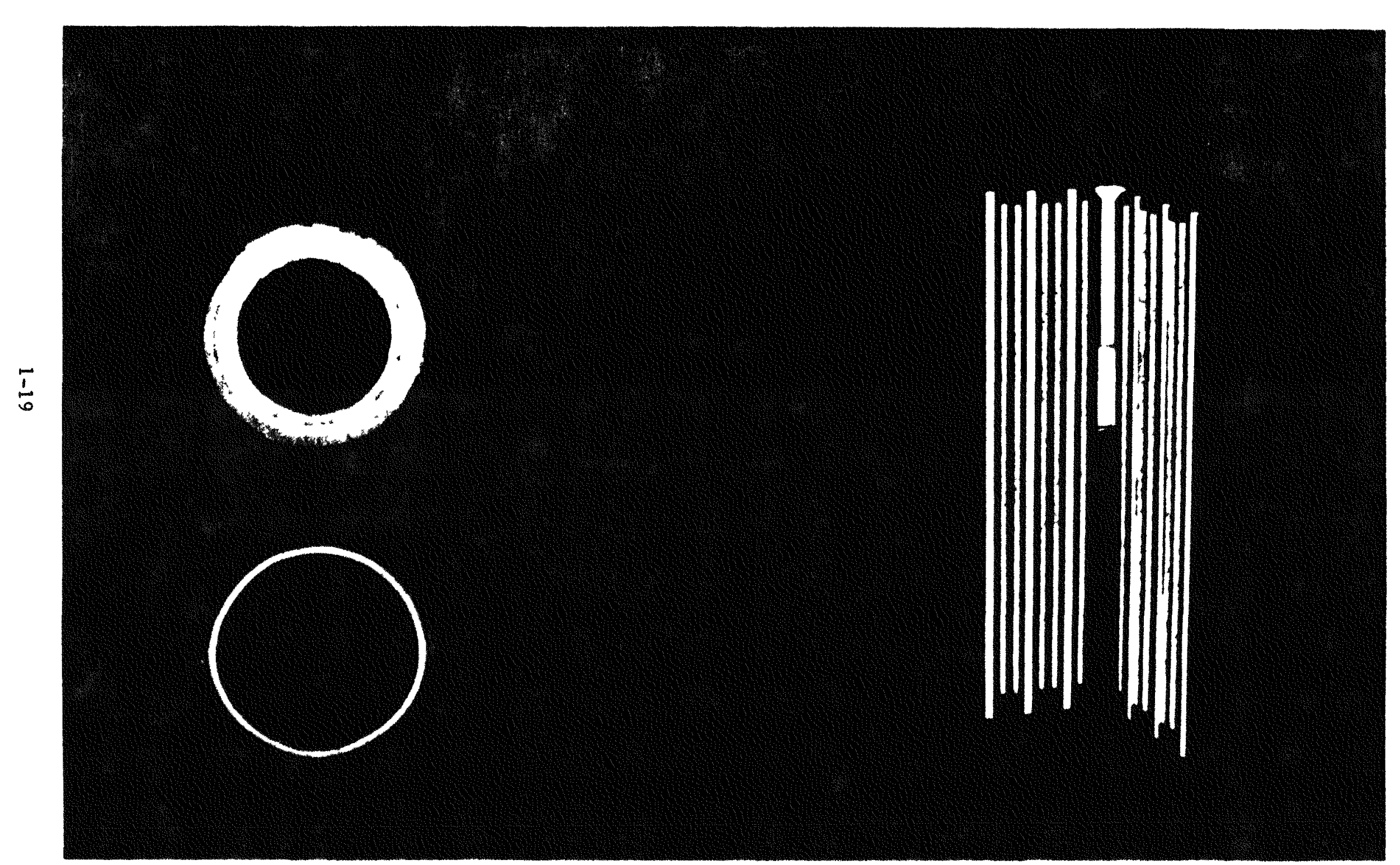


. 
- Minimized field labor and shortened schedules as a result of factory fabrication of process and structural modules

- The flexibility of sequential capacity addition in building blocks of two reactors and one turbine

The overall project schedule, from order of the Nuclear Island to commercial operation, is 68 months for the Reference Plant. As described in Section 4, simplification due to passive design features and modular construction contribute to a site construction and startup duration estimated at 36 months.

A capital cost estimate for the Reference MHTGR Plant has been prepared with detail appropriate to the degree of conceptual design completion. The estimated cost for a station having a net output of $538 \mathrm{MW}(\mathrm{e})$ is $\$ 933$ million (1986 dollars) exclusive of allowance for funds used during construction (AFUDC). Including AFUDC, the total capital requirement is $\$ 1,020$ million, which is equal to $\$ 1,896 / \mathrm{kW}(\mathrm{e})$. The high thermal efficiency and relatively low fuel cost of the MHTGR contribute to achieving a generating cost of $45 \mathrm{mills} / \mathrm{kW}(\mathrm{e})$. These figures for cost per $\mathrm{kW}(\mathrm{e})$ and product cost fall well within the established Utility/User Requirements (Table 1-1). Plant economics are discussed more thoroughly in section 5.

In summary, the modular HTGR concept is a unique approach to meeting the overall objective of safe, economic power. The safety objective is met by relying on passive safety systems such that the radiological consequences of all design and licensing basis events are within the EPA's Protective Action Guideline limits for public evacuation and sheltering without reliance on operator action or ac-powered systems. The economic objective is met principally through the use of modular design concepts, simple passive safety systems in lieu of complex active ones, and separation of the Nuclear Island from the Energy Conversion Area. 
. SECTION 2

OVERALL PLANT DESCRIPTION

\section{I SITE CHARACTERISTICS}

Detailed site parameters for the MHTGR Plant are presented in the Utility/User Requirements (Reference 1-3). The site parameters chosen for the Reference MHTGR plant envelope approximately 85 percent of potential sites in the United states. The plant is designed for a site adjacent to a source of cooling water such as a river or lake with an assumed elevation range of $30.5 \mathrm{~m}$ (100 $\mathrm{ft})$ to $1,829 \mathrm{~m}(6,000 \mathrm{ft})$ above mean sea level. Based upon an assumed exclusion area boundary (EAB) of 425 meters, a minimum of 66 hectares (163 acres) is required for the site.

The reference MHTGR plant is separated into two major areas: a Nuclear Island (NI) containing the four reactor modules, and the Energy Conversion Area (ECA) containing the two turbine generators. All safety-related structures, systems, and components are contained within the standard NI permitting procurement and construction of the ECA to conventional standards.

\subsection{NUCLEAR ISLAND}

The plant arrangement as shown in Figure 2-1 consists of four reactor modules with common support facilities. The four modules are cross-headered, to feed two turbine-generators operating in parallel, to produce a combined net output of $538 \mathrm{MW}(e)$. All four modules and the balance-of-plant systems are controlled from a single non-safety related control room. Systems containing radionuclides and safety-related systems are minimized and contained within a well-defined Nuclear Island (NI) which is separated physically and functionally from the remainder of the facility. 


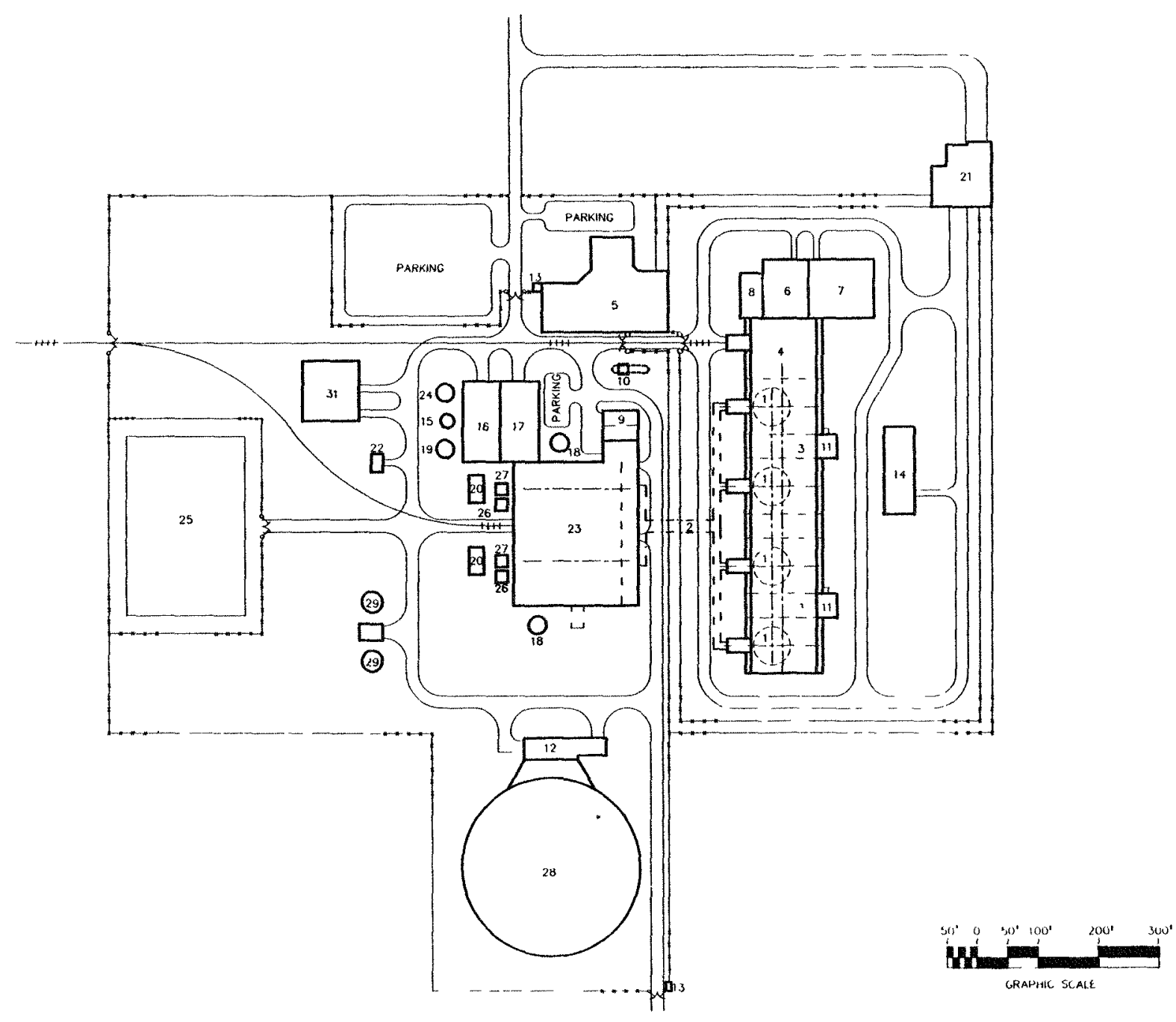

\section{(4)}

LLGEND

MAN STEAM Q FEDWAIER PIPING

REACTOR AUXILARY GULLONG

DeERATIONS CENIER

RACES BUILD DING

SIL MANAGEMENT BULLDING

WUCLEA ISLANO COCLNNG WAIER BUULDING

FUEL CUL STORAGE TANK FUMP HOUSE

HELUM STORAGE BUH.LING

MAKEUP WATER TREATMENT \& AUXILARY BOHLER BULLOING

MANTENANCE BURDANG

LONDENSATE SURCE TANK
DEMINERAHZED WATER STORAGE YANK

UNIT TRANSF ORMER

MII WAREHOUSE

HYDROGEN STORAGE ARE

TURBWE BUILDING

FLLTRED WATER STOOAGC

SWTCHYARD

RANSFORMER

STE W COOLING TOWER

IRE WATER STORAGE TANK

FRE PUAP SOUSE 
" 
Within the NI, each reactor module is housed in adjacent, but separate, reinforced concrete structures located below grade. Figure 2-2 shows a sectional view of one of these structures. This below-grade location provides significant design benefits such as reducing the seismic amplifications typical of above-grade structures. With the exception of the Class $1 E \mathrm{DC}$ and Uninterruptible Power Supply and spent fuel storage pools, safety systems for each module are independent of other modules and are located within the individual concrete structures. These dedicated safety systems include safety-related control and decay heat removal systems. Support functions which are not safety-related but which are located within the Nuclear Island include normaI cooling water, ventilation, helium processing, radioactive waste processing, and fuel handling.

Figure 2-3 shows a cutaway of the reactor module, which is the basic building block of the reference MHTGR. This module consists primarily of a reactor vessel and steam generator connected by a coaxial crossduct. The reactor vessel is similar in size to a large boiling water reactor (BWR) vessel. The single steam generator vessel houses a helically coiled steam-generator bundle as well as a single motor-driven circulator. The pressure-retaining components are constructed of steel and designed using existing technology. The reactor vessel is uninsulated to provide for decay heat removal under accident conditions. Key reactor module parameters are listed in Table 2-1.

Figure 2-4. is a simplified flow diagram illustrating how reactor heat is transferred in normal operation. Within the Vessel system, helium coolant flows to the reactor vessel in the outer annular region of the crossduct, flows down through the core, returns through the center region of the crossduct, down through the steam-generator bundle, then back up the annular region around the steam-generator back to the inlet of the single helium circulator. on the secondary coolant side, feedwater enters the separate steam generator vessel at the bottom and then flows through helical coil tube bundle, exiting as superheated steam at the side of the vessel. 


\section{SAFETY OF MODULAR HTGR WITH ANNULAR PRISMATIC CORE IN SILO}

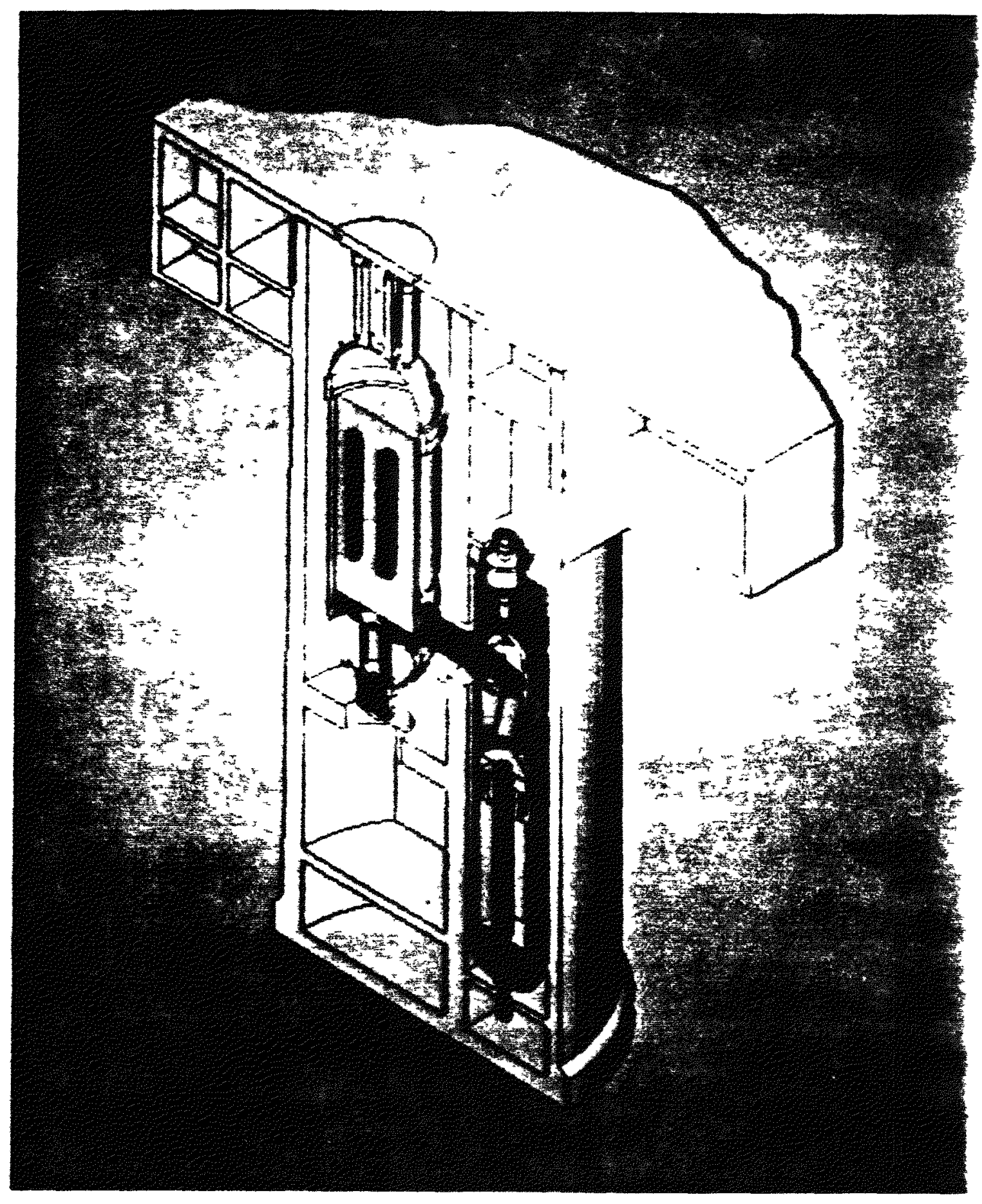

Figure 2-2 Safety of :Odular HTGR with Annular Prismatic Core 
. 


\section{MODULAR HTGR WITH ANNULAR PRISMATIC CORE}

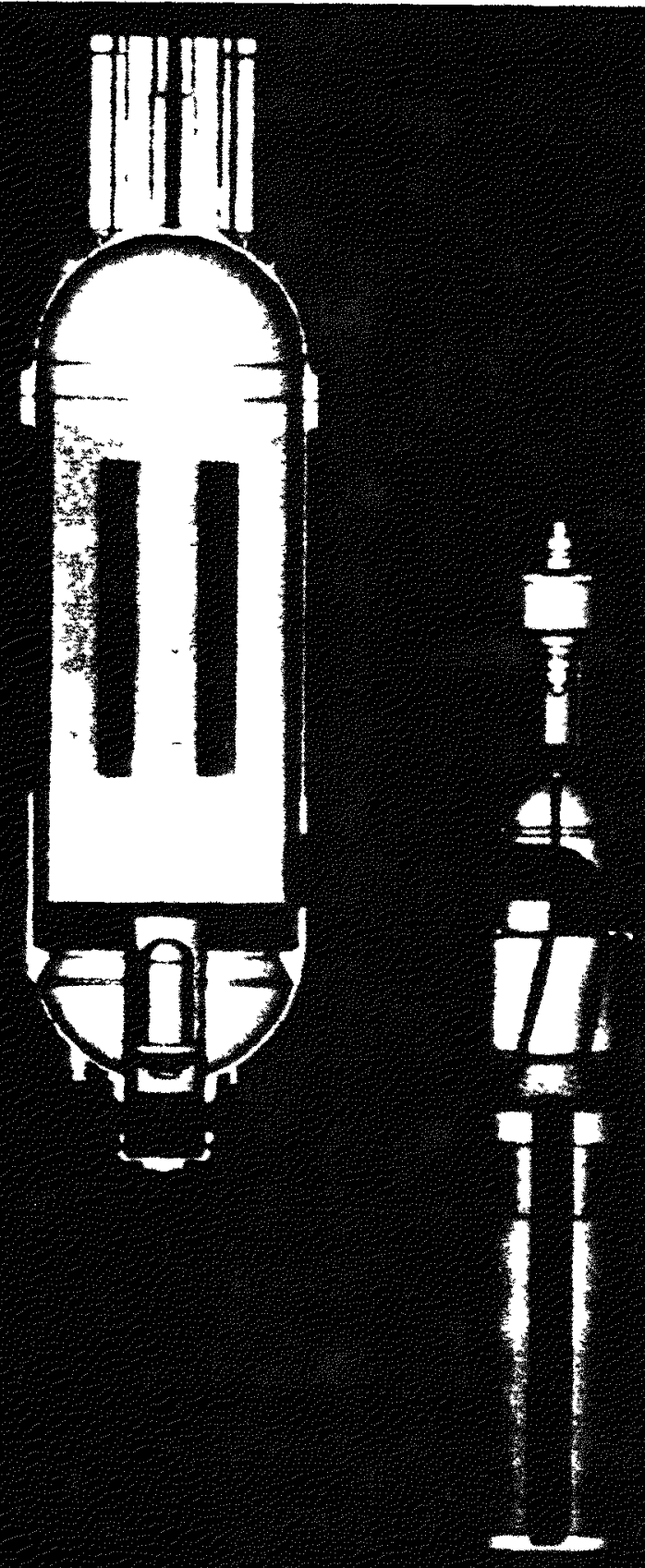

Figure 2-2 
. 
Table 2-1

REACTOR MODULE DESIGN PARAMETERS

\section{Item}

Configuration Description

Heat Transport System

Modules per station

Power per module

Coolant and pressure at rated power

Cold helium temperature

Hot helium temperature

Core helium flow rate

Core helium pressure drop

Feedwater temperature/pressure

Steam temperature/pressure

Vessel material

Reactor Vessel overall height

Reactor Vessel outside diameter

Plant design lifetime

Design basis operation

Number of Components Per Module

Steam generators

Main circulators

Shutdown cooling heat exchangers

Shutdown circulators

Control rods

Reserve shutdown channels

Core and Fuel Cycle

Fuel element

Active core configuration

Fissile material

Power density

Coolant volume fraction

Average enrichment

Power peak/average axial ratio

Fertile material

Initial core loading, $\mathrm{kg}: \mathrm{U} / \mathrm{Th}$

Equilibrium reload, $\mathrm{kg}: \mathrm{U} / \mathrm{Th}$

Equilibrium burnup, $M W(d) / T$

\section{Parameter}

Side-by-Side (SBS)

4

$350 \mathrm{MW}(\mathrm{t})$

Helium at $6.39 \mathrm{MPa}$ ( $925 \mathrm{psia}$ )

at circulator discharge

$259^{\circ} \mathrm{C}\left(498^{\circ} \mathrm{F}\right)$ at circulator discharge

$687^{\circ} \mathrm{C}\left(1268^{\circ} \mathrm{F}\right)$ at core exit

$157.1 \mathrm{~kg} / \mathrm{s}(1,246,000 \mathrm{lb} / \mathrm{h})$

$34.5 \mathrm{kPa}(5.0 \mathrm{psi})$

$193^{\circ} \mathrm{C} / 21.0 \mathrm{MPa}\left(380^{\circ} \mathrm{F} / 3,000 \mathrm{psia}\right)$

$541^{\circ} \mathrm{C} / 17.3 \mathrm{MPa}\left(1005^{\circ} \mathrm{F} / 2,515^{\mathrm{psia}}\right)$

Low alloy steel, manganese-molybdenum

SA533 Grade $B$, Class 1

$22 \mathrm{~m}$ ( $72 \mathrm{ft})$

$6.8 \mathrm{~m}(22.4 \mathrm{ft})$

$40 \mathrm{yr}$

80 percent capacity factor

1

1, electric motor-driven

1

1 , electric motor-driven

30 ( 6 inner, 24 outer reflector rods)

12 (inner row of core fuel elements)

Prismatic hex-block, $36.0 \mathrm{~cm}$ across flats $\times 79.3 \mathrm{~cm}$ height

66-column annulus, 10-blocks high

Uranium gxycarbide

$5.9 \mathrm{~W} / \mathrm{cm}^{3}$

0.19

19.9 percent U-235

$1.4: 1$

$\mathrm{ThO}_{2}$

$1726 / 2346$

$1030 / 706$

92,200 


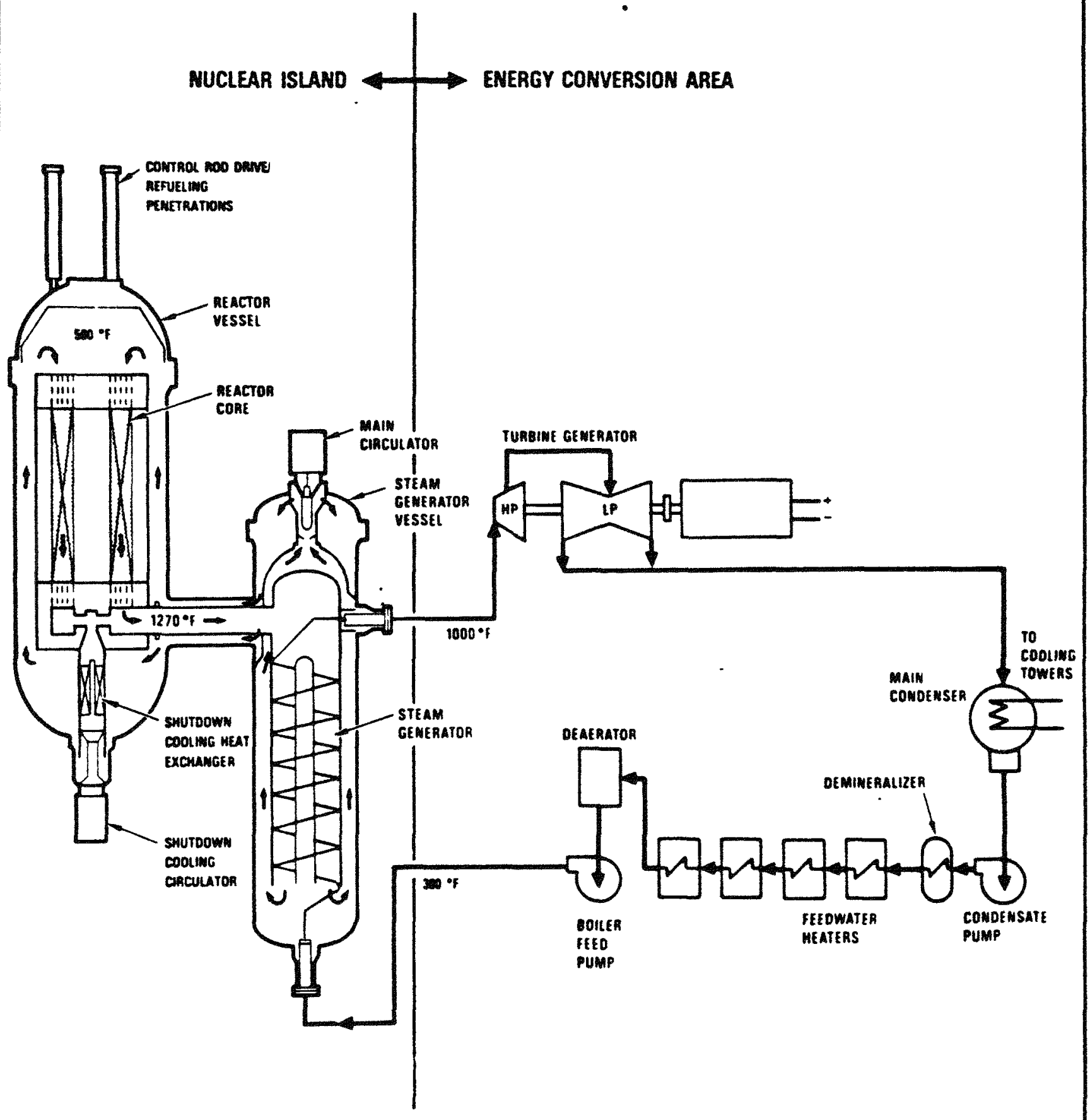

Figure 2-4 Simplified Flow Diagram -

Plant Power Generation 
When the reactor is shut down for maintenance or refueling, decay heat can be removed from the core by the normal heat Transport System described above, or by the independent Shutdown cooling system (SCS). The sCS consists of a motor-driven circulator coupled with a compact heat exchanger mounted underneath the reactor core within the reactor vessel. The shutdown heat exchanger is cooled by water. pumped through the heat exchanger tube bundle. The SCS is not safety-related.

As a third means of providing decay heat removal, a safety-related Reactor Cavity Cooling System (RCCS) as shown schematically in Figure 2-5 is provided to remove heat radiated from the uninsulated reactor vessel. Reactor cavity cooling is provided by natural circulation of outside air through enclosed cooling panels along the reactor cavity walls. In order minimize release of Argon-41 from the reactor cavity, cooling air does not communicate with air inside the cavity. Air naturally circulates through the RCCS continuously and is, therefore, always available to remove decay heat under accident conditions without reliance on active components, power supplies, or operator action. The RCCS provides cooling of the reactor cavity concrete during nomal operation.

\subsection{ENERGY CONVERSION AREA}

The Energy Conversion Area (ECA) contains conventional power plant structures and equipment separate from the Nuclear Island. As shown in Figure 2-1, the principal structures in the ECA are the operations center (including the control room), turbine building, and main cooling tower.

Steam from the four reactor modules is delivered to two steam turbinegenerators which produce 588 MWe gross ( 538 MWe net) of electrical energy. The turbine cycle heat balance is shown on Table 2-2. The turbine-generator plant is similar to a modern fossil-fired plant, except that a non-reheat steam cycle is employed. A mechanical draft cooling tower is used to reject the condenser heat load to the atmosphere. 


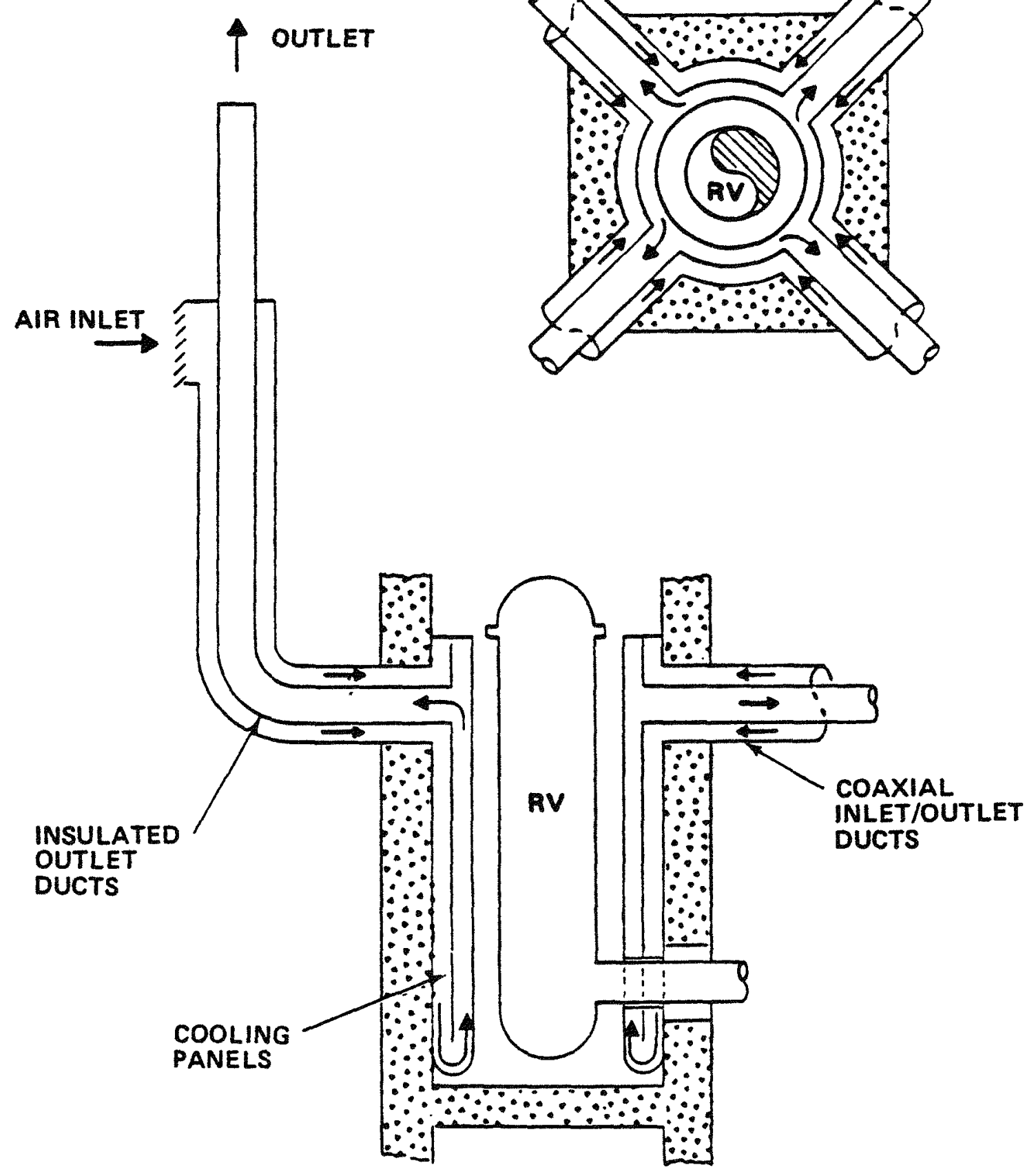

1. COOLS THROUGH PANEL WALL.

2 OPERATES UNDER ALL MODES OF REACTOR OPERATION.

3 SIMPLE TO OPERATE, VIRTUALLY MAINTENANCE FREE.

Figure 2-5 Passive Air-Cooled RCCS 
Table 2-2

OVERALL PLANT HEAT BALANCE

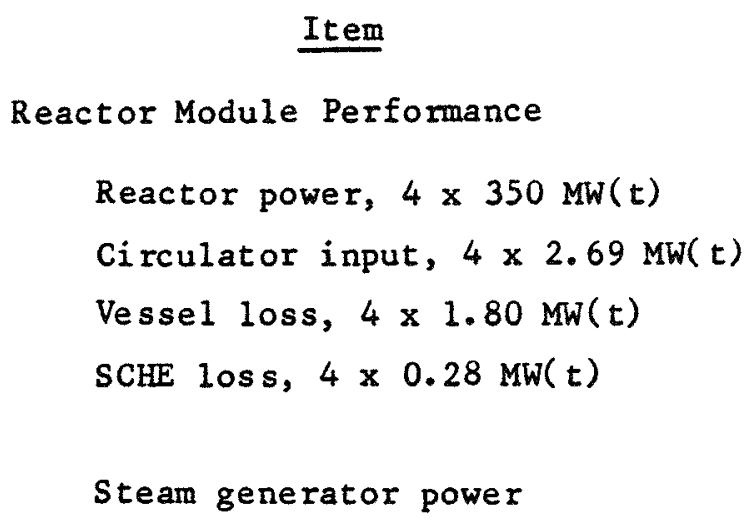

Amount

$$
\begin{array}{r}
1,400.0 \mathrm{MW}(t) \\
10.8 \mathrm{MW}(t) \\
-7.2 \mathrm{MW}(t) \\
-1.1 \mathrm{MW}(t) \\
\hline
\end{array}
$$

$1,402.5 \mathrm{MW}(\mathrm{t})$

$587.5 \mathrm{MW}(e)$

$14.4 \mathrm{MW}(\mathrm{e})$

$35.5 \mathrm{MW}(\mathrm{e})$

49.9 MW(e)

$537.6 \mathrm{MW}(\mathrm{e})$

38.4 percent

$8,886.0 \mathrm{Btu} / \mathrm{kWh}$ 
SECTION 3

PLANT TECHNICAL DESCRIPTION

\subsection{REACTOR SYSTEM}

The primary functions of the Reactor System are to generate heat from fission energy, to transfer that heat to the primary coolant, to control neutron generation rate in the core, and to support and restrain the core. The Reactor System also provides barriers to the release of radioactivity into the primary coolant, provides sufficient reactivity control for shutdown assurance under all postulated conditions, and shields the reactor vessel from direct neutron. irradiation.

The Reactor System is comprised of four identical $350 \mathrm{MW}(t)$ reactor modules. Each consists of a Reactor Core Subsystem, a Neutron Control Subsystem, and a Reactor Internal Subsystem contained in a reactor pressure vessel which is connected to a steam generator vessel by a concentric cross duct. An elevation view of the Reactor system is shown in Figure 3-1 and a plan view is shown in Figure 3-2.

\subsubsection{Reactor Core Subsystem}

The Reactor Core Subsystem consists of hexagonal graphite fuel and reflector elements, plenum elements, startup sources, and reactivity control material, located inside the reactor pressure vessel. The active core consists of hexagonal graphite fuel elements, shown in Figure 3-3, containing blind holes for fuel compacts and full length channels for helium coolant flow. Columns of fuel elements in 12 locations also contain channels for reserve shutdown material. 


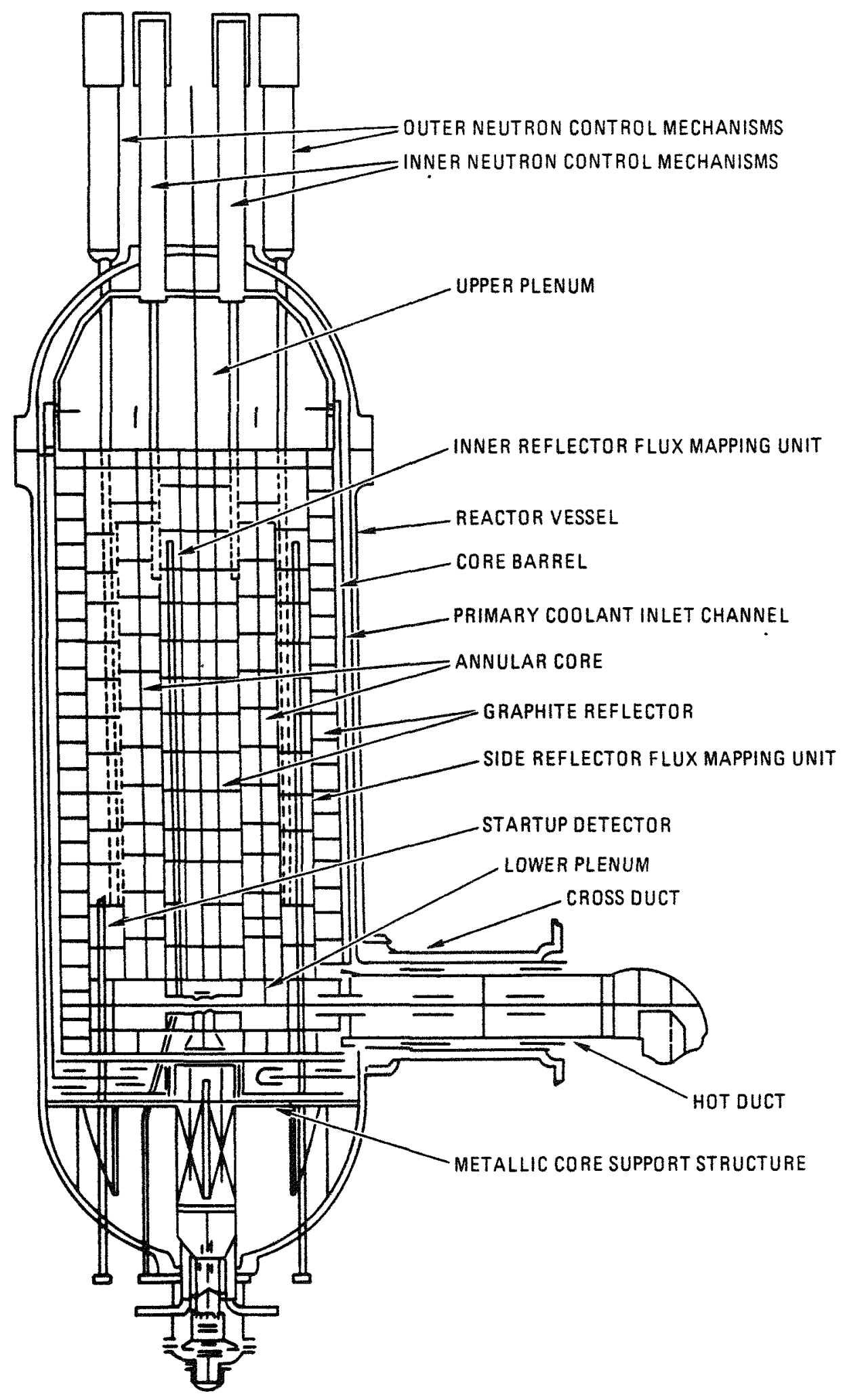

Figure 3-1 Reactor System - Elevation View 


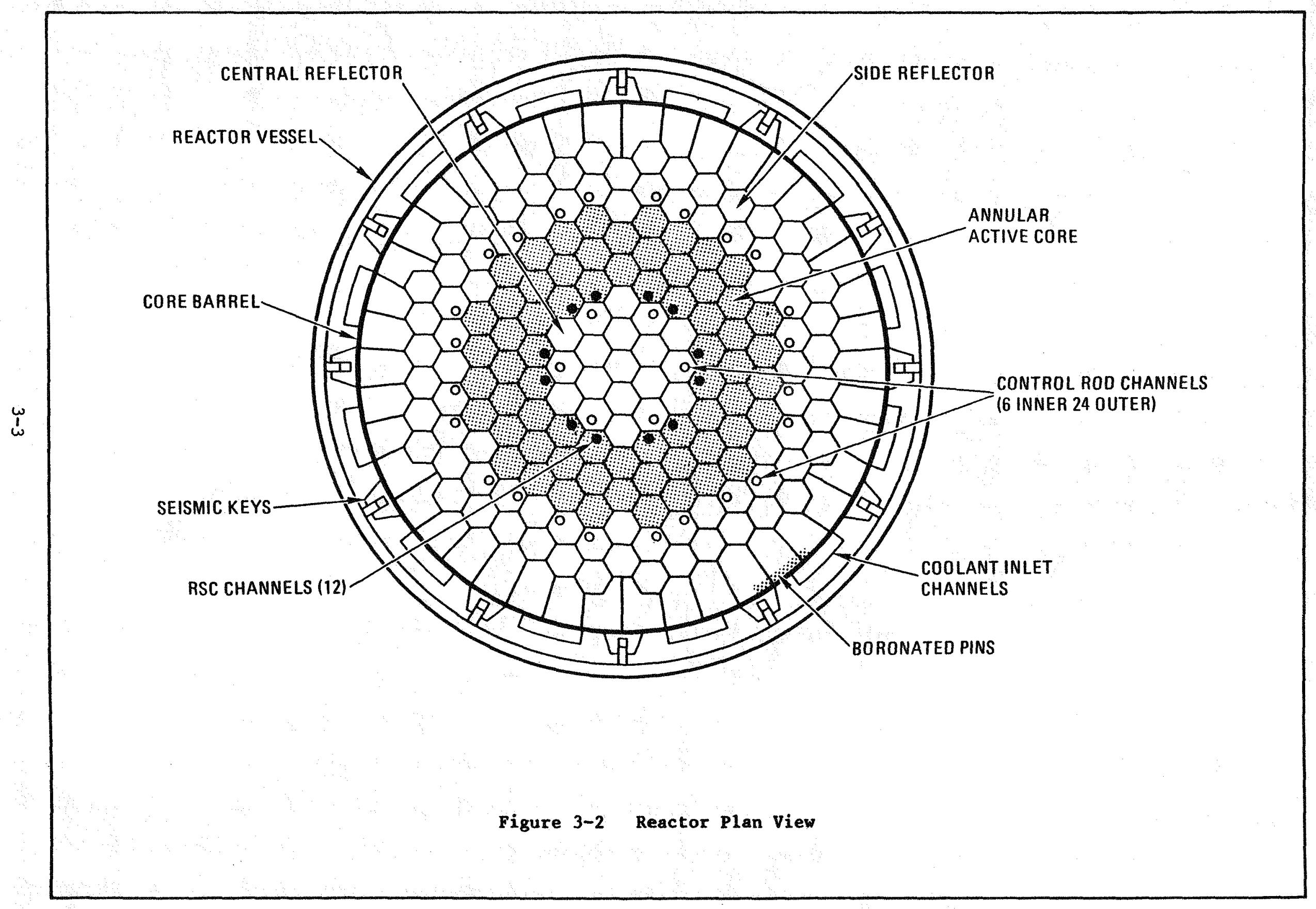



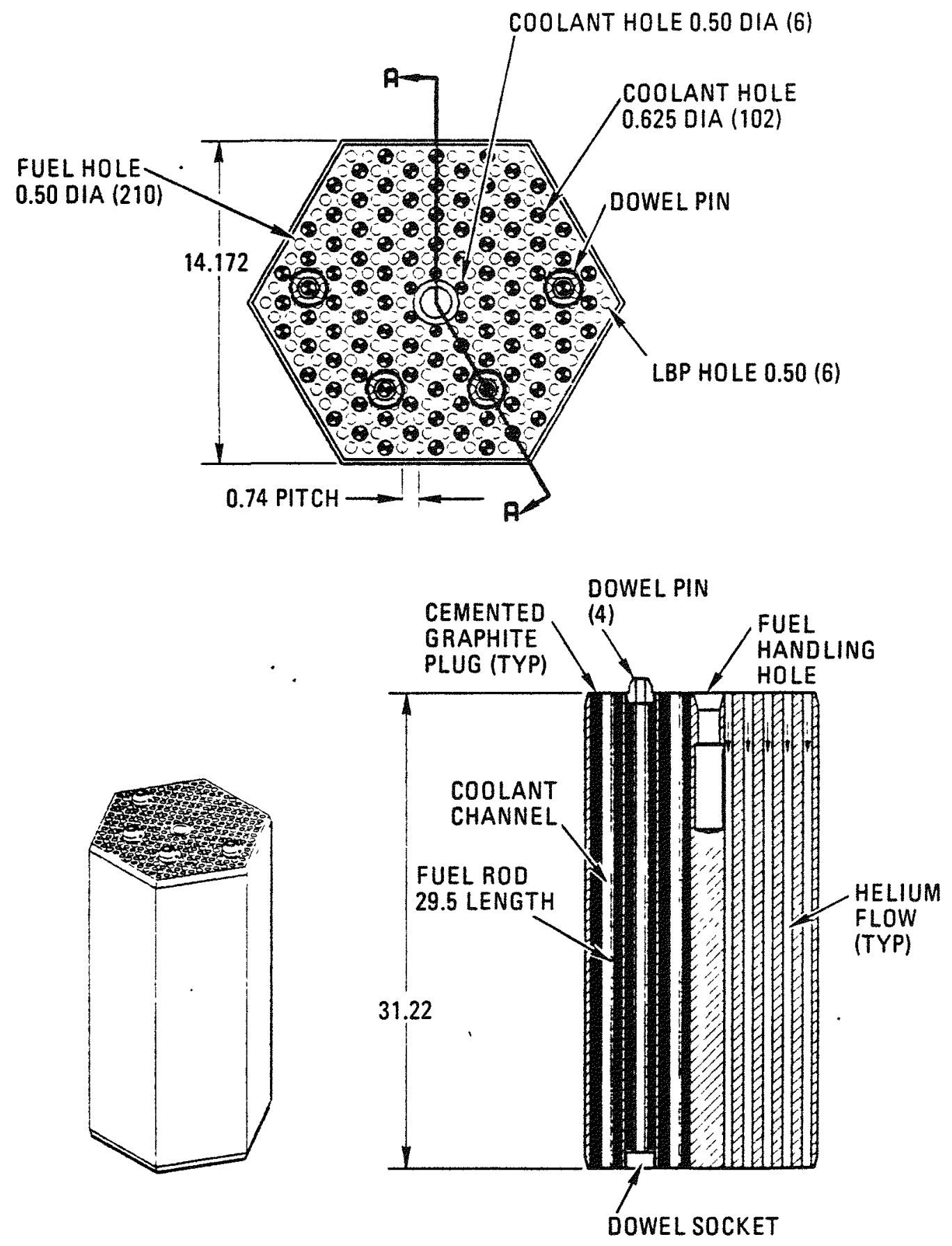

SECTION A-A

DIMENSION IN INCHES

Figure 3-3 Standard Fuel Element 
The fuel elements are stacked to form columns ( 10 fuel elements per column), which rest on support structures as shown in Figure 3-1. The columns of the active core form an annulus with columns of hexagonal graphite reflector elements in the central and outer regions (see Figure 3-2). Six central reflector elements and 24 side reflector elements contain channels for control rods.

The annular core configuration is selected, in combination with the power density of $5.9 \mathrm{MW} / \mathrm{m}^{3}$, to achieve maximum power rating and still permit passive core heat removal while maintaining maximum fuel temperature below $1600^{\circ} \mathrm{C}$ $\left(2912^{\circ}\right.$ F) during a conduction cooldown event. The active core outer diameter is $3.5 \mathrm{~m}$ ( $138.0 \mathrm{in.})$ and is sized to maintain a minimum reflector thickness of $1.0 \mathrm{~m}$ (39.4 in.) within the reactor vessel of $6.55 \mathrm{~m}$ ( $258.0 \mathrm{in.}$ ) inner diameter. These dimensions allow for a lateral restraint structure between the reflector and vessel. An inner core diameter of $1.65 \mathrm{~m}(65.0 \mathrm{in.})$ is selected on the basis of studies on the reactivity worth of control rods with annular cores. To meet a 13 percent projected reactivity control requirement, using reflector control rods (inner and outer), the annular width of the core can be no greater than $1 \mathrm{~m}$ ( $39.4 \mathrm{in}$ ). The core height is limited to $7.9 \mathrm{~m}$ ( 311.0 in.) to allow a maximum power rating while assuring axial power stability to xenon transients over the entire burnup cycle.

The reference fuel cycle employs low-enriched uranium. The fissile fuel is a two-phase mixture of 19.8 percent enriched $\mathrm{UO}_{2}$ and $\mathrm{UC}_{2}$, usually referred to as UCO, having an oxygen-to-uranium ratio of 1.7 . The fertile fuel is thorium in the form of $\mathrm{ThO}_{2}$. Both fertile and fissile fuels are in the form of dense microspheres coated in a fluidized bed with a TRISO coating (as previously shown in Figure 1-3) whose primary purpose is to retain fission products. The coated fissile and fertile particles are blended and bonded together with a carbonaceous binder into the form of fuel compacts, which are stacked into the fuel holes in the graphite fuel element as shown in Figures $1-4$ and $3-3$.

The core reactivity is controlled by a combination of fixed lumped burnable poison, movable poison, and a negative temperature coefficient. The fixed 
poison is in the form of lumped burnable poison rods and the movable poison is in the form of metal clad control rods. In the event that the control rods become inoperable, a backup, reserve shutdown control is provided in the form of boronated pellets that may be released into channels in the active core. The operational mechanisms for the control rods and for the reserve shutdown are a part of the Neutron Control Subsystem.

The normal operating control rods are fabricated from natural boron in annular graphite compacts with metal cladding for structural support. The rods are located in channels in the outer ring of the central reflector elements and in the inner ring of the hexagonal side reflector (Figure 3-2). These control rods enter the core through top reactor vessel penetrations, in which the control rod drives are housed. The 24 control rods located in the side reflector are used for normal control and for trip from high power. The location of the rods in the side reflector prevents damage during depressurized or pressurized passive heat removal. The 'six control rods in the central reflector are only inserted for cold shutdown.

Boronated graphite pellets, housed in hoppers above the core, provide a reserve shutdown capability. Upon actuation, these pellets drop into channels in selected columns of the active core to provide reactor shutdown in the event that the control rods are inoperable, or if necessary, to provide additional shutdown margin over that provided by the control rods located in the hexagonal side reflector.

Both the outer control rods and the reserve shutdown pellets have sufficient reactivity worth to meet shutdown requirements, although both the outer and inner control rods are utilized to meet a cold $\left[27^{\circ} \mathrm{C}\left(80^{\circ} \mathrm{F}\right)\right]$ shutdown.

The core incorporates a graded LEU/Th fuel cycle with an initial cycle length of $1.9 \mathrm{yr}$. Subsequent burnup cycles are 3.3.yr. with one-half of the active core being replaced each $1.65 \mathrm{yr}$. The fuel cycle is based on a 66-column annular core which operates at $350 \mathrm{MW}(t)$, corresponding to a power density of $5.9 \mathrm{MW} / \mathrm{m}^{3}$. This fuel cycle achieves a high burnup while minimizing fuel 
cycle costs and ensures a strong negative temperature coefficient of reactivity over all normal operation and accident temperature ranges.

The core is refueled by column, and the two reload segments consist of onehalf of the fuel element columns distributed uniformly throughout the core. Each refueling column extends the full height of the active core, i.e., ten fuel elements.

Both radial and axial power distributions are controlled to limit fuel temperature, to limit fuel element stresses, and to meet gas temperature hot streak requirements. The principal means of power distribution control is the creation of zones of differing average fuel concentrations.

The power tailoring by zone is achieved by redistributing the fissile and fertile fuel separately, basically providing heavier concentrations of fissile material (uranium) in the higher power zones, but keeping the total core or reload fuel loadings unchanged.

The current zoning scheme consists of three radial and three axial zones. The three axial zones consist of 5, 3, and 2 fuel elements in the top, middle, and bottom zones, respectively. The three radial zones correspond to the three annular rings of fuel elements, i.e., 18, 24, and 24 fuel elements per ring as seen in Figure 3-2. This fuel zoning decreases the average power in the inner two fuel zones, and increases the average power in the outer fuel zone such that the radial relative power of $0.87,1.00,1.10$ is achieved and maintained over most of the operating cycle. The axial power distribution indicates 65 percent of the power in the top zone, 25 percent in the middle zone, and ten percent in the bottom zone. These power distributions maintain the maximum time-averaged fuel temperature to less than $1250^{\circ} \mathrm{C}\left(2282^{\circ} \mathrm{F}\right)$.

Heat generated in the core is removed by the downward flow of helium. Most of this flow traverses the core in the fuel element coolant channels, but some is directed to the control rod channels and some passes through the gaps between columns. The coolant channels flow is collected in the lower reflector, and 
exits the core via coolant passages at the corners of the hexagonal blocks. The core inlet coolant temperature is $250^{\circ} \mathrm{C}\left(498^{\circ} \mathrm{F}\right)$ and the average core exit coolant temperature is $687^{\circ} \mathrm{C}\left(1268^{\circ} \mathrm{F}\right)$.

Alignment of the elements within the columns is provided by dowels and sockets. These dowel/socket combinations are designed to withstand the highest shear forces generated during seismic conditions to maintain alignment for coolant flow and for control rod insertion.

The fast neutron fluence will cause the graphite elements to shrink slightly. Since the flux field is nonuniform, the elements will also distort, however, the distorted elements will always fit inside the original space envelope so that there will not be any interference with reactor operation or with refueling. The nonuniform flux fields in combination with the temperature gradients will also cause stresses in the graphite elements. These themal/ irradiation induced stresses are added to the stresses from other sources, of which seismic loads is the most important one, and the total stresses are generally kept at levels below half the strength of the material to preclude functional failures and to avoid any safety consequences.

\subsubsection{Neutron Control Subsystem}

The Neutron Control Subsystem (NCSS) consists of the drive mechanisms for. positioning the control rods, the rod controls, the reserve shutdown equipment with its controls, and the instruments for measuring neutron flux levels within the reactor vessel (i.e., in-vessel flux mapping units and startup detectors) and around the perimeter of the reactor outside the vessel (i.e., ex-vessel flux detectors). The control rod assemblies, below the interface of the connectors to the drive cables, are part of the reactor core subsystem.

Most of this equipment is configured into assemblies which are normally installed in penetrations in the top or bottom of the reactor vessel. These assemblies are periodically removed either to provide access to the core for 
refueling or for maintenance of the equipment.

Five types of assemblies are provided for each reactor module:

1. Twelve outer neutron control assemblies (ONCA).

2. Six inner neut ron control as semblies (INCA).

3. Six ex-vessel neutron detector assemblies.

4. Three startup detector assemblies (SDA).

5. Five in-vessel flux mapping units (IFMUs).

Each ONCA is equipped with two independent control rod and drive assemblies. These assemblies are interchangeable with each other'in any of the assigned penetrations. Figure 3-4 shows an overall view of an ONCA.

Each INCA is equipped with one control rod and drive assembly and two independent sets of reserve shutdown control equipment. These assemblies are also interchangeable with each other in any of the assigned penetrations. Figure 3-5 shows an overall view of an INCA. Figure 3-6 shows the ONCAs and INCAs installed in the reactor vessel.

The ex-vessel neutron detection equipment consists of fission chamber neutron detectors mounted in six equally spaced vertical wells located just outside the reactor vessel as illustrated in Figure 3-7. The signals from these detectors are supplied to the nuclear instrumentation cabinet and safety protection subsystem equipment located primarily in the Reactor Building. These data are used by the automatic control systems to operate the control rod drives or the reserve shutdown equipment and the reby change the neutron flux levels within the reactor core.

The startup detector assemblies (SDA) are fission chambers with the appropriate cabling and support structure. The SDAs are inserted into vertical channels in the reflector elements near the bottom of the core through three equally spaced penetrations in the bottom head of the reactor vessel and are interchangeable with each other in any of the assigned locations. 
CONTROL ROD

DRIVE MECH. (2 REO)

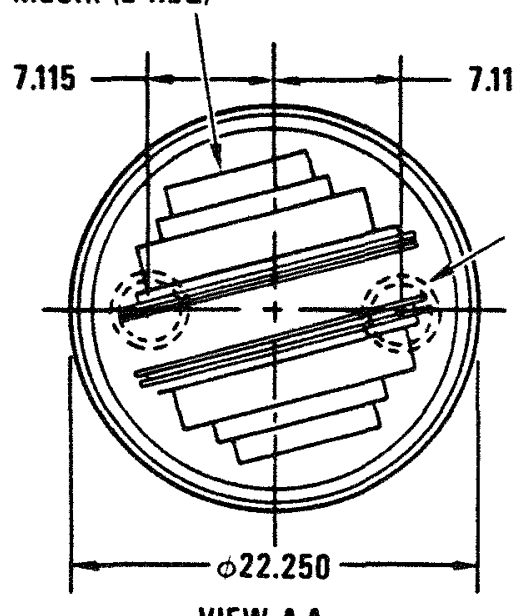

VIEW A.A ENLARGED
7.115

CONTROL

ROD GUIDE

TUBE

(2 REQ)

\section{$\stackrel{A}{7}$}

UPPER STRUCTURE SUPPORT \& SEAL

15 FT-9.25 in.

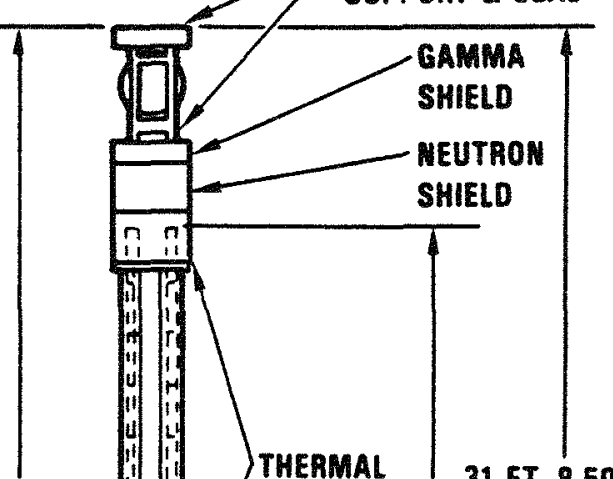

31 FT-8.50 IN.

THERMAL

BARRIER

THERMAL

BARRIER SEAL. TYP

4 FT-1.00 IN

(t)

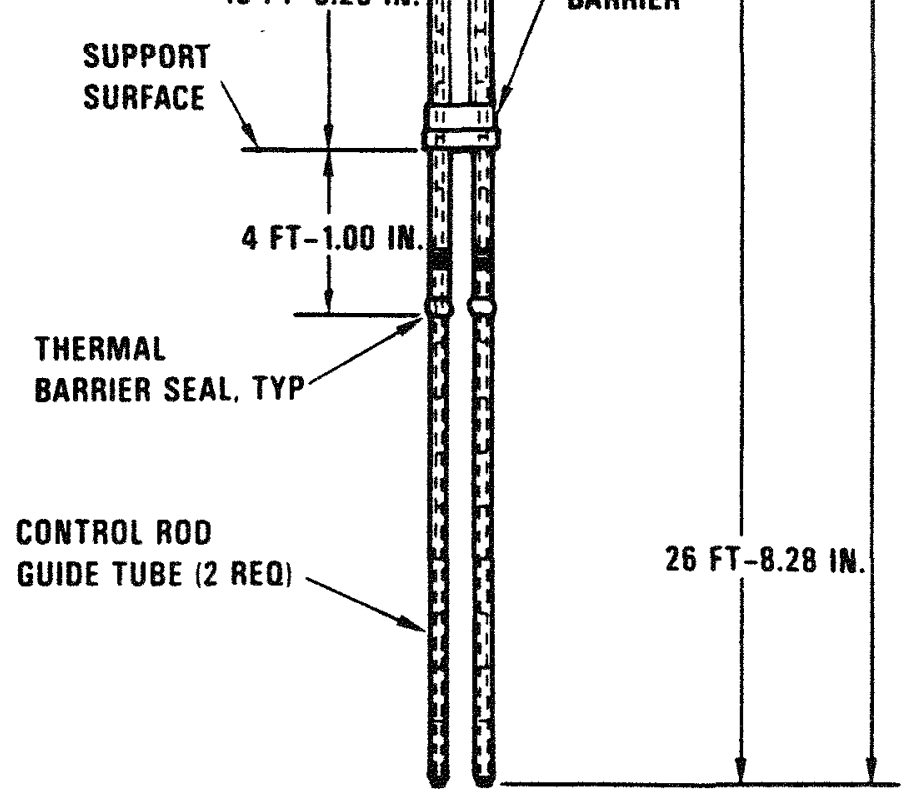

Figure 3-4 Outer Neutron Control Assembly 


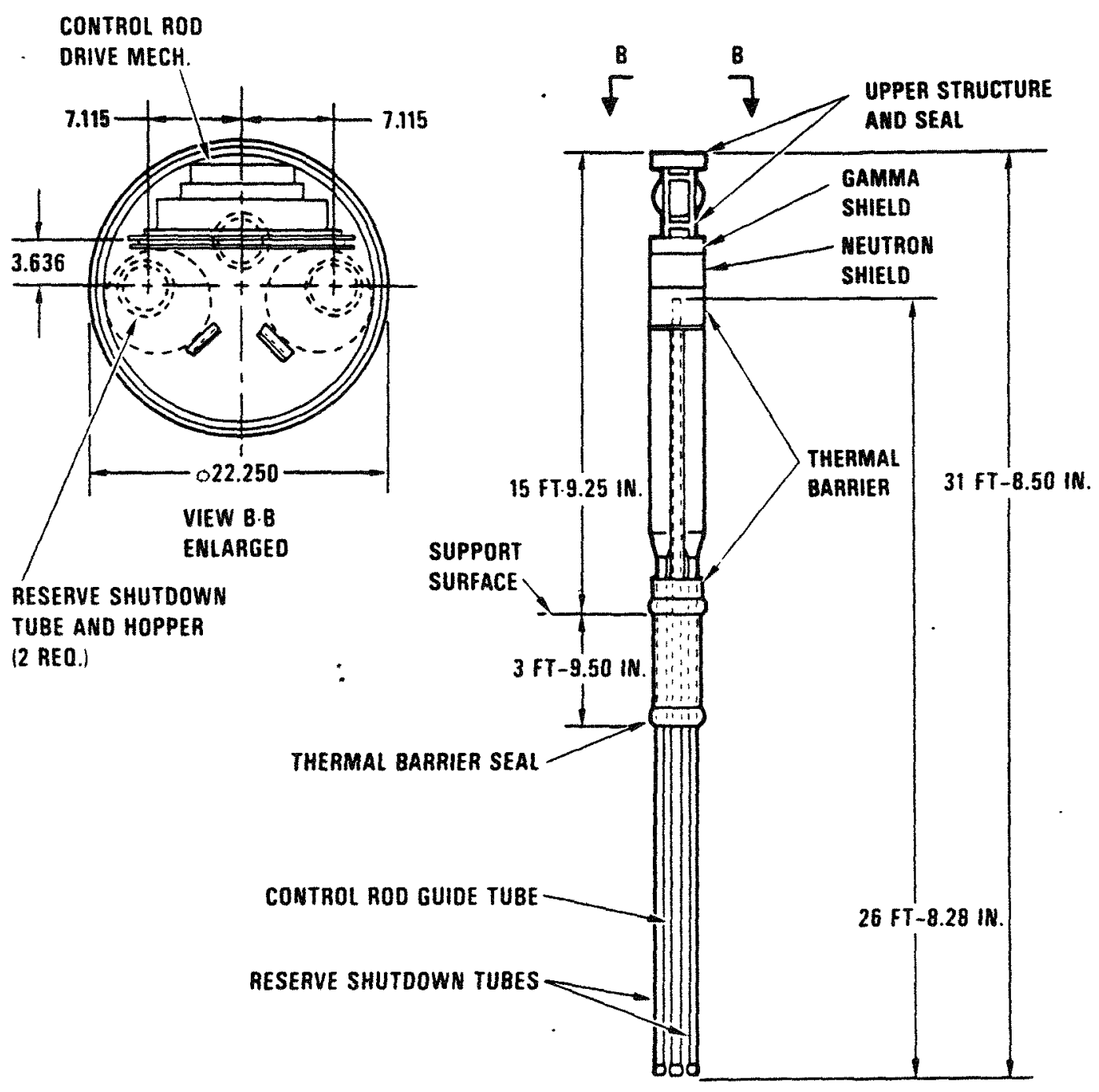

Figure 3-5 Inner Neutron Control Assembly 


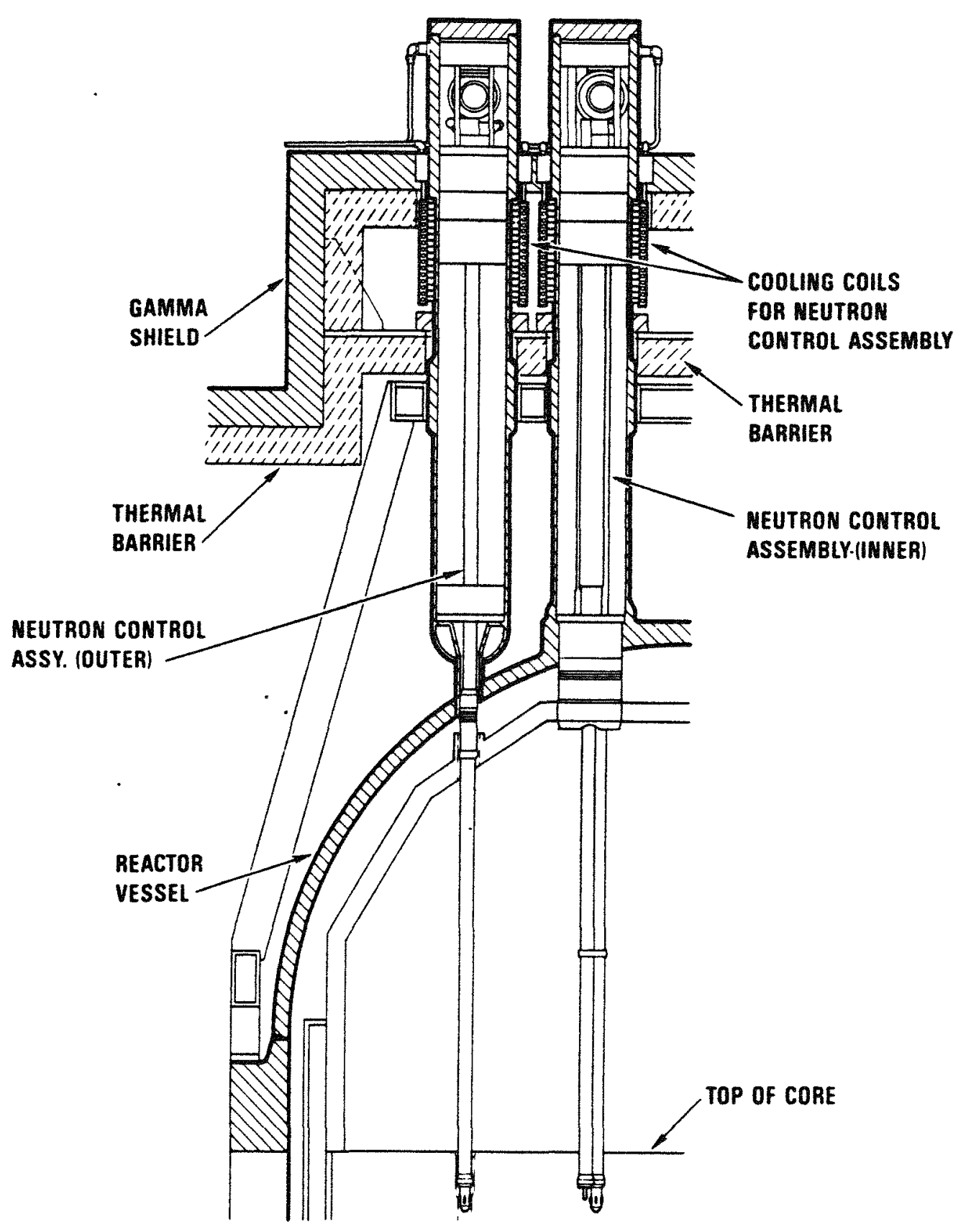

Figure 3-6 Control Assemblies Installed in Vessel 


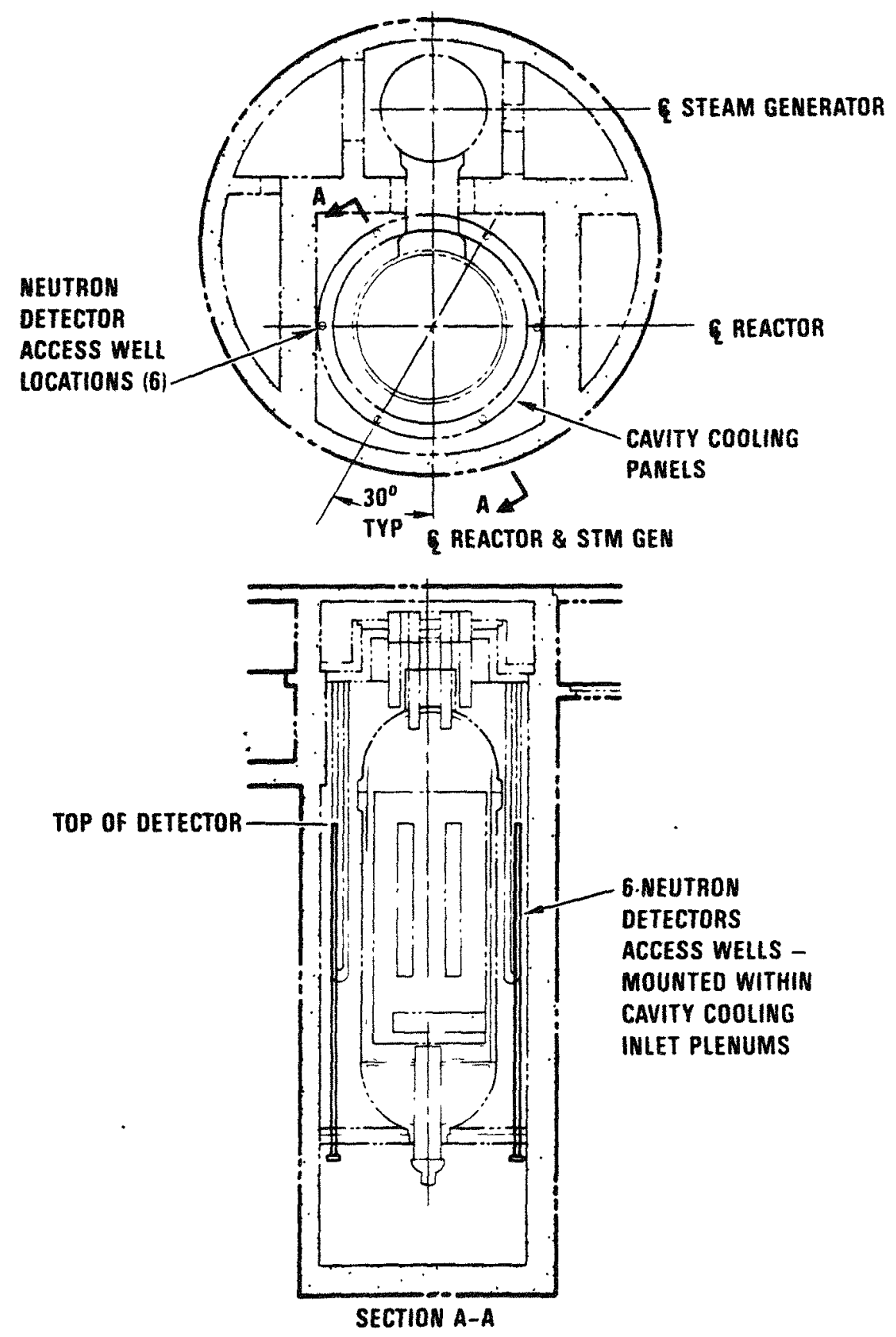

Figure 3-7 Ex-vessel Detectors and Locations 
Each in-vessel flux mapping unit (IFMU) consists of a small vertical rod with multiple integral gamma detectors along its axis. The IFMUs are installed in vertical channels in the inner and outer reflector elements through penetrations in the bottom head of the reactor vessel. The integral gamma detectors are monitored periodically to obtain data on the axial power profile of the reactor fuel. Identical assemblies are installed at all locations, but the IFMUs are not normally interchanged between locations since the activation which they experience while installed in the reactor will normally require their destruction upon removal.

The control equipment for the control rod drives, reserve shutdown control equipment, etc., is not illustrated but consists of four control and instrumentation cabinets mounted in accessible areas adjacent to the reactor modules. The cabinets are identified as follows:

1. Rod drive control cabinets.

2. Reactor trip power control cabinet.

3. Reserve Shutdown System control cabinet.

4. Nuclear inst rumentation cabinet.

\subsubsection{Reactor Internals}

The reactor internals consist of the core lateral restraint (CLR), permanent side reflector (PSR), graphite core support structure (GCSS), metallic core support structure (MCSS), upper plenum thermal protection structure (UPTPS), and the hot duct. Figure 3-8 illustrates the location of the components of the Reactor Internals Subsystem within the Reactor System.

The core lateral restraint and the permanent reflector surround the core; the graphite core support structure and metallic core support structure are located below the core; the upper plenum thermal protection structure is located above the core; and the hot duct is located within the cross duct between the reactor vessel and the steam generator vessel. 


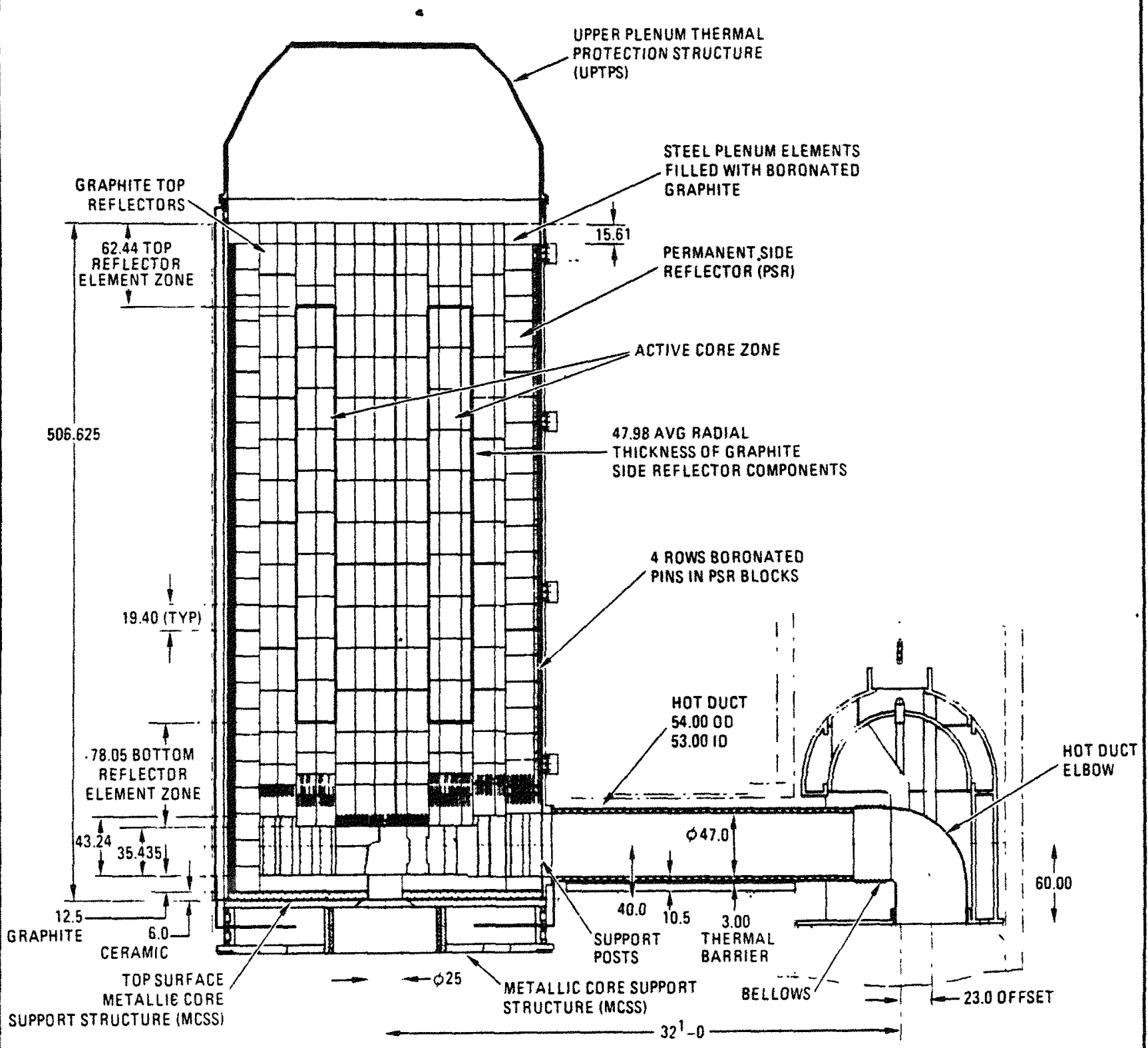

Figure 3-8 Reactor Core and Internals Arrangement Elevation View 
Stability and alignment of the reactor core components, as well as shielding for the Reactor Vessel System, is provided by the permanent side reflector, which consists of graphite blocks stacked to form a cylinder around the core, as shown in Figures $3-8$ and 3-9. Radial restraint is provided to the core, through the permanent side reflector, by the core lateral restraint (Figures 3-10 and 3-11) located between the permanent side reflector and the reactor vessel. The core lateral restraint includes the core barrel with attached coolant inlet channels, and the core barrel seismic keys.

The hexagonal side reflector and the reactor core columns are supported by the graphite core support structure which consists of two layers of graphite blocks supported by graphite posts to form a core outlet plenum. The graphite core support structure (in the lower plenum) under the central reflector columns and above the SCS inlet port consists of 12 column supports. Half are hexagonal columns and the other half are double columns which form a vaulted support with the centermost column. Figure 3-8 shows the lower plenum support structures. The entire array of graphite posts and column supports is supported on the lower plenum floor which consists of a layer of graphite on top of a layer of ceramic block, the latter acting as an insulator on top of the metallic core support structure.

Vertical support of the reactor core components is provided by the metallic core support structure which is a weldment of two circular plates separated by radially oriented beams which meet at a central hub as shown in Figure 3-12. The structure is supported by a forged ring that is integral with the reactor vessel.

The upper plenum thermal protection structure consists of metallic plates formed into a shroud within the top head of the reactor vessel to create the core inlet plenum as shown in Figure 3-13. It includes a thermal barrier attached to the outside of the shroud. It is supported by a flange on top of the core barrel. 


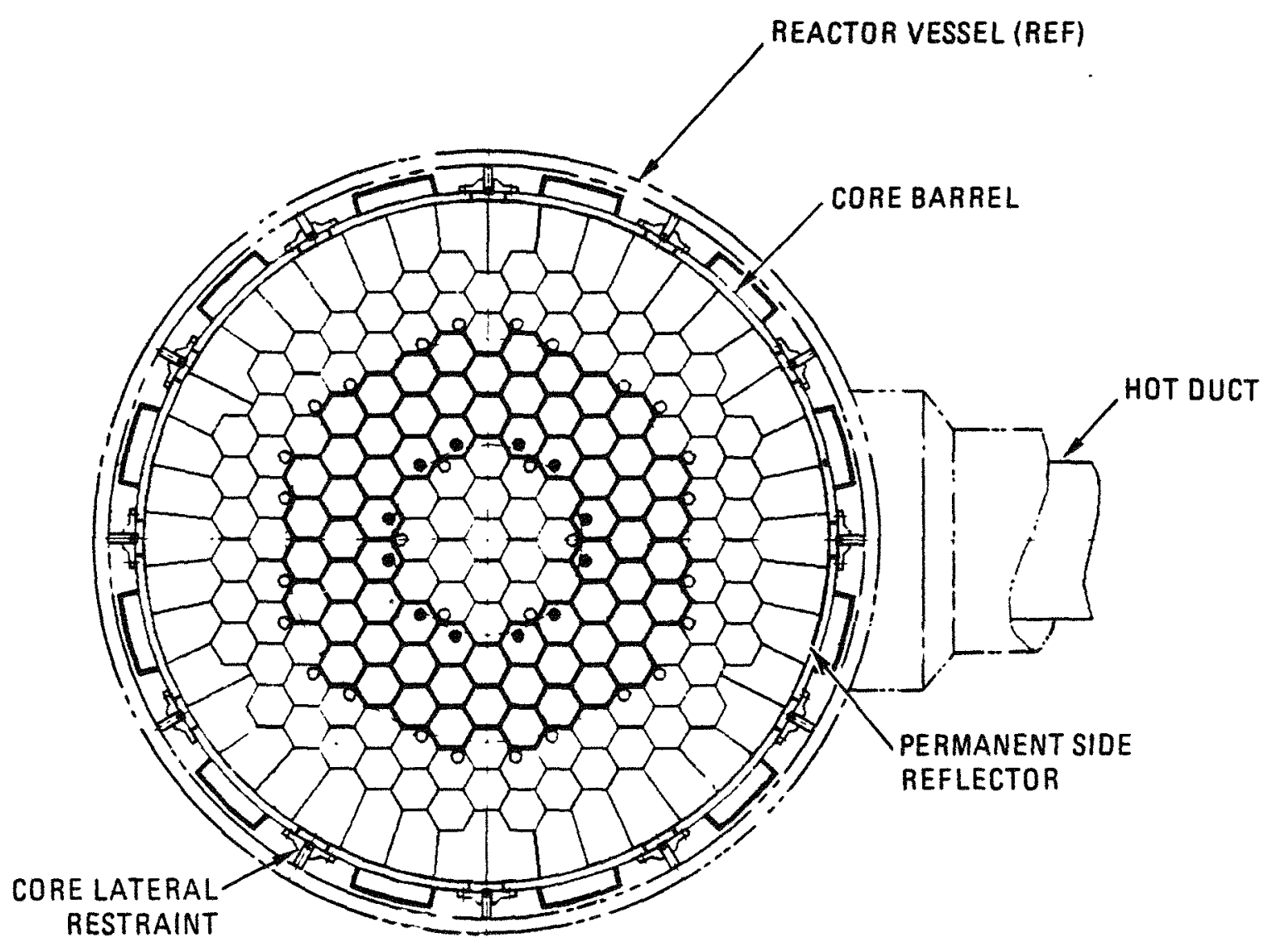

Figure 3-9 Reactor Core and Internals Arrangement Plan View 


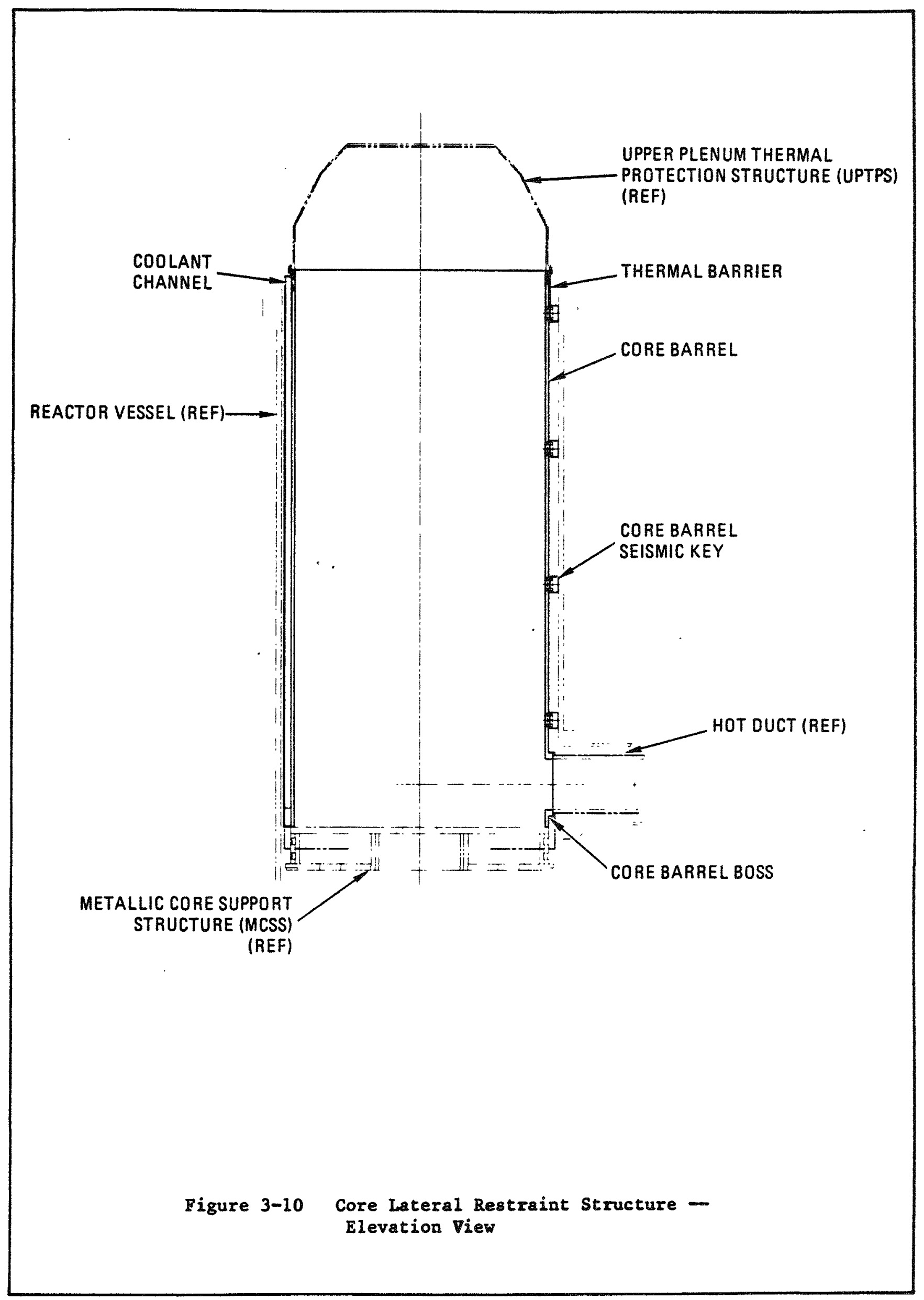




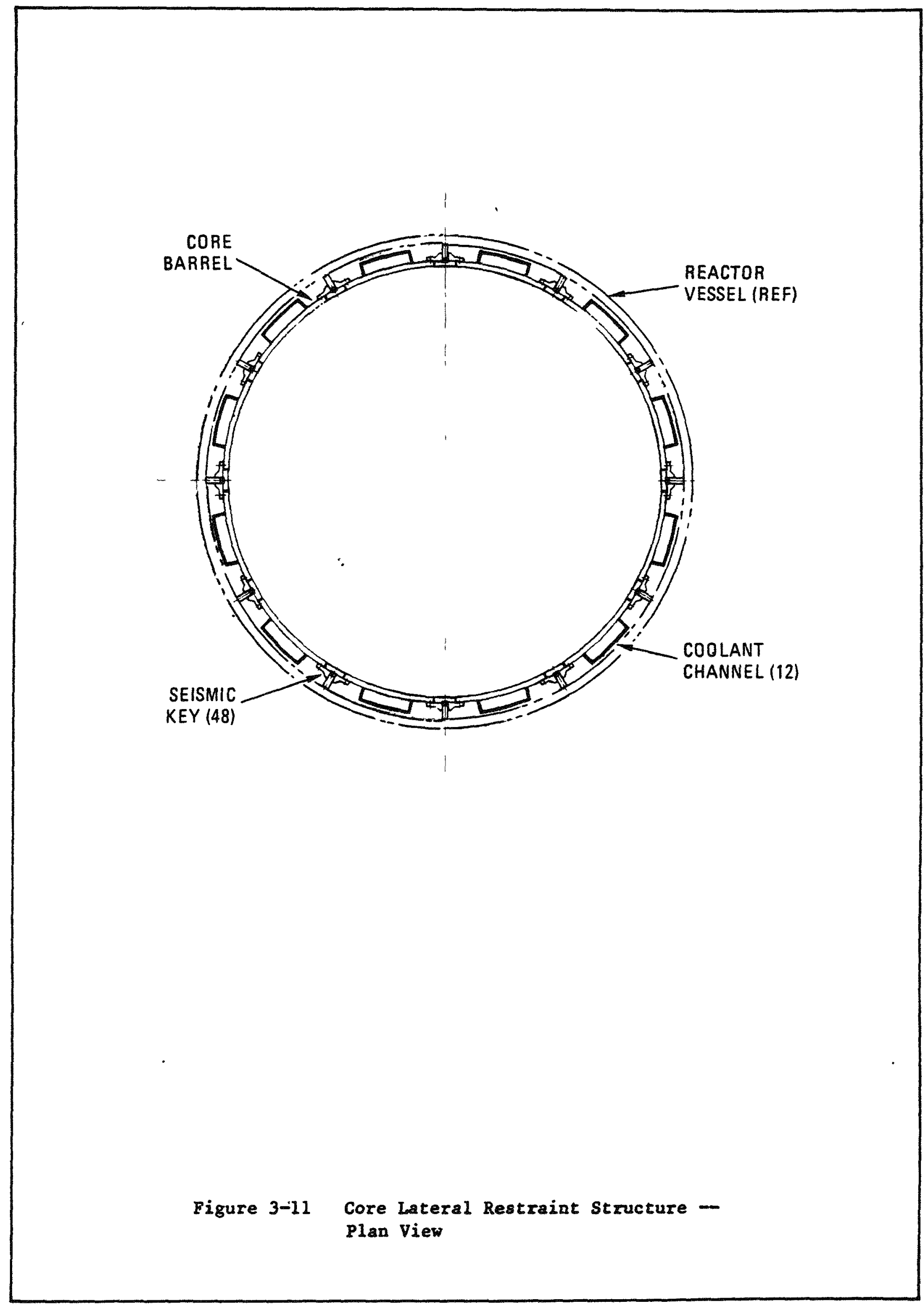




\section{CORE SUPPORT FLOOR GRID}

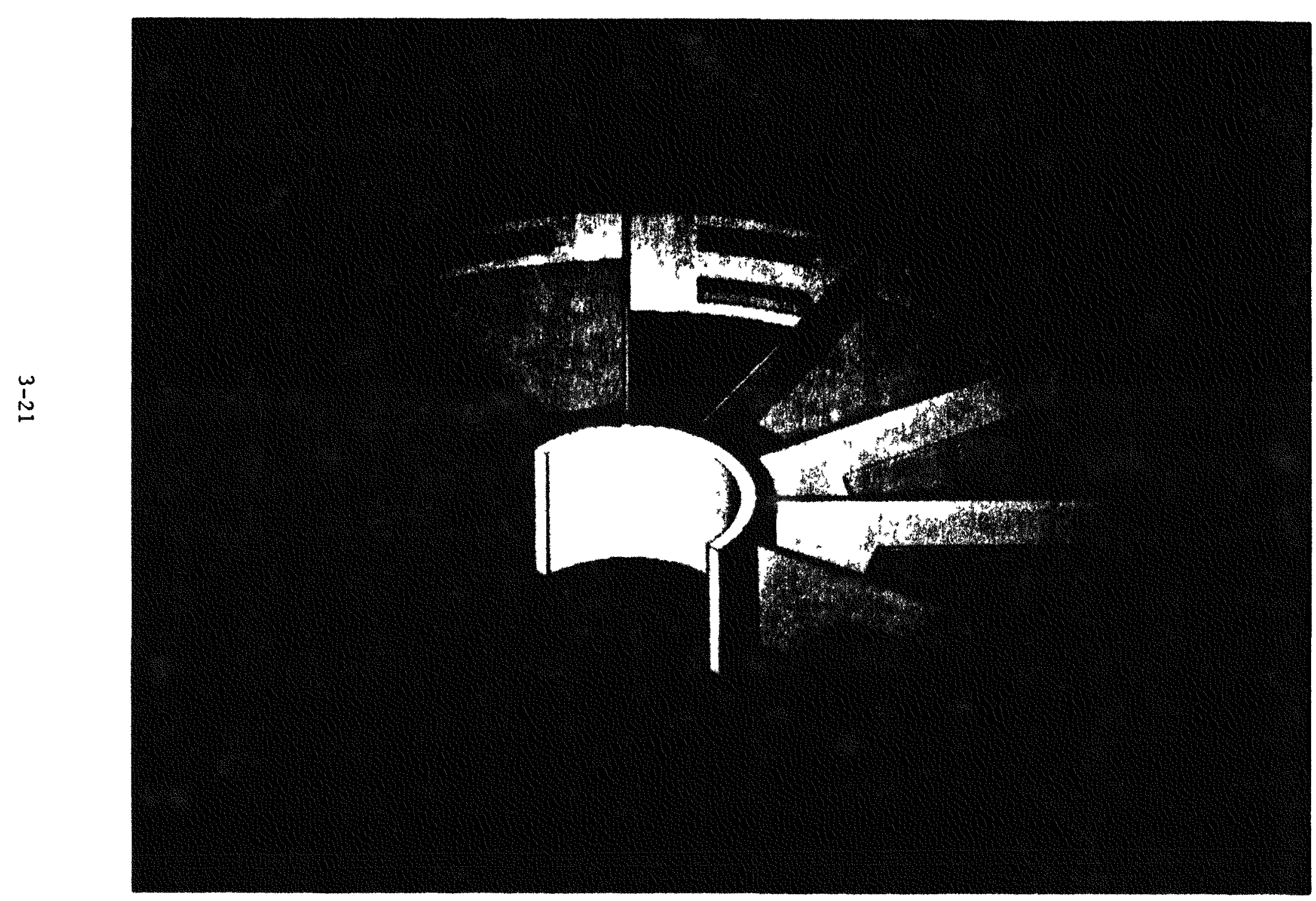





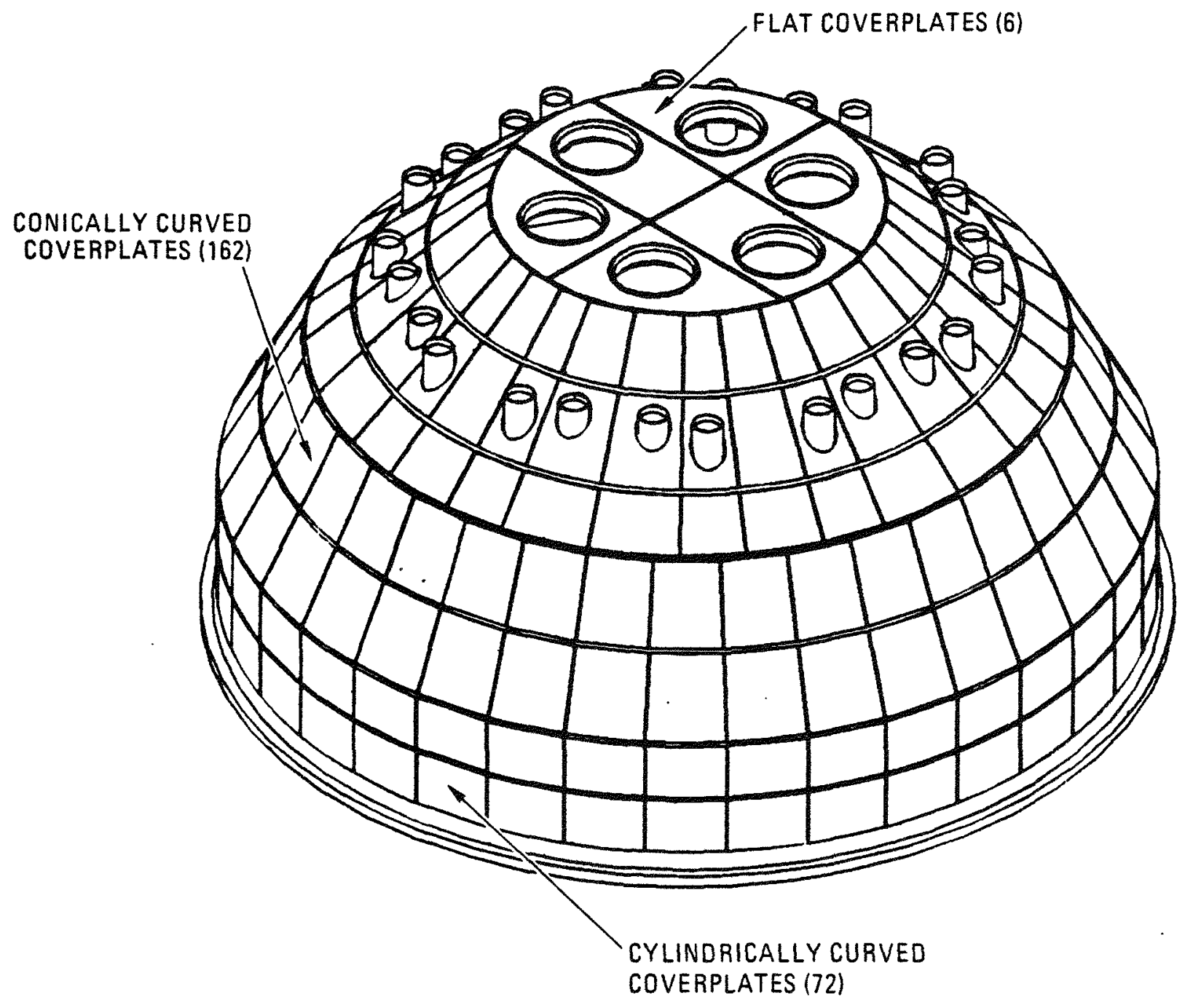

Figure 3-13 Upper Plenum Thermal Protection Structure -Isometric View 
The hot duct assembly consists of three sections of metallic pipes, two of which are covered with thermal barrier (see Figures 3-8 and 3-14). The assembly is attached to the core barrel and extends through the crossduct to the upper portion of the steam generator. The hot duct includes a bellows to accomodate thermal and seismic movements and seals to prevent bypass flow. Shrouds are attached to the elbow section of the duct. The inner shroud provides the means for installing and removing the elbow/bellows, and together with the outer shroud, channels the primary coolant from the steam generator to the main circulator. Guide rails, attached to the crossduct, assist the installation and removal of the horizontal sections and serve as seismic restraints. 


\section{CROSS DUCT TO STEAM GENERATOR}

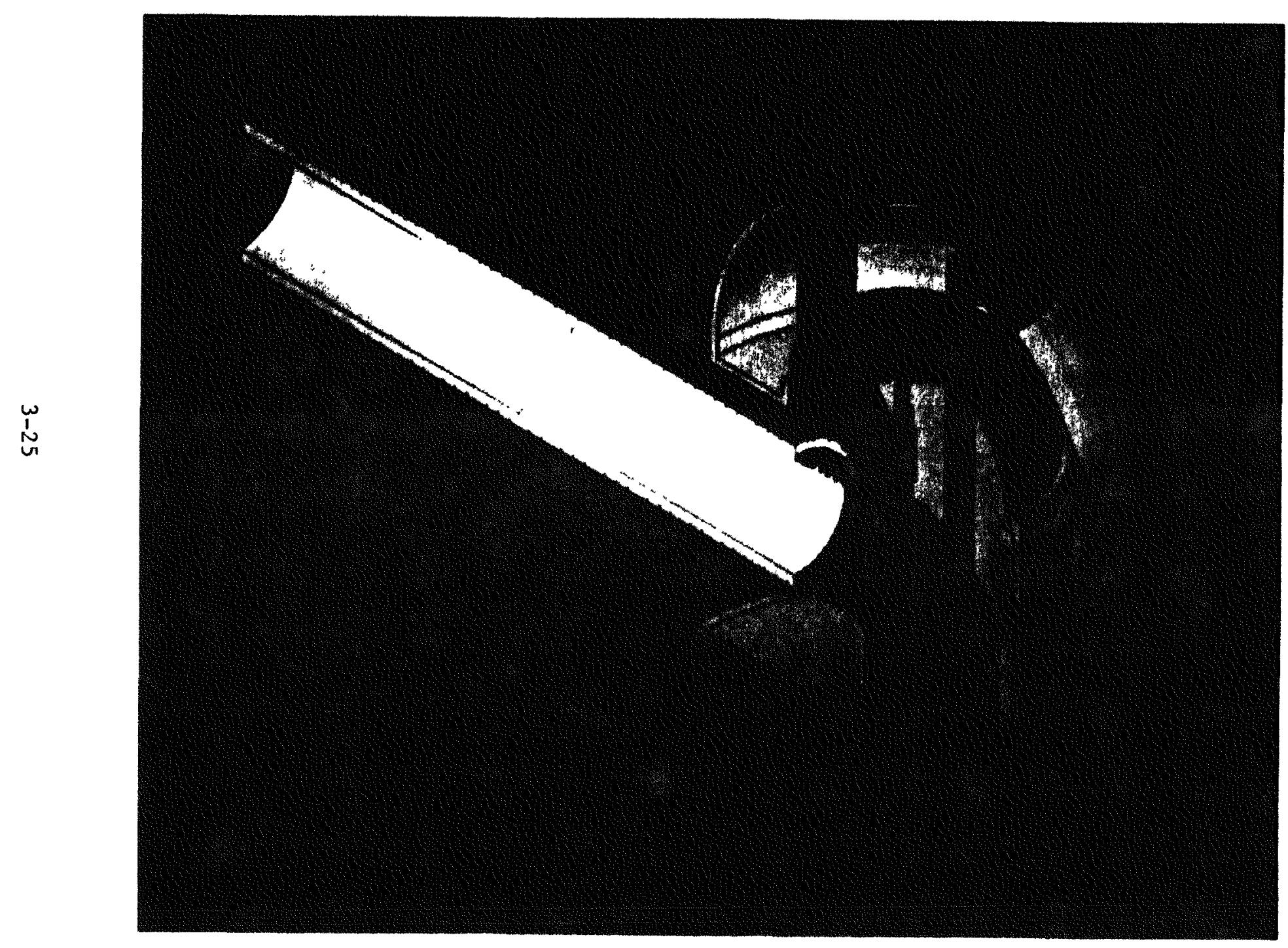




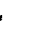




\subsection{VESSEL SYSTEM .}

The principal functions of the Vessel System (VS) are to contain the primary coolant inventory within a gas-tight pressure boundary and to provide the necessary flow paths and overpressure protection for this pressure boundary. The VS also houses and supports the components of the Reactor System (RS), the Heat Transport System (HTS), the Shutdown Cooling System (SCS), and minor components of other systems.

Each $350 \mathrm{MW}(\mathrm{t})$ reactor module consists of a reactor vessel and a steam generator vessel connected by a crossduct. The VS consists of the steel vessels and crossduct, penetrations, closures, and a pressure relief system. The steel vessels and crossduct designs use existing technology. The construction material is manganese-molybdenum, SA533 Grade B, Class 1 steel. The design temperature and pressure are $288^{\circ} \mathrm{C}\left(550^{\circ} \mathrm{F}\right)$ and $6.38 \mathrm{MPa}(925$ psia), respectively. The vessels are located below grade level, enclosed in a concrete structure. The concrete cavity partition walls and exterior walls plus the surrounding earth provide biological shielding.

The principal reactor vessel and steam generator vessel data are shown in Table 3-1.

The reactor vessel, shown on Figure $3-15$, has a $6.55 \mathrm{~m}(21.5 \mathrm{ft})$ inside diameter, a $13.3 \mathrm{~cm}(5.25 \mathrm{in})$ thickness at the side wall and lower head and a $15.6 \mathrm{~cm}$ ( $6.13 \mathrm{in})$ thickness at the upper head, and is $22 \mathrm{~m}(72 \mathrm{ft}$ ) 1ong. The reactor vessel is stiffened at the crossduct elevation and near the upper flange with a $19.0 \mathrm{~cm}(7.5 \mathrm{in})$ thickness to sustain seismic loading. The vessel is supported in a plane near the bottom at the crossduct elevation. In overall length, diameter, material, and fabrication technology, it is similar to a large boiling water reactor (BWR) vessel.

The shutdown cooling circulator is located at the reactor vessel bottom head. The circulator closures are part of the vessel system. The control rod drive housings and the fuel handing/control rod drive housings penetrate the reactor vessel top head. 
Table 3-1

REACTOR VESSEL AND STEAM GENERATOR VESSEL DATA

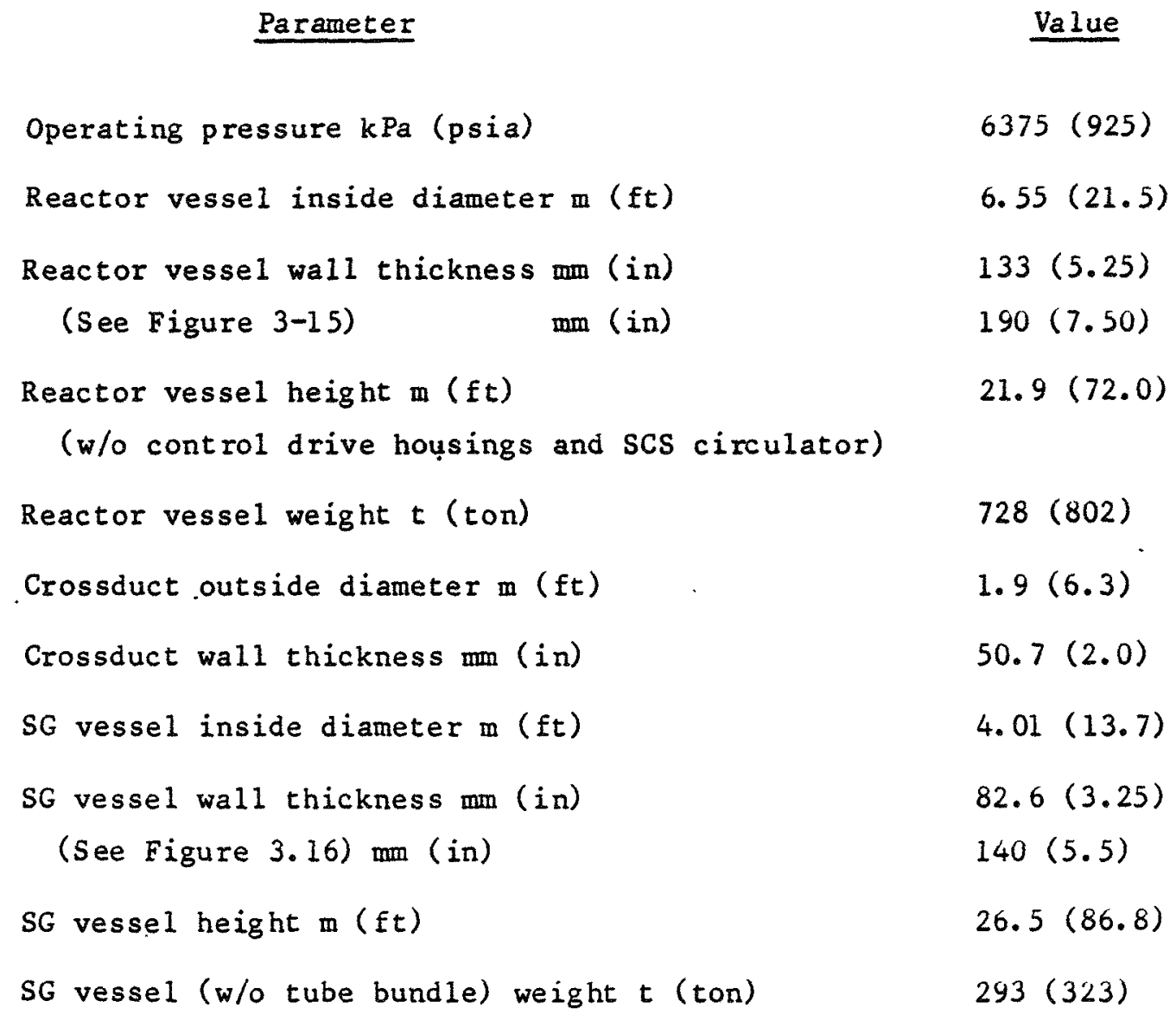




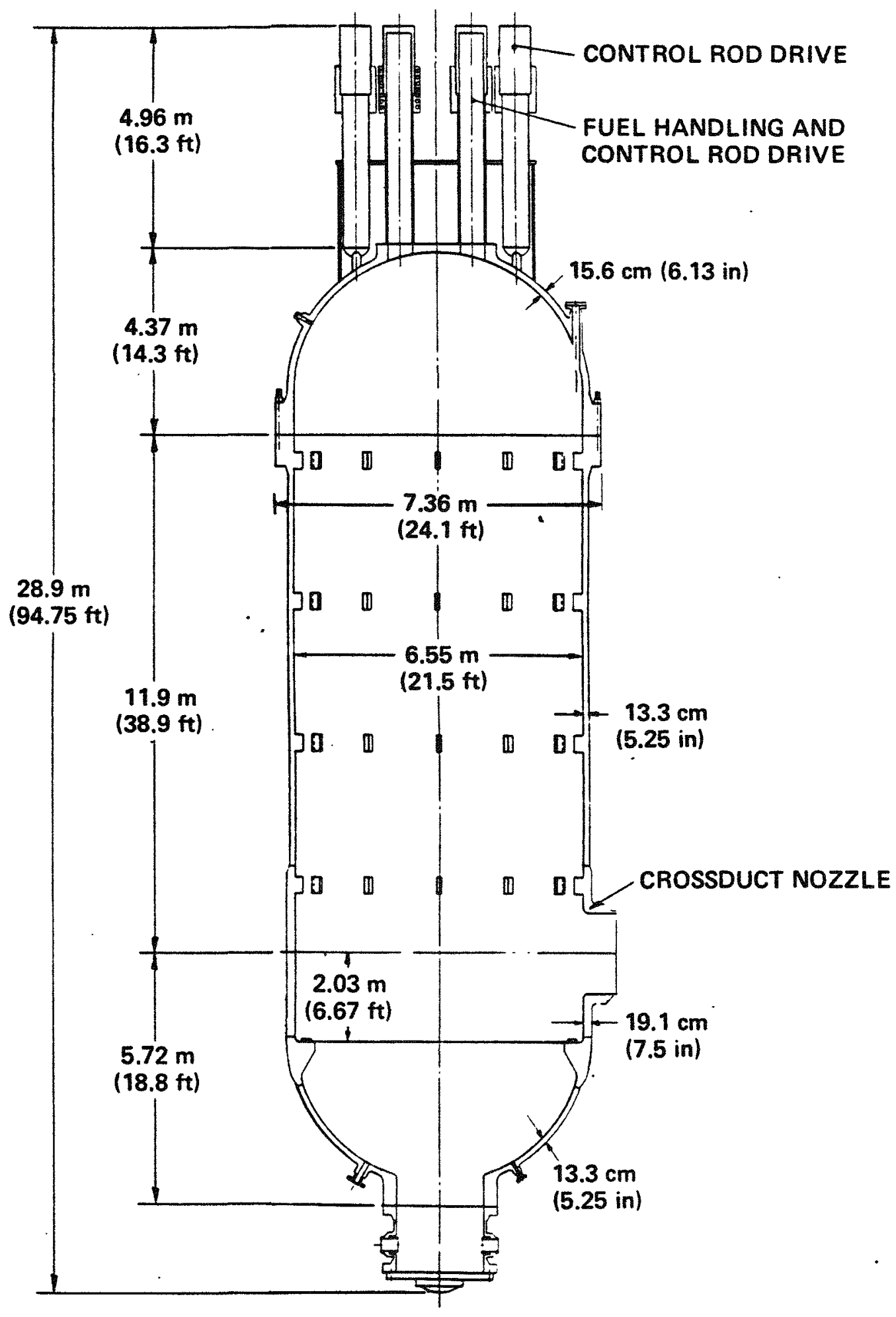

Figure 3-15 Reactor Vessel Arrangement 
The steam generator vessel, shown on Figure $3-16$, has a $4.01 \mathrm{~m}$ ( $13.7 \mathrm{ft})$ inside diameter, a $8.26 \mathrm{~cm}(3.25 \mathrm{in})$ thickness at the side wall, and is $28.9 \mathrm{~m}$ ( $94.96 \mathrm{ft})$ long. The vessel is $14.0 \mathrm{~cm}(5.5 \mathrm{in})$ thick at the crossduct elevation where it is supported. The steam generator is located in the bottom portion of the vessel and the main circulator is located at the top of the vessel.

The crossduct connects the reactor vessel and the steam generator vessel. Within the crossduct, the hot and cold gas streams are separated by an inner duct which is insulated to limit regenerative heat losses. The cold (core inlet) gas passes through the outside annulus and the hot (core outlet) gas passes through the inner circular duct. The duct outer wall shown on Figure 3-17 is $1.9 \mathrm{~m}(6.3 \mathrm{ft})$ in outside diameter and $5.1 \mathrm{~cm}(2.0 \mathrm{in})$ thick.

Pressure relief assemblies are designed to provide overpressure protection to ensure that the primary coolant pressure in the vessel system does not exceed the design pressure. These assemblies are connected to the upper head of the steam generator vessel. 


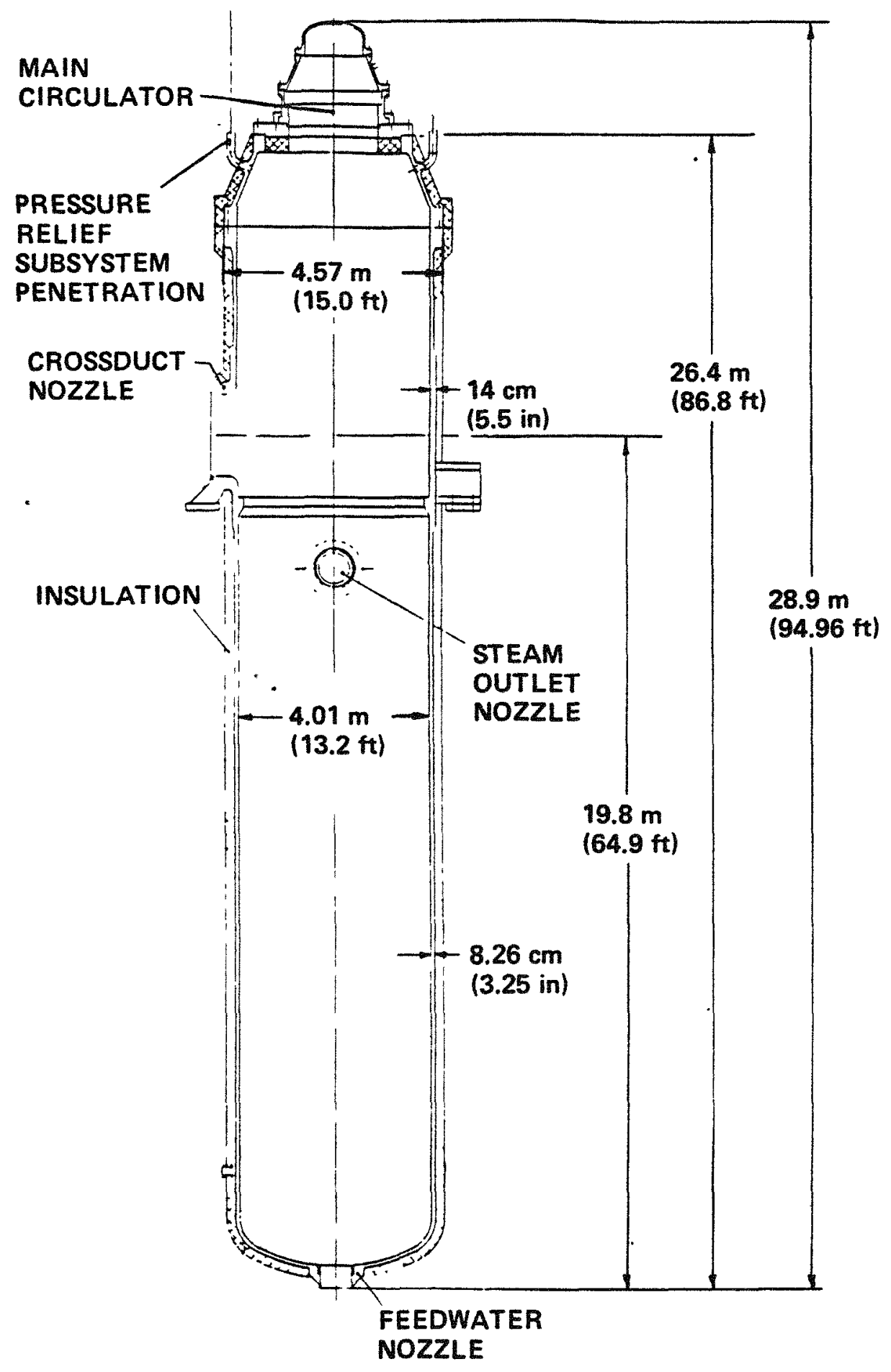

Figure 3-16 Steam Generator Vessel Arrangement 

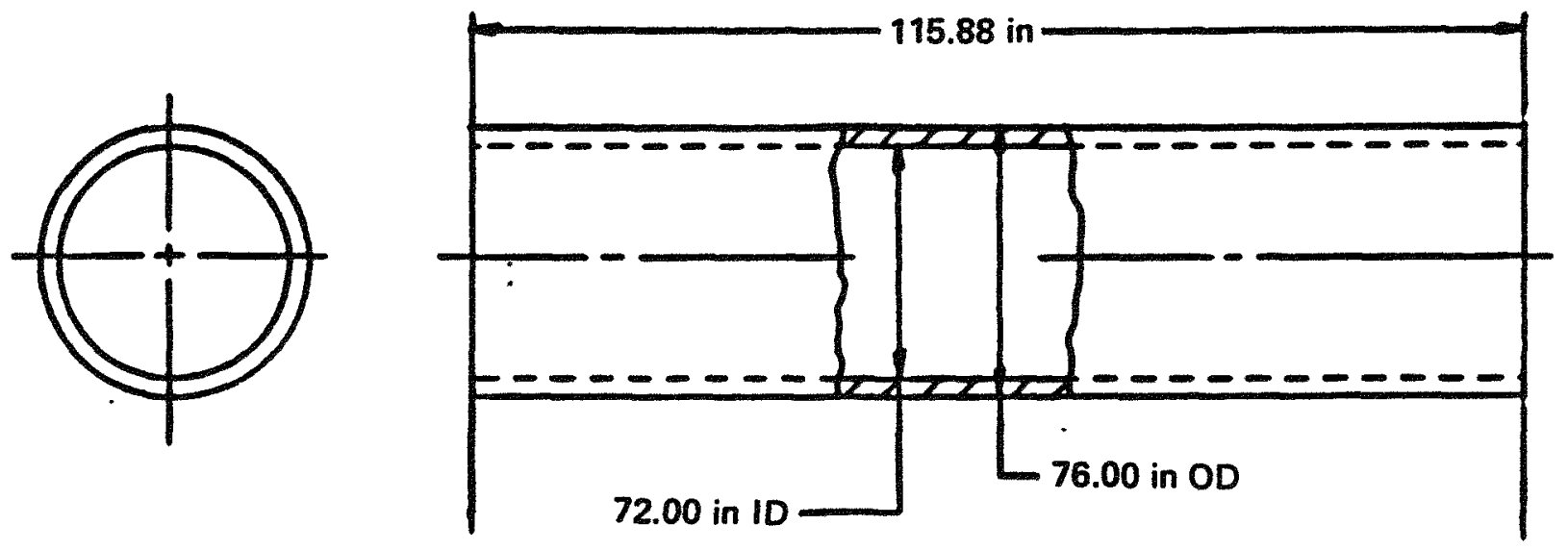

Figure 3-17 Crossduct Arrangement 


\subsection{HEAT TRANSPORT SYSTEM}

The Heat Transport System (HTS) consists of the Steam Generator Subsystem (SGS) and the Main Circulator Subsystem (MCS).

Figure 3-18 gives a three-dimensional overview of the HTS general arrangement and its relationship to the rest of reactor module. Not shown in this figure are the electric motor control and power module, the magnetic bearings and power module control, and the main loop shutoff valve service module. The electric motor control and power module is located outside the Reactor Building in the Auxiliary Building. The magnetic bearings control and power module and the main loop shutoff valve service module are located in the Reactor Building in close proximity to the main circulator (MC).

\subsubsection{Steam Generator}

The steam generator is located in the steam generator vessel, with its thermal center located below that of the reactor core. The steam generator (see Figures 3-19 and 3-20) is a vertically oriented, upflow boiling, crosscounter-flow, once-through shell-and-tube heat exchanger. It utilizes a multitube, helically wound tube bundle with a heat duty of $350 \mathrm{MW}(t)$. The design provides access for tube leak detection and plugging from both ends of each tube. In addition, the design makes possible the removal and replacement of the steam generator tube bundle through the removable upper vessel head even though the unit is designed with a service life equal to that of the plant. The steam generator data are listed in Tables 3-1 and 3-2.

The primary steam generator support is provided by the steam generator vessel at the bottom of the tube bundle. The ducting and shrouds forming the helium inlet and stagnation regions are supported at an elevation just below the crossduct. Seismic loads are taken through radial keys and lockup snubbers at the crossduct elevation and on the lower portion of the steam generator vessel. Support of the helical tube bundle is by means of drilled radial 


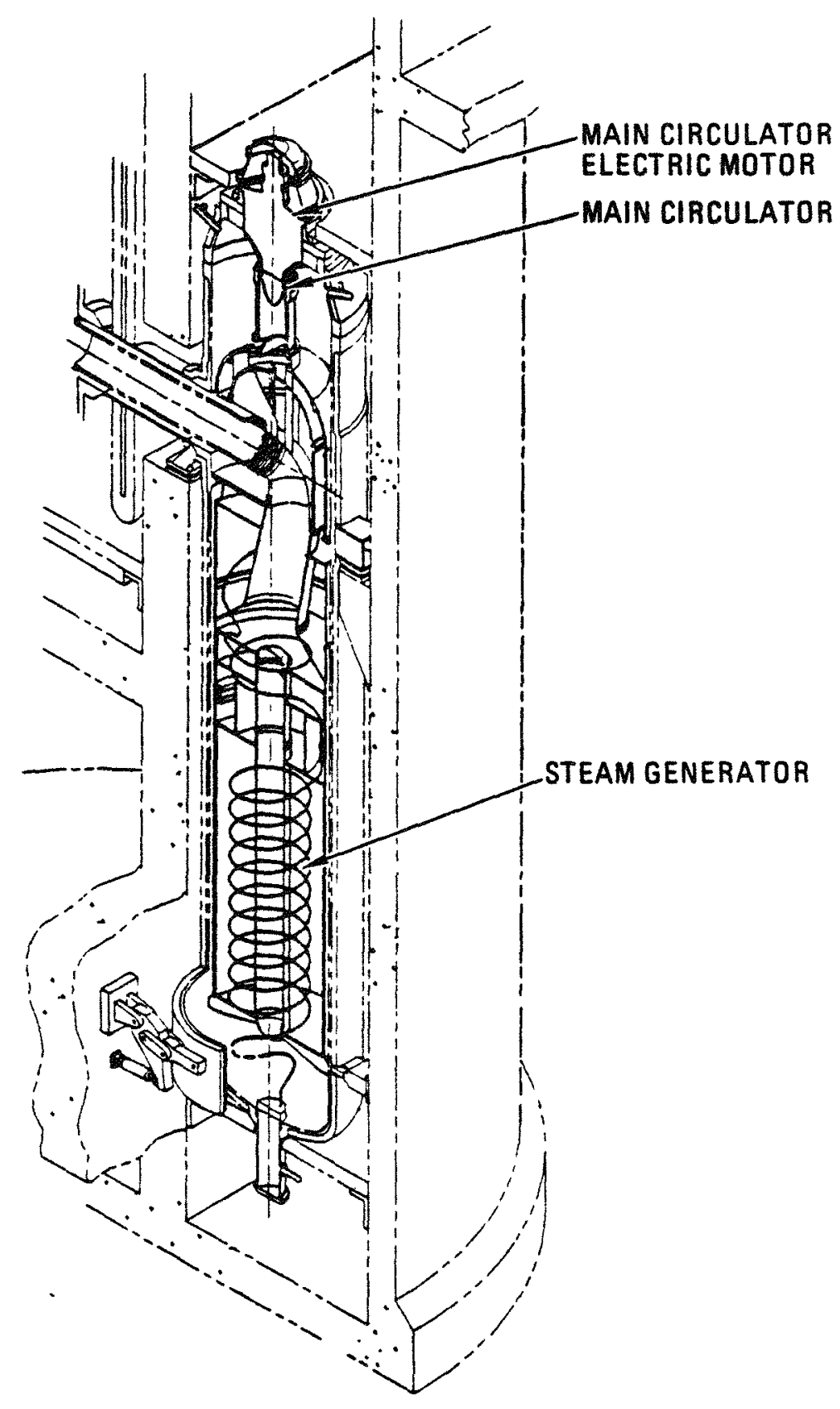

Figure 3-18 Heat Transport System Arrangement 


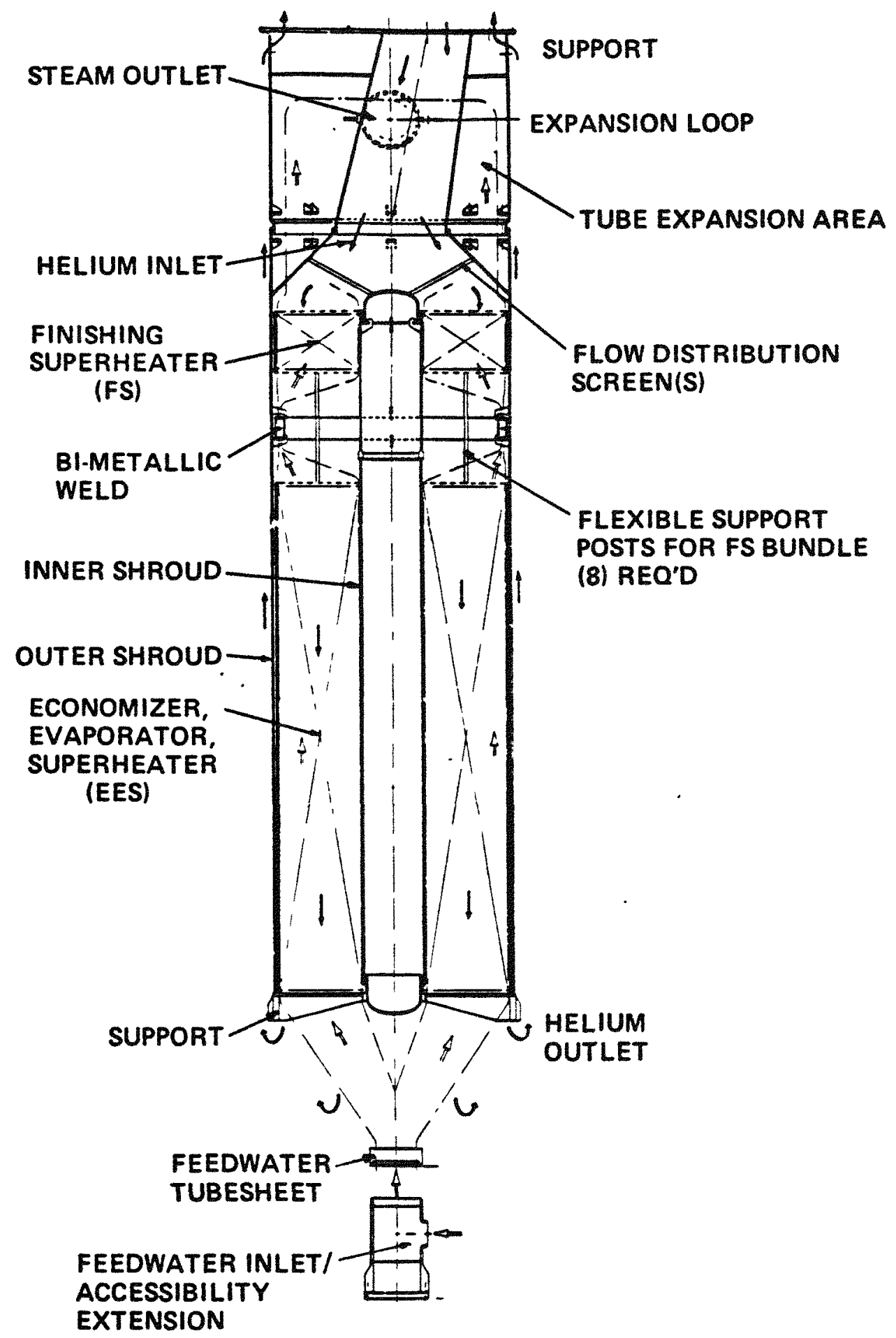

Figure 3-19 Steam Cenerator Configuration 


\section{MAIN STEAM GENERATOR}

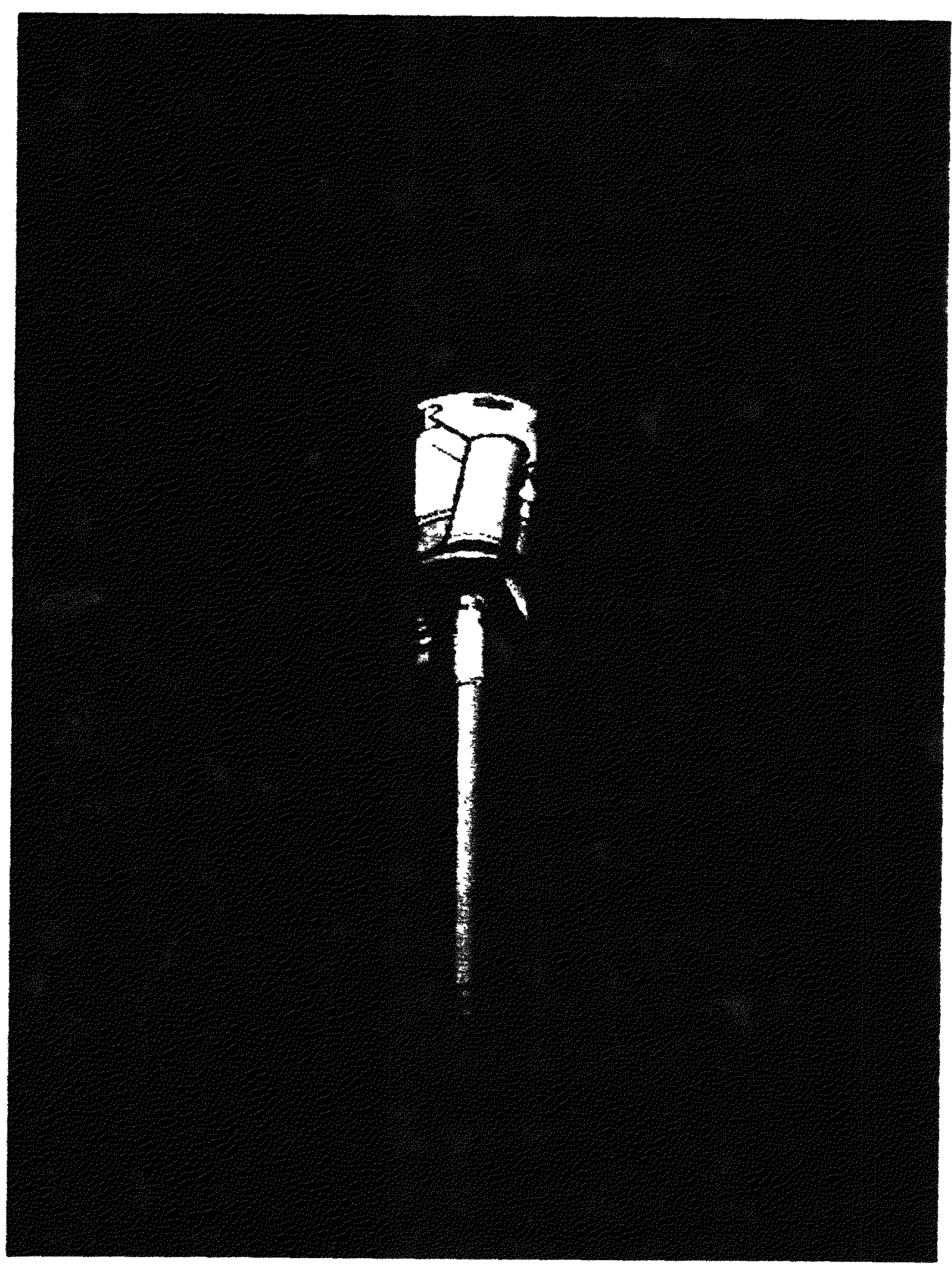

Figure 3-20 

Table 3-2

STEAM GENERATOR DATA

\section{Configuration}

Type

Water flow direction

Tube support method

(number of supports)

Feedwater tubesheet location

Supe rheated steam tubesheet location

Tube Bundle

$B$ undle height (inclusive of mid-elevation expansion region) $m(f t)$

Bund le

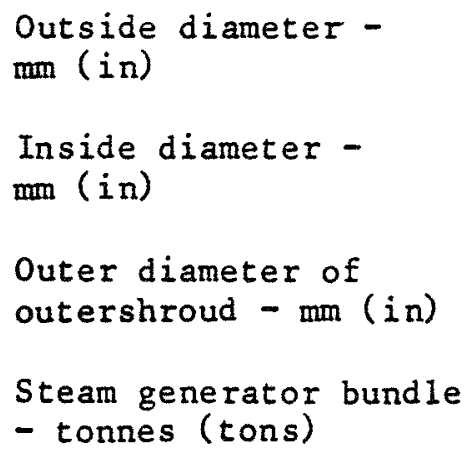

\section{Parameter}

Once-through helical, with mid-bundle expansion loop

Uphill boiling

Drilled radial plates

(4 full, 4 partial)

Bottom centerline of SG vessel

High in the $S G$ vessel on side

$10.56(34.63)$

$3560(140)$

$960(38)$

$3720(146.5)$

$208(229)$ 
Table 3-2 (Cont'd)

\section{Configuration}

Tube

$$
\begin{aligned}
& \text { Number of tubes } \\
& \text { Average tube length, } \\
& \text { (active heat transfer) } \\
& \text { m( } f t)
\end{aligned}
$$

Tube size -

Outer diameter mm (in)

Wall thickness $\operatorname{mon}(i n)$

\section{Parameters}

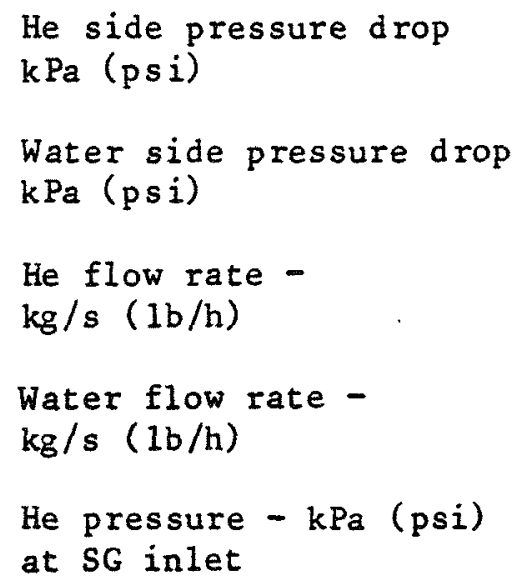

\section{Parameter}

350

$164.5(539.7)$

$22.2(0.875)$

$3.30(0.130)$
$25.5(3.70)$

$3400(485)$

$157.2\left(1.248 \times 10^{6}\right)$

$137.2\left(1.089 \times 10^{6}\right)$

$6310(915.8)$ 
support plates through which the tubes are wound. The plates are supported vertically at the lower extremity of the steam generator and horizontally by the inner and outer floating shrouds.

Feedwater is introduced through a nozzle assembly in the bottom of the steam generator vessel (see Figure 3-18); superheated steam is discharged through a nozzle assembly in the upper side wall of the steam generator vessel.

From the feedwater tubesheet, the tubes are splayed out to form a lower-bundle expansion loop (this expansion loop accomodates the differential expansion between the feedwater tubesheet and the lower extremity of the tube bundle) and routed to the lower end of the helical section of the tube bundle. After being spiraled upward through the economizer/evaporator/initial superheater section of the tube bundle, the tubes are splayed outward to the peripheral region of the tube bundle envelope to form a mid-bundle expansion loop. This mid-bundle expansion loop is used to help accommodate differential radial expansion between the economizer/evaporator/initial superheater bundle and the finishing superheater bundle. The bi-metallic tube weld is located in this region. Above the mid-bundle expansion loop, the tubes are routed inward to form the helical finishing superheater bundle. After having spiraled through the finishing superheater bundle, the tubes are routed to form an upper-bundle expansion loop (to accommodate the gross axial expansion which will exist between the bundle and steam generator vessel) and converged to their attachment points on the superheated steam outlet tubesheet.

Hot helium enters a plenum above the steam generator bundle from the hot duct. The gas flows downward across the heat transfer surface between the inner and outer steam generator shrouds, and exits into a lower outlet plenum. In this plenum, the helium is turned 180 degrees into a return annulus formed between the outermost shroud and the steam generator vessel wall. After flowing upward in this annulus, the gas enters the circulator inlet plenum. 


\subsubsection{Main Circulator}

The circulator assembly is installed in the top plane of the steam generator vessel (see Figures $3-21$ and 3-22). Based on preliminary studies, a single stage axial flow unit was selected. The electric motor is submerged in the system and forms an integral part of the compressor rotor. The rotating assembly is fully floating on a set of active magnetic bearings, backed up with a set of antifriction catcher bearings.

The circulator consists of the following components:

1. Electric motor/compressor rotor assembly

2. Compressor stator and diffuser assembly

3. Electric motor stator and internal structural supports

4. Helium-to-water heat exchanger

5. Two radial and one double acting axial, active magnetic bearings

6. Two angular contact (radial-axial), catcher bearings

7. Hermetically sealed connectors for electric power, cooling water, helium buffer, magnetic bearing controls and inst rument ation

Primary flow control is provided by the variable speed motor capability; the circulator is required to operate over the range of $310 \mathrm{rpm}$ ( 5 percent) to a maximum $6280 \mathrm{rpm}$ ( 110 percent). Upstream of the compressor impeller a flowactuated check valve is incorporated in the cylindrical inlet duct. This valve isolates the heat transport system from the reactor vessel when the circulator is not operational (i.e., prevents natural circulation flow of hot gas entering the steam generator). The valve consists of two semi-elliptical plates which are held open by the circulator dynamic head, and closure is effected by gravity. A helium jet mechanism to assist in closing the valve (if necessary) is included in the design. 


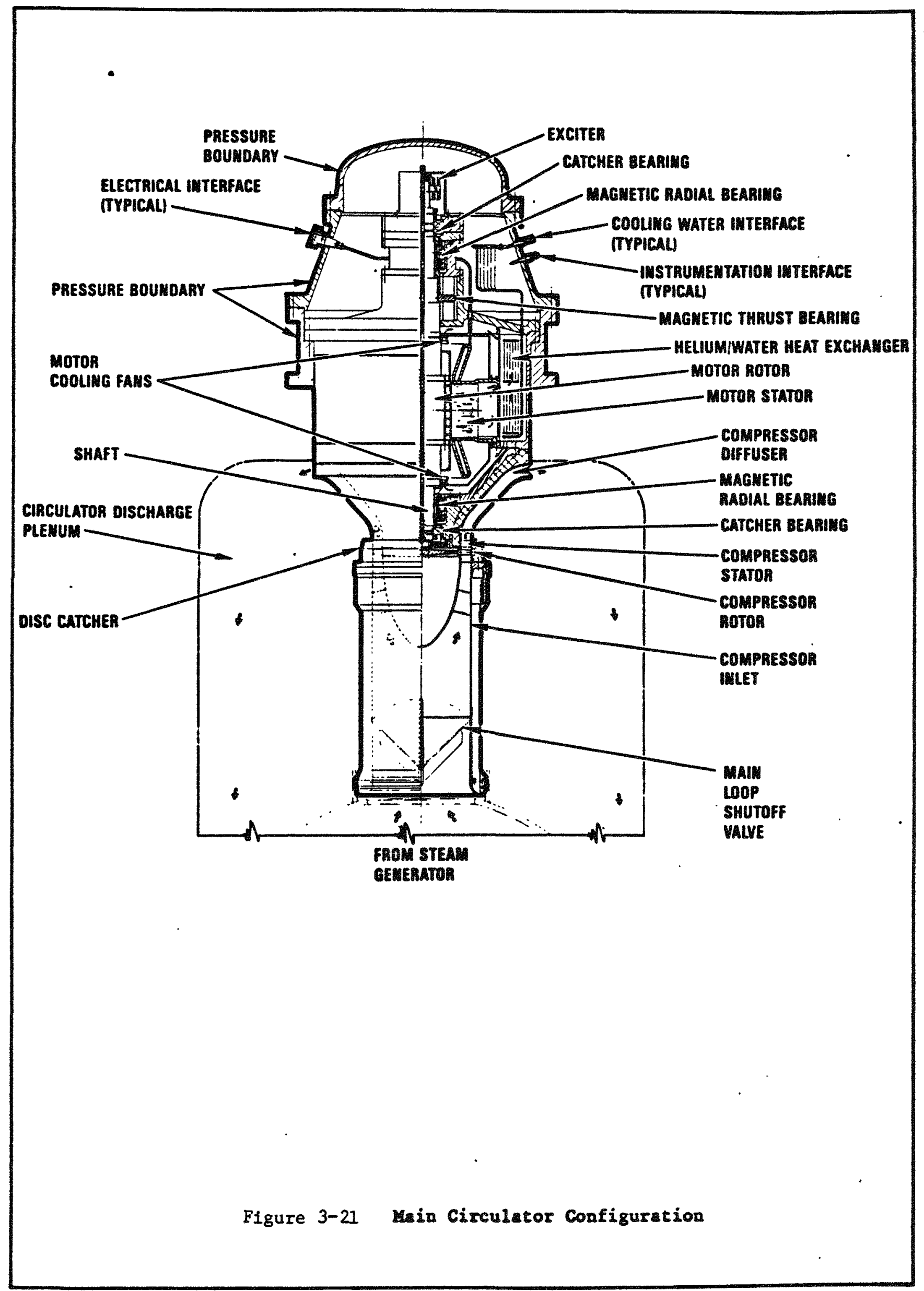




\section{MAIN HELIUM CIRCULATOR}

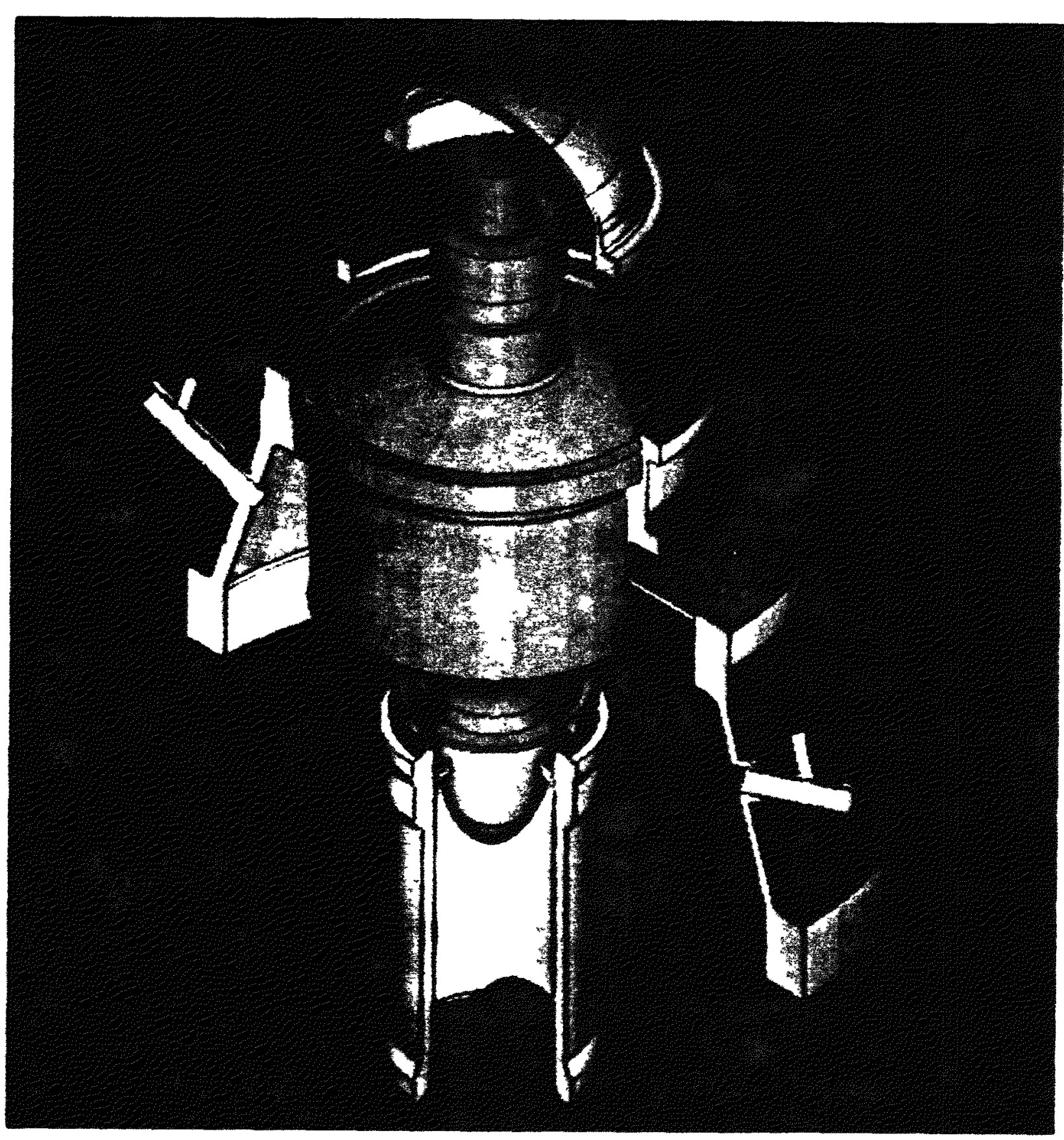

Figure 3-22 


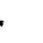


For the reference circulator design a bearing trade study led to the selection of active magnetic bearings. The magnetic bearings (to accommodate radial and axial thrust loads) consist of two fully redundant circuits, which include sensors, electromagnets, and electronic controls. The advantages of magnetic bearings for this application are:
- Unlimited Bearing Service Life (No contact or wear surfaces)
- High Rotational Speed Capability
- Elimination of System Contamination by Lubricant Ingress
- Reduced Bearing Frictional Losses
- Elimination of Lubrication System and Complex Seals
- Vibration Free Operation (Ability to pass critical speeds)
- Alignment and Balancing Simplification
- Continuous Monitoring of Rotor
- Reduced Maintenance
- Potential for High Reliability

Since the active magnetic bearing is a non-contact bearing, some means must be provided as a backup to ensure that no harmful rotor-to-stator contact occurs in the unlikely event that both primary and secondary electrical power sources are lost. A metallic ball-bearing catcher system is incorporated in the machine.

The helium compressor is driven by a variable speed electric motor submerged in a helium environment. Studies led to the selection of a 3,210 KWe (4302 hp) variable speed, nonsalient pole, vertical synchronous motor. It has a brushless exciter that embodies a solid-state rectifier designed for variable speed operation. The motor speed controller is a solid-state adjustable frequency power supply with output ratings compatible with motor operating and stability requirements over the entire speed range.

A sumary of the major features of the circulator is given on Table 3-3. 
Table 3-3

MAJOR FEATURES OF MAIN CIRCULATOR

\begin{tabular}{|c|c|}
\hline & Design Data \\
\hline $\begin{array}{l}\text { Design } \\
\text { Conditions }\end{array}$ & $\begin{array}{l}\text { Helium Flow, } \mathrm{kg} / \mathrm{sec}(\mathrm{lb} / \mathrm{sec}) \\
\text { Inlet Temperature, }{ }^{\circ} \mathrm{C}\left({ }^{\circ} \mathrm{F}\right) \\
\text { Inlet Pressure, MPa (psia) } \\
\text { Circulator Pressure Rise, } \mathrm{kPa} \text { (psi) }\end{array}$ \\
\hline $\begin{array}{l}\text { Compressor } \\
\text { Details }\end{array}$ & $\begin{array}{l}\text { Compressor Type } \\
\text { Rotational Speed, rpm } \\
\text { Compressor Tip Diameter, mo (in) } \\
\text { Tip Speed, m/s (ft/s) } \\
\text { Overall Efficiency, \% } \\
\text { Flow Control: }\end{array}$ \\
\hline $\begin{array}{c}\text { Mechanical } \\
\text { Features }\end{array}$ & $\begin{array}{l}\text { Installation } \\
\text { Machine Orientation } \\
\text { Bearing Type } \\
\text { Catcher Bearing Type } \\
\text { Catcher Bearing Lubrication } \\
\text { Rotor Weight, kg (Ib) } \\
\text { Overall Machine Diameter, m(ft) } \\
\text { Overall Machine Length, m (ft) }\end{array}$ \\
\hline Motor Drive & $\begin{array}{l}\text { Configuration } \\
\text { Motor Drive } \\
\text { Power, kWe ( hp) }\end{array}$ \\
\hline Design Status & $\begin{array}{l}\text { Equipment Classification } \\
\text { Design Status } \\
\text { Technology Status }\end{array}$ \\
\hline
\end{tabular}

Parameter

158 (348)

$255(491)$

$6.29(912)$

$91(13.2)$

Single stage axial

flow

$6200(100 \%)$

$889(35.0)$

$289(947)$

80

Variable speed

Top of steam generator vessel

Vertical

Magnetic bearings

Duplex ball bearings

Dry-film

2722 (6000)

$2.4(8.0)$

$3.7(12.0)$

Submerged in reactor system

Variable speed synchronous motor 3210 (4302)

Non-safety class component

Preconceptual

state-of-the-art 


\subsection{SHUTDOWN COOLING SYSTEM}

The Shutdown Cooling system (SCS) consists of the shutdown cooling Circulator Subsystem (scCS), the Shutdown Cooling Heat Exchanger Subsystem (SCHES), and the shutdown Cooling Water subsystem (SCWS). The scS consists of a single loop (per module) on the helium side with a shutdown cooling heat exchanger (SCHE) in series with a shutdown cooling circulator (SCC) and shutdown loop shutoff valve (SLSV) assembly located at the bottom of the reactor vessel. A single water cooling loop services all four reactor modules. Heat is rejected from the sCWS to the Service Water system. The heat exchanger, circulator, and cooling water subsystems are described in more detail in subsequent sections.

The SCWS is sized to cool all four reactor modules simultaneously, immediately following reactor trip and loss of HTS cooling (pressurized). This results in a peak cooling capacity of $23.7 \mathrm{MW}(\mathrm{t})\left(80.9 \times 10^{6} \mathrm{Btu} / \mathrm{hr}\right)$ per module $\left[6.8\right.$ percent of rated reactor power of $350 \mathrm{MW}(t)\left(1194 \times 10^{6} \mathrm{Btu} /\right.$ $h r)]$ or a total plant capacity of $94.8 \mathrm{MW}(\mathrm{t})\left(323 \times 10^{6} \mathrm{Btu} / \mathrm{hr}\right)$. In addition, the SCC and the SCHE are sized to remove $3.0 \mathrm{MW}(t)\left(10 \times 10^{6}\right.$ $\mathrm{Btu} / \mathrm{hr}$ ) per module under depressurized maintenance conditions at one day after reactor shutdown.

For high reliability the SCS can be powered by either normal or standby non-Class $1 E$ electrical power.

Figure 3-21 illustrates the location of the heat exchanger and the circula- tor in the SCS cooling loop and its relationship to the rest of the NSSS. Components of the SCC service module are located within the Reactor Building close to the circulator. All major components of the SCWS are located in the Nuclear Is land Cooling Water Building. 


\subsection{Shutdown Cooling Heat Exchanger (SCHE)}

The SCHE is located below the core support floor shield at the bottom center line of the reactor vessel as shown on Figure 3-23; the detail design is shown on Figure 3-24 and 3-25. It is a vertically-oriented, shell-and-tube, cross-counter-flow heat exchanger with subcooled water in the tubes and helium on the shell side. The helical tubes are supported by drilled radial plates. The entire SCHE assembly is removable through the shutdown cooling circulator penetration at the bottom of the reactor vesse1. Key parameters of the SCHE are given in Table 3-4.

Water inlet and outlet are through the tubesheets located in the lower region of the heat exchanger. The tubes are attached to the inlet tubesheet, routed to the helical bundle, spiraled upward through the helical bundle, and routed back down to the outlet tubesheet. Thus, the tubes are continuous from tubesheet to tubesheet and are accessible from both ends for tube plugging.

Helium enters the bundle via the core outlet plenum and flows downward over the cross-counterflow helical bundle, through the shutdown loop shut off valve, and is returned to the lower reactor vessel cavity through the shutdown cooling circulator and the annulus formed between the bundle shroud and vessel wall.

The shutdown heat exchanger transfers heat from the helium to the cooling water flowing through the tubes. During normal plant operation, the secondary coolant (water) is at a pressure less than the primary coolant (helium) so that any leaks result in flow of helium into the water side. Therefore, leaks will be detected on the water side. However, during depressurized conditions, leakage would be in the reverse direction.

\subsubsection{Shutdown Cooling Circulator}

The design condition for this circulator is with the reactor system depressurized, yet a requirement exists for very low speed operation when 


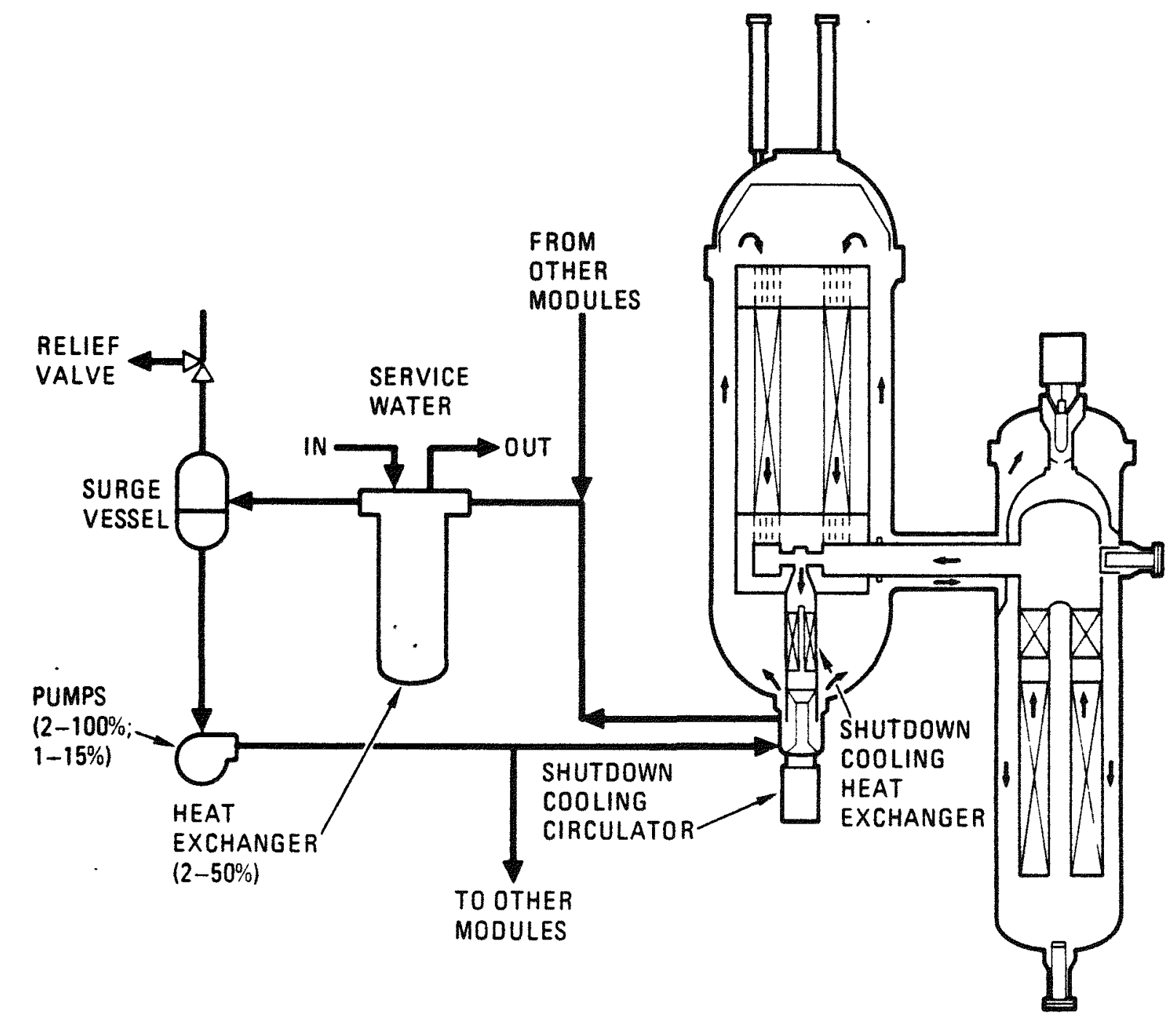

Figure 3-23 Shutdown Cooling System Configuration 


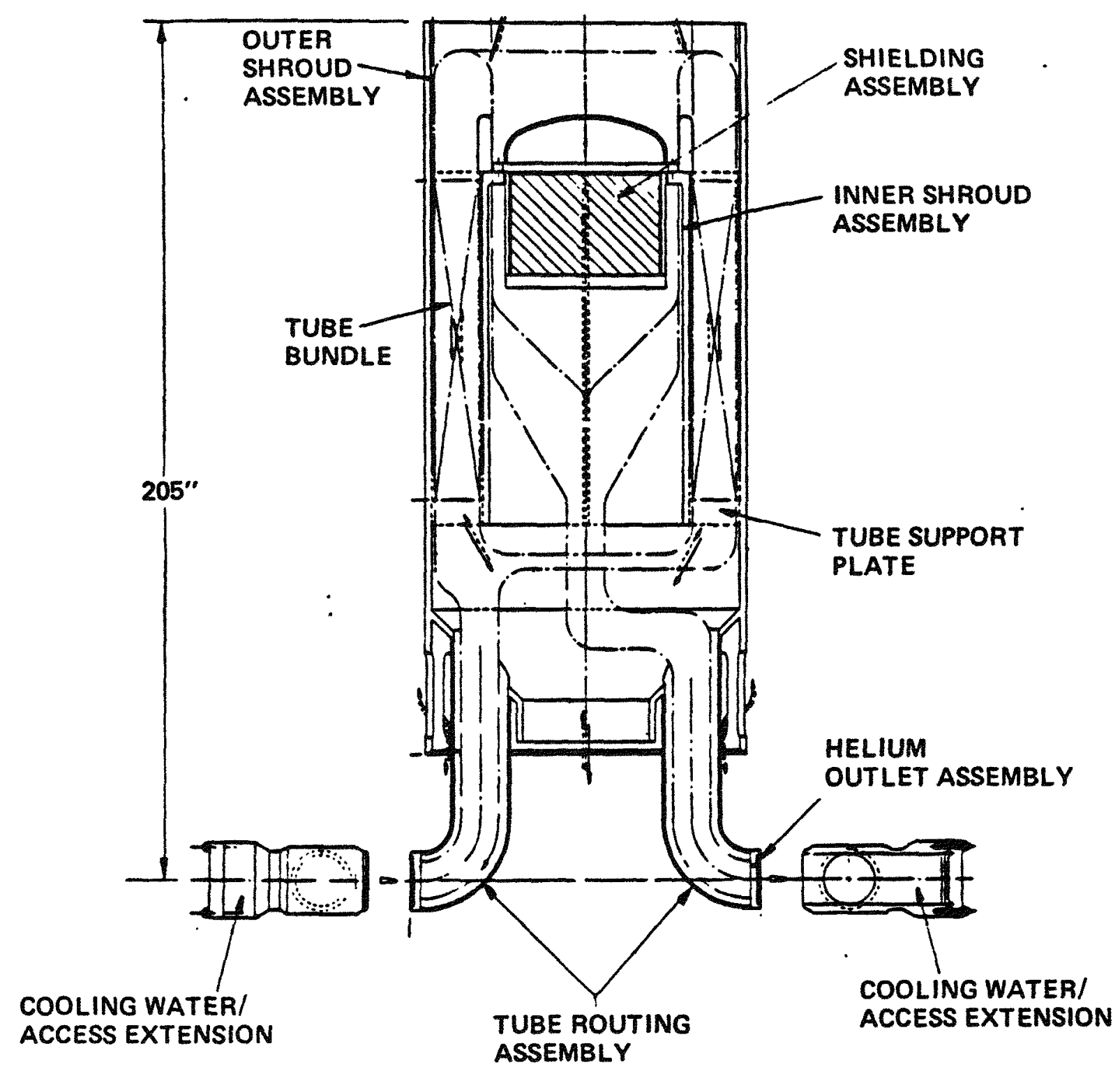

Figure 3-24 Shutdown Cooling Beat Exchanger Configuration 


\section{SHUTDOWN CIRCULATOR AND HEAT EXCHANGER}

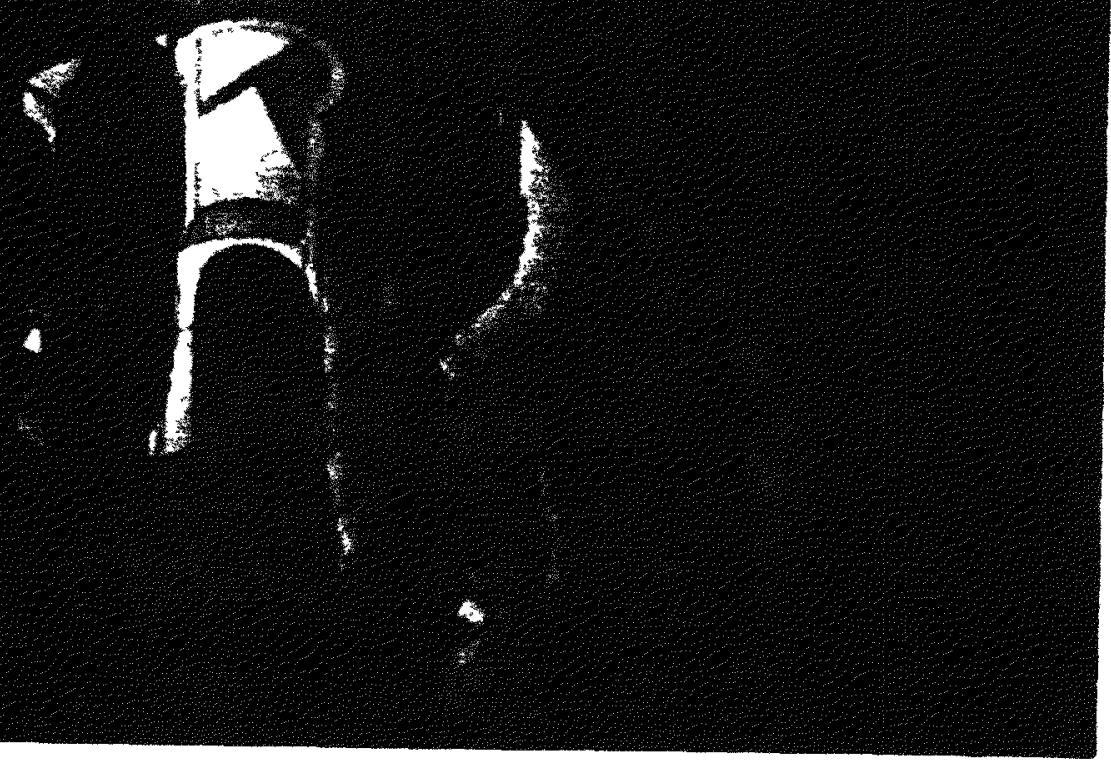

Figure 3-25 
Table 3-4

SHUTDOWN COOLING SYSTEM DATA

Item

Item

Shutdown Circulator

Exit pressure, $\mathrm{kPa}$ (psia)

Inlet temperature, ${ }^{\circ} \mathrm{C}\left({ }^{\circ} \mathrm{F}\right)$

Helium pressure drop, $\mathrm{kPa}$ (psi)

Helium flow, $\mathrm{kg} / \mathrm{h}(\mathrm{lb} / \mathrm{h})$

Horsepowe $r, \mathrm{~kW}\left(h_{p}\right)$

Speed, rpm

$\frac{\text { Parameters }}{\text { (Depressurized state) }}$

$97(14.0)$

72 (161)

$3.66(0.53)$

$13,300(29,320)$

149 (200)

10,000

Shutdown Heat Exchanger

Heat duty (depressurized), MW( $t$ )

3.0

Surface area, $\mathrm{m}^{2}\left(\mathrm{ft}^{2}\right)$

138.6 (1492)

No. of tubes

Weight ${ }^{(a)}, t$, (ton)

43

Tube bundle height, $m$ ( $f t$ )

$18.1(20)$

Outer shroud, i.d., m (in)

$1.94(6.35)$

Active tube length, m ( $f t$ )

$1.86(73.25)$

$46.18(151.5)$

(a) Weights in dry weights of the heat exchanger plus the spool piece 
pressurized. Operating with a very low inlet gas density it was clear that the adiabatic head (i.e., pressure rise/density) of $4420 \mathrm{~m}(14,500 \mathrm{ft}$ ) exceeded the capability of a single stage axial flow compressor.

Using the same analytical procedures as for the main circulator a design concept was established based on a two-stage axial flow configuration, and a layout of the machine is shown on Figure 3-26. No trade studies have been performed at this stage of conceptual design; however, advantage was taken of experience in the design of the auxiliary circulator for the large HTGR.

The SCC is a two stage axial flow vertically oriented machine driven by an integral electric motor. The motor is submerged in the primary coolant and its housing serves as a reactor vessel closure. Installed in the bottom of the reactor vessel the machine is accessible for inspection, repair, and replacement. The shaft and rotor are supported on oil-lubricated rolling element bearings which cariy the axial and radial loads. The bearings are located on each end of the motor rotor, and the compressor is overhung. Each bearing is mounted on the shaft through an inverted U-shaped extension. Oil is prevented from escaping down the shaft by a stationary dam. Oil vapor is prevented from entering the primary coolant circuit by means of a labyrinth seal, buffered by purified helium flow.

The circulator drive is a four-pole squirrel-cage induction motor. In order to meet the wide range of required operating conditions (depressurized and pressurized) the electric motor has a solid-state variable frequency speed controller. Motor cooling is performed by circulating cool helium through the rotor and stator windings with small shaft-mounted fans.

The major features of the SCS circulator established to date are given on Table 3-5. The proposed design is not considered optimized, but is technically defensible. In follow-on conceptual design efforts, the following should be addressed, 1) establish parameters that are compatible with a single stage compressor, and 2) establish a design concept with magnetic bearings, to obviate the need for oil-lubrication. 


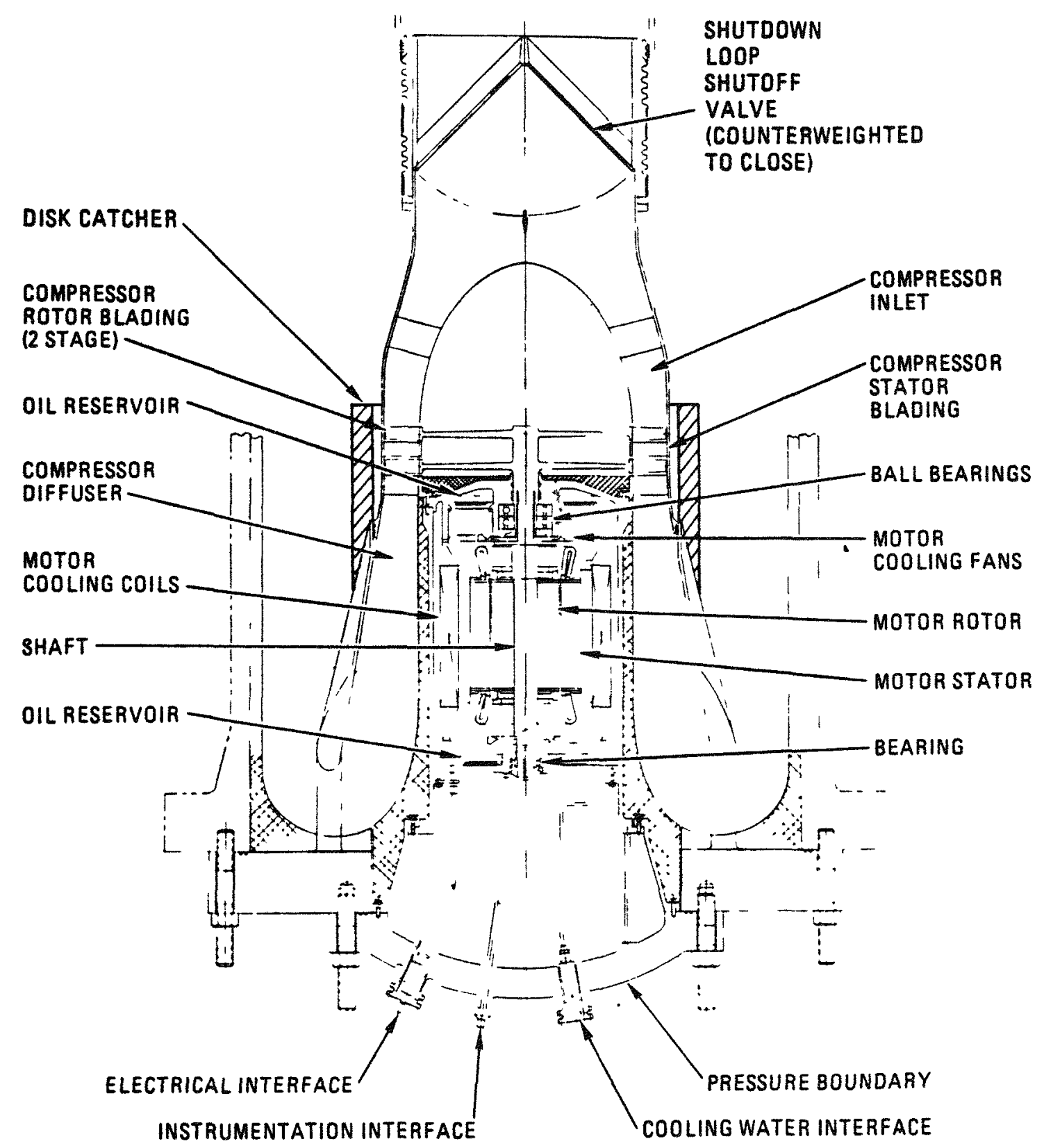

Figure 3-26 Shutdown Cooling Circulator Configuration 
Table 3-5

MAJOR FEATURBS OF SHUTDOWN COOLING CIRCULATOR

Design Data

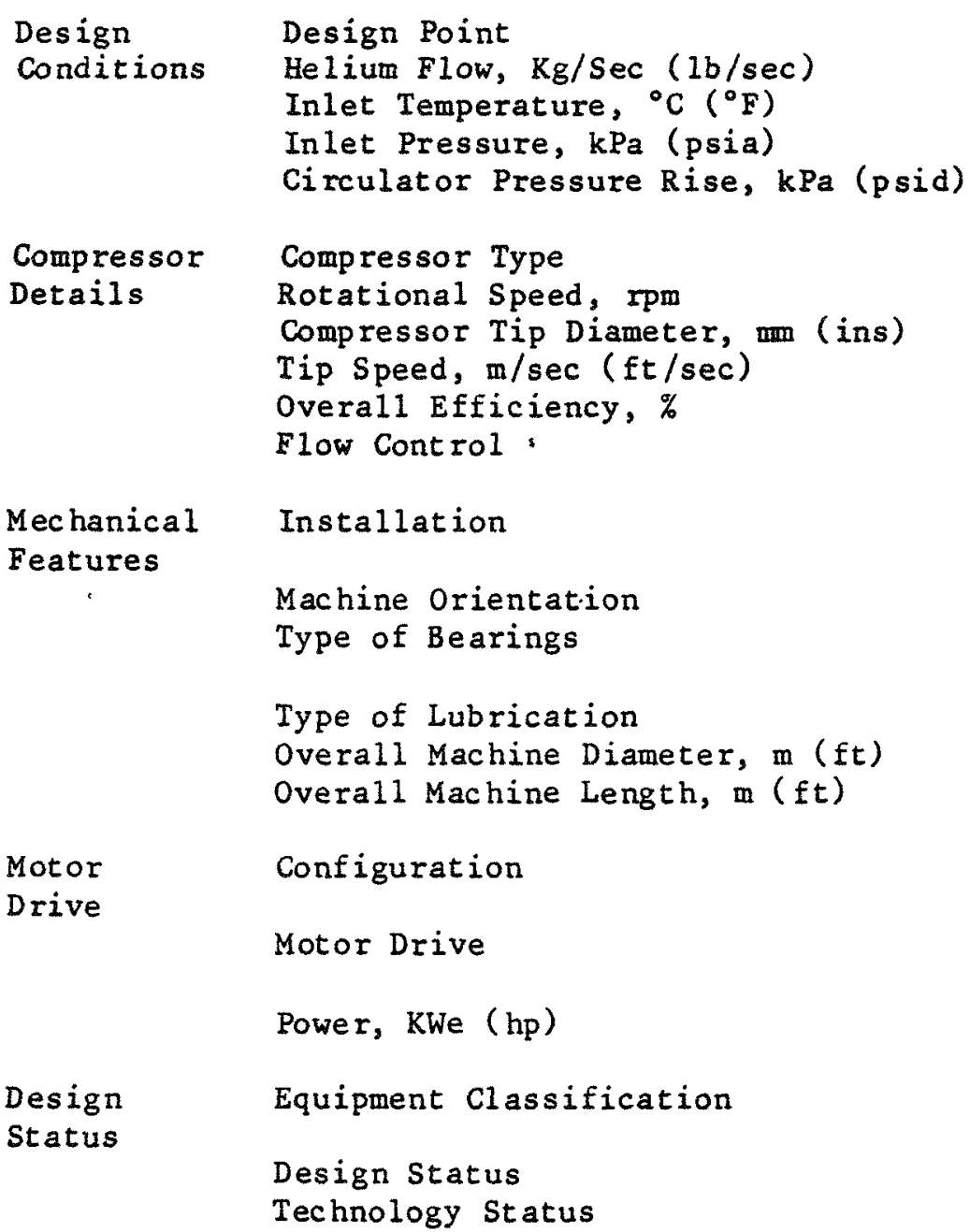

Parameter

Reactor depressurized

$2.89(6.36)$

$116(240)$

$97(14.0)$

$4.92(0.713)$

Two-stage axial flow

10,000

737 (29)

386 (1265)

80

Variable speed

Bottom of reactor

-vesse 1

Vertical

Tandem rolling element

oil-lubricated

$1.02(3.3)$

$2.6(8.5)$

Submerged in reactor system

Squirre1-cage induction motor

154(207)

Non-safety class component

Preconceptual

State-of-the-art 


\subsubsection{Shutdown Cooling Water Subsystem}

The shutdown cooling water subsystem (SCWS) is a closed cooling loop that serves all four reactor modules. The function of the SCWS is to remove heat from the SCHE and SCC and reject this heat to the service water system.

The design consists of two 100 percent capacity (one backup) pumps, one 15 percent jockey pump, and two 50 percent capacity shell and tube heat exchangers. The system has two modes of operation:

- Standby mode -- normal power operation, approximately $1.2 \mathrm{MW}(t)$ total heat rejection using the jockey pump

- Cooldown mode -- SCS cooling with loss of one or more HTS loops resulting in heat loads ranging from $95 \mathrm{MW}(t)$ to $12 \mathrm{MW}(t)$

In the standby mode, the 'system must operate continuously to remove heat leaking to the SCHE and SCS circulator. In the cooldown mode, the SCS accelerates cooldown to temperatures compatible with maintenance activities and maintains decay heat removal. The highest heat load corresponds to a simultaneous loss of all the four HTS loops and the lowest heat load corresponds to the end of a 24 hours cooldown with only one HTS loop out of service.

The arrangement of components allows continued operation if either pump fails and maintenance of one 50 percent heat exchanger in the standby mode. The system includes a flow controller to maintain a constant flow rate through the SCHE. 


\subsection{REACTOR CAVITY COOLING SYSTEM}

A unique feature of the Standard MHTGR is the use of an uninsulated steel reactor vessel to provide a passive decay heat removal path from the core to the reactor cavity. The air-cooled Reactor Cavity Cooling system (RCCS) provides a passive means for removing this decay heat from the reactor cavity to the outside environs.

During normal shutdown, decay heat is removed through the steam generator and associated Heat Transport System or through the Shutdown Cooling System; however, in the event that these paths are not available, decay heat is then removed by conduction through the graphite reflector and by radiation and convection from the uninsulated reactor vessel to the RCCS cooling panels which form a cylindrical wall around the vessel. The RCCS removes heat from the reactor cavity by the natural circulation of outside air through the cooling panels.

The natural draft air cooling concept is shown schematically in Figure 3-27. The design has no valves or active components. The surface of the cooling panels serves as a barrier separating the outside atmosphere from the reactor cavity atmosphere. This minimizes the off-site radiological dose due to release of air activated in the reactor cavity. The RCCS consists of cooling panels located in the reactor cavity, two inlet/outlet structures on the Reactor Building above grade, and air ductwork connecting the panels and inlet/outlet structures.

The general layout of the system down to the top of the cooling panels is shown in Figure 3-28. The rectangular outlet duct is routed inside the inlet air passage to protect the structural concrete from the hot outlet air. The outlet duct is insulated to minimize regenerative heating of the inlet air. The inlet passage is not actually a metal duct but a passage in the Reactor Building st ructure.

Four pairs of inlet/outlet ports provide a high degree of redundancy in the 
$[$ COXWL $-434-$ WOR $]$

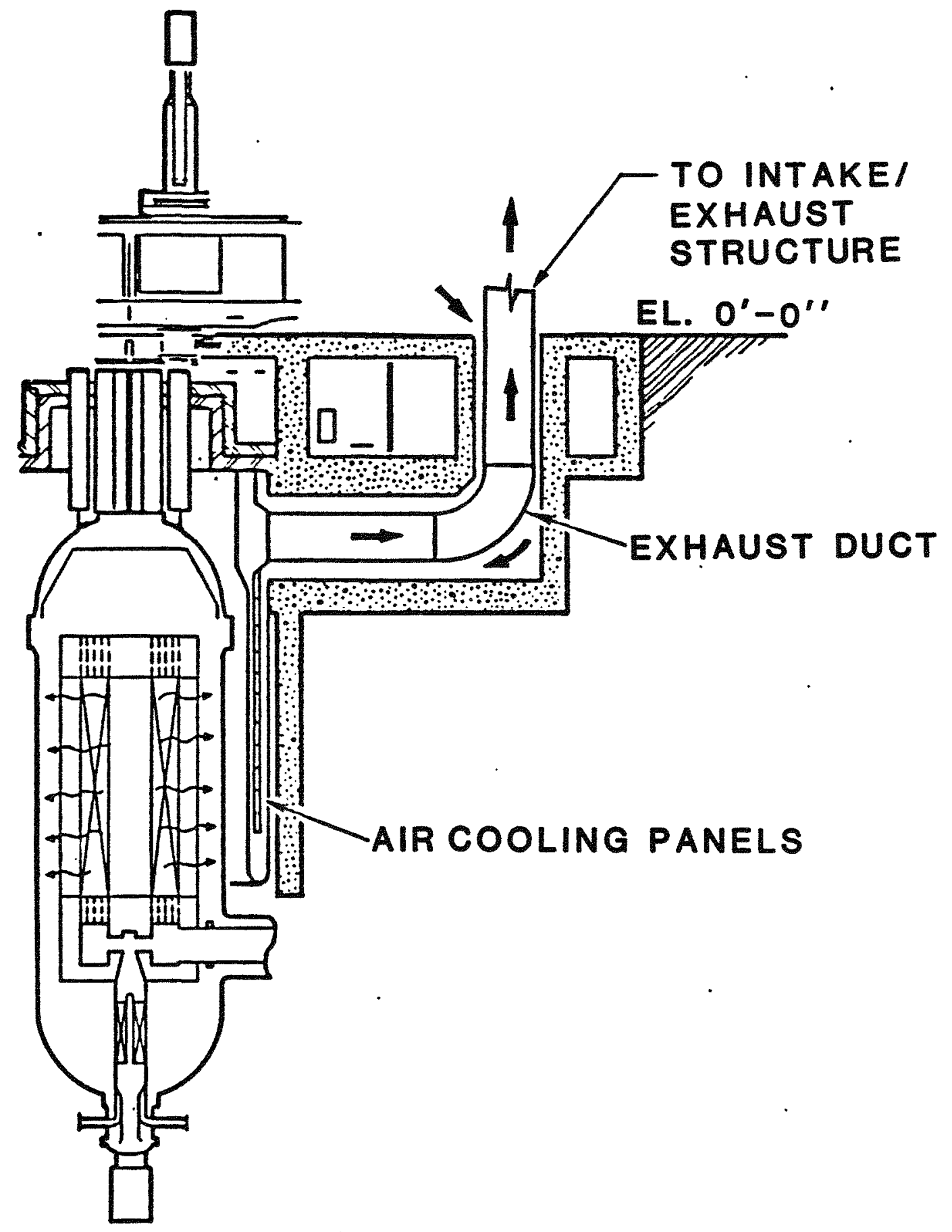

Figure 3-27 Passive decay heat removal 


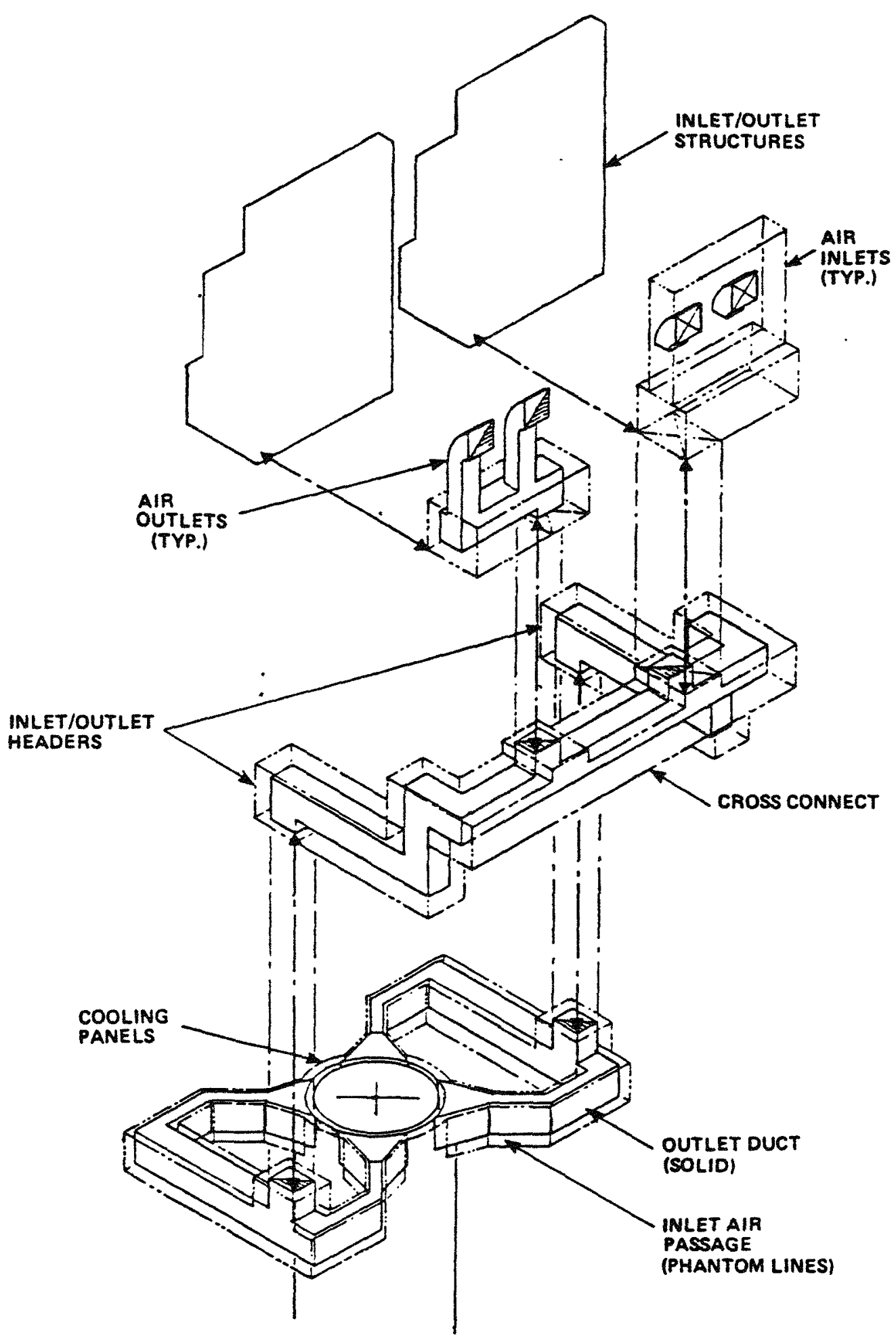

Figure 3-28 Air RCCS Ductwork Isometric 
event of inlet/outlet blockage. The inlet/outlet ports are housed in two separate inlet/outlet structures. These structures are tornado missilehardened and designed to meet seismic requirements.

Since all the cooling panels are cross-connected at the plenum section, blockage of one or more inlets or outlets will not prevent cooling air from reaching all the panels. The air inlet is located high enough above grade to discourage unauthorized access and to minimize blockage by wind-borne debris. The inlet also has gratings and screens for protection from tornado missiles, birds, and wind-borne debris. The inlet is large to minimize the pressure loss due to the screens and to reduce the possibility of total inlet blockage. The outlet duct is run as high as practical, currently $25.9 \mathrm{~m}(85 \mathrm{ft}$ ) above the top of the core, to maximize natural circulation (chimney effect). With the Reactor Building embedded, this results in an outlet duct extending only $13.7 \mathrm{~m}$ ( $45 \mathrm{ft}$ ) above grade.

The ducts between the cooling panels and inlet/outlet structures are routed with a number of elbows in order to minimize neutron streaming through the ducts.

The cooling panels protect the cavity walls from overheating during normal operation and provide an alternate means of decay heat removal in the event that normal cooling systems (HTS and SCS) are lost.

The current RCCS cooling panel design is illustrated in Figures 3-29 and 3-30. The cooling panels are divided into four quadrants and each quadrant into three panels. Each panel has two parts: a plenum section, upper $4.6 \mathrm{~m}$ $(15 \mathrm{ft})$, and a heat transfer section, lower $17.4 \mathrm{~m}(57 \mathrm{ft})$. The middle panel in each quadrant connects to a coaxial pair of inlet and outlet ducts. Air flows to/from the adjacent panels via the plenum section. Also, all the quadrants communicate with one another via the plenum section. Cold inlet air from the inlet/outlet structure enters the middle cooling panel of each quadrant and is distributed to all three panels via the cold plenum. The cold air drops to the bottom of each panel through the downcomer channels in 


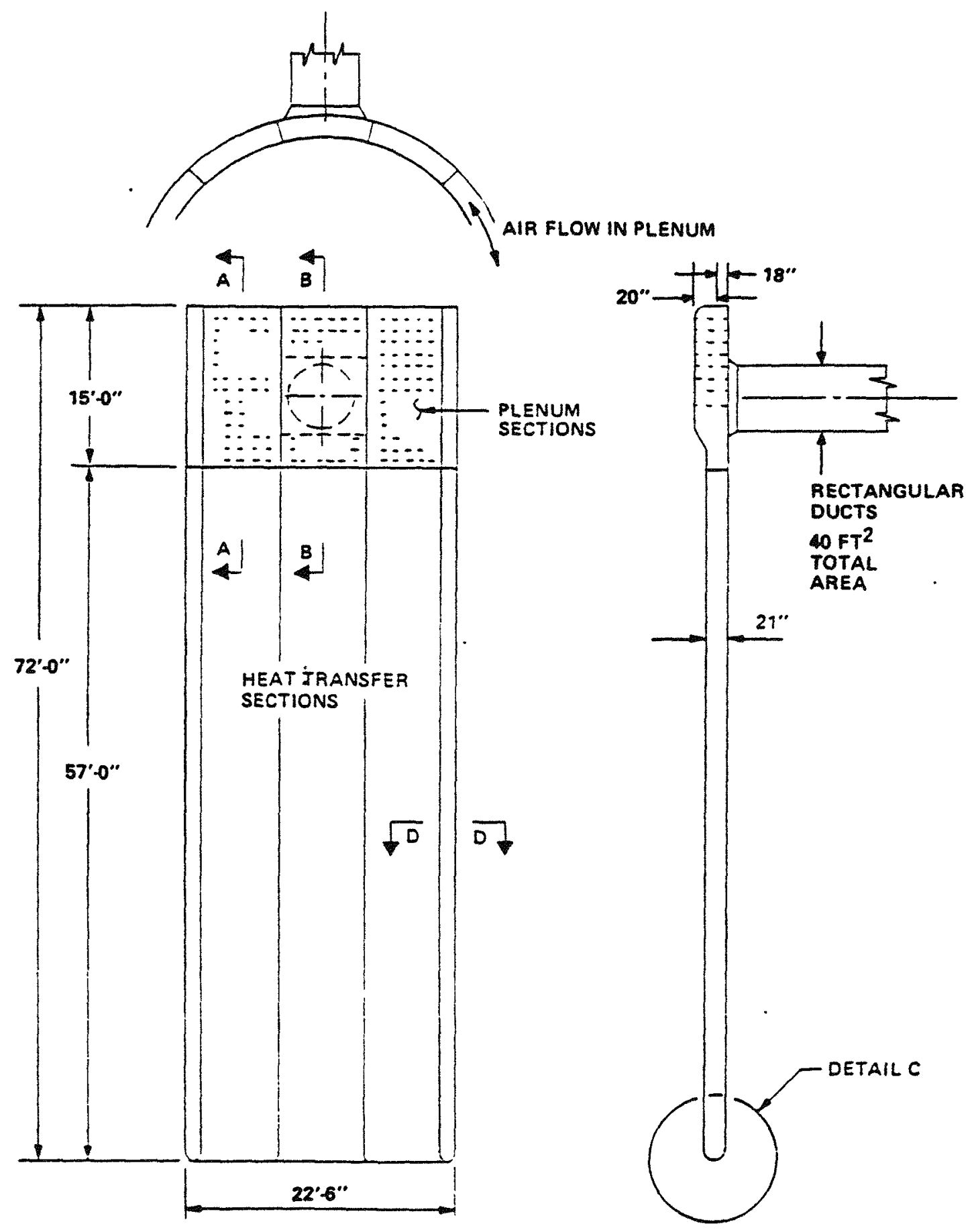

Figure 3-29 Air Cooling Panel Conceptual Design Plan and Sections 


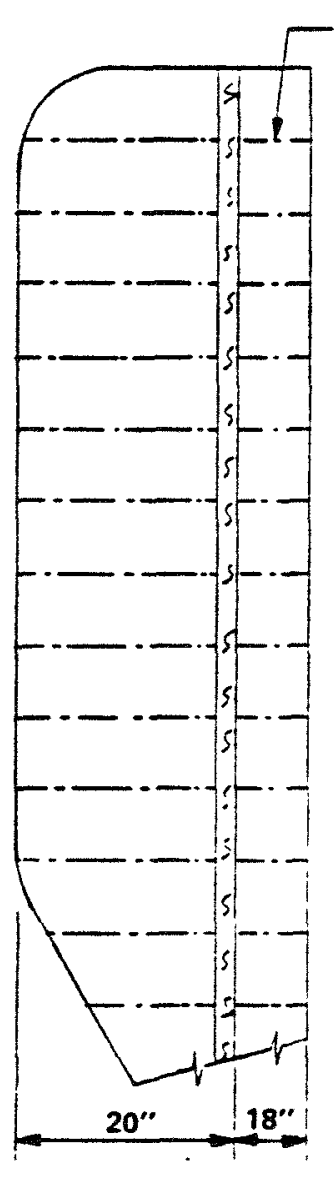

SECTION A.A
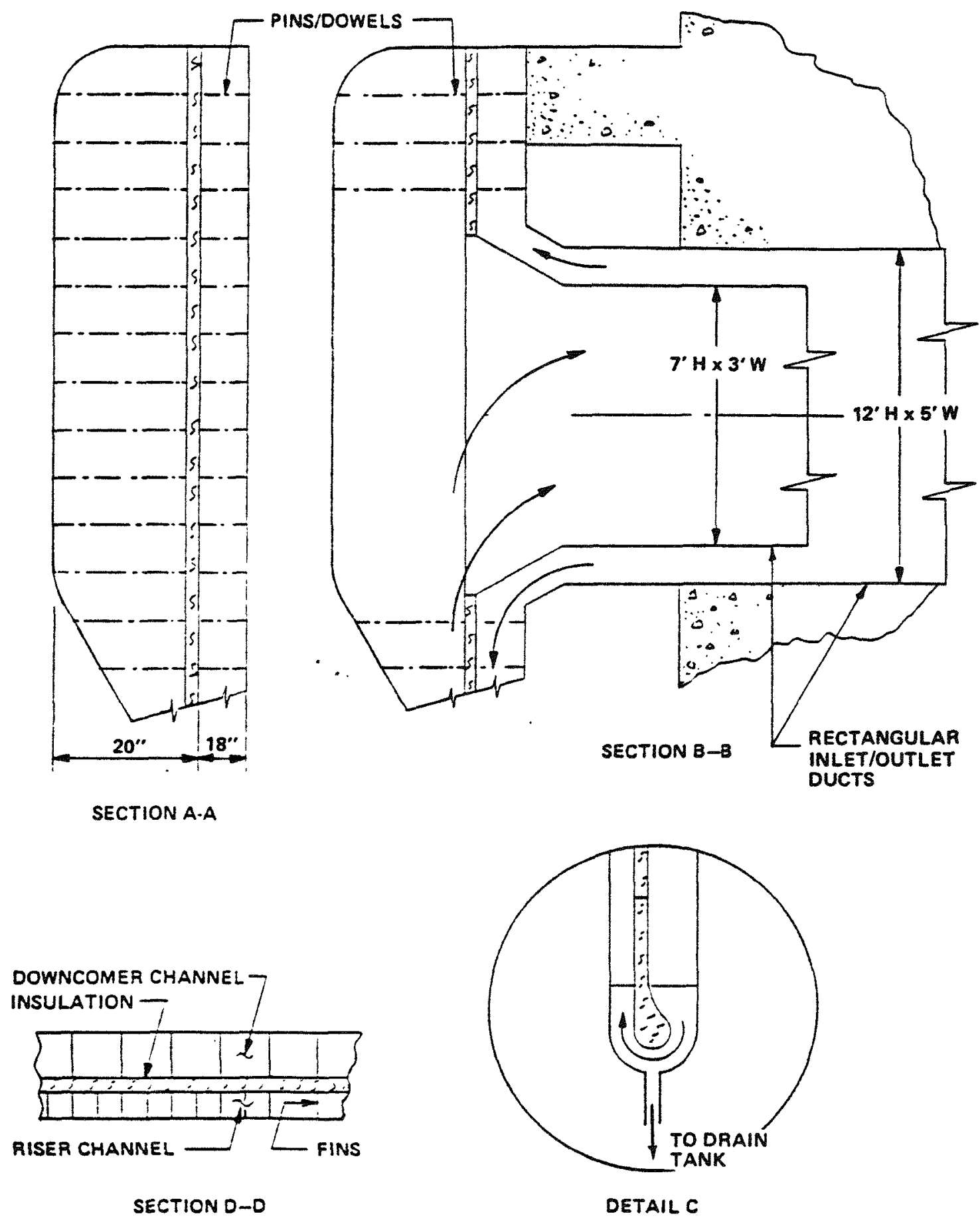

SECTION D-D

DETAILC

Figure 3-30 Air Cooling Panel Conceptual Design -Details 
the back side of the heat transfer section. This air is then heated in the riser channel on the front side of the panel. The heated air exits the panel via the hot plenum and outlet duct. The hot side of the panels is insulated from the cold side to minimize regenerative heat transfer to the inlet air. The total cross-sectional area in the riser section is reduced to increase the air velocity and the heat transfer coefficient.

The panels are constructed of carbon steel.

The RCCS is a passive system and, therefore, has no controls. However, instrumentation is provided to monitor thermodynamic performance and potential activity releases.

The passive natural draft RCCS has no valves or active components so there is only one system alignment and only one operating mode. For all modes of reactor operation, air flow through the RCCS is a function of the reactor vessel temperature and the outside air temperature. The performance of the RCCS for normal and accident conditions is summarized in Table 3-6. For the pressurized conduction cooldown event, core decay heat is distributed over the vessel surface by the natural circulation of primary helium resulting in higher heat rejection, but lower peak vessel temperatures, than in the depressurized case. In the depressurized case, decay heat is primarily rejected by conduction through the graphite reflector to the vessel sidewall. 
Table $3-6$

SUMMARY OF RCCS PERFORMANCE

\begin{tabular}{|c|c|c|c|c|c|}
\hline \multirow[b]{2}{*}{ Parameter } & \multicolumn{3}{|c|}{ Normal Operation * } & \multicolumn{2}{|c|}{ Conduction Cooldown Events * } \\
\hline & $\begin{array}{l}100 \% \\
\text { Power }\end{array}$ & $\begin{array}{l}\text { Begin } \\
\text { Cooldown ** }\end{array}$ & $\begin{array}{c}\text { End } \\
\text { Cooldown } * *\end{array}$ & Pressurized & Depressurized \\
\hline \multicolumn{6}{|l|}{ Reactor Vesse 1} \\
\hline He at loss to RCCS, $\mathrm{kW}$ & 887 & 216 & 34.8 & 1780 & 1600 \\
\hline Peak midwall temperature, ${ }^{\circ} \mathrm{C}\left({ }^{\circ} \mathrm{F}\right)$ & $219(426)$ & 99 (209) & $40(104)$ & $400(752)$ & $456(854)$ \\
\hline Time, hours & Continuous & 1 & 24 & 125 & 140 \\
\hline \multicolumn{6}{|l|}{ Cooling Panel } \\
\hline Maximum temperature, ${ }^{\circ} \mathrm{C}\left({ }^{\circ} \mathrm{F}\right)$ & $104(219)$ & $51(124)$ & $29(85)$ & $208(407)$ & $220(428)$ \\
\hline Air inlet temperature, ${ }^{\circ} \mathrm{C}\left({ }^{\circ} \mathrm{F}\right)$ & $21(70)$ & $21(70)$ & $21(70)$ & $43(110)$ & $43(110)$ \\
\hline Air out let temperature, ${ }^{\circ} \mathrm{C}\left({ }^{\circ} \mathrm{F}\right)$ & $86(186)$ & $45(113)$ & $28(82)$ & $163(325)$ & $153(307)$ \\
\hline Air inlet flow, $\mathrm{m}^{3} / \mathrm{sec}$ (CFM) & $\begin{array}{l}11.3 \\
(24,000)\end{array}$ & $\begin{array}{c}7.55 \\
(16,000)\end{array}$ & $\begin{array}{c}4.20 \\
(8,900)\end{array}$ & $\begin{array}{c}13.3 \\
(28,200)\end{array}$ & $\begin{array}{c}13.4 \\
(28,300)\end{array}$ \\
\hline Air outlet flow, $\mathrm{m}^{3} / \mathrm{sec}$ (CFM) & $\begin{array}{l}13.8 \\
(29,300)\end{array}$ & $\begin{array}{c}7.99 \\
(16,900)\end{array}$ & $\begin{array}{c}4.30 \\
(9,100)\end{array}$ & $\begin{array}{c}18.3 \\
(38,800)\end{array}$ & $\begin{array}{c}18.0 \\
(38,100)\end{array}$ \\
\hline Maximum velocity, $\mathrm{m} / \mathrm{sec}(\mathrm{ft} / \mathrm{sec})$ & $3.0(10)$ & $2.0(6.4)$ & $1.1(3.5)$ & $4.6(15.3)$ & $4.6(15.0)$ \\
\hline \multicolumn{6}{|l|}{ St ructure } \\
\hline Concrete surface temperature, ${ }^{\circ} \mathrm{C}\left({ }^{\circ} \mathrm{F}\right)$ & $21(70)$ & $21(70)$ & $21(70)$ & $43(110)$ & $43(110)$ \\
\hline
\end{tabular}

* Assumed ambient air temperature is $21^{\circ} \mathrm{C}\left(70^{\circ} \mathrm{F}\right)$ for normal operations and $42^{\circ} \mathrm{C}\left(110^{\circ} \mathrm{F}\right)$ for conduction cooldown events.

** Accelerated 24 hour cooldown for maintenance following reactor $t$ rip from 100 percent power. Cooldown begins with reactor pressurized. At end of cooldown ( 24 hours) reactor is 81 ightly sub-atmospheric. Calculations are based on primary helium conditions defined in OPDs (Kef 1-2) Appendix G, Tables G-3 and G-4. 


\subsection{REACTOR SERVICE SYSTEMS}

\subsubsection{Helium Purification}

The helium purification subsystem (HPS) is a single process train of filters, absorbers, oxidizers, coolers, heaters, compressors and associated piping, valves, and instrumentation and controls necessary to purify primary coolant (see Figure 3-31). The HPS includes regeneration modules which remove and process the absorbed impurities from saturated beds to restore their capacity.

This subsystem purifies primary coolant helium, removing fission products and chemical impurities, and returns the helium to the primary coolant loop as a purge gas for selected vessel penetrations and for the main and shutdown helium circulators. The HPS is effective in controlling (reducing) the activity of only a few long-lived radioactive species in the reactor (i.e., tritium, $\mathrm{Kr}-85$, some of the Xenon isotopes and, at a lower activity, Ar-37).

The subsystem also compresses helium recycled from the main and shutdown circulator service subsystem, and purifies helium from the vessel before it is transferred to the helium storage and transfer subsystem (HSTS).

The overall subsystem is made up of modularized components housed in the immediate vicinity of the HTGR vessels (i.e., in the reactor building, in separate enclosures). These modularized components provide the capabilities. for removal of chemical and fission product impurities, for helium compression to accommodate its return back to the SG vessel, and for effective equipment regeneration(s) after the various adsorbers have become saturated.

A single HPS process section serves each of the $350 \mathrm{MW}(t)$ HTGRs while one regeneration section accommodates two of the HTGR modules.

In the process section, there are five HPS module groups ( carry out cleanup of the helium in each HTGR module, and there are three HPS modules in each regeneration section which satisfy regeneration requirements 


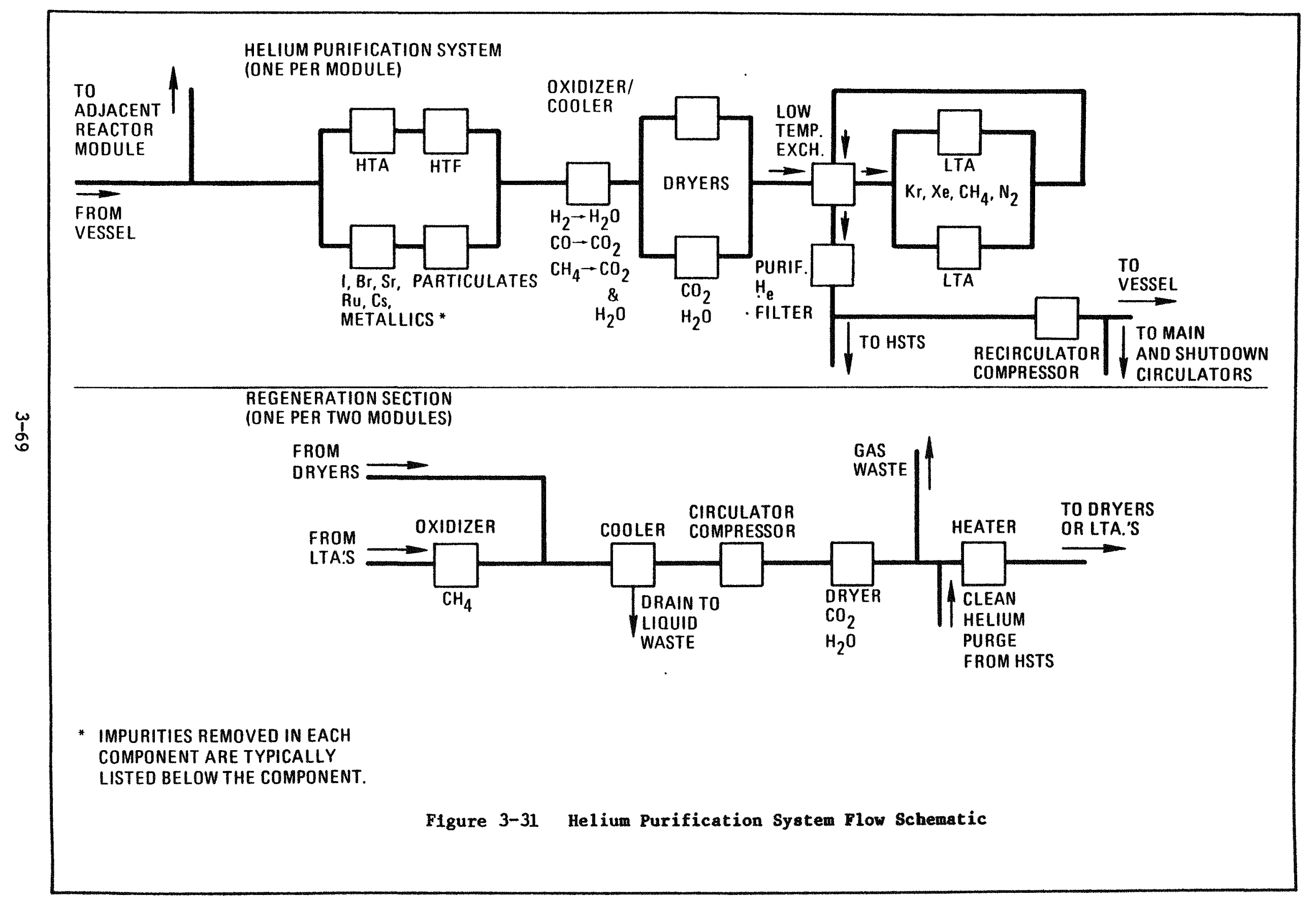


for two HTGR modules. The piping arrangement/helium flow path ensures return of processed helium to its own HTGR during normal operations. This feature is not maintained during regeneration operations.

HPS modules and their components are located in shielded enclosures downst ream of the HPS outlet piping connected to the HTGR reactor vessel. The equipment is designed for high pressure, operating in the range of about $6.72 \mathrm{Mpa}$ (975 psia) to $6.48 \mathrm{kPa}(940)$ psia.

\subsubsection{Radioactive Waste Processing}

The radioactive waste prociessing system (radwaste system) consists of the gaseous, liquid, and solid waste management systems. All the equipment for the radwaste system, except for some hold-up capacity in tanks and sumps, is located in the Radioactive Waste Management Building.

Gas Waste Management System. This system collects all radioactive and potentially radioactive gas waste generated in the reactor plant. Normally, non-radioactive gases are filtered, monitored, and released directly to the reactor building ventilation system. On a high radiation signal, these gases are diverted to the gas waste compressor for processing. Low-level gas wastes that do not require processing are held for temporary storage, allowing for activity decay followed by release to the reactor building ventilation system.

The gas waste system consists of two waste gas filters, two waste gas exhaust blowers in the normally non-radioactive loop, one gas waste vacuum tank with a moisture drain tank, two multi-stage gas waste compressors, and three gas waste surge tanks in the process loop. The gas waste surge tanks are normally operated at $0.34 \mathrm{MPa}$ ( $50 \mathrm{psig}$ ); however, they are designed for $3.5 \mathrm{MPa}$ ( 510 psig) to give the system a one-year storage capacity. 
Liquid Waste Management System. This system collects and treats radioactive liquid waste. The system disposes of the treated liquid by recycling for additional treatment, recycling for re-use in the plant, or discharging to the environment after proper monitoring for radioactive and chemical concent rations.

The system consists of three receiving tanks with a total of three associated transfer pump; a bank of portable/disposable filter demineralizers; and two test tanks, each with its own discharge pump. The system can be used for the cleanup of activation products in the core auxiliary cooling water, reactor building closed-loop cooling water, or spent fuel pool cooling system. Main and auxiliary circulator service systems, balance-of-plant equipment, and floor drains generally contain a low level of radioactivity of variable conductivity and are normally directed to one of the receiving tanks. Highactivity variable conductivity sources (such as the steam generator drains, helium purification system decontamination waste streams, and gas waste management system liquid effluents) are normally directed to a separate receiving tank to facilitate analyses.

Detergent waste, originating in the laundry and shower rooms, or from radiochemistry lab rinse operations, is normally directed to a hold-up tank. After testing to ensure low activity, the tank is pumped via a cartridge filter to the station cooling tower basin. If not suitable for discharge, the waste is directed to the third receiver tank in the Radioactive Waste Management Buil- . ding. The three receiver tanks are mounted together with a header to allow excess flow to one of the tanks to flow over to the others, but sump and holdup tank capacity in the reactor building and reactor services building should make this an unusual occurrence. Chemical waste originating from the laboratory drains is typically high in conductivity and has variable radioactivity content. This waste is collected in hold-up tanks in the laboratory and is neutralized in a batching process before being pumped to the Radioactive Waste Management Building for solidification. 
The portable demineralizer equipment consists of a process control skid, shielding, disposable vessels, dewatering skid, and resin sluicing equipment. The equipment is provided by any one of a number of decontamination services organizations.

Solid Waste Management System. This system consists of a ventilated storage room for $d r y$ and compactible wastes, a dry waste compactor, a drum roller for solidifying liquid waste with cement, and a Gantry series industrial robot for performing compaction and solidification operations. The robot also services a laydown area used to cut up large non-compactible waste items for solidification with the liquid waste. The laydown area is sized to receive and handle the high-temperature filter absorber from the helium purification system.

The Radioactive Waste Management Building contains shielded storage space for the anticipated compacted and solidified waste from all operations during one fuel cycle. The storage space capacity requirement is controlled by the storage of drumed and solidified core reflector blocks. These blocks are drummed in the temporary fuel storage area and transferred to the Radioactive Waste Management Building for storage.

\subsubsection{Reactor Plant Cooling Water}

The reactor plant cooling water subsystem (RPCWS) is a single cooling water loop which cools all the nonsafety-related heat loads for all four reactor modules. The RPCWS removes heat from the following plant components:

1. Helium purification system (HPS) coolers and compressors

2. HPS regeneration coolers and compressors

3. Main helium circulator motor

4. Moisture monitor compressor modules

5. Neut ron control assemblies

6. Miscellaneous equipment 
Since the RPCWS is a closed system, it provides a barrier to direct transport of radioactivity to the environs.

The system consists of two 100 percent (one backup) pumps, two 100 percent (one backup) heat exchangers, a surge tank and a water chemistry package. The system is also equipped with the required instrumentation and control. One RPCWS pump circulates water through an RPCW heat exchanger and the rest of the system. The surge tank maintains the system pressure and the on-line chemistry package maintains the purity of the water in the system. The heat is removed from the RPCWS by the service water system.

During all normal plant operating modes, one pump and one heat exchanger of the RPCWS is operating handling 100 percent of the system heat load. The non-operating pump and heat exchanger are on automatic standby or out of service for maintenance or repair. The total maximum heat load serviced by the RPCWS is $3 \mathrm{MW}\left(10 \times 10^{6} \mathrm{Btu} / \mathrm{hr}\right)$ RPCWS supply temperature is maintained within its programed band by automatic regulation of the service water temperature. To provide reliability and flexibility, the pumps and heat exchangers are connected in such a way that any one pump together with any one heat exchanger can provide the requisite cooling capability.

\subsubsection{Reactor Service Equipment and Storage Wells}

Reactor Service Equipment. The reactor service equipment subsystem is comprised of components and structures which facilitate in-vessel and exvessel service and maintenance operations, as well as the handing and storage of a number of reactor components. The subsystem contains the:

- Main circulator service equipment

- Shutdown circulat or service equipment

- Core service tools

- Auxiliary service cask and transporter assembly

- Service facility tools 

- Equipment storage wells
- Hot duct service equipment
- Neutron detector service equipment

The components and structures within this subsystem are somewhat unrelated as to functions and are grouped primarily for convenience. The circulator handling equipment consists of shielded casks, isolation valves, and other assorted adapters to provide the capacity for removal and replacement of the main and shutdown circulators and their respective loop shutoff valves.

The core service tools are used in conjunction with the fuel handling machine and the auxiliary service cask to accommodate the removal of reserve shutdown material and various defective core components, including broken fuel elements and control rods.

The auxiliary service cask is a gas-tight, shielded vessel which handles long cylindrical components. Its primary function is the handing of neutron control assemblies during refueling outages but is also accomodates hightemperature filters and absorbers, the reserve shutdown vacuum tool, and the fuel transfer cask guide sleeve. It is supported and positioned by its integral transporter mechanism.

The service facility tools are a collection of tools and fixtures provided to accomplish specific remote maintenance within the reactor equipment service facility. Typical tasks include replacement of control rods, checkout of the portable core refueling equipment, and packaging solid waste.

The equipment storage wells are permanent structures which provide a shielded storage area for the main circulator, the shutdown circulator, the neutron control assemblies, and miscellaneous components comparable in size to the neutron control assemblies.

The hot duct service equipment is designed to remove and replace a section of the hot duct. 
The neutron detector service equipment is designed to remove and/or replace three different types of neutron detectors from their operating positions in or adjacent to the reactor vessel.

Equipment Storage Wells. The Equipment Storage Wells are metal housings embedded in the concrete structure of the RSB. They provide a shielded storage area for major reactor module components. Each type of well provides appropriate features for support and alignment of the components placed within the well.

Three types of storage wells are provided:

1. Main circulator storage wells

2. Shutdown circulator storage wells

3. Neutron control assembly storage wells

\subsubsection{Helium Storage and Transfer}

The helium storage and transfer subsystem (HSTS) consists of two parts. The first is a high-pressure storage system that provides makeup for various helium users. The makeup helium is need to compensate for NSSS leakages, leakage past vessel penetrations (seals), analytical sampling leakages, etc. Typical helium purge requirements include that for the helium purification regeneration equipment, for the fuel storage facility, etc. The second larger part of the system is for low pressure storage of reactor inventory of 6080 $\mathrm{kg}(13,400 \mathrm{1b})$ of helium. The system serves all four (4) reactor modules. The low pressure storage part of the system receives helium from the discharge of the helium purification subsystem and is activated during depressurization and pumpup operations only. 


\subsubsection{Liguid Nitrogen}

The liquid nitrogen subsystem provides liquid nitrogen to all the four reactor modules for cooling the low temperature adsorber modules of the HPS and analytical instruments for the noble gas cold tramps, and gaseous nitrogen for other reactor module users.

The system design consists of two separate trains each with two nitrogen recondensers, pumps, and a single phase separator storage tank. Each train serves two reactor modules and provides storage for $5.7 \mathrm{~m}^{3}(1500-\mathrm{gal})$ of liquid nitrogen and $20 \mathrm{~kW}\left(0.07 \times 10^{6} \mathrm{Btu} / \mathrm{hr}\right)$ refrigerating capacity. Initially, the system will be filled from an external source.

\subsubsection{Nuclear Island HVAC}

The (NI) HVAC system supplies conditioned outdoor air to the reactor buildings, reactor auxiliary buildings, reactor service building and personnel service building for cooling, ventilation, and purging. The air flows from clean spaces to potentially contaminated spaces before being exhausted at the roof level. Air exhausted from potentially radioactive spaces is continuously monitored, and if necessary, filtered through HEPA filters which remove over 99 percent of the airborne particles.

Ventilation ducts serving the reactor cavities and steam generator cavities are normally sealed by cavity isolation valves. To prevent condensation on the RCCS panels, a small amount of air is purged from the cavities, filtered, monitored and discharged to the atmosphere. This purge air flows through bypass pipes, with filter and flow control valves, that connect to the exhaust duct upstream of the exhaust fans.

Prior to personnel entry into a cavity during shutdown, the large isolation valves are opened and the cavity is purged with 100 percent outdoor air, which is exhausted, filtered, and monitored before release to the atmosphere. 
Recirculating unit coolers provide air cooling for rooms in the reactor buildings which have large heat loads such as the CRD cells, the steam generator cavities and electrical equipment rooms. Standby HEPA filtration trains are provided in the exhaust ducts serving potentially radioactive cells.

Heat is rejected from the NI supply air handing units and unit coolers to the chilled water system.

The HVAC system for the Radioactive Waste Management Building supplies conditioned air to the office, lab, compactor, and general areas of the building. The system is designed to maintain suitable environmental conditions for personnel and equipment protection and to control and minimize the release of radioactive materials from the building to the outside environment and to the general areas of the building during normal modes of plant operation.

\subsubsection{Other Reactor Service Systems}

Several other systems support the operation of the reactor:

- Decontamination system, which provides service points for water, steam, and detergent for plant decontamination

- Nuclear Island equipment and floor drain system, which provide drainage of potentially contaminated liquids to the Radioactive Liquid Waste System 
3. 7 FUEL HANDLING, STORAGE AND SHIPPING SYSTEM

\subsubsection{Core Refueling}

The Core Refueling Subsystem (CRS) consists of the following major components:

1. Fuel handling equipment support structure

2. Reactor isolation valves

3. Fuel handling machine

4. Fuel transfer cask adapter

5. Fuel transfer cask

6. Fuel handling equipment positioner

7. Plug actuator and turntable assembly

8. Refueling accessories

9. Fuel handling control station

The basic purpose of the core refueling equipment is to accomplish the periodic, remote replacement of core fuel and reflector elements in a safe and efficient manner.

Core refueling operations are predicated on a 3.3 year fuel residence time whereby one-half of the fuel columns are replaced with new fuel every 20 months. Each fuel column consists of a vertical stack of ten elements. Temporary reflector elements adjacent to the active core have a ten-year life. Approximately one-sixth are replaced every 20 months.

The basic equipment for replacing fuel and replaceable reflector elements is illustrated in Figures 3-32 through 3-34. The refueling procedure involves the exchange of new core elements from the spent fuel storage facility for spent core elements. This exchange occurs after the reactor has been shut down and depressurized. Figure 3-35 illustrates the handing features of core elements. Figure 3-36 illustrates the general arrangement of the refueling penetration and other components in the top head and upper plenum of the reactor vessel. The exchange of elements occurs in one-sixth of the core area (i.e., a core sector) at a time as shown in Figure 3-36. 


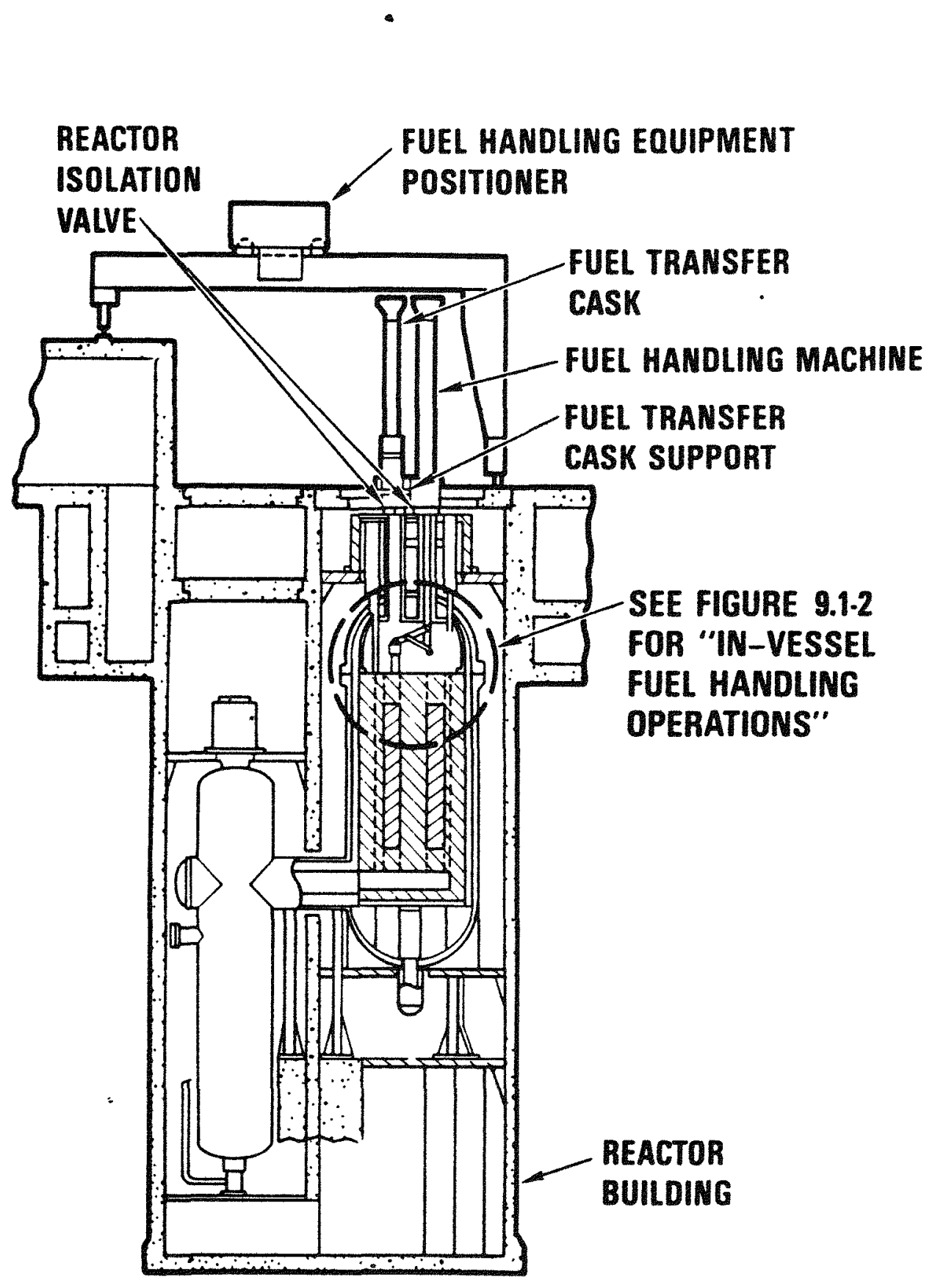

Figure 3-32 Location of Fuel Handling Equipment 


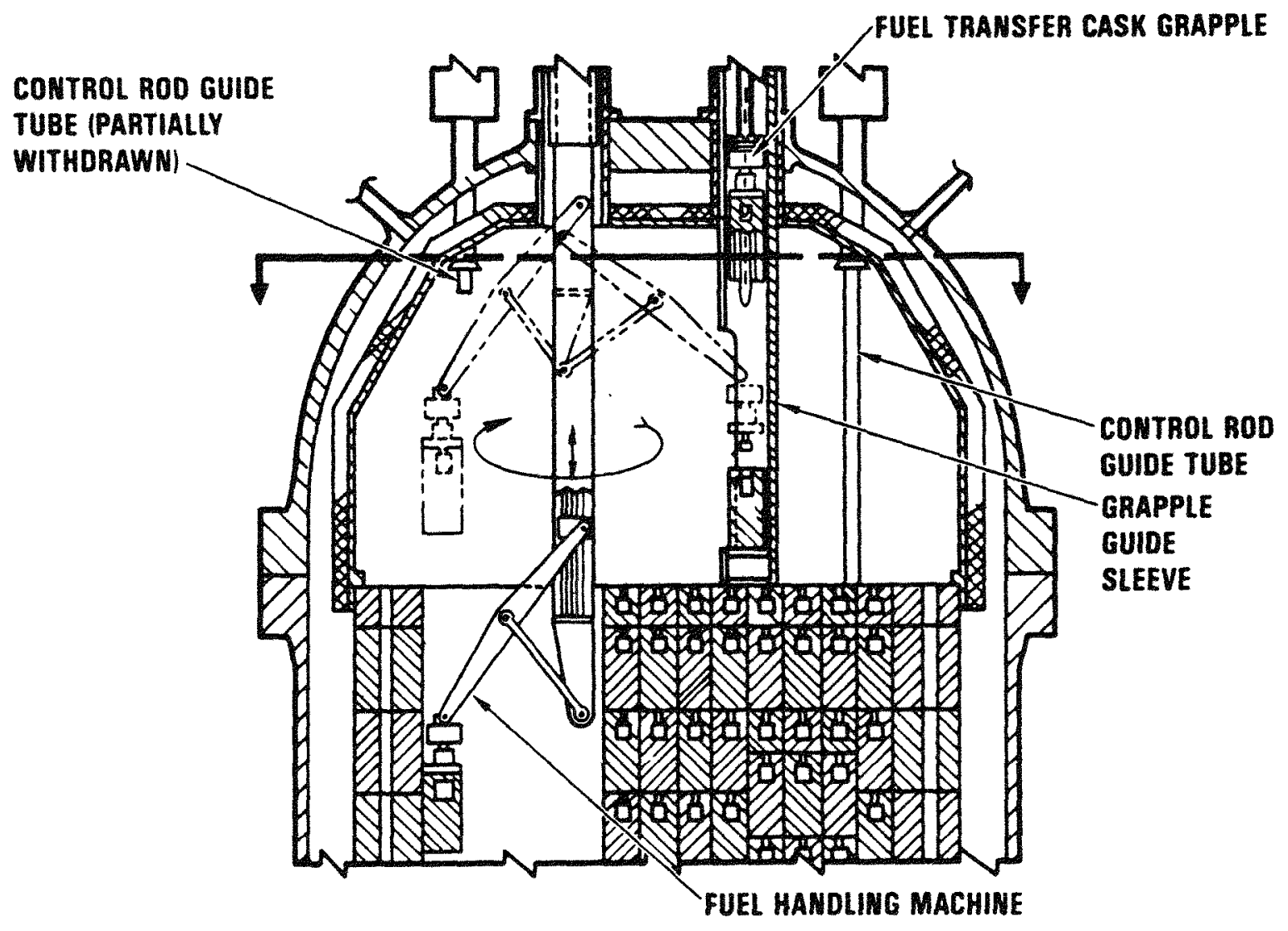

Figure 3-33 In-vessel Fuel Handling Operations 


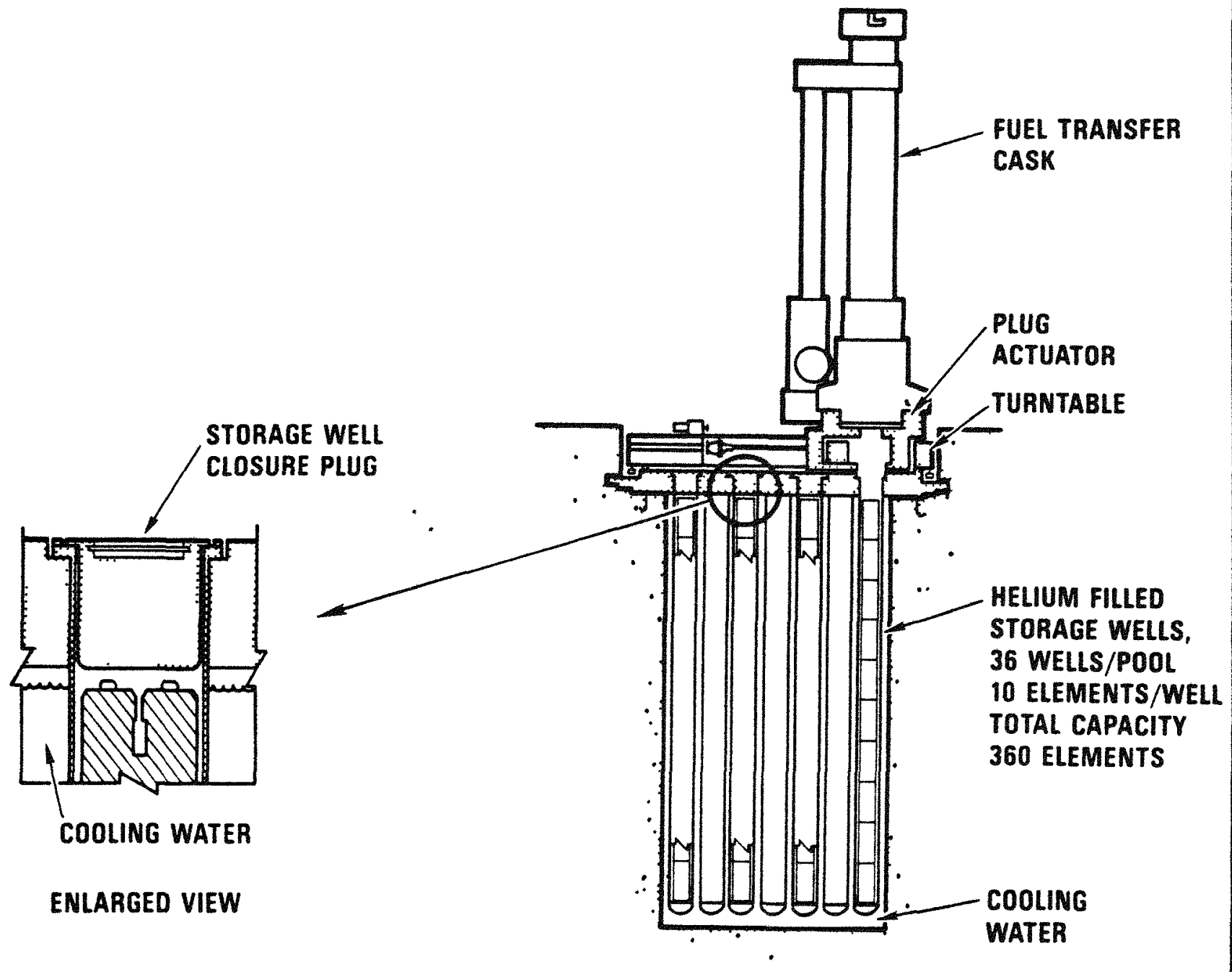

Figure 3-34 Spent Fuel storage Facility 

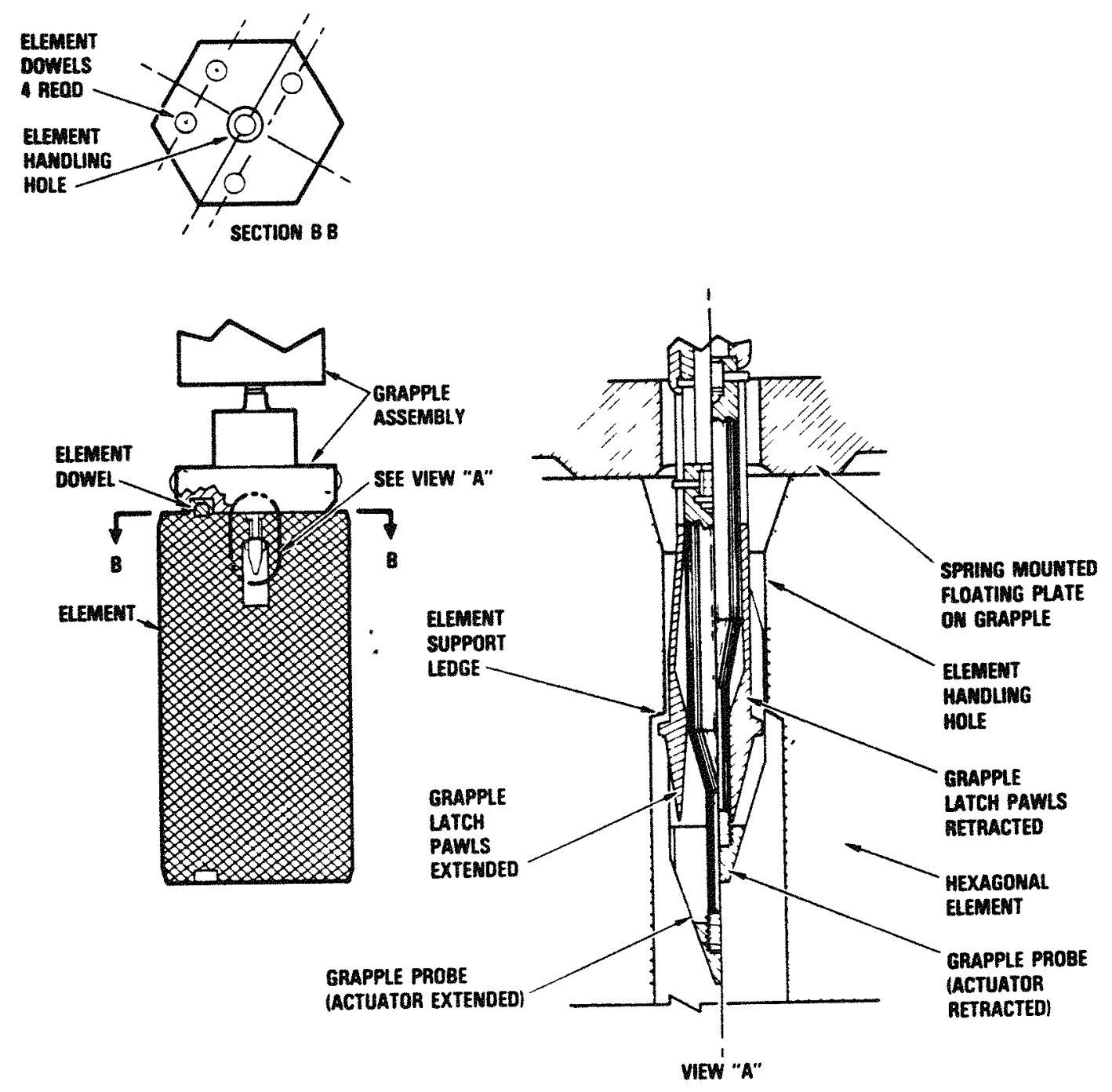

Figure 3-35 Fuel Element Construction for Handling 


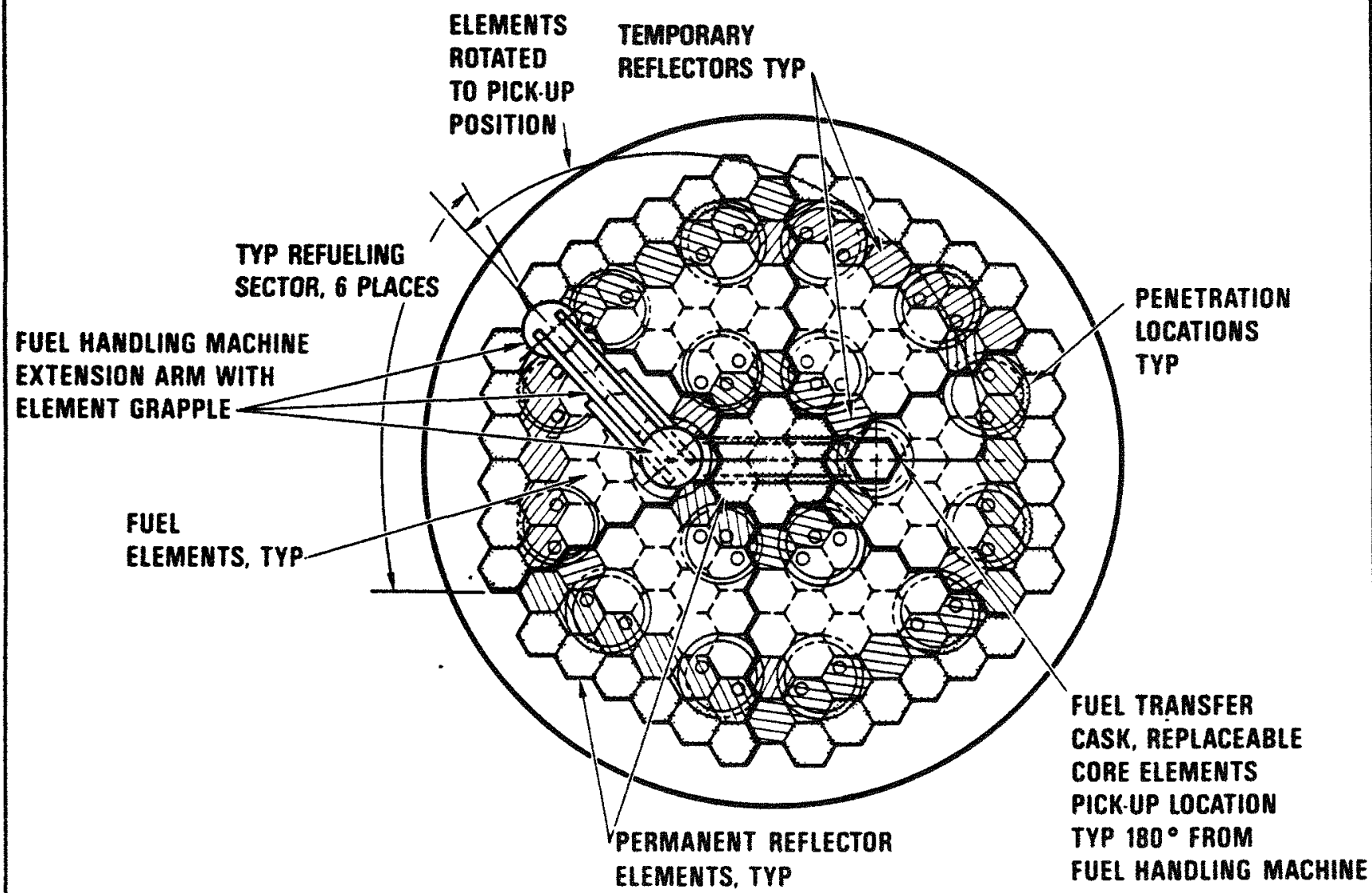

Figure 3-36 Arrangement of Refueling Penetrations and Equipment 
To replace the outer reflectors that contain the control rods of a refueling sector, two of the four rods in the sector are retracted during the refueling of the sector, and the corresponding reflectors are removed. The remaining two rods remain in the side reflector to assure adequate shutdown margin. Half of the side reflectors in two refueling sectors are replaced with each refueling process, which results in total side reflector replacement every ten years.

Although only half of the fuel from each sector is replaced with each refueling process, nearly all of it is removed and transferred to the spent fuel storage facility to provide access for the fuel handling machine. When the partially used fuel is returned to the core sector, it is returned to its initial location. The balance of the reactor is filled with new fuel.

The CRS uses a digital computer to control all refueling operations and to monitor related refueling activities. Refueling of a sector is normally accomplished in an "automatic" mode with minimum operator involvement after initiation of the refueling cycle. The computer ensures the machines are operated within acceptable limits and in a predetermined sequence. This process of removal and replacement of fuel, sector by sector, is repeated until the entire core has been emptied and replaced. All refueling equipment is removed from the vessel upon completion of refueling.

\subsubsection{Site Fuel Handling}

The Site Fuel Handling Subsystem (SFHS) consists of equipment and facilities located in the Reactor Service Building which are used to handle hexagonal graphite fuel and reflector blocks. This equipment interfaces closely with the core refueling equipment described in section 3.7.1. The SFHS uses some of the equipment in the Core Refueling Subsystem to transfer fuel elements between the Spent Fuel Storage Facility (part of the Core Refueling Subsystem) and the Fuel Sealing and Inspection Facility (FSIF).

The FSIF is the focal point for all site fuel handling operations. This 
facility is strategically located in the Reactor Service Building (RSB) and all elements entering or leaving the reactor site must pass through the FSIF.

The SFHS includes all of the equipment used to perform the following operations at the FSIF:
- Receiving new elements
- Inspecting new elements
- Inspecting spent or damaged elements
- Packaging spent fuel for shipment
- Positioning packaged spent fuel within the shipping cask
- Packaging spent reflector elements for shipment
- Positioning spent fuel in shielded casks for on-site storage. *

Other SFHS equipment located outside the FSIF includes components for closing, sealing, and handling the fuel shipping casks within the RSB. The actual shipment of spent fuel from the reactor site will be the responsibility of the DOE (or its agent) in accordance with provisions of the Civilian Waste Repository Act. The DOE will provide empty shipping casks to the site on a predetermined schedule. The Nuclear Island bridge crane will be used to remove the shipping cask from its transporter. The site fuel handing equipment will be used to: (1) open the casks, (2) position the cask below the shipping port of the FSIF, (3) position cannisters of spent fuel in the cask, (4) close and seal the casks, and, finally, (5) reposition the cask for lifting onto its transporter. The site fuel handling equipment is to be capable of performing the preceding tasks for either a truck-mounted shipping cask or a railcar-mounted shipping cask. Fuel and reflector block handing operations are shown schematically in Figure 3-37.

New fuel and reflector blocks enter the site by truck. Each block is individually packaged in a shipping container resembling a 55 gallon drum. New elements are stored in their containers in storage racks located in the Reactor Service Building (RSB). Following inspection, elements required for

* Spent fuel storage casks are not part of the standard MHTGK design, but can provide expandable on-site storage for spent fuel if necessary. 


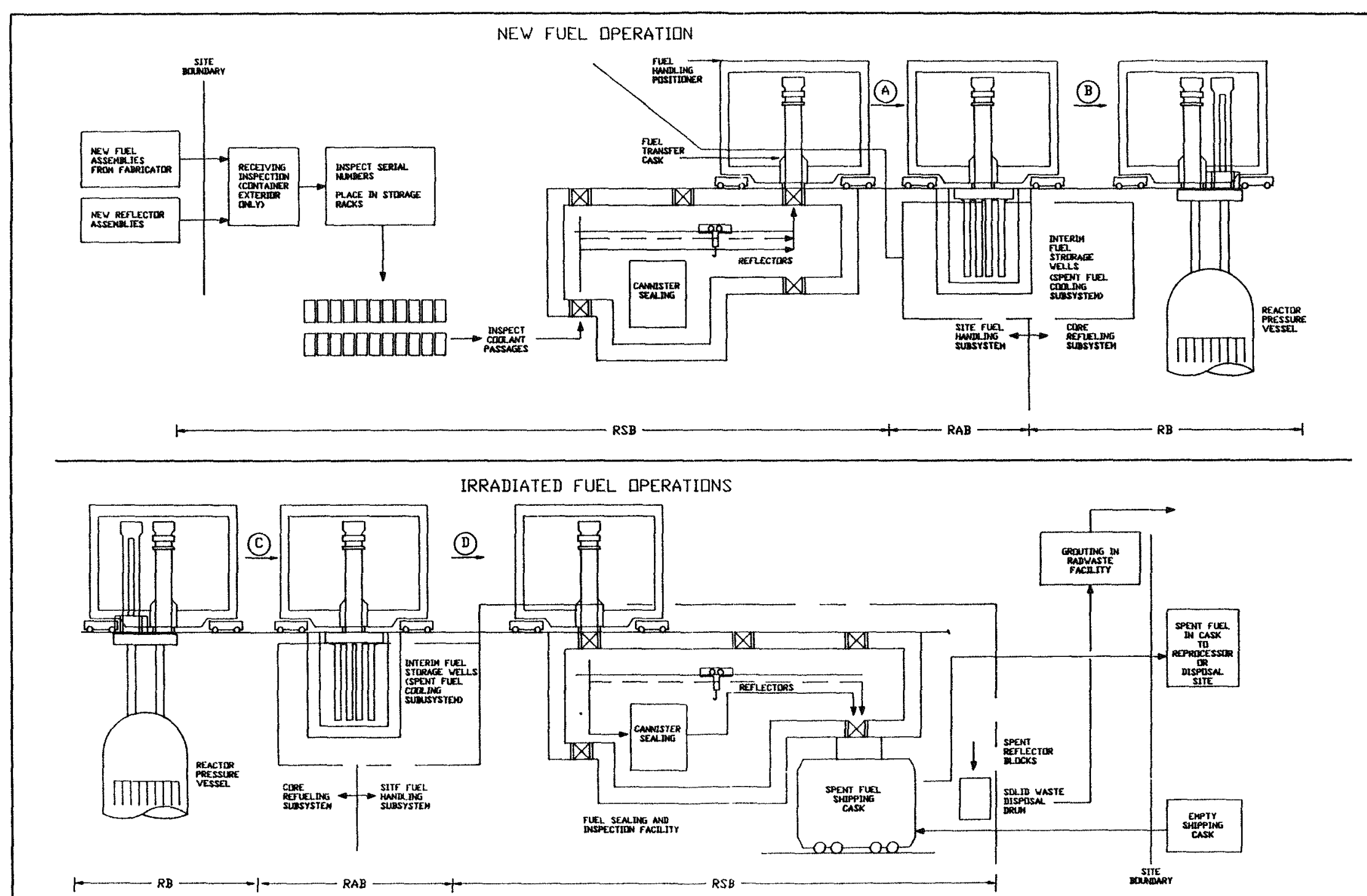

Figure 3-37 Site Fuel Handling Operatzo block Diagram 
an impending core refueling operation are transferred through the FSIF to the spent fuel storage pools. The transfer is accomplished using the FSIF hoist, the Fuel Transfer Cask (FTC), and the Fuel Handling Equipment Positioner (FHEP). During the core refueling operation, the core Refueling system replaces the new fuel and reflectors in the storage pools with irradiated elements.

After an appropriate decay period (a minimum of 100 days for fully exposed fuel blocks), the elements are moved, with the FTC and FHEP, to the FSIF. The FSIF is located in a shielded concrete vault in the RSB. Spent reflector blocks are placed in shielded drums and treated as solid radioactive waste. Spent fuel elements are inspected and placed into metal cannisters which are then sealed and loaded into spent fuel shipping casks. Spent fuel is then shipped off-site for disposal. The standard MHTGR design is based on an ability to store up to one. year's production of irradiated elements on site.

\subsubsection{Spent Fuel Cooling}

The Spent Fuel Cooling Subsystem (SFCS) removes decay heat generated by the spent fuel elements until their heat generation rate decreases sufficiently to allow shipment to permanent storage off-site. The SFCS also maintains temperature of the spent fuel elements and the surrounding spent fuel storage structure within acceptable limits.

Two spent fuel storage pools are provided for one year on-site storage of the spent fuel before off-site shipment. Each pool normally serves the two adjacent reactor modules and contains 72 storage wells. Each storage well has space for ten spent fuel elements. The cooling water circulating in a closed loop removes the decay heat transferred from the spent fuel to the storage wells. The cooling water loop consists of two 100 percent capacity heat exchangers (one backup) and four 50 percent capacity pumps. Each pool has two dedicated pump, one of which is a backup. 
Heat from the cooling water loop is transferred to the Service Water Subsystem (SWS). The SFCS is designed to function continuously. To provide spent fuel cooling at all times, a passive backup cooling mode is provided. In this mode, the large water inventory in the storage pools provides a large thermal capacitance and ultimately heat is removed by boiling. Water loss through boiling is replaced from a makeup water supply.

The configuration of the SFCS is shown schematically in the system flow diagram, Figure 3-38.

The SFCS consists of one cooling loop serving the two spent fuel storage pools. The two storage pools in turn serve the four reactor modules. Each storage pool normally serves the two adjacent reactor modules. 


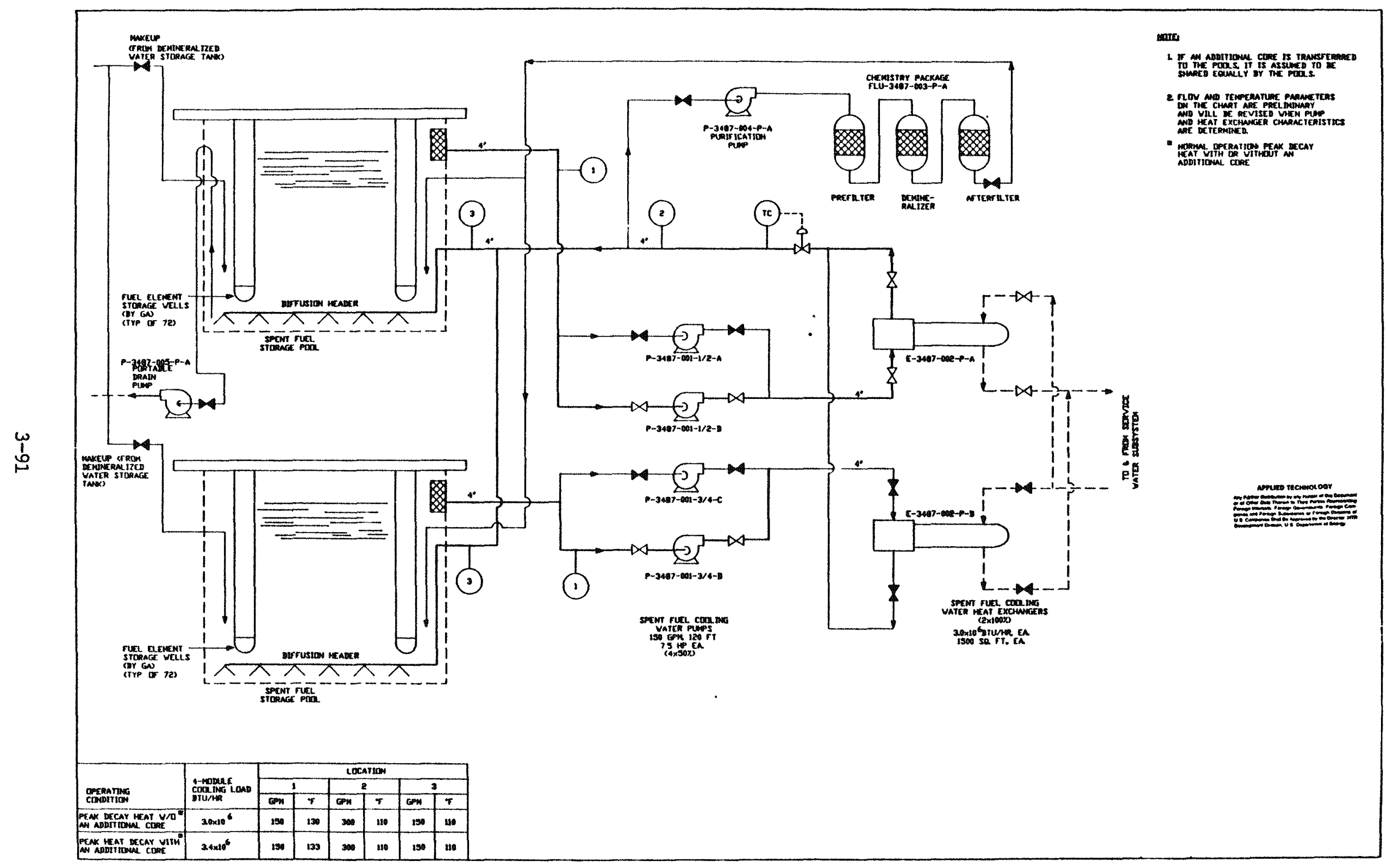

Figure 3-38 Spent Fuel Cooling Flow Diagram 


\subsection{TURBINE PLANT SYSTEMS}

The turbine plant systems receive steam from the heat transport system and convert steam energy to electrical energy. The turbine cycle data are included in the preliminary overall plant heat balance, Table 2-2 and Figure $3-39$.

The following systems are needed to support the power generation cycle:

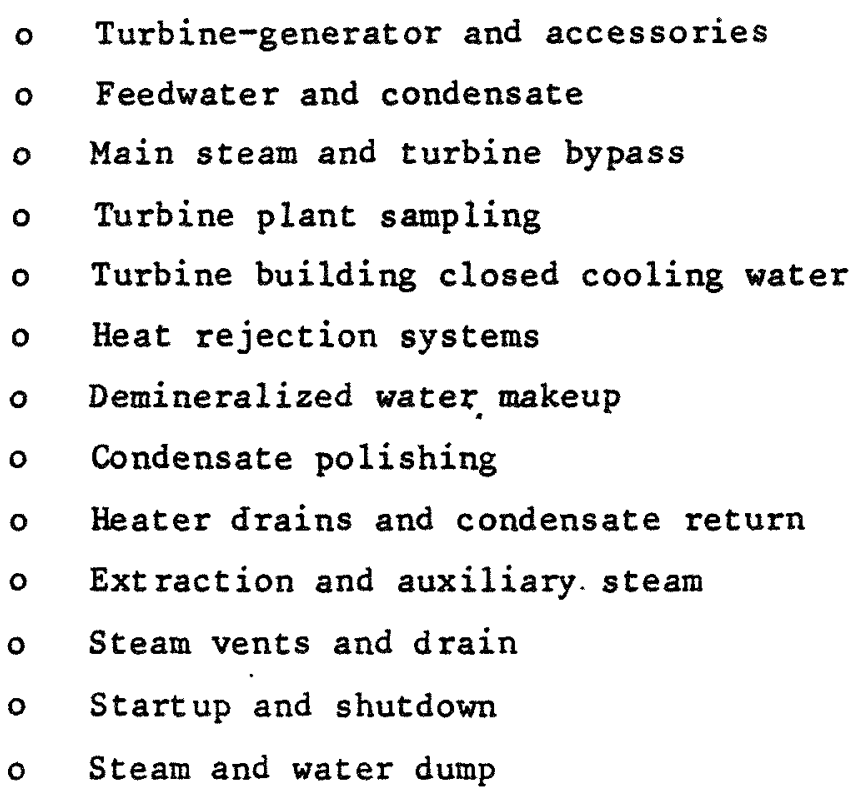

The power conversion cycle is composed of two identical systems, each delivering steam from two reactor/steam generator modules to one $300 \mathrm{MW}(\mathrm{e})$ turbine generator unit. Each system is fully independent and the systems are cross-connected.

The conceptual design of these systems is described in the following paragraphs. 


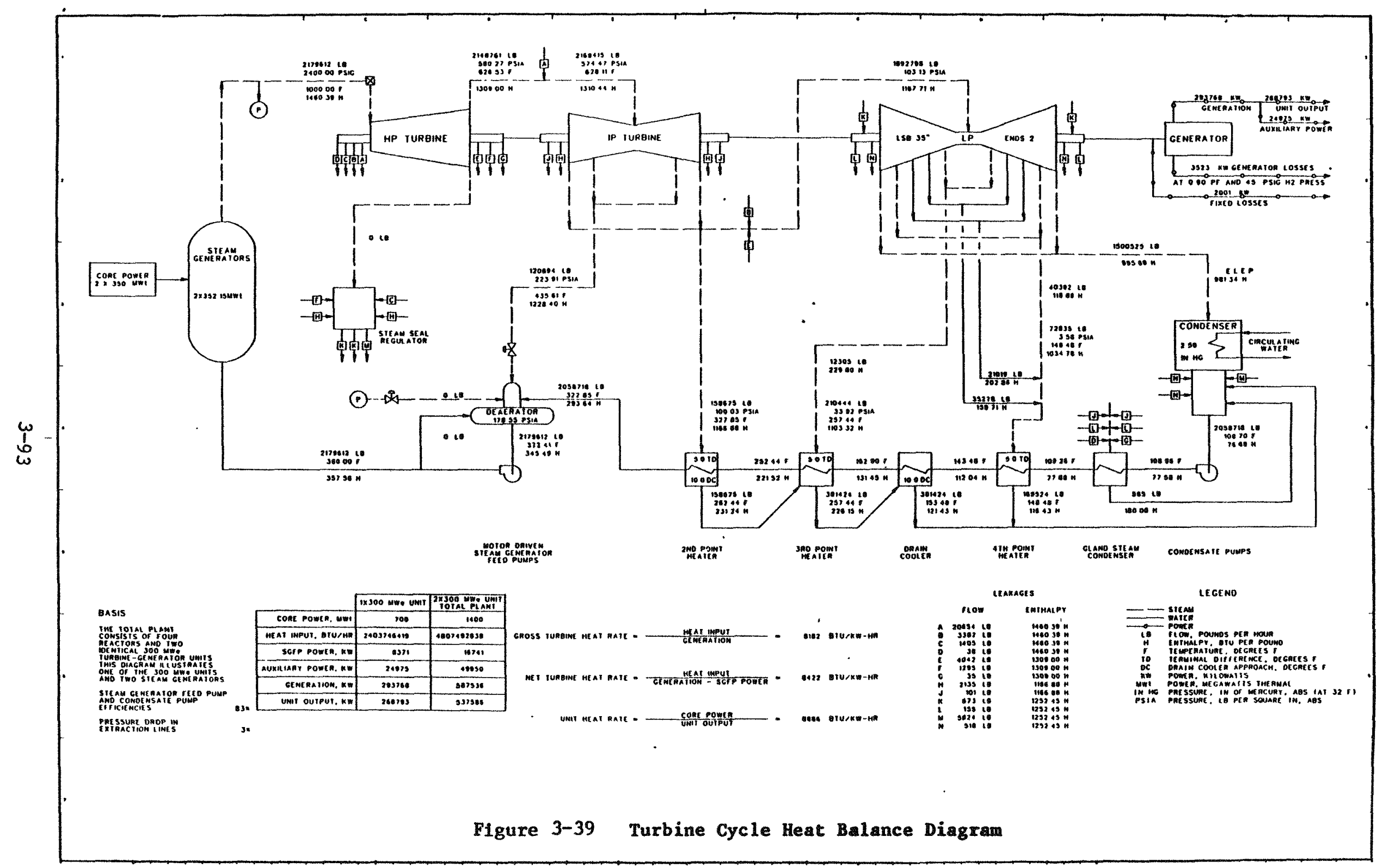




\subsubsection{Turbine-generator and Accessories}

Each turbine-generator is nominally rated at $300 \mathrm{MW}(\mathrm{e})$, gross output. The throttle conditions are $16.5 \mathrm{MPa}(2,400 \mathrm{psig}) / 538^{\circ} \mathrm{C}\left(1,000^{\circ} \mathrm{F}\right)$. The turbines are 3,600 rpm non-reheat designs with single-flow HP and IP elements and a double-flow LP element.

\subsubsection{Feedwater and Condensate Systems}

The condenser associated with each $300 \mathrm{MW}(\mathrm{e})$ turbine generator unit operates at $8.5 \mathrm{kPa}$ (2.5 in $\mathrm{Hg}$ ) abs. The condenser is a single shell, double pass tube configuration and is designed to handle the heat rejection loads associa- . ted with the following modes of plant operation:

- Plant startup and shutdown (approximately 25 percent of steam generator thermal rating)

- Normal steady-state plant operation (reactor module power and turbine generator load ranges of 25 to 100 percent)

- Plant transients (heat rejected is limited to approximately one-half of the maximum steam flow rate provided to the turbine under steady-state plant operation)

Four one-third capacity mechanical vacuum pumps are supplied. for removing non-condensible gases from each condenser. The vacuum pumps are motor-driven rotary two-stage units.

Two 100 percent capacity condensate pumps take suction from the condenser associated with each turbine-generator unit. The pumps discharge through three half-size condensate polisher vessels, then pass through four stages of feedwater heaters. The heaters are placed in series and operate under the increased pressure of various stages of extraction steam from the turbine. The second, third, and fourth point heaters are full-sized horizontal units with $\mathrm{U}$-tube arrangement. The first point heater is a direct contact deaerating heater which maintains a constant outlet temperature of $193^{\circ} \mathrm{C}\left(380^{\circ} \mathrm{F}\right)$. 
The deaerator supplies two variable-speed feedwater pumps. Downstream of the feedwater pumps, the feed lines from each turbine-generator unit combine into a single header. Branch piping from the header leading to each steam generator contains feedwater control valves and isolation valves.

Throughout the feedwater and condensate systems, suitable branch connections are provided for chemical addition, sampling and support of startup, shutdown, and transient modes of operation.

\subsubsection{Main Steam and Turbine Bypass Systems}

The main steam and turbine bypass system provides a continuous steam supply to two turbine-generator units at $16.6 \mathrm{MPa}(2,400 \mathrm{psig}) / 538^{\circ} \mathrm{C}\left(1,000^{\circ} \mathrm{F}\right)$. In the event of turbine generator load rejection or during startup and shutdown, the turbine bypass is equipped with pressure reducing and de-superheating stations to automatically condition the main steam before dumping into the condenser.

\subsubsection{Startup and Shutdown System}

The startup and shutdown (SU/SD) system serves to startup or shutdown any reactor module or any turbine unit while the other reactor module and turbine(s) are in operation or shutdown. This is accomplished by having a separate startup/shutdown cycle in addition to the power cycle.

The startup phase, from 0 to 25 percent power, or shutdown phase, from 25 to 0 percent power, is accomplished by the startup and shutdown (SU/SD) system. The system produces minimum perturbations in the power cycle during transfer from startup to normal operation and from normal operation to shutdown.

The SU/SD system delivers feedwater and steam to the steam generator and turbine, respectively, at the specified temperature and pressure, flow rate, 
and fluid chemistry. The system consists mainly of one SU/SD feedpump, one SU/SD deaerator, four SU/SD tanks and associated piping, valves, controls, and attemperators.

The SU/SD system is sized for sequential startup and shutdown of the reactor modules. Should a simultaneous startup or shutdown of the reactor modules and turbine be required, the main deaerators and feedpumps of the main steam and feedwater systems will be used along with the SU/SD tanks.

On loss of the feedwater system, the SU/SD tank water inventory could be used to provide a temporary limited source of cooling water. If on-site power is available, the SU/SD system could also transfer water to shut down the steam generators by using the demineralized water makeup system as the source of water.

\subsubsection{Steam and Water Dump System}

The steam and water dump system serves to eliminate further ingress of water into the primary coolant as a result of a steam generator tube leak or rupture. This is accomplished by dumping the steam/water inventory of the steam generator into the system's dump tank. The dump system's action minimizes possible damage to the reactor core by limiting the amount of water made available for fuel hydrolysis and graphite oxidation.

The dump system bottles up the steam generator steam/water inventory, including any in-leakage from the primary coolant, for subsequent disposal through the Gaseous and Liquid Radioactive Waste Management systems. This ensures that no direct primary coolant is released to the environment.

The dump system serves each of the four steam generator modules independently. The portion of the system associated with each steam generator consists of a dump tank, two trains of dump valves, a drain pump, and interconnecting piping and valves with the Gaseous and Liquid Radioactive 
Waste Management systems. Isolation of the steam generator is accomplished by two power-operated valves mounted in series on the feedwater inlet and steam outlet of the steam generator. Dumping is executed by two parallel trains of dump lines, each equipped with two dual-actuated, motor-operated valves mounted in series. The system's dump and isolation valves are powered from a reliable power source.

\subsubsection{Turbine Plant Cooling Water System}

The turbine building closed cooling water systems are two closed-loop systems, each with two 100 percent capacity, motor-driven water pumps; surge tank; and two 100 percent capacity, shell-and-tube heat exchangers that provide cooling to various turbine plant components. This system dissipates heat to the station cooling tower via the circulating water systems, and makeup to the systems is provided by the Demineralized Water Makeup System.

\subsubsection{Heat Rejection System}

The heat rejection system consists of the circulating water, service water, and the makeup and blowdown systems.

\subsubsection{Circulating Water System}

The circulating water system consists of two open-loop system flow paths associated with each turbine generator and includes the cooling tower and circulating water pumps. Its main function is to remove the heat load rejected to the condensers and to convey and dissipate it in the cooling tower.

Two 50 percent capacity circulating water pumps are provided for each flow path to deliver water to each condenser. The pumps are of the vertical mixed-flow type.

One round mechanical draft wet cooling tower is provided. The tower is sized to provide the cooling requirements for the circulating water system and the service water system. The tower is sectioned into two halves to allow for isolation and maintenance of one unit without impact on the operation of the second unit. 
Chlorination is provided for the circulating water system to protect each main condensor and cooling tower fill from biofouling. Two evaporators, one operating and one spare, and two chlorinators, one operating and one spare, are provided. Chlorine will be injected into the pump bays immediately upstrean of the circulating water and service water pumps.

A schematic of the Circulating Water System is shown in Figure 3-40.

\subsubsection{Service Water System}

The service water system is an open-loop system that removes waste heat from the station chilled water system, the reactor plant cooling water system, the spent fuel storage cooling system, and the shutdown cooling water system. Two flow paths are provided for heat removal capability during normal and shutdown modes of plant operation.

The normal portion of the system consists of two 100 percent capacity vertical-type pumps which take suction from the cooling tower basin. The shutdown portion of the system consists of three 50 percent capacity vertical-type pumps which supply water to the SCWS heat exchanger during the cooldown and shutdown modes of any reactor module that uses the SCWS.

Al1 of the service water pumps are arranged to allow for suction to be taken from either side of the cooling tower basin which allows for isolation and maintenance of one side of the basin without impact on the operation of the system.

\subsubsection{Circulating Water Makeup and Blowdown System}

Two 100 percent capacity vertical-type pumps are provided in the intake pump house structure for the makeup system. One trash rake and two traveling screens are provided, each suitable for 50 percent of the flow requirements. Two 100 percent capacity screen wash pumps service the traveling screens, which are protected by a bar rack and trash screen. Makeup is provided continuously to each half of the cooling tower basin.

Chlorination is also provided at the makeup water intake structure to protect makeup water pipelines from biofouling. Two evaporators and two chlorinators, one operating and one spare, are provided. Also included are injectors, diffusors, and chlorine storage facilities. Chlorine will be injected into the intake pump house structure pump bays.

\subsubsection{Other Turbine Plant Systems}

\subsubsection{Turbine Plant Sampling System}

A turbine plant sampling system is provided to monitor and record 


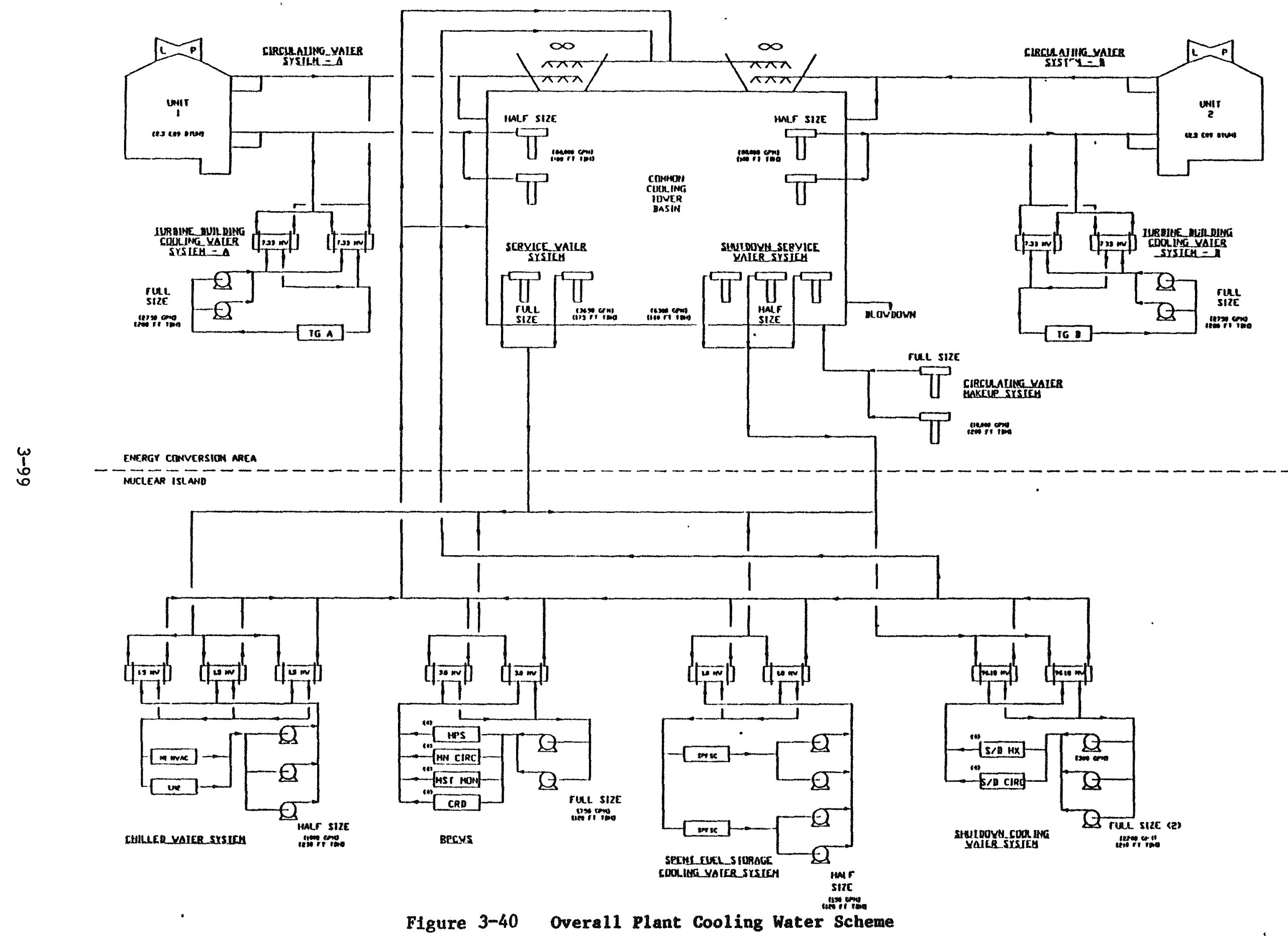


the chemical makeup of condensate, feedwater, steam generator water, turbine building closed cooling water, circulating water, and steam conditions. The sampling system consists of two arrangements with each arrangement containing a free-standing conditioning and analysis panel, as well as a free-standing recorder and control panel. These panels will be located in the turbine building.

\subsubsection{Demineralized Water Makeup}

The Demineralized Water Makeup System is a storage and distribution system which receives demineralized water from the Raw Water Treatment System and distributes it to various users throughout the plant. The system includes one demineralized water storage tank, two demineralized water transfer pumps, and associated piping, valves, and hose connections.

\subsubsection{Condensate Polishing System}

An externally regenerated deep-bed type condensate polishing system is provided to remove ionic impurities from each condensate stream. Three polisher vessels are provided, each designed to treat 50 percent of the total condensate flow from one condenser of $15.1 \mathrm{~m}^{3} / \mathrm{min}$. (4,000 $\left.\mathrm{gpm}\right)$. Equipment for external regeneration of resins includes a cation regeneration vessel; anion regeneration vessel; resin mix and storage tank; caustic dilution water heater; acid, caustic, and ammonia storage tanks and feed equipment; sample sink; and control panel. To improve condensate polisher system performance and reduce waste water volumes, ammoniation equipment is provided in addition to acid and caustic regeneration. This arrangement will reduce potential sodium leakage and allow longer service runs to ion exchange exhaustion. The Condensate Polishing System is located in the Turbine Building.

\subsubsection{Chemical Feed System}

Chemical feed equipment is provided to adjust the $\mathrm{pH}$ of the condensate and remove oxygen from the feedwater. Ammonia feed equipment is provided for $\mathrm{pH}$ adjustment and includes a day tank and three 100 percent capacity chemical metering pums, one for each condensate stream plus a common spare. Ammonia is stored in the area provided for the condensate polisher system. Hydrazine feed equipment is provided for oxygen scavenging and includes a day tank and three 100 percent capacity chemical metering pumps. Hydrazine is stored in drums and transferred to the day tank by a hand pump. Chemical feed equipment is located in the Turbine Building.

\subsubsection{Heater Drains and Condensate Returns System}

The Heater Drains System removes condensed extraction steam from the shell side of the low pressure heaters in accordance with the established thermal cycle. 
The Condensate Returns System collects condensate from the Auxiliary Steam System, and returns the drains to the Condensate System.

\subsubsection{Extraction and Auxiliary Steam System}

The Extraction Steam System distributes steam from the intermediate and low pressure turbines to four stages of condensate heaters and to the Auxiliary Steam System.

The Auxiliary Steam System distributes steam throughout the plant for auxiliary services.

The Extraction and Auxiliary Steam System is suitably manifolded to assure the distribution of steam during all modes of normal plant operation.

During certain abnormal conditions, the system is designed to remain operational to support other subsystems with the Power Conversion Group.

\subsubsection{Steam Vent and Drain System}

The Steam Vent System conveys steam and non-condensible gases to the atmosphere or appropriate terminal point as determined by the thermal cycle.

Typical steam vent systems are:

- Low pressure heater shell relief valve piping to the atmo sphere

- Low pressure heater shell vent piping which conducts non-condensible gases to the condenser.

The Drain System conveys high temperature water to the condenser to maintain the inventory of secondary fluid during startup. 


\subsection{PLANT ELECTRICAL SYSTEM}

The Plant Electrical System transfers the electrical power generated by the plant to the high-voltage switchyard through unit transformers, controls, meters electrical energy, and protects the power-carrying components. It is the source of electrical power for the plant auxiliaries, including the plant control, protection, and surveillance systems and the Class $\mathrm{IE}$ equipment. The systems needed to perform and support these functions are as follows:
- Non-Class IE AC Distribution System
- Non-Class IE DC Power System
- Class IE Uninterruptable Power Supply System
- Class IE DC Power System
- Off-site and Main Generator Transmission System
- Non-Class IE Uninterruptable Power Supply System
- Grounding, Lightning, Heat Tracing and Cathodic Protection
- Communication System
- Lighting and Service Power System

The plant one-line diagram is shown on Figure 3-41. The electrical loads as shown represent the $4 \times 350 \mathrm{MW}(t)$ MHTGR prismatic core concept.

\subsubsection{Non-Class IE AC Distribution System}

The Non-Class IE AC Distribution System provides electric power at $4,160 \mathrm{~V}$, threephase, and $480 \mathrm{~V}$ or less, three-phase and single-phase, $60 \mathrm{~Hz}$ to electrical switchgear associated with each unit's generator to feed the plant's auxiliaries. The Non-Class IE AC Distribution System is normally fed from the unit generators through two auxiliary transformers. For plant startup, each unit's generator buses are fed from the grid through two startup auxiliary transformers when the main generators are not running. 


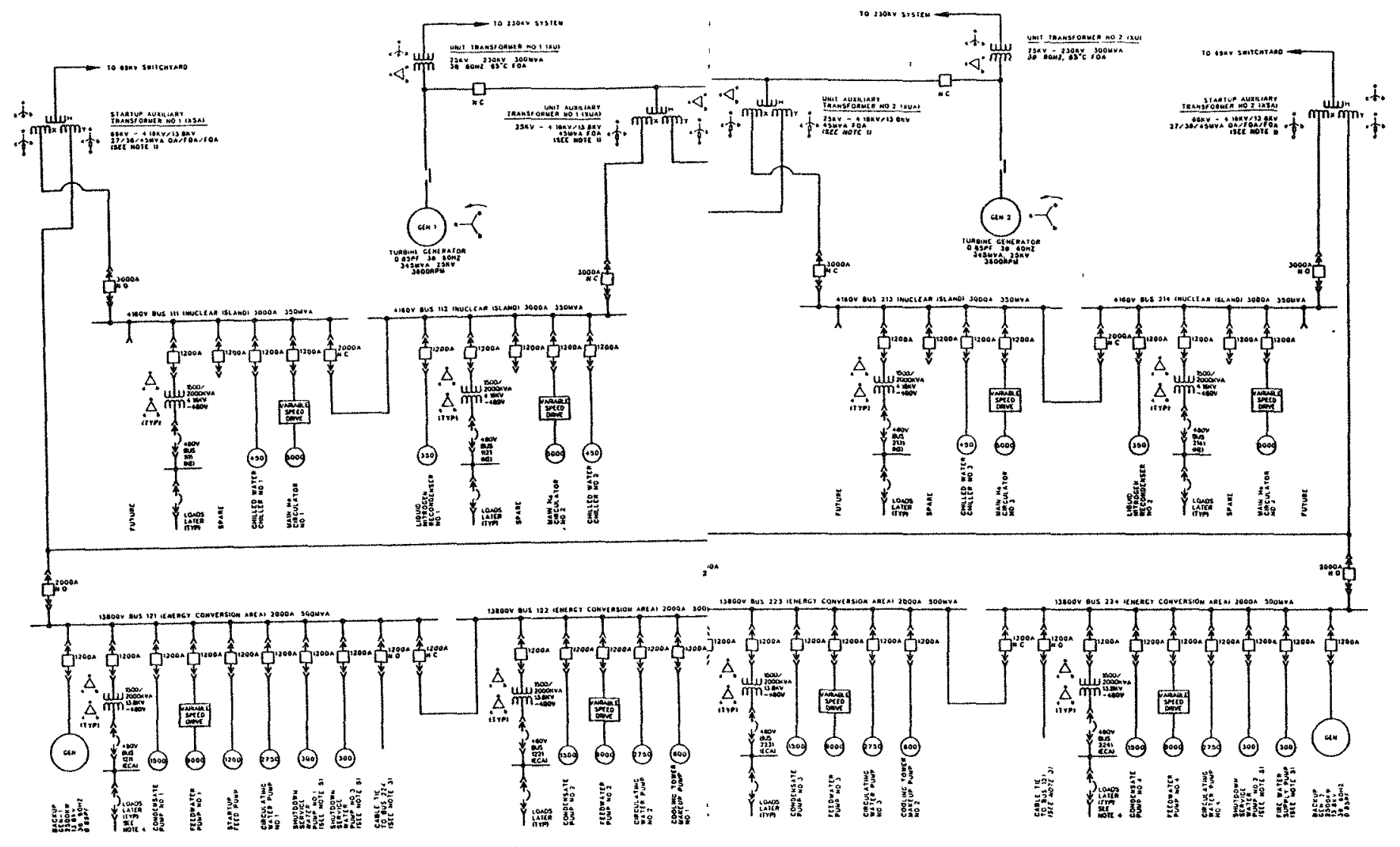

13:

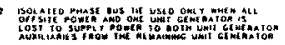

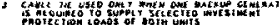

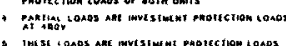

igure 3-41 Main Station One Line 


\subsubsection{Non-Class 1E DC Power System}

The Non-Class 1E DC Power System provides $125 \mathrm{~V}$ dc electric power to the plant's control and inst rumentation loads connected to the two $125 \mathrm{~V}$ dc buses, each of which is associated with a unit generator. The dc distribution system includes storage batteries, battery chargers, and distribution switchgear.

\subsubsection{Class IE Uninterruptable Power Supply (UPS) System}

The Class IE UPS System provides reliable and regulated $120 \mathrm{~V}$ ac, singlephase, $60 \mathrm{~Hz}$ electric power to the plant Class $1 \mathrm{E}$ control and instrumentation loads connected to the four redundant and independent vital buses. These four vital buses comprise the plant's four Class IE UPS control and instrument channels $A, B, C$, and $D$.

\subsubsection{Class 1E DC Power System}

The Class IE DC Power System provides reliable $125 \mathrm{~V}$ de electric power to the plant Class $1 \mathrm{E}$ dc loads connected to the four redundant and independent $125 \mathrm{~V}$ $\mathrm{Cl}$ ass $\mathrm{IE} \mathrm{dc}$ buses. These four dc buses comprise the plant's four Class $1 \mathrm{E}$ dc control and instrument channels $A, B, C$, and $D$. The dc distribution system includes storage batteries, battery chargers, and distribution switchgear.

\subsubsection{Other Electrical Systems}

3.9.5.1 Off-site Power and Main Generator Transmission System

The off-site power transmission system consists of two physically separate and independent circuits from the transmission network which, through a common switchyard, supply power to the on-site dist ribution system.

The main generator transmission system consists of two unit generators transmitting power to the grid through two unit transformers from the common switchyard. 


\subsubsection{Non-Class IE Uninterruptable Power Supply (UPS) System}

The Non-Class IE UPS System provides $120 \mathrm{~V} \mathrm{ac}$, single-phase, $60 \mathrm{~Hz}$ electric power to the plant's control and instrumentation loads connected to the two $120 \mathrm{~V}$ UPS buses, each of which is associated with a unit generator. Power is distributed via ac distribution panels from solid state inverters to the $120 \mathrm{~V}$ ac uninterruptable loads.

\subsubsection{Grounding, Lightning Protection, Heat Tracing, and Cathodic Protection}

Equipment grounding ensures personnel safety by connecting the plant's non-current-carrying metallic parts to the grounding grid. System grounding provides fast, selective clearing of the plant's ground faults to limit equipment damage.

Lightning Protection provides a metallic low impedance path to earth to direct lightning strikes, preventing lightning current from passing through non-conductive parts of a building or st ructure in the plant.

Heat Tracing provides electric heat, as required, to the plant's piping or vessels in order to maintain a desirable temperature in the liquids inside the piping or vessels.

Cathodic Protection arrests corrosion on the plant's underground and underwater structure by passing direct current from anodes in the electrolyte to the structures to be protected.

\subsubsection{Communication System}

The Communication System provides separate, independent and diverse types of intra-plant communications between essential plant areas and the control room, and plant-to-off-site comunications to locations remote from the plant during normal operations or under emergency conditions. The communication system consists of an inter-commication and paging system, a telephone system, and a sound-powered telephone system.

\subsubsection{Lighting and Service Power System}

The Lighting System provides normal ac and emergency ac and dc lighting to support plant activities. The Service Power System provides ac power to service outlets located throughout the plant for use with portable equipment, tools, and lighting. 


\subsection{ME CHANICAL SERVICES}

Mechanical services include the following systems:

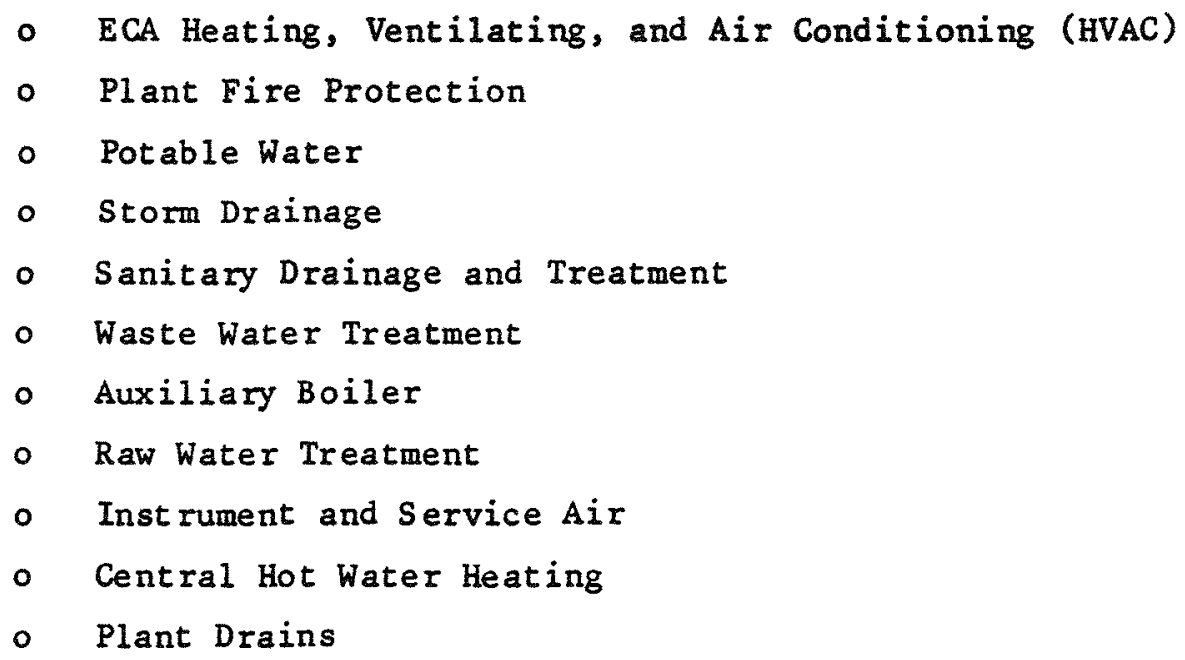

The ECA HVAC system ensures that building environments are established and maintained during plant operation to assure environmental requirements are met for operator occupancy, equipment, component, and instrumentation operability and maintenance. The ECA HVAC is designed to conventional commercial standards and prevailing fossil power plant requirements.

The HVAC system utilizes air conditioning units, unit coolers, evaporative air cooling units, vaneaxial and centrifugal fans, power roof ventilators, and unit heaters to maintain appropriate ambient environmental conditions.

The plant fire protection is provided to protect all areas of the plant by providing the means to extinguish all types of fires and to minimize their effect. The fire protection system consists of: water, carbon dioxide, and halon. Fire protection for the plant is designed to conventional commercial standards and prevailing power plant requirements.

The plant fire protection water system consists of two fire water storage tanks, two fire pumps (electric motor and diese1), controllers, a pressure maintenance system, a yard hydrant and hose house system, distribution piping 
to an underground yard piping 10op, and piping to the fire protection equipment within the plant buildings and structures.

The plant fire protection carbon dioxide system consists of one carbon dioxide refrigerated storage tank, piping, nozzles, and controls for master and selection valves, and detection and audio alarms. The system delivers carbon dioxide to the turbine generator bearings and enclosure areas for protection and purging.

The plant fire protection Halon 1301 system consists of a number of manifolded, high pressure systems with dedicated main and connected reserve cylinder banks, piping, and controls for detection and audio alarms. The main/reserve cylinder banks arrangement provides for double shot discharge capacity. The system supplies halon through a fixed piping distribution system with applicator nozzles located throughout fire hazard zones in the operations center and the reactor building.

Portable fire extinguishers are located throughout the plant to permit the immediate extinguishment of limited fires. Dry chemical, pressurized water units, and portable halon extinguishers are provided as required.

The remaining mechanical services are primarily conventional in design. Their design does not have a significant impact on the overall plant design. 


\section{11 PLANT PROTECTION AND INSTRUMENTATION SYSTEM}

The Plant Protection and Instrumentation System (PPIS) monitors and protects plant systems and equipment to protect plant investment as well as public health and safety. The system is comprised of the following three subsystems:

$$
\begin{aligned}
& \text { - Investment protection subsystem } \\
& \text { - Safety protection subsystem } \\
& \text { - Special nuclear area instrumentation }
\end{aligned}
$$

Plant systems and investment are protected by the three subsystems. However, only the Safety protection subsystem is needed for the protection of the health and safety of the public. Table 3-7 shows a functional breakdown of these subsystems.

The investment protection and safety protection subsystems include the sensors and actuation features up to the interface with the actuated equipment: The special nuclear area instrumentation includes preventive features (interlocks) and various information and display systems. The latter monitors protection system status and plant status under normal and accident conditions.

The scope of the PPIS includes process sensors and electronic logic in a two-out-of-four voting configuration, local equipment, and operator stations that communicate via protection system data highways. The actuation equipment and some system-specific process sensors are within the scope of other systems. The PPIS is functionally independent from the plant control systems. It is electrically isolated from plant control, and it is not affected by plant control system failures.

\subsubsection{Investment Protection Subsystem}

The primary purpose of this subsystem is to protect major plant equipment. It is an investment-risk-oriented subsystem that indirectly contributes to 
Table 3-7

PLANT PROTECTION AND INSTRUAENTATION SYSTEM

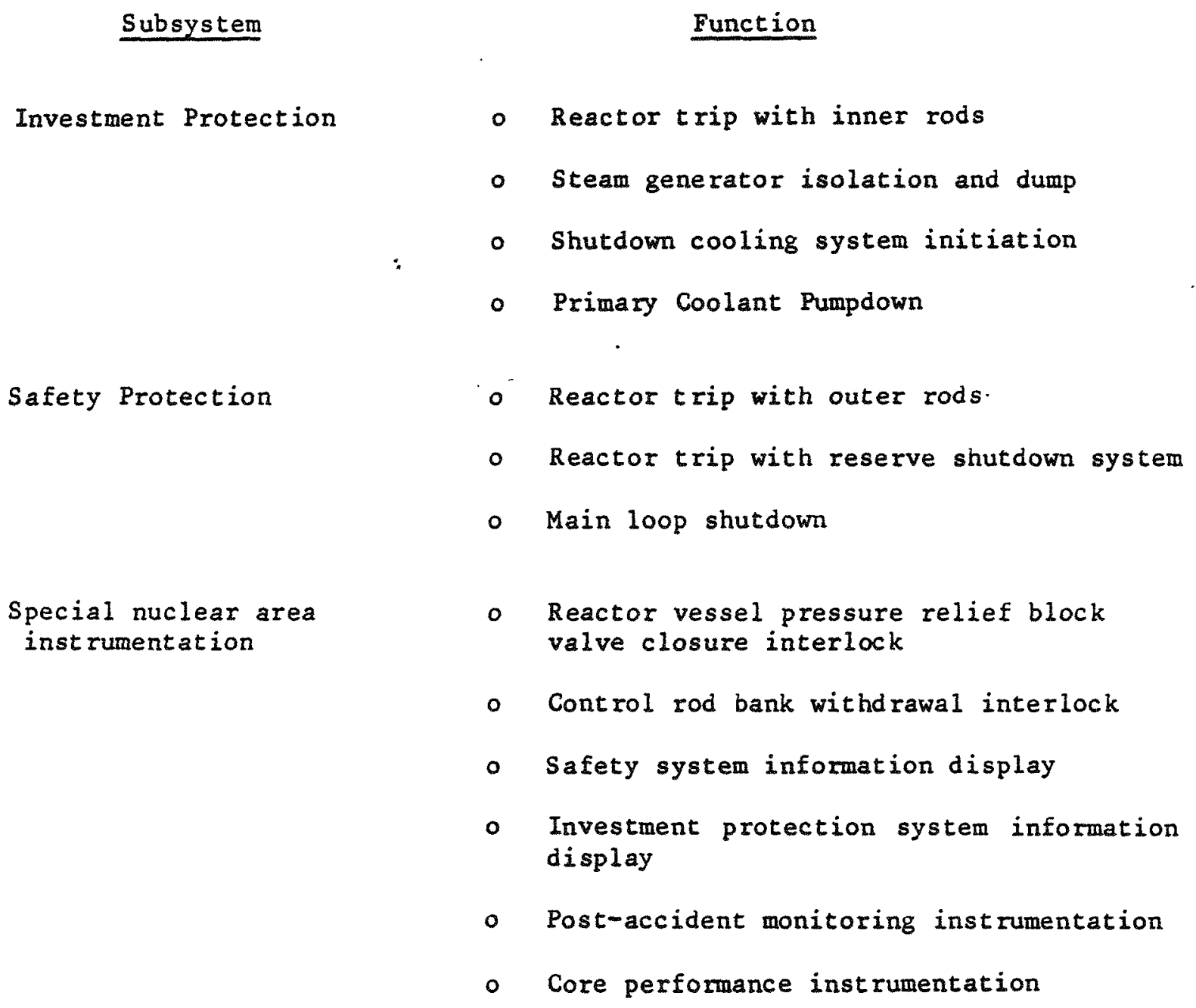


protecting the public health and safety. However, it is not safety-related. The investment protection subsystem provides an integrated response to various plant upsets and events to ensure equipment damage limits are not exceeded. The subsystem uses redundancy and other characteristics normally found in safety systems to meet the plant investment risk and availability goals. The investment protection subsystem consists of the following functions :

- Reactor trip utilizing inner control rods

- Steam generator isolation and dump, which limits the quantity of water that can leak into the core and the resulting chemical attack on reactor components

- Primary coolant pumpdown, which limits the release of radioactive helium and the thermal cycling of reactor components

- Shutdown cooling system initiation, which starts the shutdown cooling system upon loss of main loop cooling, thus reducing thermal cycling of large module components

\subsubsection{Safety Protection Subsystem}

This subsystem provides investment protection, but it is also the only subsystem that triggers protection actions needed to meet $10 \mathrm{CFR} 100$ requirements. As such, it is classified as Safety-Related, and it meets the requirements of the Institute of Electrical and Electronic Engineers (IEEE) Standard 279 and applicable portions of IEEE Standard 603. The safety protection subsystem consists of the following functions:

- Reactor trip utilizing the safety-related outer control rods, which initiates rapid reduction in reactor power following reactivity excursions or loss of adequate core cooling.

- Reactor trip utilizing the reserve shutdown system, which acts as a diverse reactor trip system, and as additional protection against reactivity excursions caused by water ingress. 


\subsubsection{Special Nuclear Area Instrumentation}

Special nuclear area instrumentation includes those control and instrumentation systems that are important in helping the operator to maintain or monitor safe plant operation. These include preventive features and systems that monitor safety system status and plant status during normal and accident conditions. The special nuclear area instrumentation includes:

- A reactor vessel pressure relief block valve closure interlock, which prevents the simultaneous closure of both the reactor vessel block valves

- Control rod bank withdrawal interlock, which prevents the simultaneous withdrawal of multiple control rod banks

- Safety system information displays, which provide safety systems channel readouts, safety systems status indications, safety system bypass indications, and preventive feature status and bypass indications

- Post-accident monitoring instrumentation, which displays and provides plant variables required by the control room operating personnel during accident situations

- Core performance instrumentation, which acquires and provides data for use in the core, limiting conditions of operation

\subsubsection{Plant Protection and Instrumentation System Hardware}

The protection system functions are implemented on a per-reactor basis with remotely multiplexed, centrally controlled, microprocessor-based modular hardware. The protection system architecture consists of four independent sensing channels, linked via four optical digital data highways. These communicate with four separate, centrally located, redundant computers to implement the four-channel protection system (see Figure 3-42). 


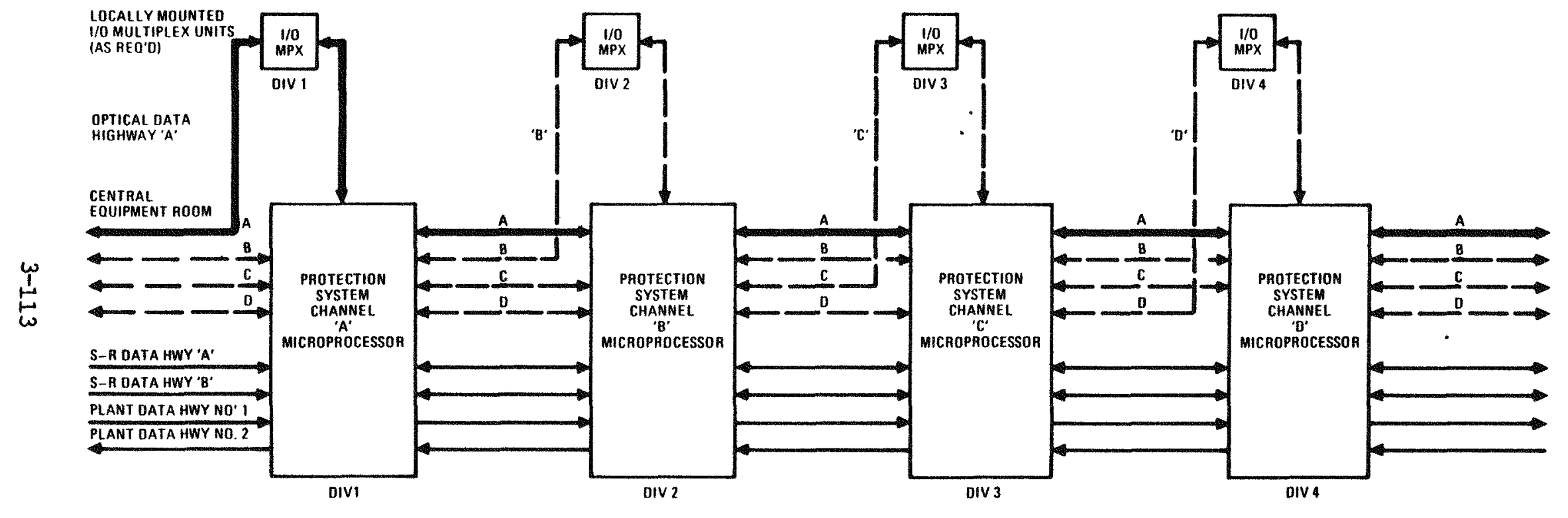

Figure 3-42 Protection System Data Buses 


\subsection{PLANT CONTROL, DATA AND INSTRUMENTATION SYSTEM}

The Plant Control, Data and Instrumentation System (PCDIS) provides automatic control for the four reactor modules and two turbine-generator systems for power generation. Automatic control is used during normal operation and abnormal events to maintain power generation while averting challenges to safety and investment protection. The multi-module plant is controlled from a single main control room with one primary operator and an assistant.

The PCDIS provides the following subsystems to control the MHTGR operation.

1. Plant Supervisory Control Subsystem (PSCS)

2. Reactor Module Control Subsystem

3. ECA Control Subsystem

4. Data Management Subsystem (DMS); and

5. Plant Operational Support Subsystem (POSS).

Figure 3-43 shows the relationship among the PCDIS subsystems. The PSCS provides supervisory control (load allocations) to the reactor module control. subsystem and the energy conversion area (ECA) controls. The PSCS also provides work stations for operator monitoring and interaction. The reactor module control subsystem provides individual control for each reactor module. The ECA control subsystem provides for control of equipment associated with each of the individual turbine plants. The Data Management Subsystem provides the communication link to transmit control signals and data between systems and the main control room. These subsystems provide an integrated control of the four reactor modules and two turbine plants.

Figure 3-44 shows the MHTGR plant process control schematic for one of the four reactor modules and one of the two steam turbines in the plant.

\subsubsection{Plant Supervisory Control Subsystem}

Plant level control functions are performed by the Plant Supervisory Control 


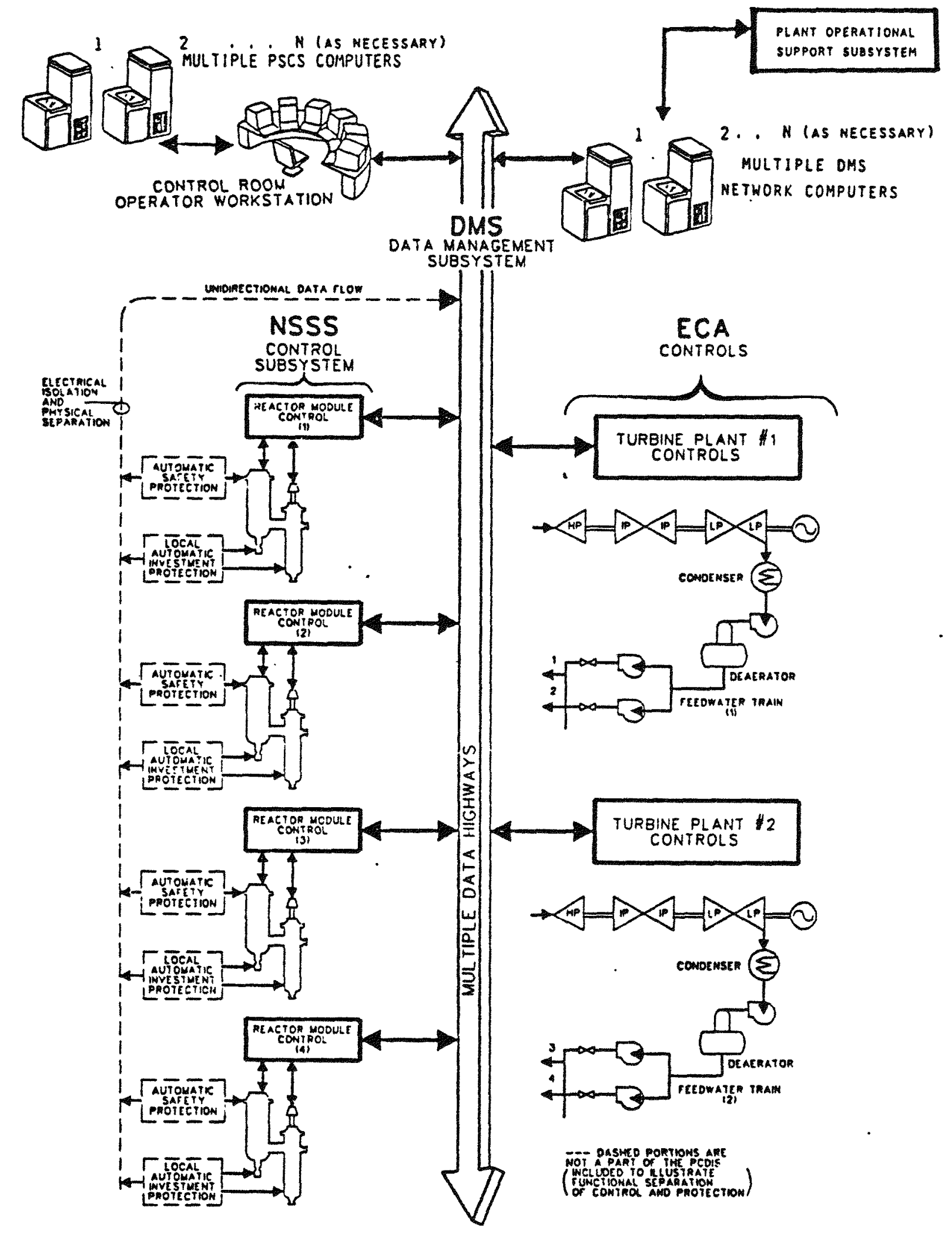


PLANT SUPERVISORY CONTROL SUBSYSTEM IPSCS)

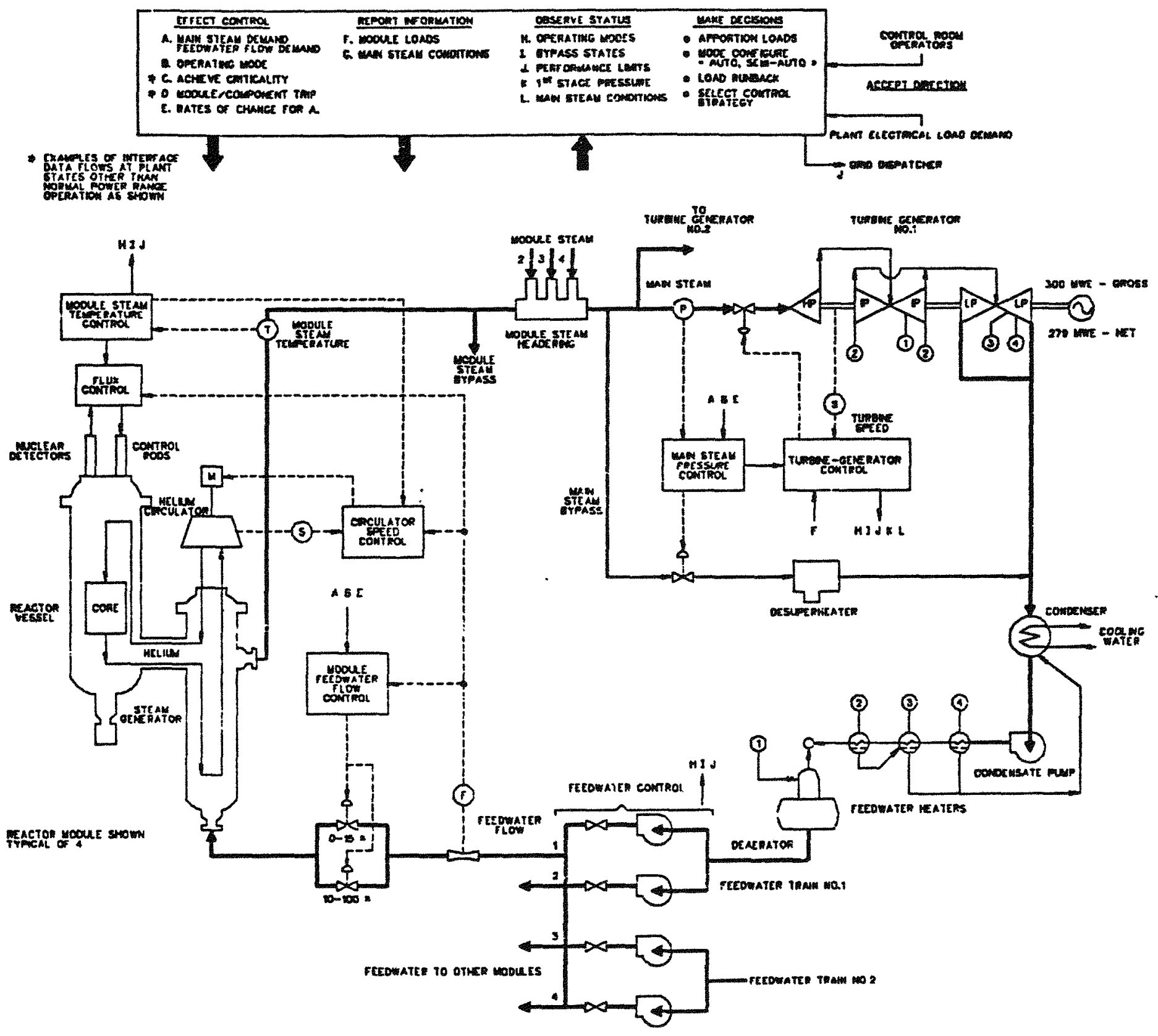

Figure 3-44 MHTGR Plant Process Control and Interface

Configuration 
Subsystem (PSCS). The PSCS automatically supervises and coordinates the balancing of load (power) levels among the energy production (reactor module) and energy conversion areas. The PSCS automatically determines what contri-. bution each reactor module will make to the ultimate delivery of steam for the energy conversion process. Likewise, the PSCS automatically determines what contribution each turbine-generator (TG) in the energy conversion area will make to the overall plant electrical output. The PSCS also monitors the performance, response and limitations of each reactor module and the ECA.

The PSCS consists of three major elements, the supervisory control hardware, supervisory control software, and control room operator workstations. Plant level control strategies and algorithms are implemented in software embedded in the computer hardware.

Included in the main control room of the plant is a seated-operator arrangement of plant control initiators and monitors required by the operator to operate the plant. The control initiators and monitors collectively form the operator workstation; the workstation is referred to as the Control Room Operator Workstation (CROW). The CROW generates displays, interprets and executes operator instructions, and communicates with the PSCS computers and the DMS.

\section{Functions}

The power generating function of the PSCS is to coordinate plant control during energy production, shutdown, refueling, and startup/shutdown. The PSCS accomplishes this function by accepting direction, observing status, making decisions, effecting control and reporting information. The PSCS does not perform any radionuclide control functions.

The PSCS computers accept and process power generation directions from the main control room (MCR), plant load requests from the grid dispatcher, and communications from the operator workstation to provide data for display. The PSCS computers observe key plant variables such as reactor module feed- 
water and steam conditions, turbine-generator performance, and reactivity levels and primary coolant temperatures. These data are used to determine load allocations and present information required by the operator. The PSCS determines how to partition and allocate the overall plant load demand to individual reactor modules and turbine-generators. The PSCS determines the rate of main steam production and feedwater flow changes necessary to achieve optimum plant response to simultaneous or unbalance load maneuvers. The PSCS effects control at the plant level by communicating operator instructions received from the CROW and communicating its own automatic control instructions for changing load. The PSCS computers report plant and self-status information required by the operators and maintenance personnel.

\section{Subsystem Configuration}

The PSCS is functionally iridependent from Plant Protection and Instrumentation System, structures, and components. The PSCS does not have any direct, physical interfaces with safety-related systems. The FSCS is physically separated from safety-related systems with data transmission between the systems provided by the DMS. Safety systems provide the electrical isolation devices at the interface with the DMS. Thus, as shown in Figure 3-43, the DMS has physical interfaces with safety systems but these interfaces are not used to perform safety functions. The CROW and the Control Room Assistant Workstation (CRAW) are located in the MCR within the Operations Center. Figure 3-45 depicts the workstation arrangements within the main control room.

PSCS Computers. The PSCS computers accept plant control and operating directions through the following:

1. An automatic plant load limiter which provides physical interface with grid dispatcher communications in order to accept, with concurrence by the operator, baseload and load following net electrical output load demands.

2. A comunication link with the operator workstations.

3. An operator instruction interpreter. 


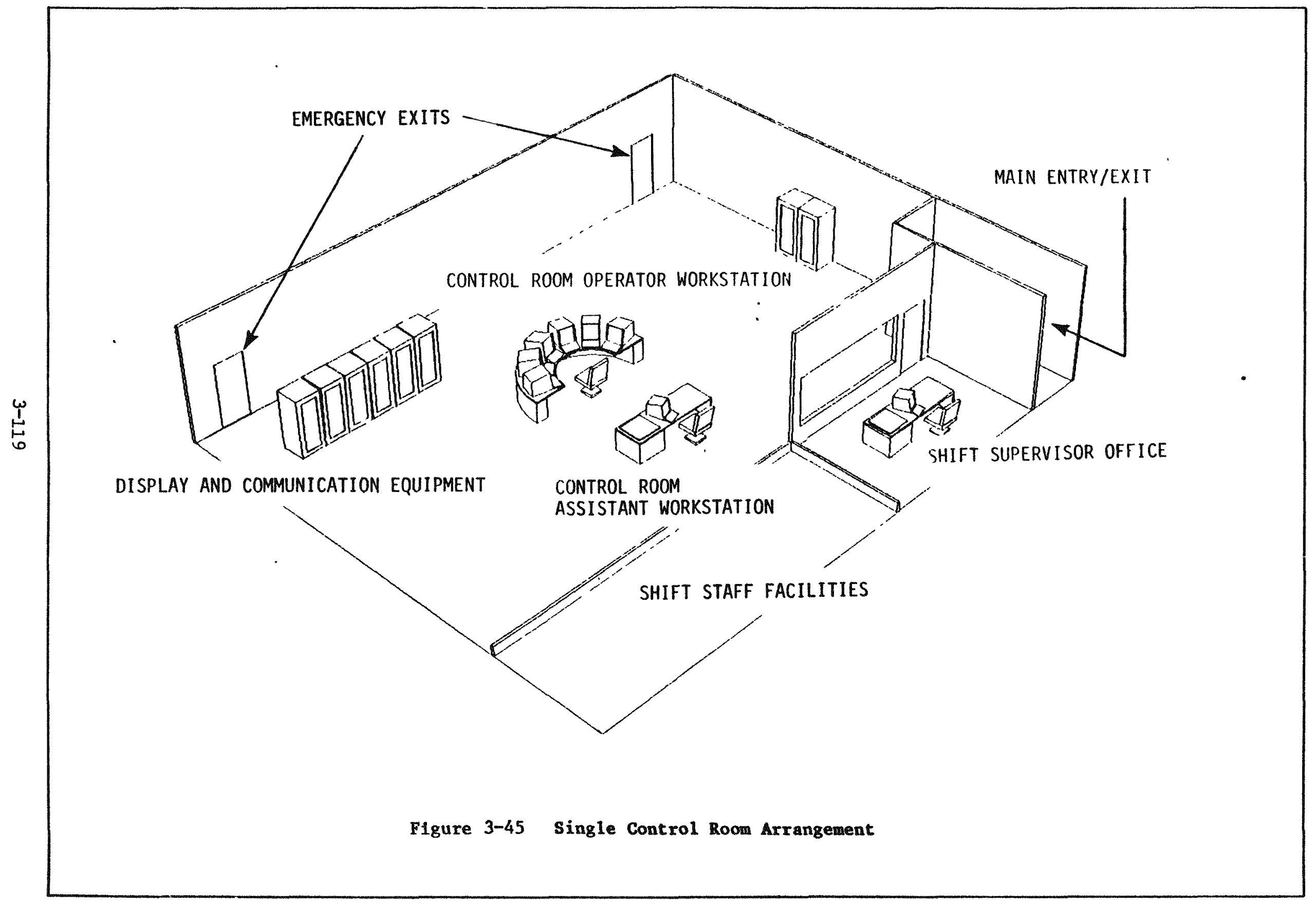


The PSCS computers observe plant status through comunication links with the DMS and plant status analyzer.

The PSCS computers make plant level control decisions through the following:

A plant control strategy selector selects the necessary mode of plant operation and the control strategy that best facilitates operation of reactor modules and turbine-generators independently and at different power levels.

A control and operator instruction validator automatically analyzes, diagnoses, verifies and validates control actions, analytic results and observations.

The PSCS computers effect control at the plant-level through the automatic control instruction generator, which is for load allocation, startup, data requests, etc.

The PSCS computers report plant information through the following:

A communication link with the DMS, which is for communicating control comnands, directions, and instruction to other systems.

A communication link with the operator workstation which is for display or printing.

The configuration of the PSCS computer elements is diagramed in Figure 3-46.

The PSCS computers coordinate overall operational control of the plant during normal and off-normal power generation, startup, refueling, and shutdown.

Control Room Operator Workstation. The control room operator workstation contains the control initiators and monitors required in the main control room for a single operator to control four reactor modules and two turbine generators in the plant. The operator manages (supervises and monitors) automatic process control within the energy production (reactor module) and 


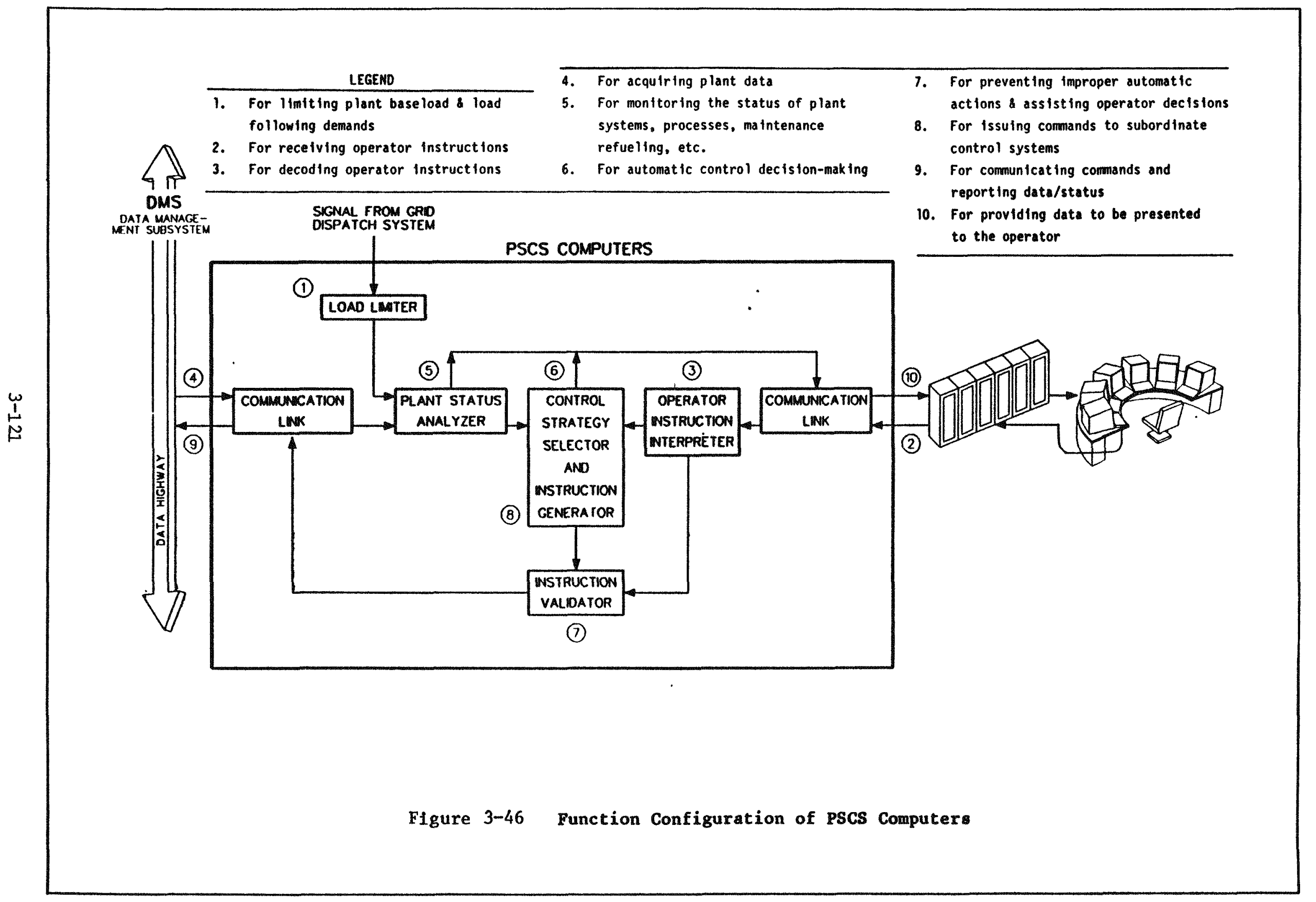


energy conversion areas in conjunction with the PSCS computers.

The CROW accepts plant operating directions through touch-activated control devices (e.g., push-button switches).

The CROW observes plant operating status through a commications link with the PSCS computer and a communications link with the DMS.

The CROW makes operator workstation decisions through the operator instructions decoder and PSCS computer instruction interpreter.

The CROW effects (generates) plant operating instructions through the operator instruction digitizer.

The CROW reports plant operations information through video display generators.

The configuration of the workstation elements is indicated in Figure 3-47.

Control Room Assistant Workstation. The control room assistant workstation (CRAW) is a workstation for a licensed assistant operator. The CRAW contains display generation and printing equipment that can generate any display or print any information normally available to the operator at the CROW. It. provides the capability to access plant data bases maintained by the Data Management Subsystem. Plant systems, equipment and components cannot be cont rolled or operated from the CRAW.

During normal plant operations, the role of the assistant operator at the CRAW is to monitor startup, shutdown and refueling activities and auxiliary systems whose operations are not a direct function of the main energy production and energy conversion process. During abnormal plant conditions, the assistant operator monitors the remainder of the plant while the operator at the CROW tends to the controls of the affected portion of the plant. The assistant operator monitors the affected portion of the plant once it is restored to nomal operating conditions or removed from service while the operator at the CROW resumes normal operating tasks. 


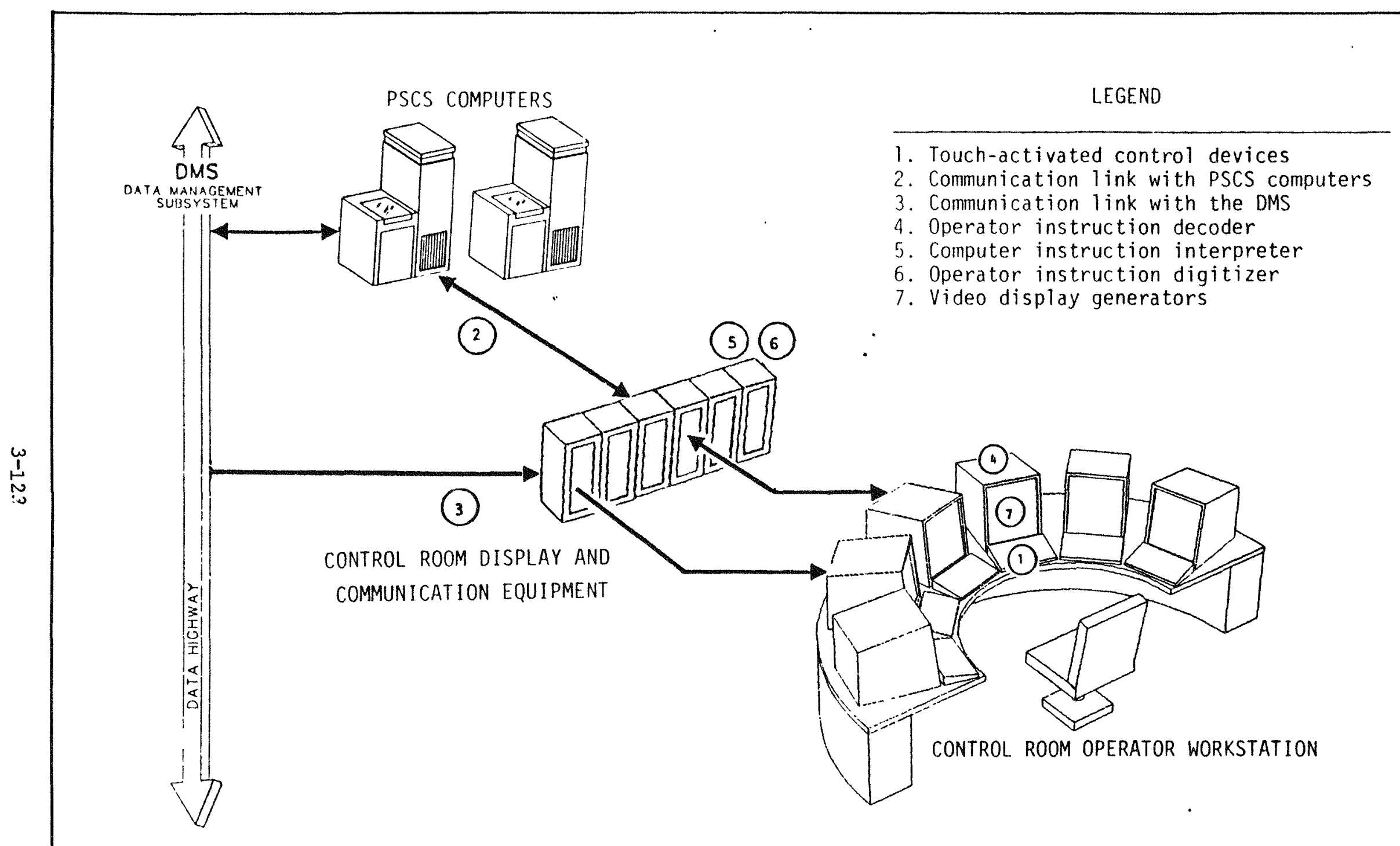

Figure 3-47 Functional Configuration of Operator Workstation 
Communication and Display Generation Equipment. Cabinets located behind the CROW contain communication and display generation equipment associated with the touch control devices and video monitors, respectively, in the CROW. This equipment is part of the PSCS. The cabinets also house data communication interface equipment. This equipment is part of the DMS and it provides the capability to communicate operator instructions and plant data in and out of the MCR, respectively. Communication, test and maintenance instrumentation is also housed within these cabinets. Peripheral equipment is located in the control room to meet operator and shift supervisor information requirements (e.g., low-noise printers, display copiers, etc.). A workstation is provided for the shift supervisor as part of the DMS.

\subsubsection{Reactor Module Cont rol Subsystem}

There are individual Reactor Module Control Subsystems, one for each reactor module, that control reactor conditions and the supply of steam to the main steam header. The system utilizes a distributed computer control architecture. For power generation, the individual Reactor Module Control Subsystems respond to individual load demands allocated to them by the Plant supervisory Control Subsystem. Each reactor module control system controls its feedwater flow demand to meet its allocated load and the delivery of steam at the rated conditions of $16.5 \mathrm{MPa}(2,400 \mathrm{psig})$ and $538^{\circ} \mathrm{C}\left(1,000^{\circ} \mathrm{F}\right)$.

The power generation function of the reactor module control subsystem is to coordinate reactor module control during energy production, shutdown, refueling and startup/shutdown. The reactor module control subsystem has no radionuclide control functions.

During power generation, the reactor module control subsystem performs its function by accomplishing five operations:

1. To follow the mission prescribed by the PSCS, the reactor module control subsystem automatically accepts, with operating staff concurrence, load apportionment and sequence hold signals. This includes startup and shutdown sequences. 
2. The system also senses, processes, and analyzes those variables, states, modes, limits, and conditions required for the reactor module processes and subsystems to be observable.

3. Subsequently, the reactor module control subsystem decides what strategy, based on the sensed data, shall be used within the reactor module to produce steam.

4. On the basis of the decision made, reactor module control subsystem effects final control element action to bring steam conditions to the desired levels.

5. Finally, the reactor module control subsystem generates display information regarding reactor module status and conditions and provides it to the PSCS and the operator stations.

Subsystem Configuration. The reactor module control subsystem accepts energy production direction through a comunications link between module data highways and the DMS data highway, and local operator interfaces.

The reactor module control subsystem observes energy production status through the reactor module process sensors connected to module data highways and BOP sensors connected to DMS and module data highways.

The reactor module control subsystem makes energy production control decisions through the decision logic resident in reactor module control software and hardware, and interaction with ECA and PSCS decision logic.

The reactor module control subsystem effects energy production control through the programmable control algorithms and final control elements interfaced with reactor module data highways.

The reactor module control subsystem reports energy production information through the module data highways that pass information to the DMS data and display, annunciator, and alarm drivers resident in the reactor module control subsystem.

Figure $3-43$ shows the relative location of the reactor module control 
subsystem in the modular hierarchy of the PCDIS architecture. Figure 3-48 shows the main loops of the reactor module controls. As shown in the figure, the major functions of the reactor module controls are:

1. Module feedwater flow control demand.

2. Reactor module circulator speed characterization.

3. Reactor module power characterization.

4. Module main steam temperature control.

5. Module main steam pressure control during startup. Pressure in the main steam header is controlled by the turbine throttle valve and the indexed feedwater flow in the individual reactor modules.

Reactor module controls are designed to automatically follow the load apportioned to each module by the PSCS over the range between 25 and 100 percent of full module output. In addition, the reactor module automatic control loops are configured to accommodate feedwater, reactor, and turbine trips. Special compensation and limiting are used after these events to minimize transient extremes, thereby protecting major equipment and increasing module availability.

Reactor module feedback control algorithms are proportional plus integral plus derivative expressions (commonly known as $P+I+D$ ). The result of this feedback algorithms is normally sumed with a feedforward signal (if used for the specific control algorithm). The sum of the compensation output and the feedforward signal are then passed through limiter logic which may provide high, low, and/or rate limits. The control algorithms output from the limiter is then set to the manipulated variable (dependent variable). When and if the limiter is on one of the limits, a signal is sent to the $P+I+D$ function to force it to "track" such that the sum of the compensation output and the feedforward indeed satisfy the limit condition.

Distributed digital control electronics are used for data acquisition display, control logic, status assessment, and calculations. The reactor module 


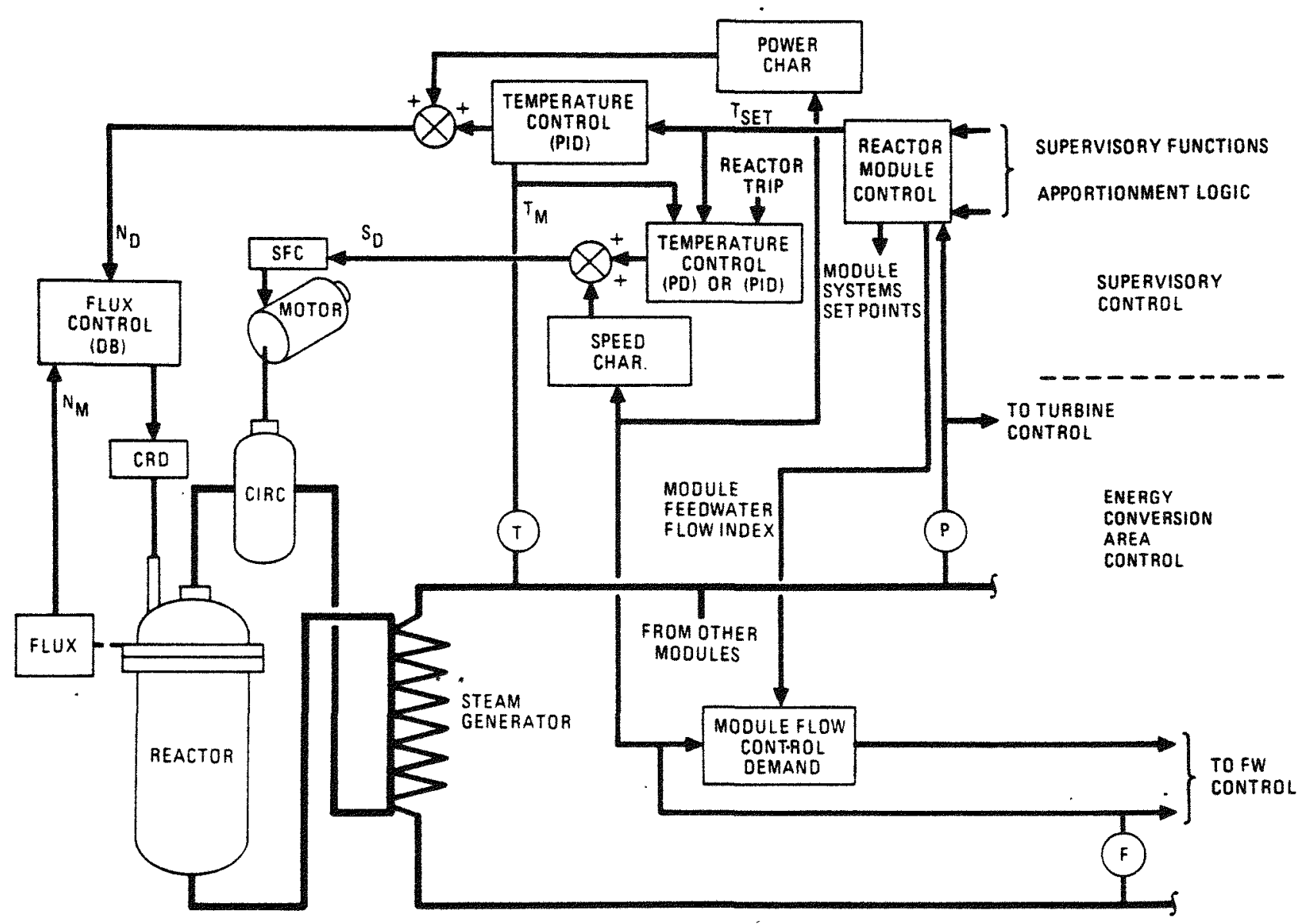

Figure 3-48 Reactor Module Control Functions 
control subsystem is part of a hierarchical data highway system which provides the communications paths between active NSSS components. The subsystem is both redundant and functionally partitioned so that a single failure in any attached electronic module can at most only eliminate the functions associated with that module.

Each reactor module has its own dedicated highway system. These data highways communicate with the DMS highway system. The conceptual architecture of the reactor module control subsystem is shown in Figure 3-49.

The multiplexers and controllers are connected to the redundant module data highways. The highways receive supervisory control commands via the DMS data highway system, and transmit reactor module data through it. The basic functions of each multiplexer are controlled by instructions contained in its hardware.

The reactor module control subsystem is designed to supply information and control capabilities to personnel with responsibilities for operations, test and calibration, engineering, maintenance (hardware and software), and management. Typical locations where the reactor module control systems have man-machine interfaces are the control room, the computer room, the test and calibration stations, local control stations, and engineering offices.

Information handling equipment consists of a variety of computers which are distributed on the various data highways to satisfy reactor module control subsystem functional and reliability needs. Processing and storage functions are provided for alarm handling, core performance monitoring, status assessment, operator guides, historical data base and logs, and other information needs.

Redundant capacity for both reactor module data processing and storage is utilized so that no single failure can eliminate information handing functions. All detectable failures are alarmed. 


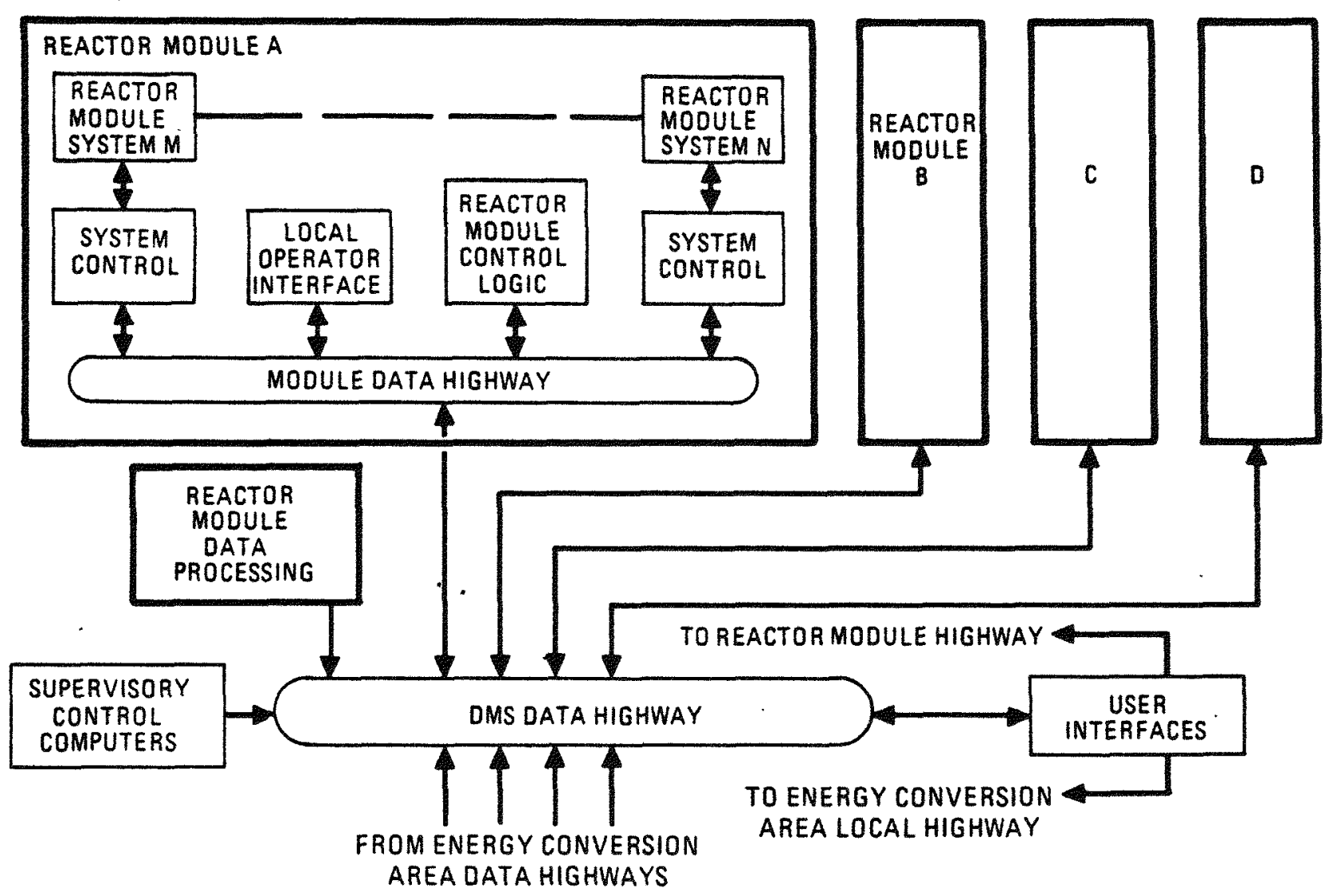

Figure 3-49 Conceptual Reactor Module Control Subsystem Archltecture 
Since the reactor module control subsystem has a data highway network for each reactor module which is linked to the DMS highways network, all reactor module data users are supported by a common and consistent set of information which includes current values as well as historical data.

Controls and displays required to monitor and operate the reactor module equipment are located in the main control room and at local control stations installed near major components. Sensors and sampling systems are located near the point of measurement. Additional display terminals, keyboards, printers, and removable storage devices are located in the primary work areas of others who need access to the reactor module data base.

Other devices such as NSSS data processing computers (heat balances, etc.), computer peripherals, maintenance stations, data highways, and communication controllers, etc., are installed in computer and relay rooms.

\subsubsection{Balance of Plant Control Subsystem}

The balance of plant (BOP) portion of the Plant Control and Data Instrumentation System (PCDIS) provides monitoring and control from the main control room (MCR) for those systems which directly impact continuity of power generation. For auxiliary and support systems which do not have an immediate impact on power generation, primary control will be from local control panels with selected controls and displays provided in the MCR.

For the following systems, primary monitoring and control will normally be from the MCR with provision for secondary monitoring and control from local panels to facilitate maintenance activities:

1. Power Conversion Group

Turbine Generator and Auxiliaries

Feedwater and Condensate

Demineralized Water Makeup

Main and Bypass Steam 


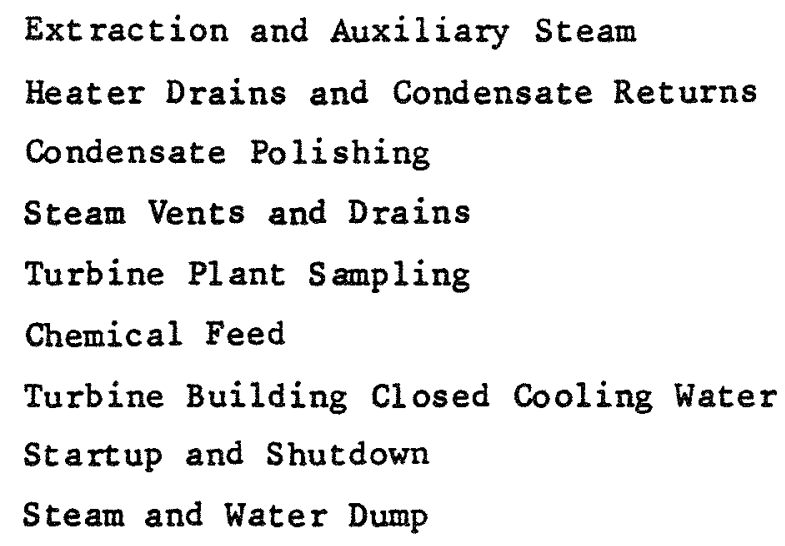

2. Heat Rejection Group

Circulating Water

Circulating Water Makeup and Blowdown

Plant Service Water

Shutdown Service Watex

Shutdown Cooling Water

3. Electrical Group -- all systems and subsystems

4. Reactor Services Group

Helium Storage and Transfer

Liquid Nitrogen

Reactor Plant Cooling Water

The following systems and facilities will normally be monitored and controlled from local control panels or a console. Key parameters and alarms will be displayed in the MCR to indicate proper operation/readiness or malfunctions.

1. Reactor Services Group

Reactor Equipment Service Facility

Decontamination Service Facility

Radwaste System 
2. Fuel Handing, Storage and Shipping System

Site Fuel Hand ling

Spent Fuel Storage cooling

3. Mechanical Service Group

Potable Water

Plant Fire Protection

Waste Water Treatment

Auxiliary Boiler

Raw Water Treatment

Inst rument and Service Air

Central Hot Water Heating

Plant Drains

Backup Power Generator Fuel Oil

HVAC Systems, including chilled water subsystem

\subsubsection{Data Management Subsystem}

The Data Management Subsystem (DMS) serves two plant level PCDIS functions: (1) plant-wide data communication, and (2) centralized data processing. The DMS acquires, transmits, processes, records, stores, diagnoses and distributes data/information for both onsite and offsite, and immediate and future use. Distributed data communication controllers and high-speed digital computers perform the two plant level DMS functions, respectively. A distributed comunication network (illustrated in Figure 3-43) interconnects the data communication cables referred to as data highways. The DMS is required to be available and operable during every operating mode of the plant.

The DMS does not initiate any plant control or protection functions. The DMS is a non-safety-related subsystem; it does not perform any 10CFR100-related radionuclide control functions. The DMS does not directly perform any power generation functions. However, it indirectly supports the power generation 
control functions of the other PCDIS subsystems by transmitting the control and monitoring communications between them.

The DMS communication network accepts directions from the PSCS on where to send and receive communications and the purpose of the communications (e.g., control command, request, monitor, print, display, file, annunciate, etc.).

The DMS network observes communications by detecting acknowledgment of the readiness status for communication and monitoring digital signal transmission integrity. The network controllers schedule transmissions, select available communication routes, and determine and report if any communication errors occur.

The DMS data processors accept system user instructions to execute software programs (routines) and retrieve or store data. The data processors acquire data from the DMS communication network, store plant process variables and status data, and record the sequence of events. The data processor schedules execution of processing tasks and identifies unauthorized interactions or data security violations. The data processor communicates data to peripheral devices (e.g., printers, video display generators, etc.) and reports processing errors and corrective measures.

The DMS has electronic signal commuication interfaces with the instrumentation and control portions of the Nuclear Island systems. The interfaces consist of digital, analog, and discrete electrical signal wiring/cabling connections. For those interfaces with safety-related systems (e.g., the Safety Protection Subsystem of the PPIS), the interface consists of DMS optical signal conditioning electronics mounted within a DMS cabinet and an optical signal cable/coupler. The cable/coupler carries unidirectional signals transmitted from an optoisolator device that is a part of the safety-related equipment. The cable/coupler is supplied as part of the safety-related system. These interfaces, like all other interfaces within the DMS, are used for non-safety-related functions. 
Since the DMS does not perform any safety-related functions, unavailability of those portions of the DMS that interface with safety-related systems does not challenge plant safety protection. The DMS equipment is physically separated and electrically isolated from safety-related equipment.

\subsubsection{Plant Operations Support Subsystem (POSS)}

The Plant Operations Support Subsystem is the name given to the collection of computer-based workstations used by the plant engineering and technical staff whose presence in the main control room is not required. The principal function of the POSS is to provide computational, analytical and monitoring capabilities so that engineering and technical staff personnel can perform their duties without being present in the MCR. The activities performed at these workstations are supervised under the authority of the plant technical management staff. Operations and activities are carried out using the poss to supplement the plant operating requirements of the control room operators.

The facilities housing the POSS workstations provide for the following:

- Centralized normal and emergency assembly location for plant engineering, technical and operations staff

- Technical work environment in support of plant emergency response technical personnel

- Support the control of personnel access to the main control room

- Integration of group technical tasks; these tasks include required maintenance, surveillance, testing and calibration that occur during the various plant operating modes and states. 


\subsection{MISCELLANEOUS CONTROL AND INSTRUMENTATION GROUP}

The miscellaneous control and instrumentation group includes the following systems :

- Reactor module analytical instrumentation

- Radiation monitoring

- Seismic monitoring

- Meteorological monitoring

- Fire detection and alarm

- Security monitoring

These systems use microprocessor-based equipment that communicates through remote multiplexing via optical data highways.

The reactor module analytical instrumentation system provides primary coolant surveillance data needed to verify that primary coolant chemistxy is maintained within specification to prevent fuel and reactor component changes. Analytical instrumentation measures and analyzes chemical impurities and radioactivity in the primary coolant helium as required by the primary coolant system, helium service system, and the gas waste system.

The plant radiation monitoring system monitors all radioactive releases from the plant, monitors plant radiation areas, provides health physics and operation data, and gives early warning of plant equipment malfunctions that may result in a radioactivity release. The airborne radiation monitors survey airborne particulate activity, airborne iodine activity, and noble gas activity discharged from each building or from the reactor confinement building vent. The area monitors check radiation levels in designated plant areas to supplement the airborne radiation monitors, which detect abnormal migrations of radioactive materials in or from the process streams.

The Seismic Monitoring System (SMS) is intended to detect, indicate, and record the seismic accelerations experienced by structures and equipment 
needed to meet the radionuclide control requirements of 1 OCFR 100 during an earthquake. The basic set of SMS sensors is provided for two of the four identical Reactor Buildings. Because the Reactor Buildings are identical, the data from the instrumented ones will be applicable to all. The seismic instruments are designed to respond to the Reactor Building design acceleration levels. Two redundant sets of Reactor Building seismic sensors permit major maintenance on any reactor module, including removing a set of sensors from service, without jeopardizing seismic surveillance of the plant.

Security Monitoring is an integrated system of sensors for perimeter and interior intrusion detection and alarm, with closed-circuit television used for assessment. Supervisory circuits are used to detect tampering and internal system faults. Security Monitoring meets the requirements established in 1OCFR50 and 10CFR73. 


\section{14 PLANT BUILDING AND STRUCTURES}

\subsubsection{Reactor Building}

Each of the four reactor modules is housed in a separate Reactor Building (RB). Each RB consists almost entirely of a.multi-cell, reinforced concrete structure set predominantly below grade. While the inherent safety characteristics of the steel vessel MHTGR make a pressure-retaining, leaktight containment unnecessary, the $\mathrm{RB}$ does serve as a filtered, vented enclosure, providing an additional barrier to limit the release to the atmosphere of small leaks of radioactivity during normal operation.

The building is configured as a $18.3 \mathrm{~m}(60 \mathrm{ft})$ inside diameter cylinder from elevation $-47.1 \mathrm{~m}(-154.5 \mathrm{ft})$ to elevation $-10.5 \mathrm{~m}(-34.5 \mathrm{ft})$. At elevation $-10.5 \mathrm{~m}(-34.5 \mathrm{ft})$, the shape of the building changes to a rectangular structure. In the reference design, four Reactor Buildings, along with two Reactor Auxiliary Buildings and a Reactor Service Building, are set in a row and constitute the principal portion of the Nuclear Island ("NI"; see Figure 3-50). The area between modules 2 and 3 is covered with a concrete slab and will be used as laydown area during maintenance.

The cylindrical portion of the below-grade cavity is subdivided into a number of vertical cells which house reactor module equipment and provide access. Those cells housing the reactor and steam generator occupy the major portion of the building. The steam generator and reactor are separated by a $1.5 \mathrm{~m}$ ( 5 ft) thick wall which is penetrated by the crossduct. Other cells provide personnel and equipment access, pipe, cable ways and cavity vent path.

The rectangular portion of the building is divided into two levels and subdivided into several compartments. The majority of this area is occupied by Reactor Cavity Cooling System (RCCS) ducting and the cavity vent path. Other spaces house Helium Purification System (HPS) equipment, Plant Protection and Instrumentation System (PPIS) equipment, and other nuclear auxiliaries which are dedicated to each reactor module. Figures 3-51 through 3-57 show the 


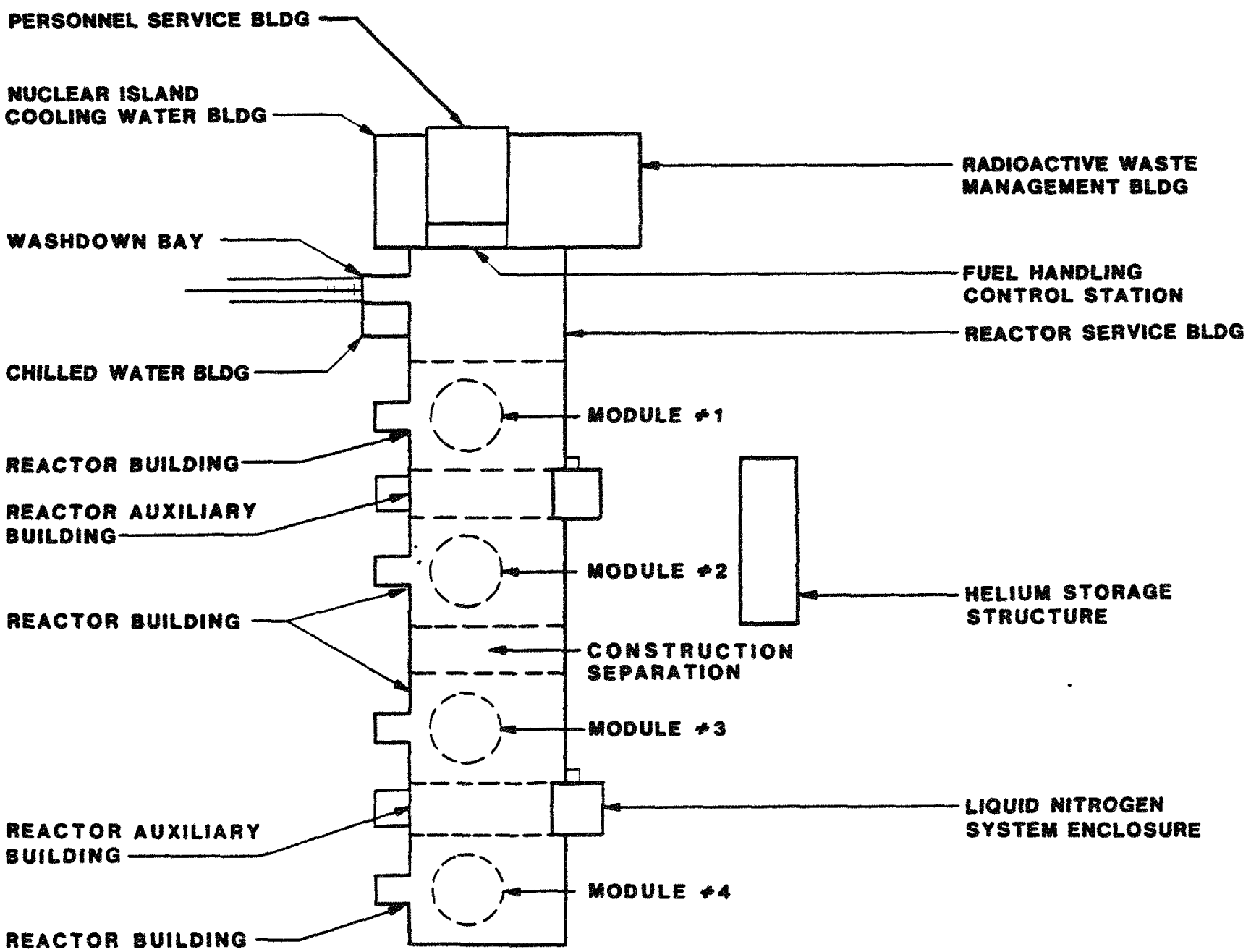




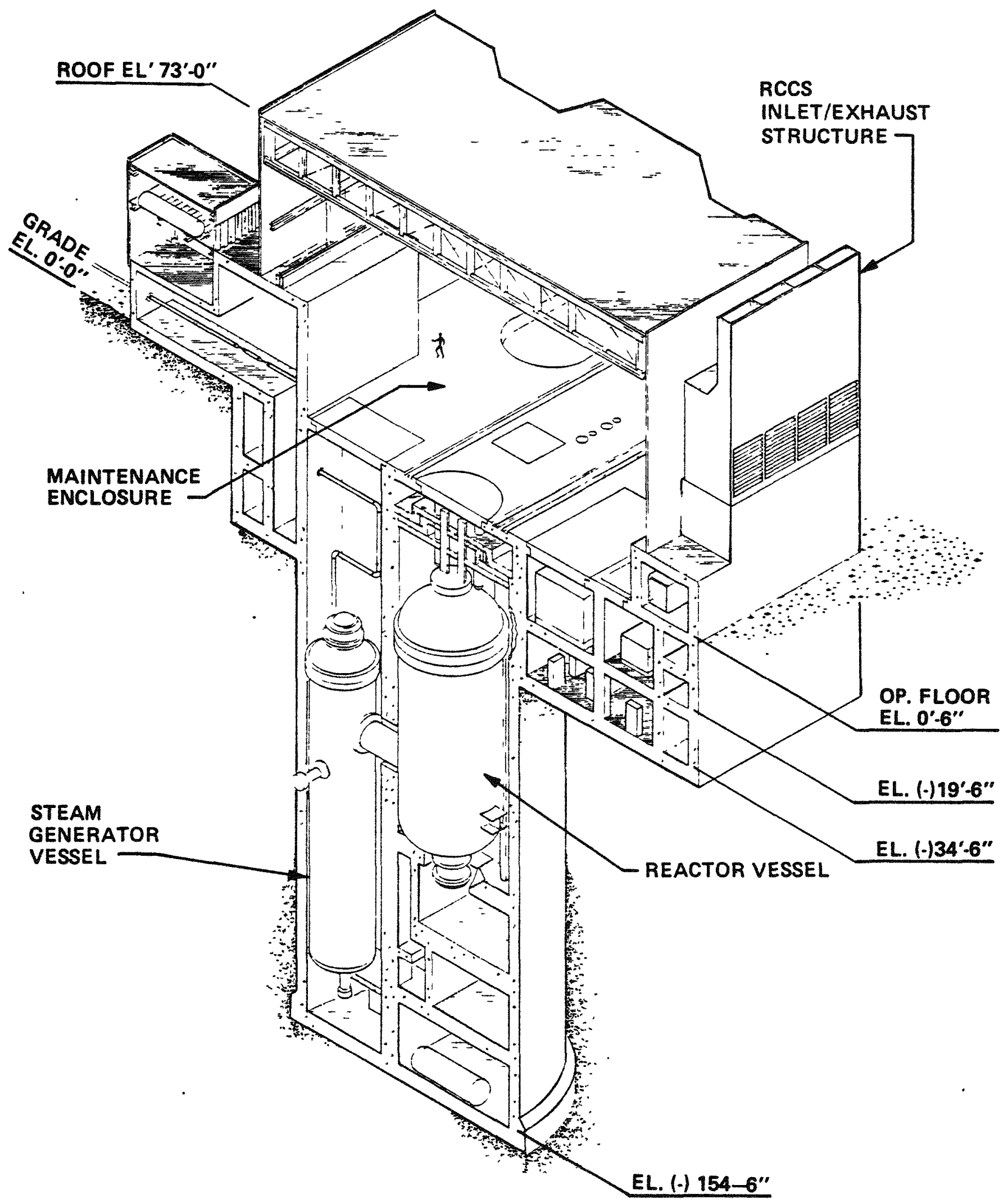

Figure 3-51. Isometric View through Reactor Building 


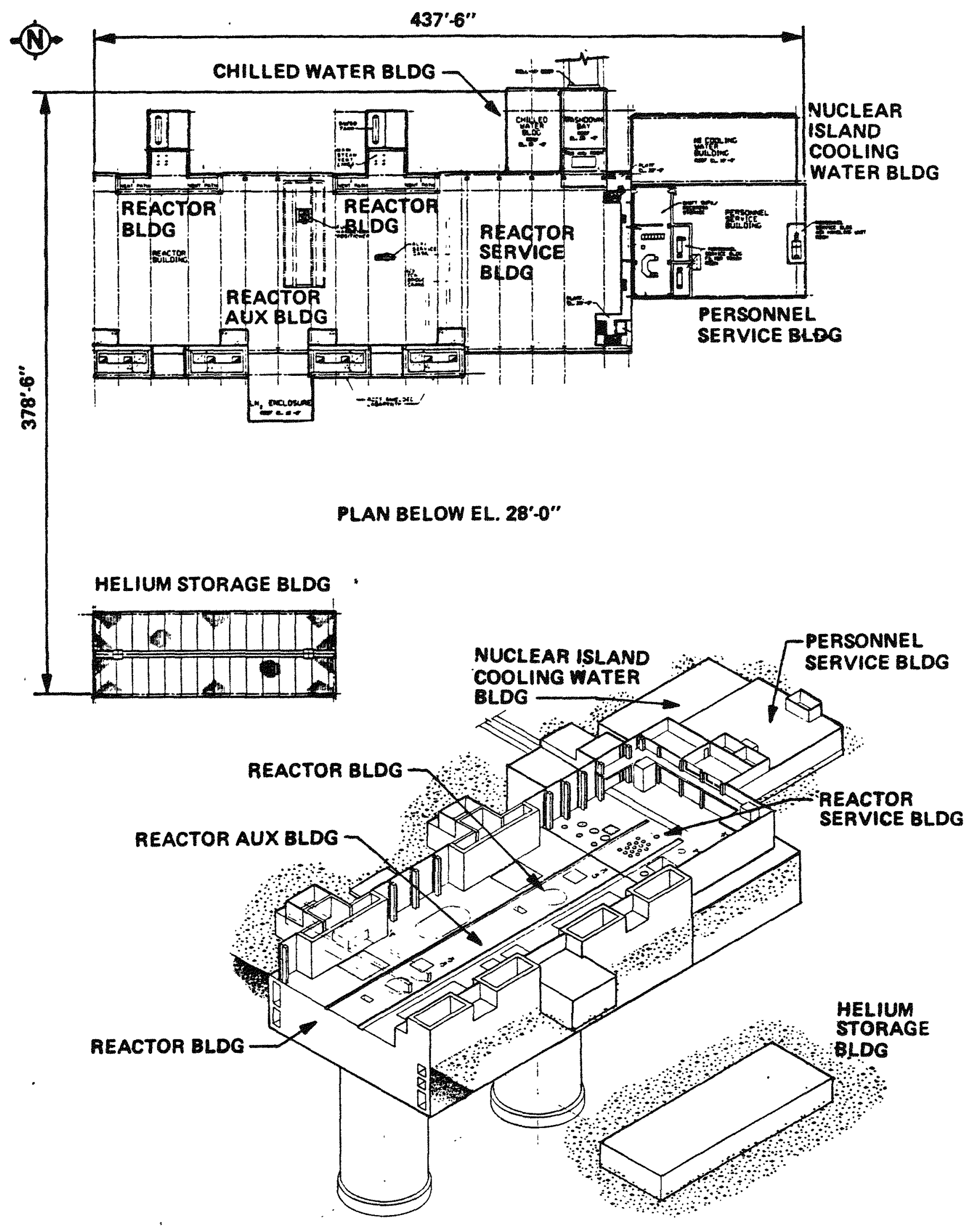

Figure 3-52 Nuclear Island Arrangement Plan and Isometric 


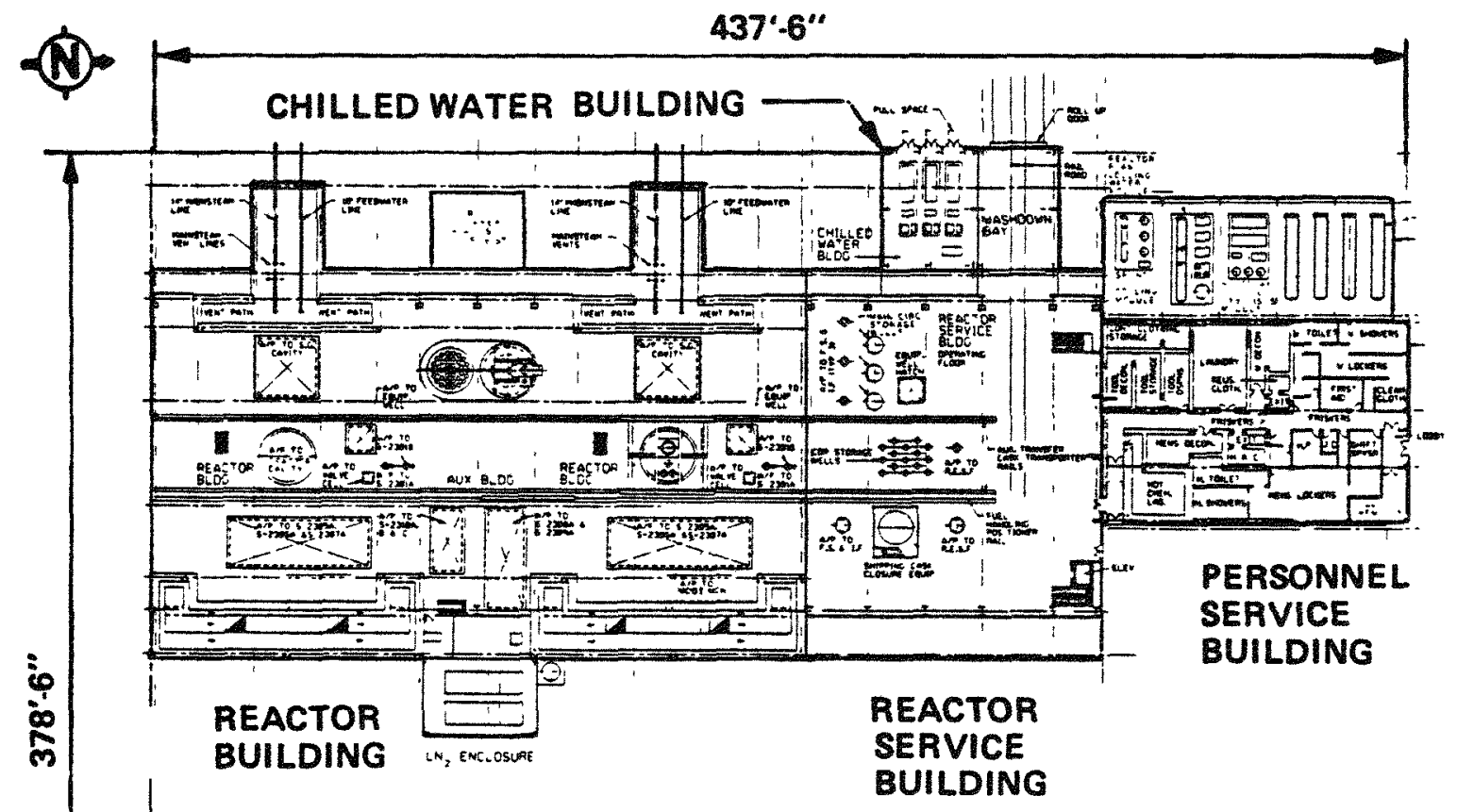

PLAN BELOW EL. 12'-0"
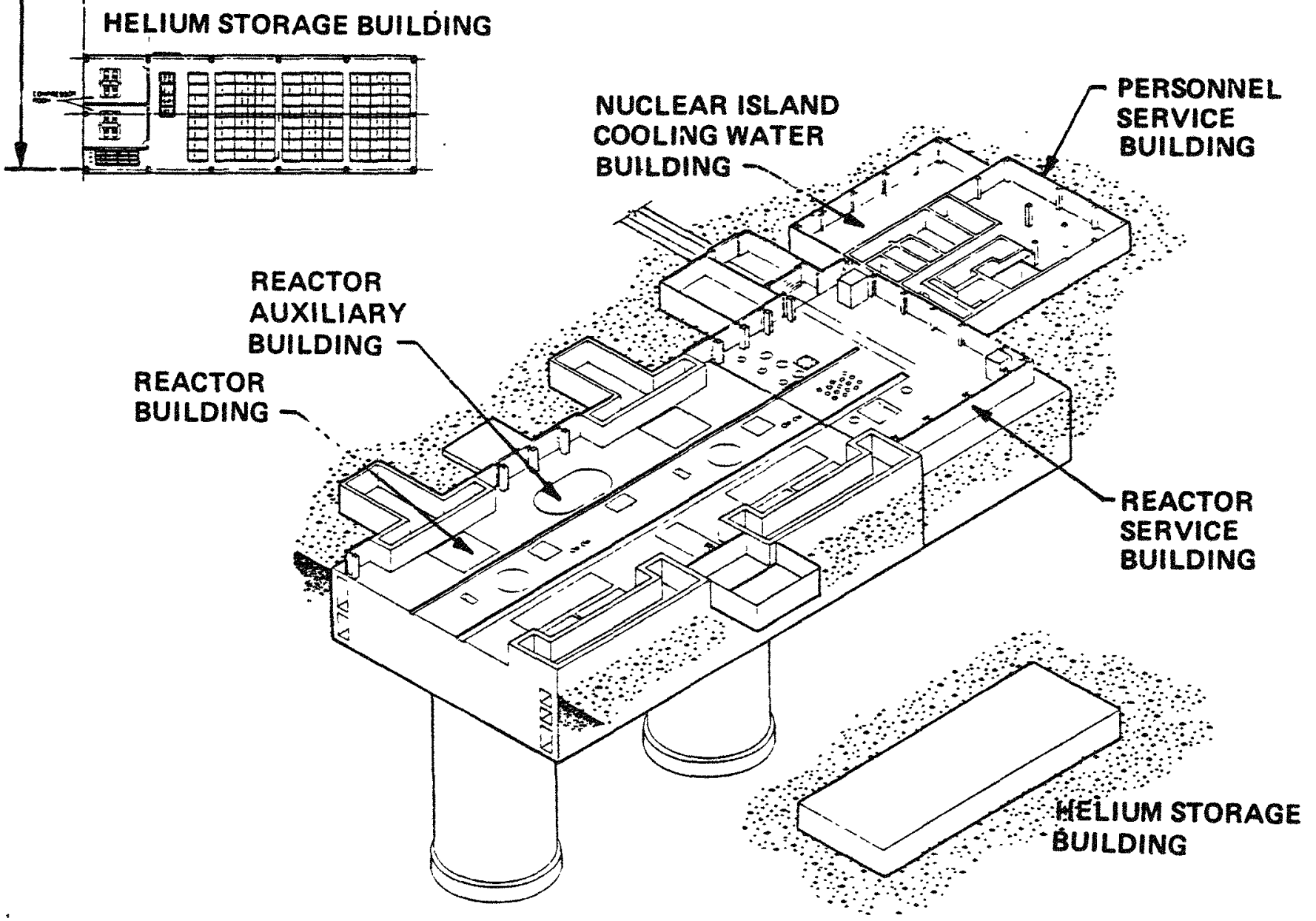

Figure 3-53 Nuclear Island Arrangement Plan and Isometric 


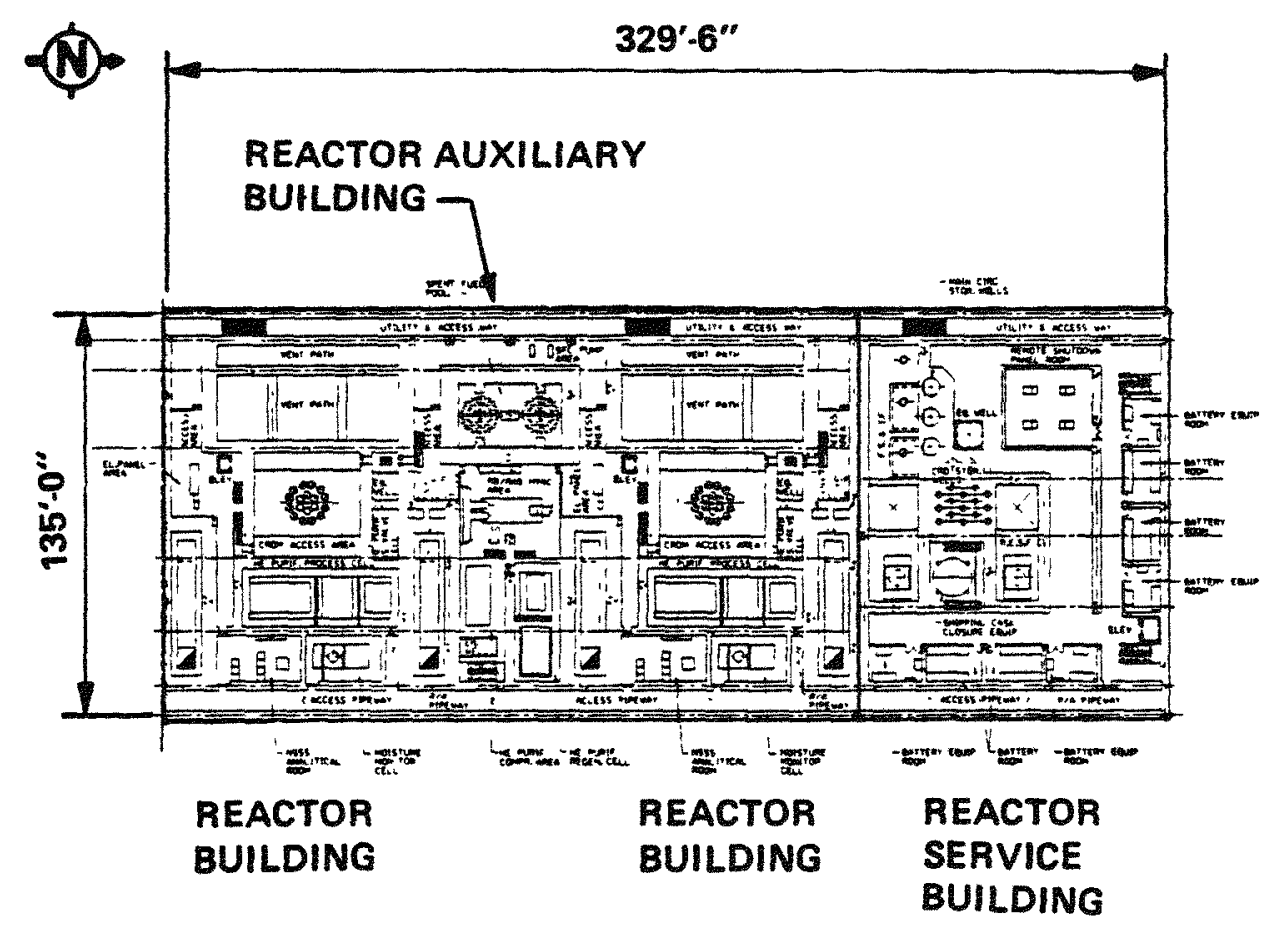

PLAN BELOW EL.(-) $15^{\prime} \cdot 0^{\prime \prime}$

:

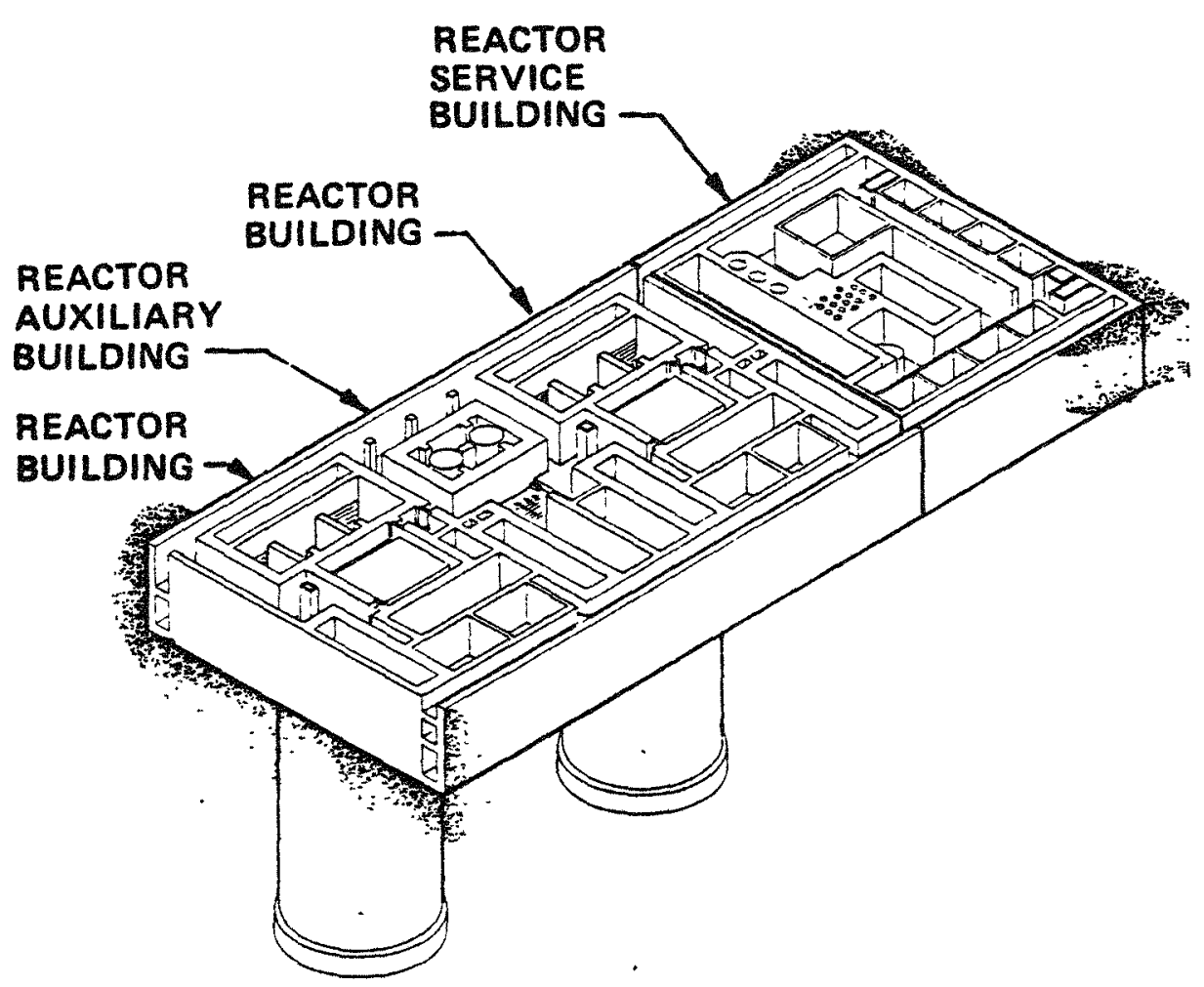

Figure 3-54 Nuclear Is land Arrangement Plan and Isometric 


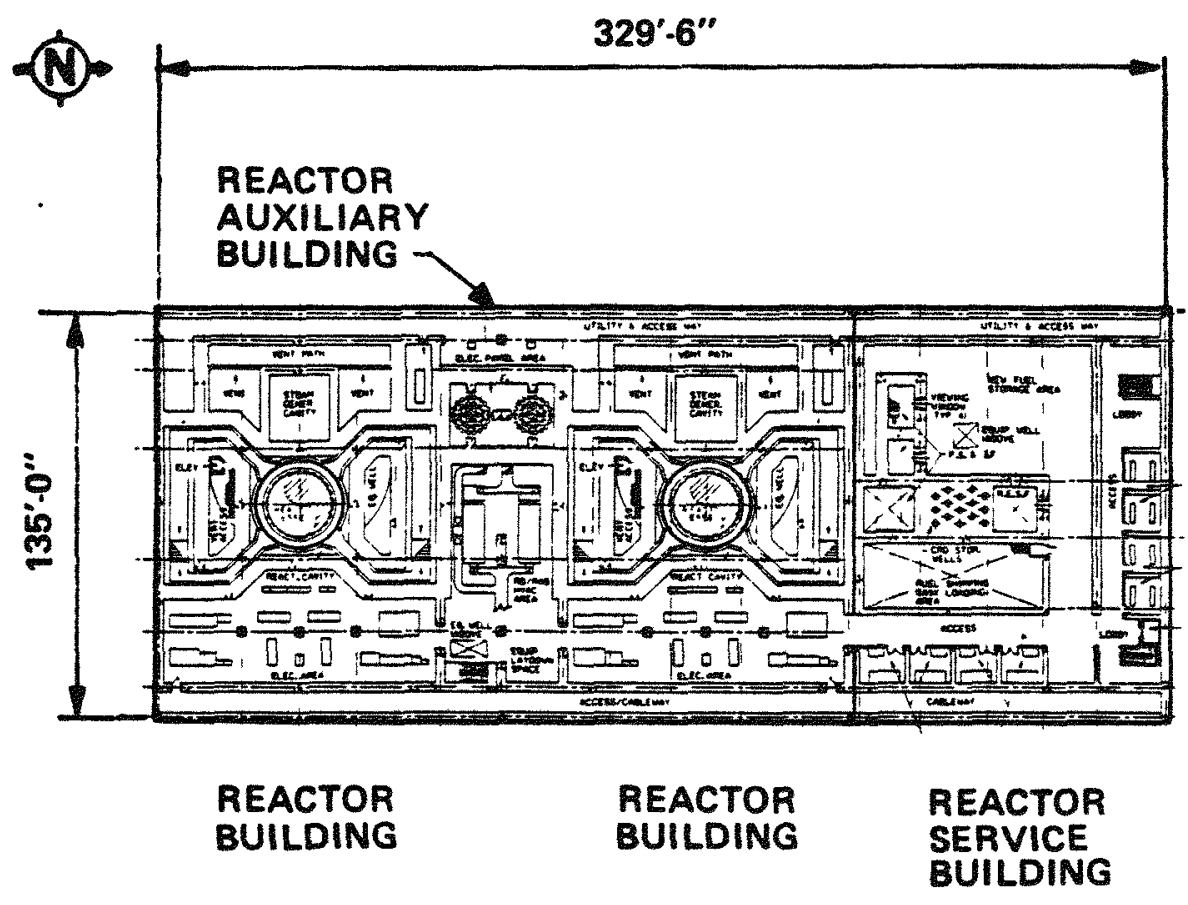

PLAN BELOW EL. (-) 23'-0"

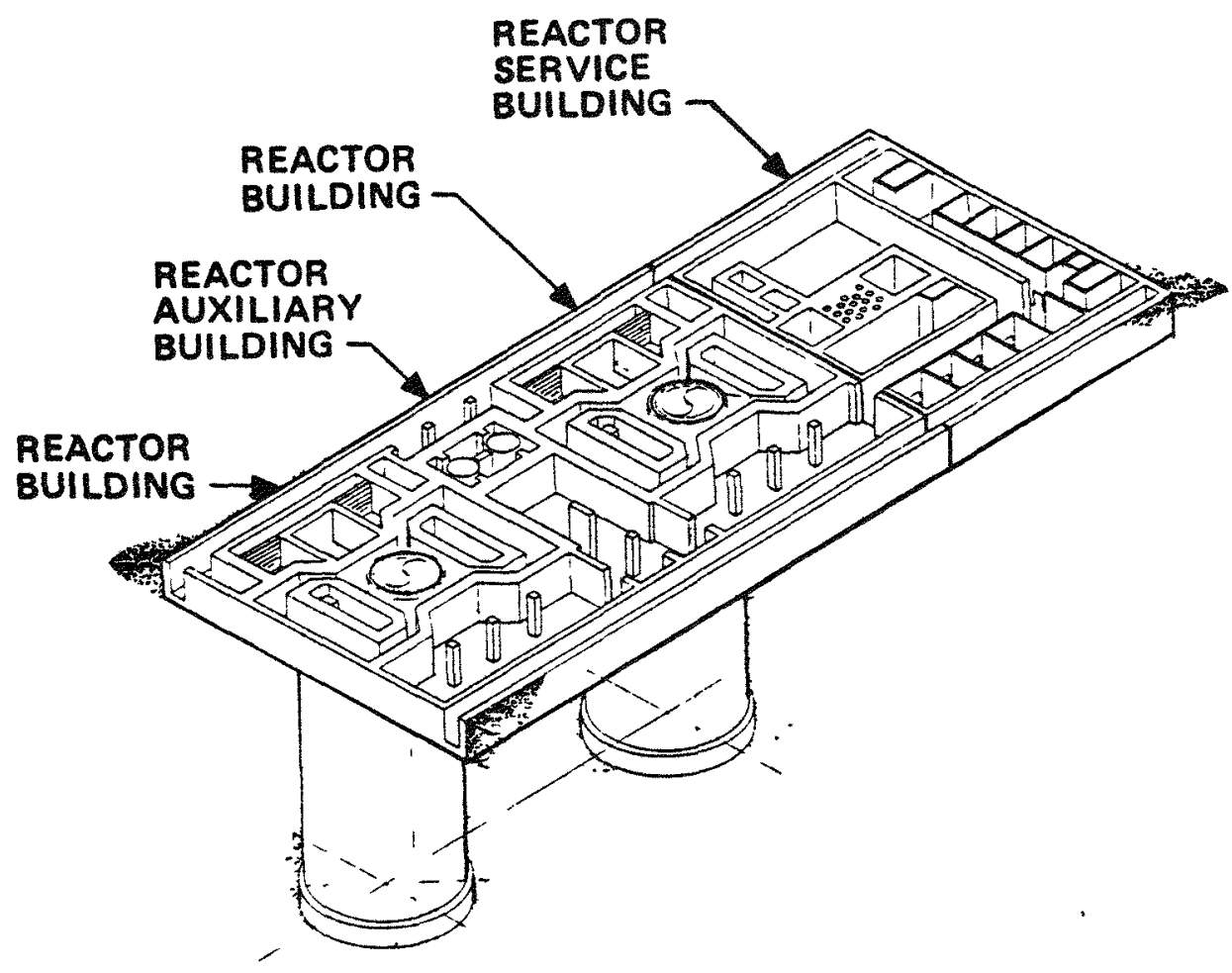

Figure 3-55 Nuclear Is land Arrangement PIan and Isometric 


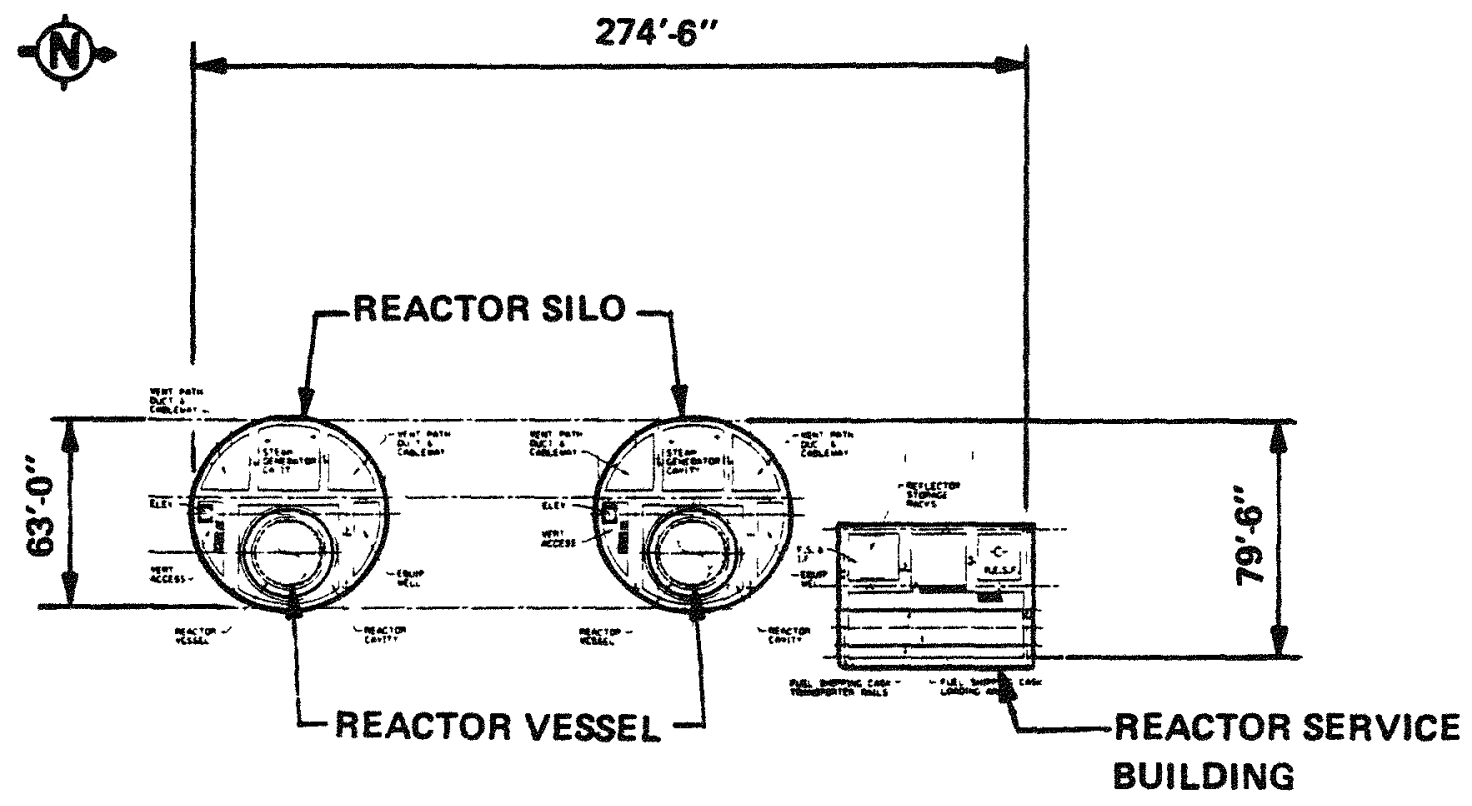

PLAN BELOW EL.(-)39'-0"

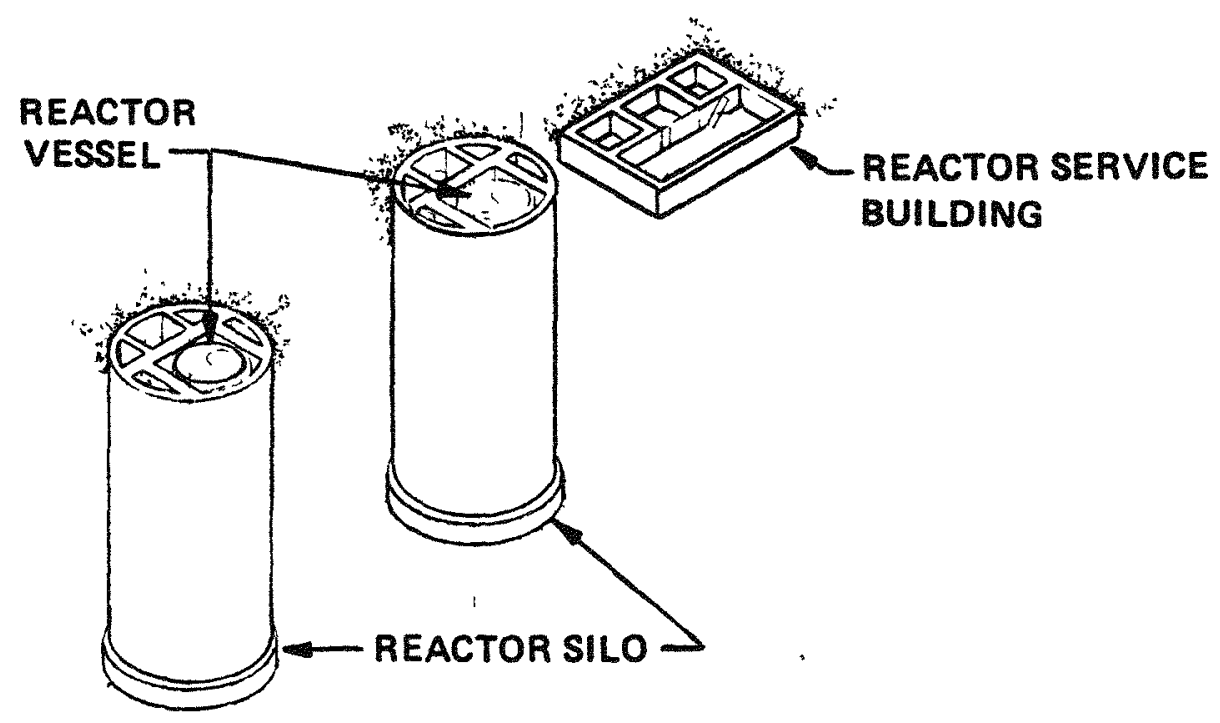

Figure 3-56 Nuclear Island Arrangement Plan and Isometric 


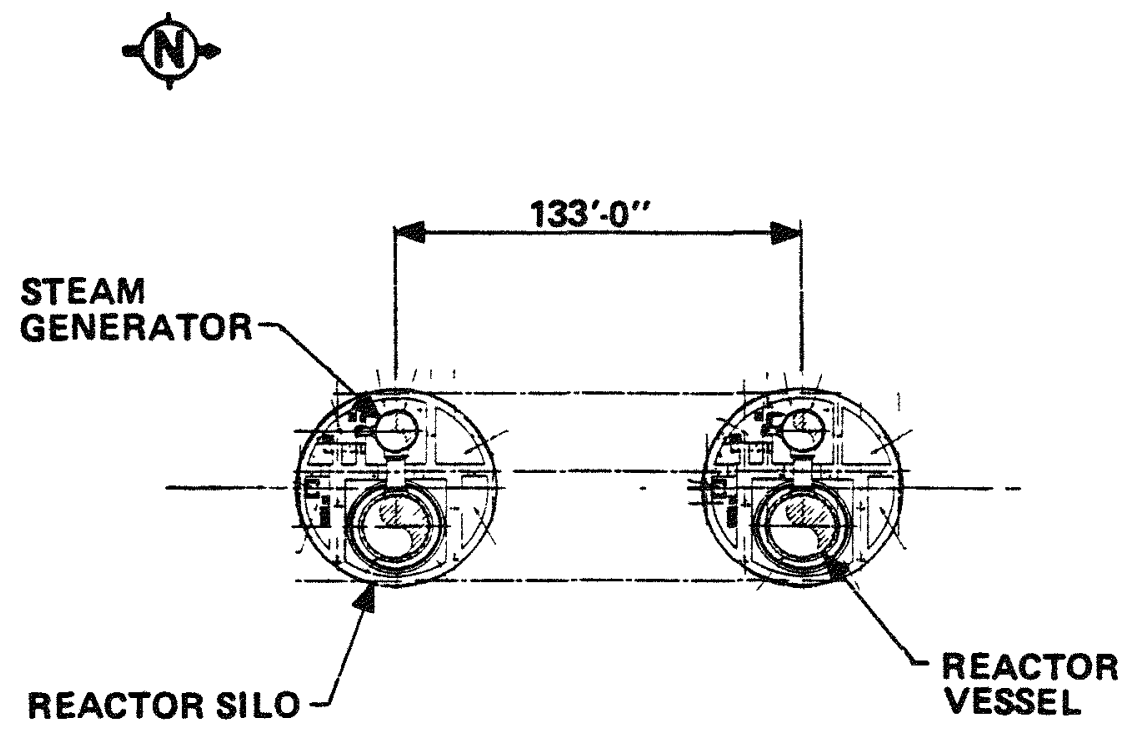

PLAN BELOW EL

PLAN BELOW EL.(-174'-0"

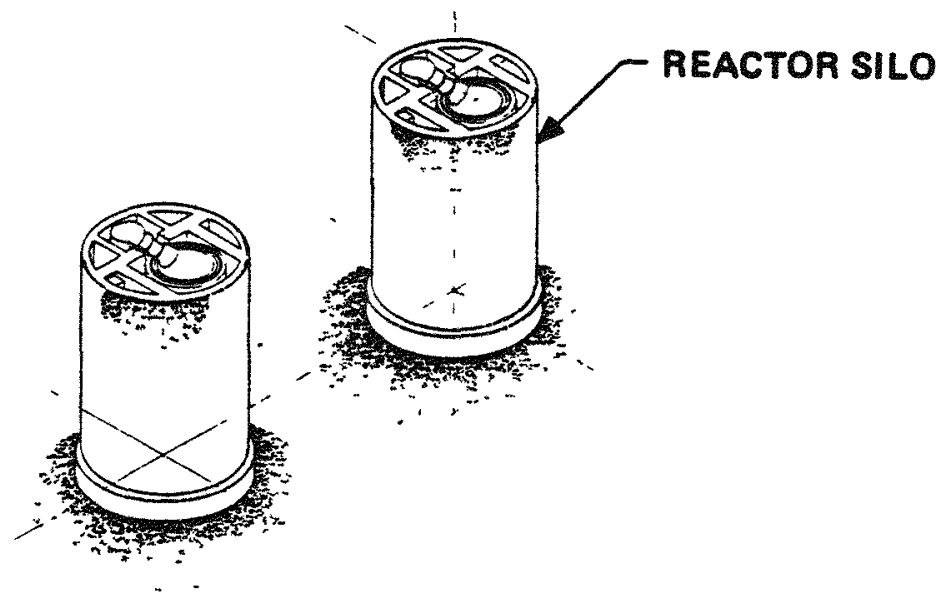

Figure 3-57 Nuclear Is land Arrangement Plan and Isometric 3-145 
nuclear island arrangement, plans and isometric views.

The vent paths from the reactor cavity to the steam generator cavity and from the steam generator cavity to the atmosphere, as well as the RCCS ducts, follow tortuous routes to limit neutron streaming from the Reactor Building. To maintain the requisite reactor cavity environmental conditions while limiting both the release of Ar-41 during power operation and the heat load on the steam generator cavity chiller, the reactor cavity vent path is fitted with blowout panels. Similarly, to maintain control of the steam generator cavity environment, the steam generator cavity vent path is fitted with dampers which open on overpressure and then re-shut. These dampers are located below eleva-

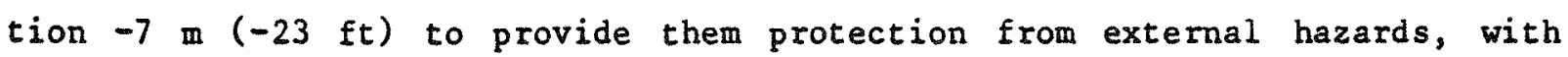
ultimate release of steam or helium to the atmosphere made through louvered openings located above elevation $3.7 \mathrm{~m}$ (12 ft) adjacent to the main steam isolation and relief valve enclosure (see Figure 3-51).

The only portions of the Reactor Building extending above grade are the intake and exhaust structures for the RCCS and the main steam isolation and relief valve enclosure. This latter structure also supports the startup/shutdown tank in addition to containing the vent discharge to atmosphere for the escape of steam or helium accidentally released in the Reactor Building.

The at-grade slabs of the sub-grade NI structures form a continuous operating floor for conducting refueling and other operations and maintenance activities. This operating floor is sheltered by a single steel-framed maintenance enclosure having insulated metal roofing and siding so that an environment conducive to the conduct of such activities may be established. The structural framework for this enclosure supports both the $113.5 \mathrm{t}$ (125 ton) bridge crane and one end of the semi-gantry crane associated with the fuel handling machine.

The below-grade placement of the Reactor Building provides improved response to seismic events over an above-grade structure and results in inherent resistance to missiles generated by tornados and other events. Openings in 
the slab at grade are normally closed with concrete access plugs to maintain the missile protection provided by the slab itself. Above-grade portions of the Reactor Building are hardened to resist missile impact and fitted with missile-resistant closures for all openings. The structural framework of the maintenance enclosure is designed not to collapse under design basis conditions.

The bridge crane serves each Reactor Building as well as the Reactor Auxiliary Buildings and Reactor Service Building. This crane is capable of accessing and lifting the various items of reactor service and core refueling equipment in both their storage and operating locations on the operating floor. It is also capable of reaching through the equipment well to the bottom of the silo for removal of equipment up to and including the shutdown circulator and cask.

\subsubsection{Reactor Auxiliary Building}

The Reactor Auxiliary Building ( $R A B$ ) consists almost entirely of a multi-level reinforced concrete structure set completely below grade. It has floors at elevations $-5.9 \mathrm{~m}(-19.5 \mathrm{ft})$ and $-10.5 \mathrm{~m}(-34.5 \mathrm{ft})$ and is subdivided into several compartments to house equipment common to a pair of reactor modules. Two identical RABs are provided, one located between modules 1 and 2 and the other between modules 3 and 4 , as shown on Figure 3-50. Detailed building arrangement and major equipment locations are shown on the Nuclear Island arrangement drawings (Figures 3-51 through 3-57).

Slabs and interior walls are of varying thickness, based upon shielding and strength requirements. A portion of the floor at elevation $-5.9 \mathrm{~m}(-19.5 \mathrm{ft})$ is a grating floor to facilitate building ventilation. The slab at grade has several hatchways normally closed with concrete plugs which provide access to the spent fuel storage assemblies and to equipment located at elevations -5.9 $\mathrm{m}(-19.5 \mathrm{ft})$ and $-10.5 \mathrm{~m}(-34.5 \mathrm{ft})$. The plugs provide biological shielding and protection from such external hazards as tornado missiles. All floors are continuous with the corresponding levels in the adjacent RBs, and the floor at 
grade forms a portion of the operating floor sheltered by the steel-framed reactor maintenance enclosure described earlier in Section 3.14.1.

Dominating the RAB arrangement is the covered spent fuel storage pool. Extending from the operating floor to elevation $-10.5 \mathrm{~m}(-34.5 \mathrm{ft})$, it occupies essentially the entire western third of the RAB. It is reinforced concrete construction and is provided with a steel liner to maintain water quality.

The above-grade structures which are considered part of the RAB are the liquid nitrogen enclosure and electrical equipment area (Figures $3-52$ and 3-53). Located external to the reactor maintenance enclosure between adjacent RCCS intake/exhaust structures, the liquid nitrogen structure is a two story steel framed structure with metal siding. It houses the liquid nitrogen storage tank, pumps, and recondensers serving the adjacent reactor modules.

\subsubsection{Reactor Service Building}

The Reactor Service Building (RSB) is a multi-level reinforced concrete structure set below grade. It houses facilities, systems or components which are shared by all four reactor modules. Reactor support activities taking place within facilities housed by the RSB include: new fuel, main circulator, shutdown circulator, neutron control assembly, and helium purification filter storage; new and spent fuel handling; irradiated core reflector block handling; and maintenance of activated or contaminated reactor components. The RSB also houses a portion of the PPIS and the dc and Uninterruptible ac Power Supply Systems, required to function under design basis conditions to control the release of radionuclides. The slab at grade forms a portion of the operating floor and is sheltered by the steel framed maintenance enclosure. The RSB is set in a row with the four Reactor Buildings and the two Reactor Auxiliary Buildings. This block of buildings constitutes the principal portion of the Nuclear Island. Conceptual building arrangement and major equipment locations are shown on the Nuclear Island arrangement drawings, Figures 3-52 through 3-56. 
The RSB is served by the $113.5 \mathrm{t}$ (125 ton) bridge crane also serving the RABs and Reactor Buildings.

Railroad and truck access to the RSB operating floor is effected through the washdown bay, which is connected to the west wall of the maintenance enclosure. The washdown bay is a structure large enough to accomodate a railroad car loaded with a fuel cask. In the washdown bay, incoming fuel casks and equipment are cleaned and outgoing spent fuel casks are decontaminated. Equipment and fuel casks are loaded onto and unloaded from the railcars and trucks by the bridge crane. The heating, ventilating, and air conditioning (HVAC) unit supplying air to the RSB is located on top of the washdown bay.

New fuel is stored at elevation $-10.5 \mathrm{~m}(-34.5 \mathrm{ft})$ in the new fuel storage area. Access to the new fuel storage area is through a plug in the operating floor, which provides protection from external hazards when in place.

Activated or contaminated helium purification filters and control rod drives are stored in 15 circular storage wells. They extend down trom the operating floor and are accessible through individual plugs in the operating floor.

The storage area for two Shutdown Cooling System (SCS) circulators is under the operating floor to the east of the access plug through which they are taken below grade. The SCS circulator storage casks are pushed up into their storage locations from below. This allows personnel access to the bottom surface of the circulators while they are in storage.

There are three main circulator storage wells at the south end of the RSB, the tops of which are below the operating floor. Access to the wells is through individual plugs in the operating floor.

Fuel handling operations that involve equipment located on or above the operating floor are controlled by operators in a fuel handing control station. The fuel handling control station is situated behind a window in the north wall of the maintenance enclosure. This location gives a clear view of the 
entire operating floor. The fuel handing station itself is actually located outside the maintenance enclosure, on top of the Personnel Service Building; however, personnel access to and from the station is by means of a stairway and an elevator located in the maintenance enclosure.

The fuel service and inspection facility (FSIF) is housed below grade in the RSB. Access is available to the FSIF from the operating floor through two access plugs. The FSIF is a multi-level rectangular facility which extends $14.2 \mathrm{~m}(46.5 \mathrm{ft})$ below grade.

Adjacent and perpendicular to the FSIF is the Hot Service Facility (HSF). The HSF is also a rectangular, below grade, multilevel facility whose greatest vertical extent is $14.2 \mathrm{~m}(46.5 \mathrm{ft})$ below grade. Access from grade to the HSF is through three plugs in the operating floor.

At elevation $-14.2 \mathrm{~m}\left(-42.5^{\circ} \mathrm{ft}\right)$, tracks are laid that run underneath the FSIF and RESF. A shipping cask transporter runs along these rails and stops under an access plug in the operating floor above. This access plug is located due south of the HSF and the FSIF.

The NI dc and ac uninterruptible power supplies are located in the RSB at elevations $-5.9 \mathrm{~m}(-19.5 \mathrm{ft})$ and $-10.5 \mathrm{~m}(-34.5 \mathrm{ft})$. As these power the PPIS and reserve shutdown equipment to effect shutdown of the reactor and, therefore, control the core heat generation rate, they are classified as safety related. As the RSB is required to assure the continued operability of these power systems under design basis conditions, it is also classified as safety-related. Also located in the RSB, and also safety-related, are the remote shutdown panels of the PPIS. These panels are located in a room at elevation $-5.9 \mathrm{~m}$ $(-19.5 \mathrm{ft})$. 


\subsubsection{Personnel Service Building}

The Personnel Service Building (PSB) is a single-story, grade-level structure housing facilities for monitoring, controlling, and minimizing personnel exposure to radioactivity. The building also houses locker rooms, a cold chemistry laboratory, and a supervisor's office.

The PSB is located at the north end of the plant, west of the Radioactive Waste Management Building (RWMB), and adjacent to the RSB (see Figures 3-52 and 3-53). The PSB provides controlled access and egress to and from the maintenance bay and the RWMB.

Located on top of the PSB and just outside the north wall of the RSB is the fuel handling control room. A window in the north wall of the RSB allows operators in the fuel handling control room a clear view of all fuel handling operations taking place on the operating floor.

\subsubsection{Radioactive Waste Management Building}

The Radioactive Waste Management Building houses the Solid Radioactive Waste System, Liquid Radioactive Waste System, and Gaseous Radioactive Waste System. Tanks, pumps, and filters which handle radioactive materials are housed in concrete cubicles to provide radiation shielding and protection for the environment.

The Radioactive Waste Management Building is a grade-founded, reinforced concrete and steel structure located on the Nuclear Island (NI). A mezzanine level houses the HVAC system for the building. Figures $3-58$ and $3-59$ show the general arrangement of the Radioactive Waste Management Building.

Radioactive Waste Management Building configuration. The Radioactive Waste Management Building is configured as a grade-founded structure with plan 



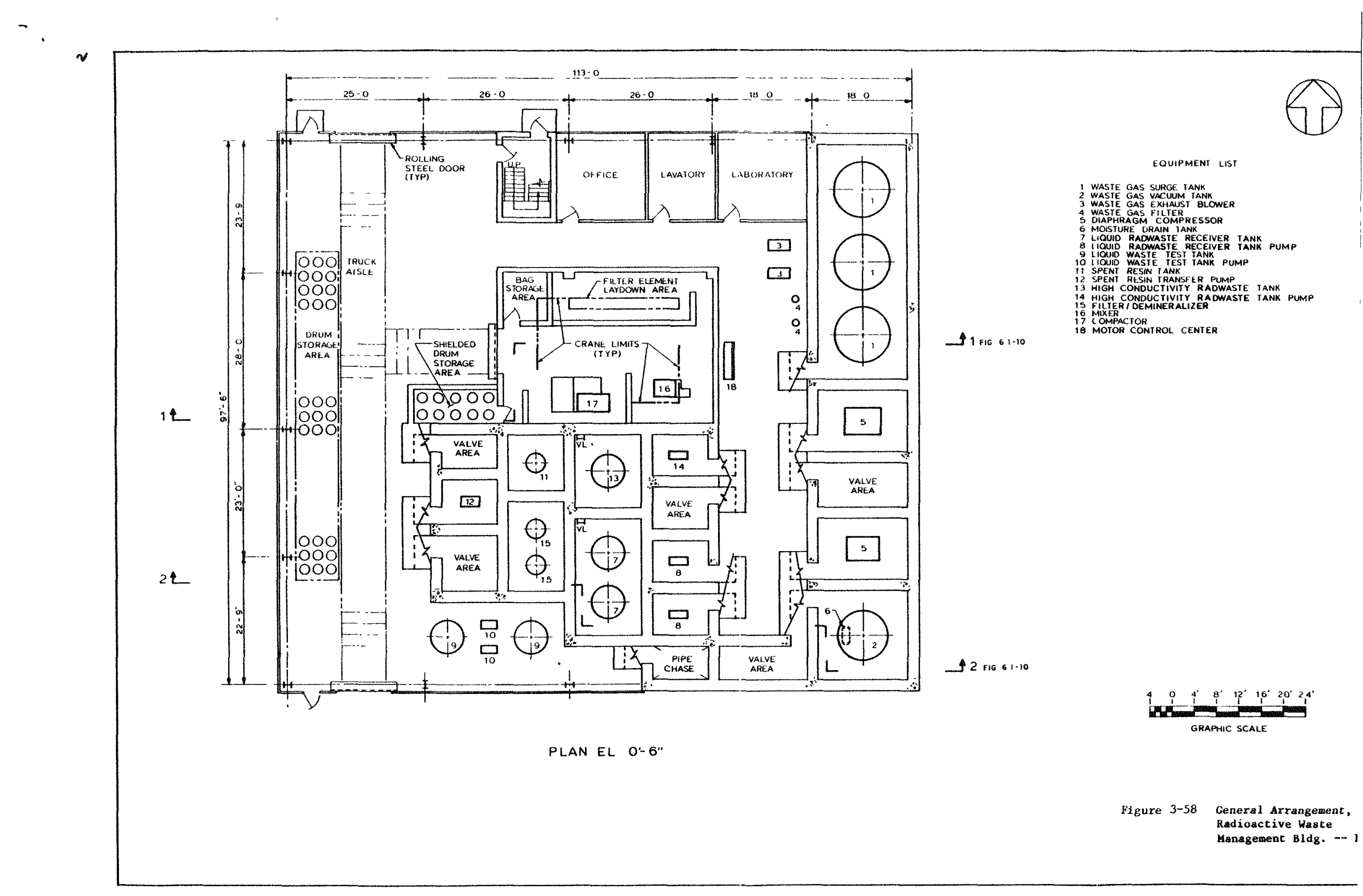




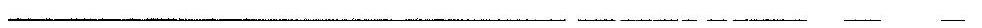


$v$

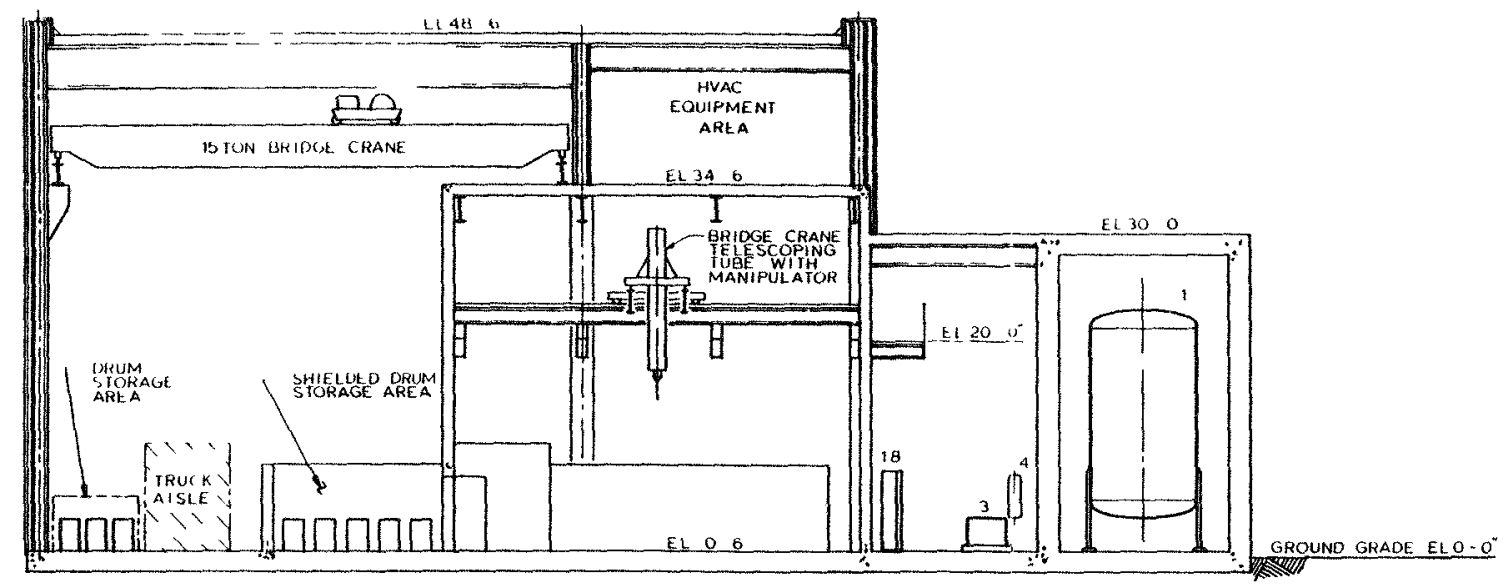

EOUPMANI LAST

WASIE GAS SURGE TANK

MMSTE Gas

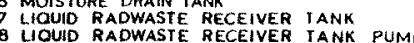

I8 MOTOR CONTROA CENTER
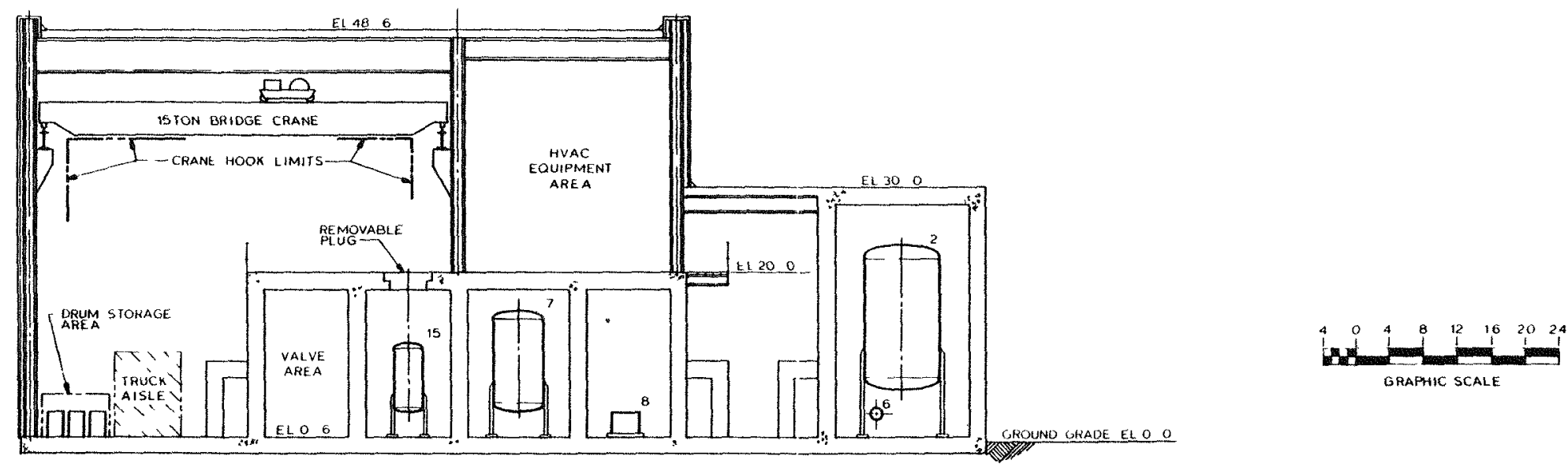

graphic SCALE

Higure 3-59 General Arrangement,

Radioact 2 ve Waste
Management Bldg. -- Section 
dimensions of $35 \mathrm{~m}(115 \mathrm{ft}$ ) by $30.5 \mathrm{~m}$ (100 ft), including a $30.5 \mathrm{~m}$ (100 ft) long and $7.6 \mathrm{~m}(25 \mathrm{ft})$ wide truck loading/unloading bay at the east end and two areas for drum storage, one shielded and the other unshielded.

The truck loading/unloading bay and the adjoining bay are served by a $13.6 \mathrm{t}$ (15 ton) capacity bridge crane. The Radioactive Waste Management Building is steel-framed with insulated sheet metal siding and roof decking covering most of the exterior surface. Individual concrete cubicles are provided for components which require radiation shielding.

The top of the concrete slabs roofing some of the cubicles in the central bay, is at elevation $6.1 \mathrm{~m}(20 \mathrm{ft})$. This area serves to house the building HVAC system, including all fans, filters, and heating and cooling units. The exterior roof, covering the truck bay and the HVAC area, is at elevation $14.8 \mathrm{~m}$ $(48.5 \mathrm{ft})$. Concrete cubicles at the west end of the building, housing tanks which are part of the gaseoús waste system, have concrete roof slabs at elevation $9.1 \mathrm{~m}$ ( $30 \mathrm{ft}$ ) which also serve as the exterior roof.

An office, toilet, and laboratory are provided.

\subsubsection{Turbine Building}

The Turbine Building (TB) houses the turbine generator and auxiliaries, Feedwater and Condensate System, Demineralized Water Makeup System, Main and Bypass Steam System, Extraction and Auxiliary Steam System, Heater Drains and Condensate Returns, Condensate Polishing System, steam vents and drains, Turbine Plant Sampling Systems, TB Closed Cooling Water System, Startup and Shutdown System, and Non-Class IE Distribution System.

The TB structure is located in the Energy Conversion Area and is designed to protect the occupants during design basis conditions. Figures 3-60 and 3-61 show the general arrangement of the $T B$. 
$\therefore$

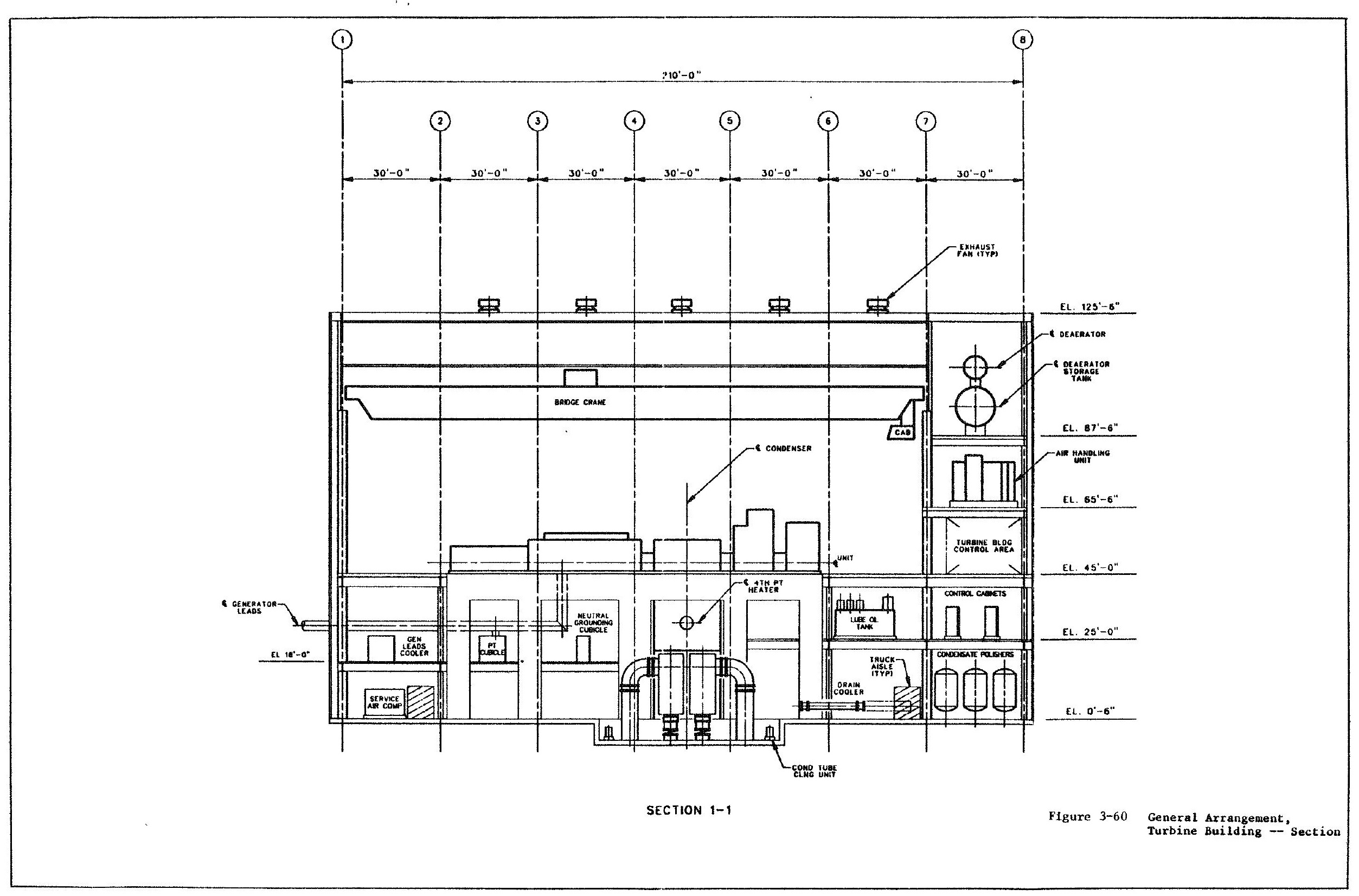





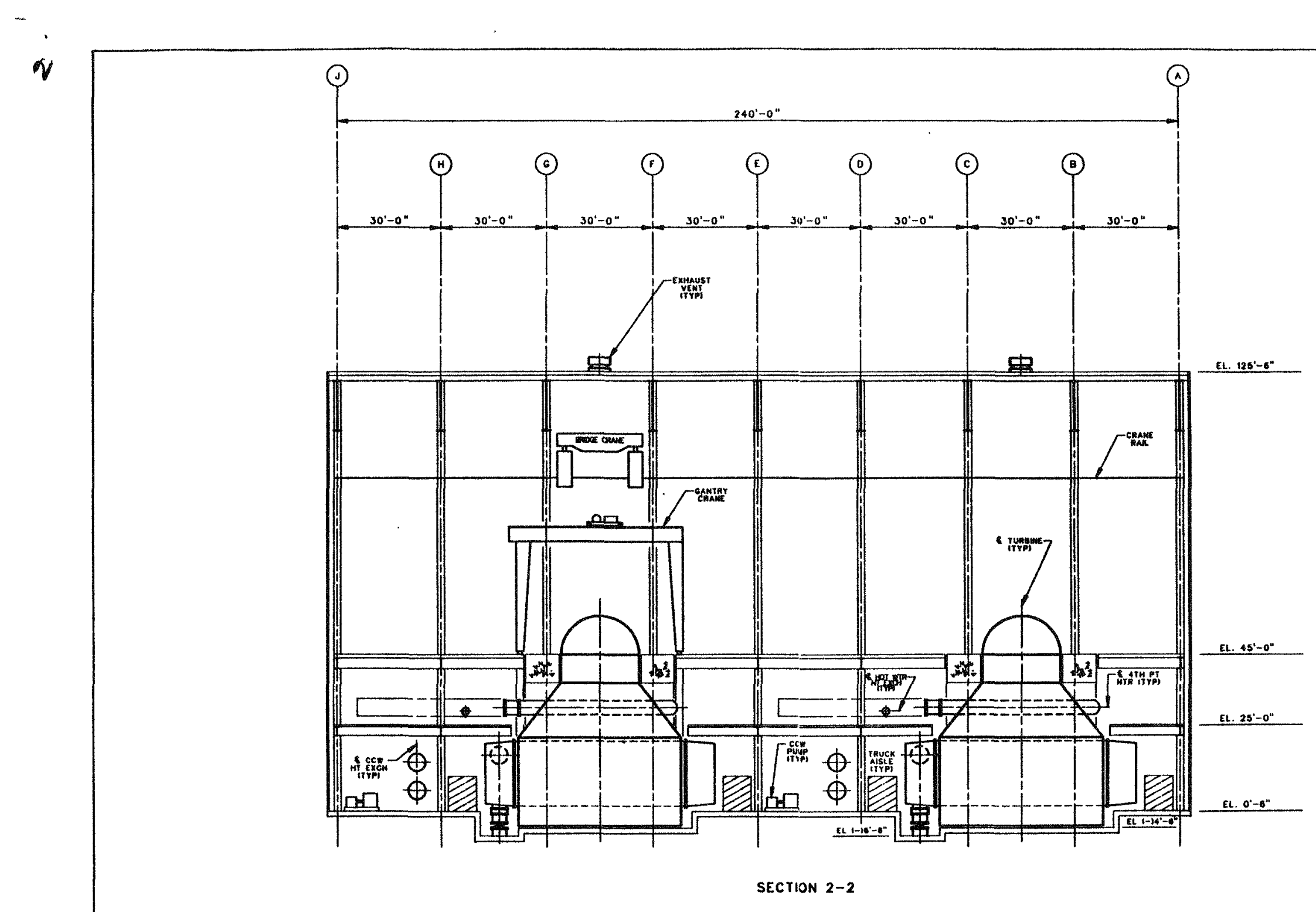

Figure $3-61$ General Arrangement,
Turbine Building -- Sectio 
. 
Turbine Building configuration. The $T B$ is configured as a steel-frame structure with insulated metal siding and roof decking which houses two 300 MW(e), non-reheat turbine generator (TG) sets and associated power generation systems and equipment. The TB is approximately $73.2 \mathrm{~m}$ (240 ft) long (parallel to the TB axes) by $64 \mathrm{~m}(210 \mathrm{ft})$ wide and $38.1 \mathrm{~m}(125 \mathrm{ft})$ high with a total volume of $178 \times 10^{3} \mathrm{~m}^{3}\left(6.3 \times 10^{6} \mathrm{cu} f t\right)$. The $T B$ arrangement has the parallel TG centerlines perpendicular to the common reactor centerline and the feedwater heater bays at the HP ends of the turbines. The TB arrangement also incorporates the features listed below:

- Conventional reinforced concrete high-tuned turbine pedestals

- Three floor levels: Ground, mezzanine, and operating

- Maintenance laydown space for each TG on the operating floor

- Lowest pressure, feedwater heater shells located in the condenser neck

- Perimeter truck aisles on ground floor

- Pull space and withdrawal areas for plant equipment

In addition to these features, provisions have been incorporated into the building design for overhead bridge crane access to equipment on the operating floor and for equipment removal via a hoist area to grade. The overhead bridge crane capacity is $68.1 \mathrm{t}$ ( 75 tons).

The foundation may vary with site conditions but will typically be reinforced concrete, with spread footing for the column supports, and a reinforced concrete bay for the turbine pedestal.

The TB and all other structures associated with the turbine plant are designed according to the Uniform Building Code. These structures are not designed to resist tornado loading; however, no components of the structures can become tornado-propelled missiles. The $T B$ is spaced a sufficient distance from all NI structures so that its collapse would not influence the nuclear safetyrelated structures. 


\subsubsection{Operations Center}

The Operations Center houses the control room and computer room, primary and secondary plant security alarm rooms, primary access facility to the NI and the energy conversion area, and activities associated with plant administration and security services.

The Plant Control, Data, and Instrumentation System (PCDIS) control/display panels and computers are housed in the control room since they are not required to be in a safety related structure.

The Operations Center structure is located in the Energy Conversion Area and is designed to protect the occupants during design basis conditions. Figures 3-62 and 3-63 show the general arrangement of the Operations Center.

\subsubsection{Other Buildings and Structures}

As shown on Figure 3-50, the other plant buildings and structures include the following:

Nuclear Is land

- NI Cooling Water Building

- Chilled Water Building

- Helium Storage Structure

\section{Energy Conversion Area}

- Standby Power Building

- NI Warehouse

- Makeup Water Treatment and Auxiliary Boiler Building

- Maintenance Building

- Fire Pump House

- Cooling Tower Basin and Circulating Water Pump House 


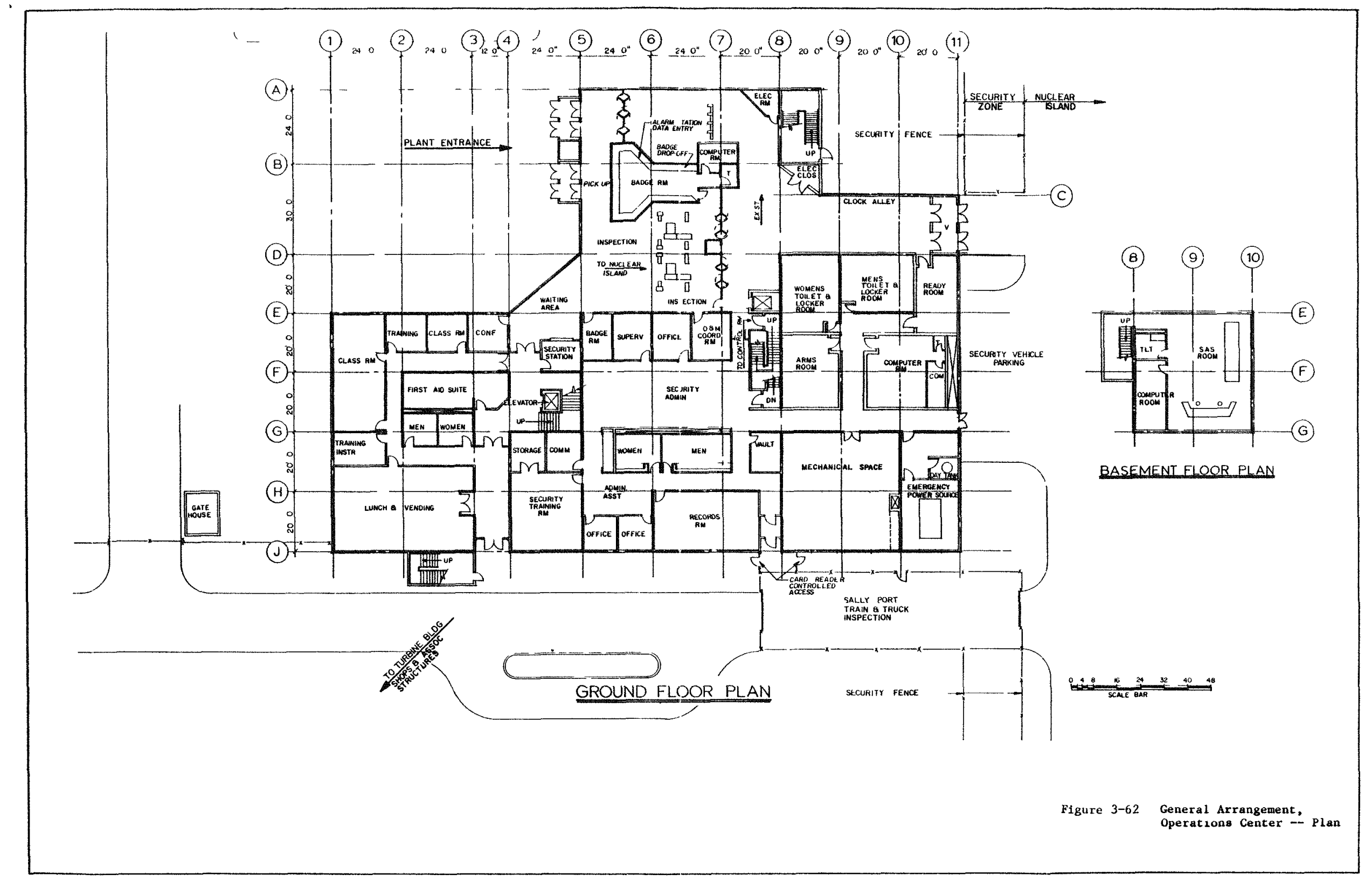




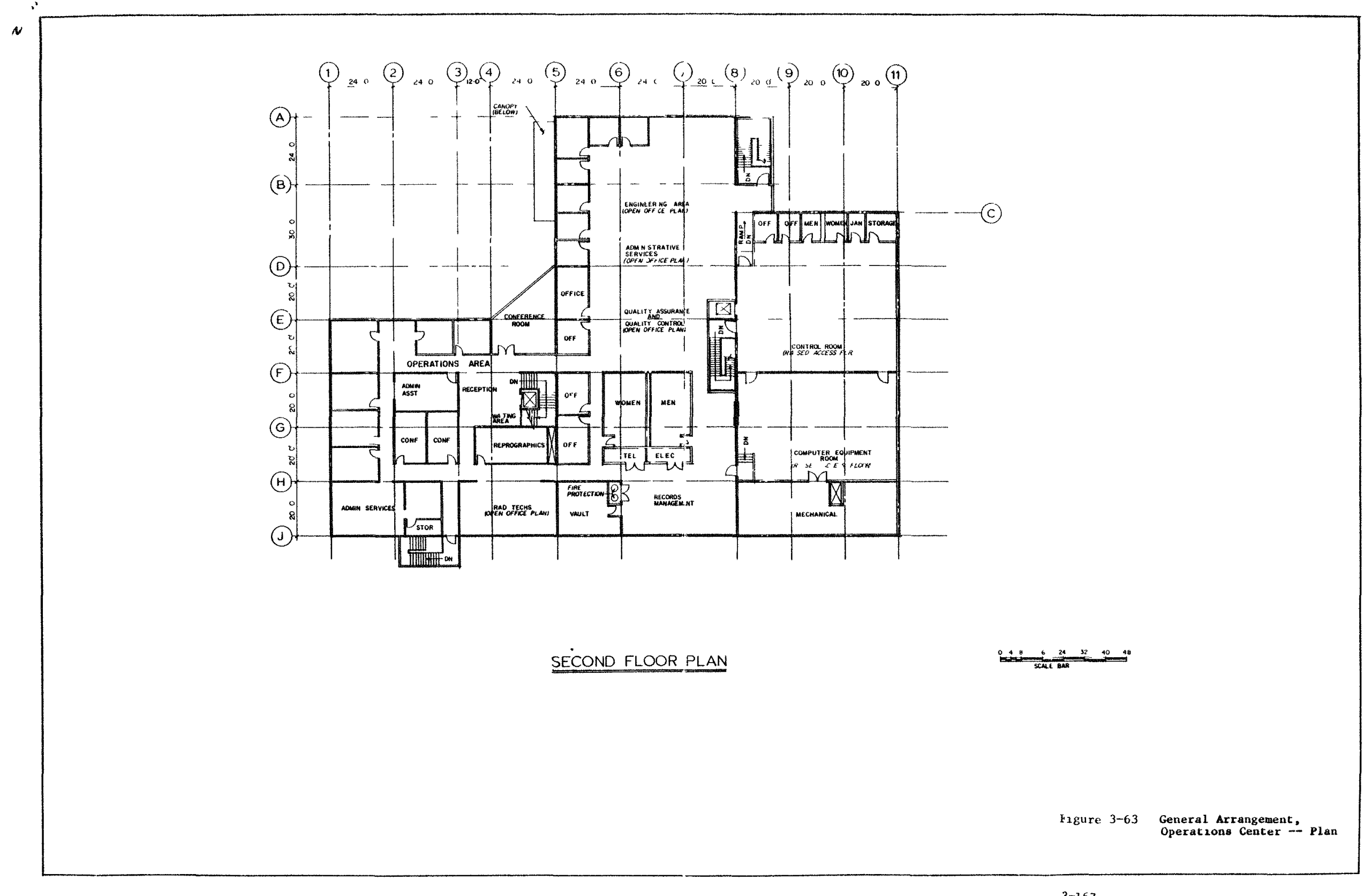

3-167 



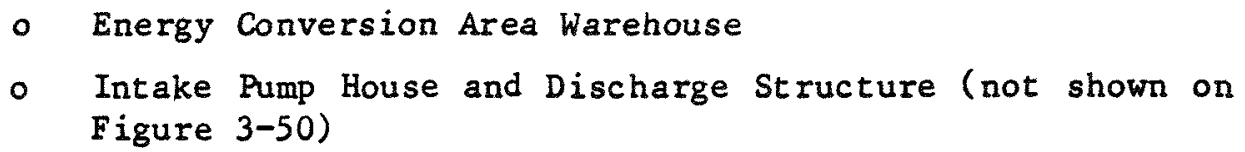

The NI structures discussed here are constructed of steel frame with metal roof and siding. Forty hours per week of personnel access are provided using the same criteria as for the reactor enclosure.

The Energy Conversion Area structures will be built to the same standards as current fossil-fueled power plants. Roof construction will consist of built-up roofing with insulation on the roof deck. Exterior walls are generally concrete masonry, or insulated metal siding on steel frames.

A brief description of these buildings and structures is provided as follows:

NI Cooling Water Building. The Nuclear Is land Cooling Water Building (NICWB) is a steel-frame, metal-sided enclosure set on a slab at grade. It is $10 c$ ated north of the RSB and to the west of the PSB, as shown in Figure 3-50. It houses the pumps, heat exchangers, and other components common to all four modules that provide cooling water for systems on the Nuclear Island.

Chilled Water Building. The Chilled Water Building (CWB) is a steel-frame, metal-sided enclosure set on a slab at grade. It is located west of.the RSB immediately adjacent to the washdown bay as shown on Figure 3-50. It houses the components necessary for providing the plant with chilled water.

Helium Storage Structure. The Helium storage Structure is a single story steel-frame building with metal siding set on a slab at grade. It is $44.5 \mathrm{~m}$ (146 ft) long, $15 \mathrm{~m}(50 \mathrm{ft})$ wide and $8.5 \mathrm{~m}(28 \mathrm{ft})$ high, located east of the Reactor Building modules. It houses low pressure and high pressure helium storage tanks and compressors. 
NI Warehouse. The NI warehouse is a grade-founded, single story, steel-frame structure, located at the periphery of the NI. This structure provides approximately $465 \mathrm{~m}^{2}(5,000 \mathrm{sq} \mathrm{ft})$ of storage area to house the spare parts inventory required for equipment, components, and systems in the NI. This building also provides for a cargo search area.

Standby Power Building. The Standby Power Building houses equipment and components comprising the switchgear, motor controls, and two gas turbine generators, each located within a separate cubicle. The Standby Power Building is a grade-founded, single story, steel-frame structure located in the Energy Conversion Area.

.

The Standby Power Building houses non-Class $1 E$ on-site ac power sources consisting of two backup generators and accessories, each housed within its separate cubicle.

Makeup Water Treatment and Auxiliary Boiler Buildings. The Makeup Water Treatment and Auxiliary Boiler Buildings are grade-founded, single story, steel-frame structure with insulated sheet metal exterior walls, and roof decking. They house the electrically heated auxiliary boiler and related equipment, and the Raw Water Treatment system. The makeup water treatment and auxiliary boiler buildings are located adjacent to the maintenance building in the auxiliary boiler conversion area of the plant.

Maintenance Building. The Maintenance Building is a grade-founded, two story, steel-frame structure located adjacent to the Turbine Building in the Energy Conversion Area. It has a reinforced concrete foundation and slabon-grade, insulated sheet metal exterior walls, and roof decking. The Maintenance Building provides facilities for the following:

- Electrical Repair Shop

- Instrument Repair Shop 


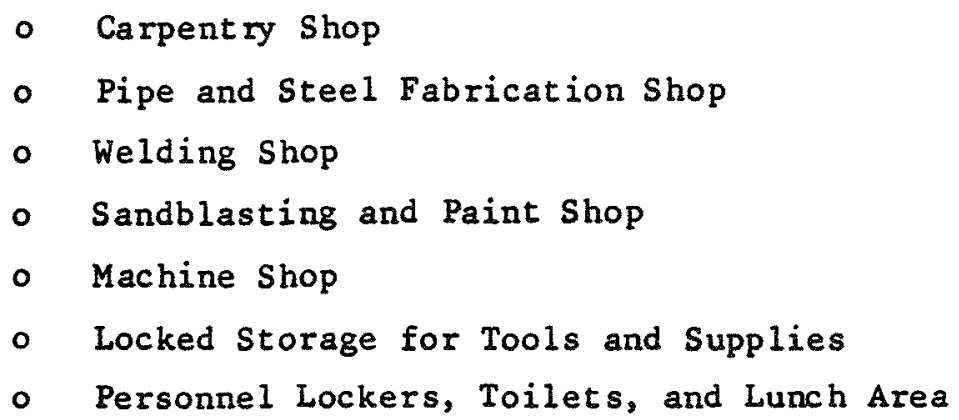

Fire Pump House. The Fire Pump House encloses pump, piping, and valves which are part of the plant fire protection system, related controls of the fire detection and alarm system, and non-Class $\mathrm{LE}$ ac distribution buses. It is a grade-founded, single story structure located in the energy conversion area between the fire water storage tanks. The fire pump house is constructed of reinforced concrete with each pump located in a separate cubicle.

Cooling Tower Basin and Circulating Water Pump House. The cooling tower basin, containing a portion of the circulating water system inventory, is a reinforced concrete pool which provides a foundation for the cooling tower. The circulating water pump house is a reinforced concrete structure located at the boundary of the cooling tower basin. It houses the pumps, valves, and some of the piping of the Circulating Water and Service Water Systems. These structures are located in the Energy Conversion Area of the plant.

Energy Conversion Area Warehouse. The Energy Conversion Area Warehouse is a 8 rade-founded, single story, steel-framed structure located in the Energy Conversion Area. This structure provides approximately $930 \mathrm{~m}^{2}(10,000 \mathrm{sq}$ ft) of storage area to house the spare parts inventory required for equipment, components, and systems in the Energy Conversion Area. 
Intake Pump House and Discharge Structure. The intake pump house and discharge structure is a reinforced concrete building with a steel supported concrete slab roof and is founded approximately (TBD) ft below the level of the plant water source. It houses the pumps, valves, and some of the piping which comprise the circulating water makeup and blowdown system. The structure is required to control the inventory of the circulating water and service water systems. It is located in the Energy Conversion Area. 


\section{SECTION 4}

COMMERCIAL PLANT SCHEDULE

The current estimate of project duration from nuclear island (NI) award to commercial operation of the first turbine-generator is 64 months. The second unit is scheduled to go into commercial operation at the end of 68 months. Of these durations, 32 months and 36 months, respectively, are for on-site activities as shown in the summary construction schedule (Figure 4-1) developed for the MHTGR plant described in this report. The assumptions discussed below were made in developing the schedule.

\section{1 SCHEDULE DEVELOPMENT}

The construction schedule development is based on the following parameters and assumptions:

- Reactor module long-lead time procurement is supported by a Notice-to-Proceed six months prior to NI award

- This is an equilibrium plant schedule (i.e., Nth-of-a-Kind)

- There are no regulatory or political constraints

- There are no manpower or cash flow constraints

- Site is preapproved and design is prelicensed

- The reactor module fabrication and NI construction schedules are based on the approach described in Reference 4-1.

- Soil, site, and other parameters are within the envelope specified in utility/user design requirements (Reference 1-3)

- Design completion and component deliveries support construction required dates 


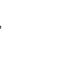




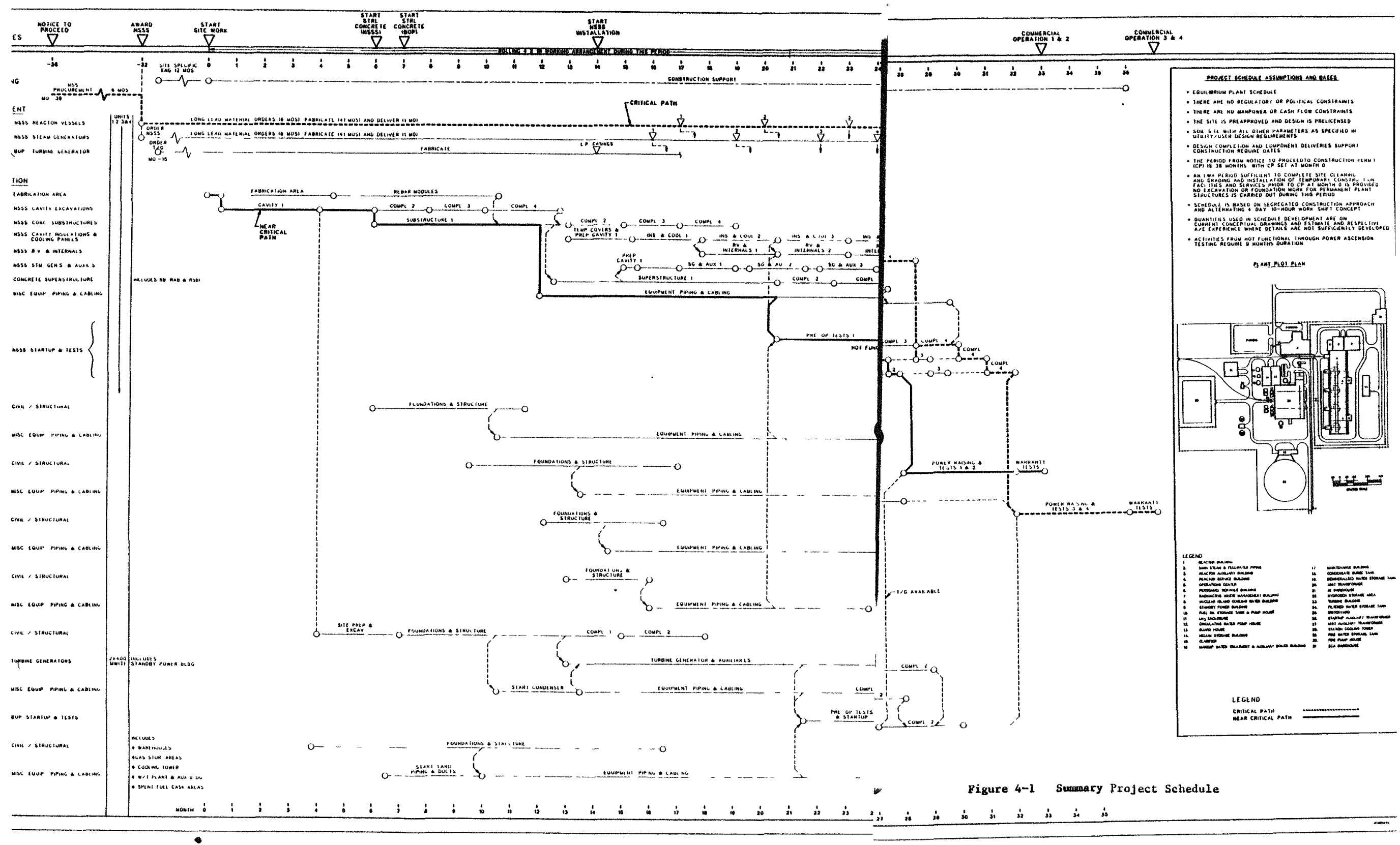




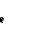


- The period from Notice-to-Proceed to construction permit (CP) is 38 months, with $\mathrm{CP}$ set at month zero

- Schedule is based on segregated construction approach and alternating four-day, ten-hour work shift concept ("Rolling 4-1 $\left.0^{\prime} \mathrm{s}^{\prime \prime}\right)$ through completion of reactor internals installation. Subsequent startup activities will be around the clock, as necessary

- Quantities used in schedule development are based on current drawings and estimate as well as respective $A / E$ experience where details are not sufficiently developed

- The complete plant (4 reactors and 2 TGs) will be completed and brought to commercial operation as one continuous project

\subsection{CONSTRUCTION SEQUENCE}

\subsubsection{Nuclear Is land}

Work in the Nuclear Island (NI) area will commence with the excavation of the two below grade cavities for Reactor Modules 1 and 2. Corresponding work for Modules 3 and 4 will immediately follow the completion of Module 2.

For most site locations, it should be possible to excavate by auger with freezewall groundwater barriers, and this method is assumed in developing the construction schedule.

Nuclear Island concrete work will begin after about six months of earthwork, with lining of the first cavity. Concrete placement in the silos will be by a single slip-formed operation up to elevation $-10.7 \mathrm{~m}$ ( -35 feet). Prefabricated rebar mats or cages will be used to permit speedy construction of the deeply embedded silos.

A construction priority is to quickly bring the cavity substructure construction to the stage where a temporary cover could be placed over the top access 
and the cavity turned over from the civil to the mechanical construction discipline. This stage will occur after about 14 months.

Initial mechanical work in the cavity will include the installation of wall insulation and cooling panels. Civil construction will proceed in parallel with construction of portions of the Reactor Service Building and fuel handling area.

Steam Generator. The SBS concept has separate cells for the reactor vessel and steam generator, with the main crossduct penetrating the separating shield wall. The RCCS cooling ducts and insulation are required in the reactor cell only. Therefore, for each module, installation of the reactor and steam generator components will occur in the following sequence:

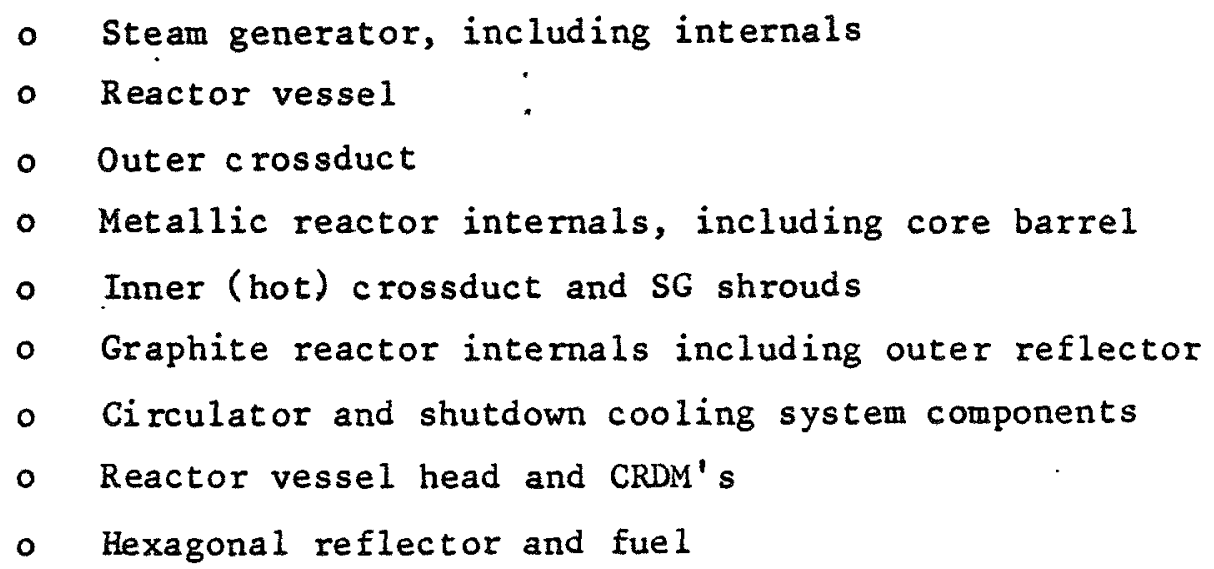

Installation of the steam generator vessel can be concurrent with completion of installation of RCCS cooling ducts and insulation in the reactor cell. Crossduct and steam generator material procurement, fabrication, and delivery to the site are estimated to require 48 months. Delivery of corresponding vessel components for each module is required at approximately 3-month intervals.

Site Equipment Handling. A heavy-lift crane is required for site handing of the major reactor module components. A Lampson mobile "Transi-lift" crane 
could easily satisfy requirements, or it may be possible to use a lesser capacity Manitowoc 4600 as an alternate.

At the earliest reasonable stage of construction, access to the Reactor Buildings will be provided to permit the maximum possible time for installation of equipment, piping, and cabling.

Preoperational Tests. Nuclear Island system preoperational tests will commence after Module 2 reactor vessel installation is complete and after sufficient equipment, piping, and cabling has been installed in the Reactor, Reactor Auxiliary, and Reactor Service Buildings.

\subsubsection{Energy Conversion Area}

Site preparation and excavation for the Turbine Building will start three months after the corresponding work for the. NI. Erection of the Turbine Building and subsequent equipment installation will also continue in parallel with similar NI activities.

\subsubsection{Miscellaneous Facilities}

Construction of other miscellaneous facilities such as radwaste, operations center, and personnel services buildings will be completed to meet individual demand requirements. These construction activities, however, will be phased as much as possible to maintain optimum general access and to maintain level on-site labor requirements. 


\subsection{CONSTRUCTION DURATION AND CRITICAL PATH ANALYSIS}

\subsubsection{Key Milestones}

The key milestones are:

$\begin{array}{lr}\text { - Award Nuclear Is land } & -32 \text { months } \\ \text { - Start site work } & 0 \text { months } \\ \text { - First concrete on site } & 6 \text { months } \\ \text { - First nuclear concrete } & 6 \text { months } \\ \text { - Install first reactor module vessel (SG) } & 17 \text { months } \\ \text { - Begin fuel load, first module } & 26 \text { months } \\ \text { - Complete fuel load, fourth module } & 32 \text { months } \\ \text { - Commercial operation, first turbine } & 33 \text { months } \\ \text { - Commercial operation, second turbine } & 37 \text { months }\end{array}$

\subsubsection{Critical Path Analysis}

The critical path runs through a sequence of activities starting with procurement of the reactor module and passing successively through fabrication and delivery of reactor vessels and internals, installation of the last reactor module, preoperational tests, hot functional test, fuel loading, power raising, and warranty tests. The critical path is indicated on Figure 4-1.

From the start of site work to commercial operation, there is a construction near-critical path of 32 months. This near-critical path runs through the cavity excavation, substructure, reactor complex installation of equipment, piping and cabling, preoperational tests of Modules 1 and 2, hot functional tests and fuel loading of Module 2 and power raising and warranty tests, modules 1 and 2 and turbine-generator 1 . This path completes during Module 3 and 4 power raising. The remaining project critical path period of four months for Modules 3 and 4, through testing to commercial operation, esta- 
blished for consistency in evaluations, may be overly conservative for followon units in an equilibrium plant.

Another near-critical path occurs through fabrication and delivery of steam generators.

The reactor module lead time shown on Figure 4-1 includes six months for vendor procurement of long-lead material prior to commencement of fabrication. In an equilibrium plant situation, where HTGR modules are being manufactured on a large scale, it is possible that many of these long-lead items would be carried in stock, thus reducing the overall project duration by six months, or more. 


\subsection{SCHEDULE ACHIEVEMENT}

The primary schedule advantage for the steel vessel concept arises from substantial off-site prefabrication of the reactor vessel, internals, and steam generator, which reduces on-site reactor module construction to relatively simple assembly work.

A below-grade cavity is another advantage, as it can be prepared quickly for reactor and steam-generator installation. Setting the building below grade also allows them to be substantially completed before the large vertical vessels are installed. Large construction openings are eliminated, and the reactor module and buildings are able to proceed in parallel, thus reducing the overall schedule. The remaining portion of the plant is located near or at grade, which facilitates good labor productivity and avoids high lifts of heavy components. The MHTGR silo concept offers the potential to slip-form much of the reactor enclosure with associated schedule improvement.

It has not been possible at this stage of development to consider total prefabrication of all potential equipment modules. However, this may be introduced in due course, to generally improve the schedule integrity, construction quality, and cost.

Reactor cavity insulation (floor and ceiling) and erection of air cooling panels have been shown as separate sequential activities. Development of a combined design, which could include substantially prefabricated large sections, would transfer a large amount of work off-site with benefit to the construction schedule. Advantages such as this would offset the complexities that can be expected to arise with progress of detailed design.

Rough estimates of bulk quantities (concrete, piping, and cabling) indicate that corresponding functional installation rates to meet the construction schedule would be significantly less than suggested by median rates for a Rolling 4-10's (70-hour week) working arrangement. 


\section{SECTION 5}

ECONOMIC ANALYSIS

\subsection{PLANT CAPITAL COST}

Plant capital costs have been estimated from the specific scope documentation developed in FY 86 by all program participants. The estimate preparation was scheduled and guided by the "Cost Estimating Plan" (Reference 5-1). The costs were developed using the Department of Energy (DOE) Energy Economic Data Base (EEDB) code of accounts. The direct and indirect accounts and their contents are as given in Table 5-1.

\subsubsection{Estimating Basis and Approach for Direct Cost}

Quantification of the plant scope is limited only by the level of detail of the design development. The current system and building SDD's and SSDD were used as reference documents and define the level of design completeness available to support the cost Estimate. For example, the nuclear island building quantities of excavation, formwork and concrete are takeoffs from the drawings of these buildings, as is the reactor cavity cooling system scope.

Telephone quotations were requested and received for the liquid nitrogen system, helium storage tanks, and the shutdown cooling water, spent fuel cooling water, and RPCW heat exchangers. Piping takeoffs were used whenever available for systems such as the shutdown cooling water, spent fuel storage, helium purification and storage, liquid nitrogen, reactor plant cooling, and decontamination service systems.

The Energy Conversion Area estimating procedure included quantity development of bulk comnodities of structures from design drawings. Engineering judgment 
Table $5-1$

EEDB CODE OF ACCOUNTS

DIRECT ACCOUNTS

ACCOUNT 20: Land and Land Rights

Site land and water rights and access for a power plant.

ACCOUNT 21: Structure and Improvements

Site improvements and all structures of the power plant.

ACcounT 22: Reactor or Boiler Plant Equipment

The steam generating plant and all nuclear or fossil related systems equipment.

ACCOUNT 23: Turbine Plant Equipment

The turbine generator and major subsystems of the power conversion system.

ACCOUNT 24: Electrical Plant Equipment

Electrical systems within the power plant.

ACCoUNT 25: Miscellaneous Plant Equipment

Transport and lifting equipment, house service system, furnishings and communications.

ACCOUNT 26: Main Condenser Heat Rejection System

The condenser cooling system for the turbine-generator.

\section{INDIRECT ACCOUNTS}

ACCOUNT 91: Construction Services

Temporary facilities, tools, equipment, payroll, taxes and insurance.

ACCOUNT 92: Engineering and Home office Services

All charges for home office support to the overall project in respect to design, planning, and building of the plant.

ACCOUNT 93: Field Office Engineering and Services

All charges associated with the field support required to build an operable plant.

ACCOUNT 94: Owner's Cost

All charges incurred by the owner/operator directly or in support of the design, licensing, building and startup of the plant. 
has been applied for those structures which do not yet have design definition sufficient to support quantity take-offs. Major piping systems were developed by utilizing system descriptions, flow diagrams and historical data. Mechanical equipment prices have been based on recent vendor quotes and historical data.

All direct construction and installation labor costs are on a force account, rather than subcontractor, cost basis. The composite wage rates (base plus benefits) were developed from R.S. Means 30-City Average Wage Rates as of January 1, 1986. Composite labor rates used in the FY 86 cost estimate are shown in Table 5-2. This derivation is consistent with ORNL/TM-10071 "Cost Estimate Guidelines for Advanced Nuclear Power Technologies" (Ref 5-2).

Direct cost estimates were provided by GA Technologies, Inc., for the reactor plant equipment and by General Electric for the plant supervising control, data management and plant operations support computer systems. These equipment costs appear in Account 22. 'All of the equipment, field labor, and field material in the Energy Conversion Area was estimated by Stone \& Webster Engineering Corp., as well as some of the non-safety related buildings in the Nuclear Is land. Other equipment, field labor, and field material in the Nuclear Island accounts were estimated by Bechtel National, Inc.

Except where provided by quotes from vendors, all equipment costs were based on historical data and engineering judgment applied by SWEC or BNI. Commodity costs were based on historical data provided by the project participants. To assure uniformity between SWEC and BNI, the values shown in Table 5-3 were used throughout the estimate. Common rates were also established for unit manthour installation rates, shown in Table 5-4.

\subsubsection{Estimating Basis and Approach for Indirect Cost}

Estimates of indirect costs were provided by individual participants to correspond to the same plant areas for which they had direct cost estimating 
Table 5-2

\section{DISCIPLINE CRAFT/CREW WAGE RATES}

Present Day Basis: January 1, 1986

Survey Area: R. S. Means, 30 City Average

Description

Civil/Structural

Mechanical

Piping

Electrical

Inst rument/Cont rols
Force

Account Rate

$\$ 20.20$

$\$ 21.85$

$\$ 22.50$

$\$ 22.35$

$\$ 22.75$

: Craft Distribution

\begin{tabular}{|c|c|c|c|c|c|}
\hline Crafts & Mech & Elec & Piping & $\begin{array}{l}\text { Civil/ } \\
\text { Struc. }\end{array}$ & $\begin{array}{r}\text { Instr. } \\
\text { Controls } \\
\end{array}$ \\
\hline B oile rmaker & $35 \%$ & - & - & - & - \\
\hline Carpenters & - & - & - & $15 \%$ & - \\
\hline Electrician & - & $95 \%$ & - & - & - \\
\hline Ironworker & - & - & - & $20 \%$ & - \\
\hline Laborer & - & - & - & $20 \%$ & - \\
\hline Millwright & $20 \%$ & - & - & - & - \\
\hline $\begin{array}{c}\text { Sheetmetal } \\
\text { Worker }\end{array}$ & $25 \%$ & - & - & - & - \\
\hline Pipefitters & - & - & $85 \%$ & $10 \%$ & $90 \%$ \\
\hline Other & $20 \%$ & $5 \%$ & $15 \%$ & $32 \%$ & $10 \%$ \\
\hline Total & $100 \%$ & $100 \%$ & $100 \%$ & $100 \%$ & $100 \%$ \\
\hline
\end{tabular}


Table 5-3

COST OF MAJOR MATERIALS - BULRS

Present Day Basis: July 1, 1985

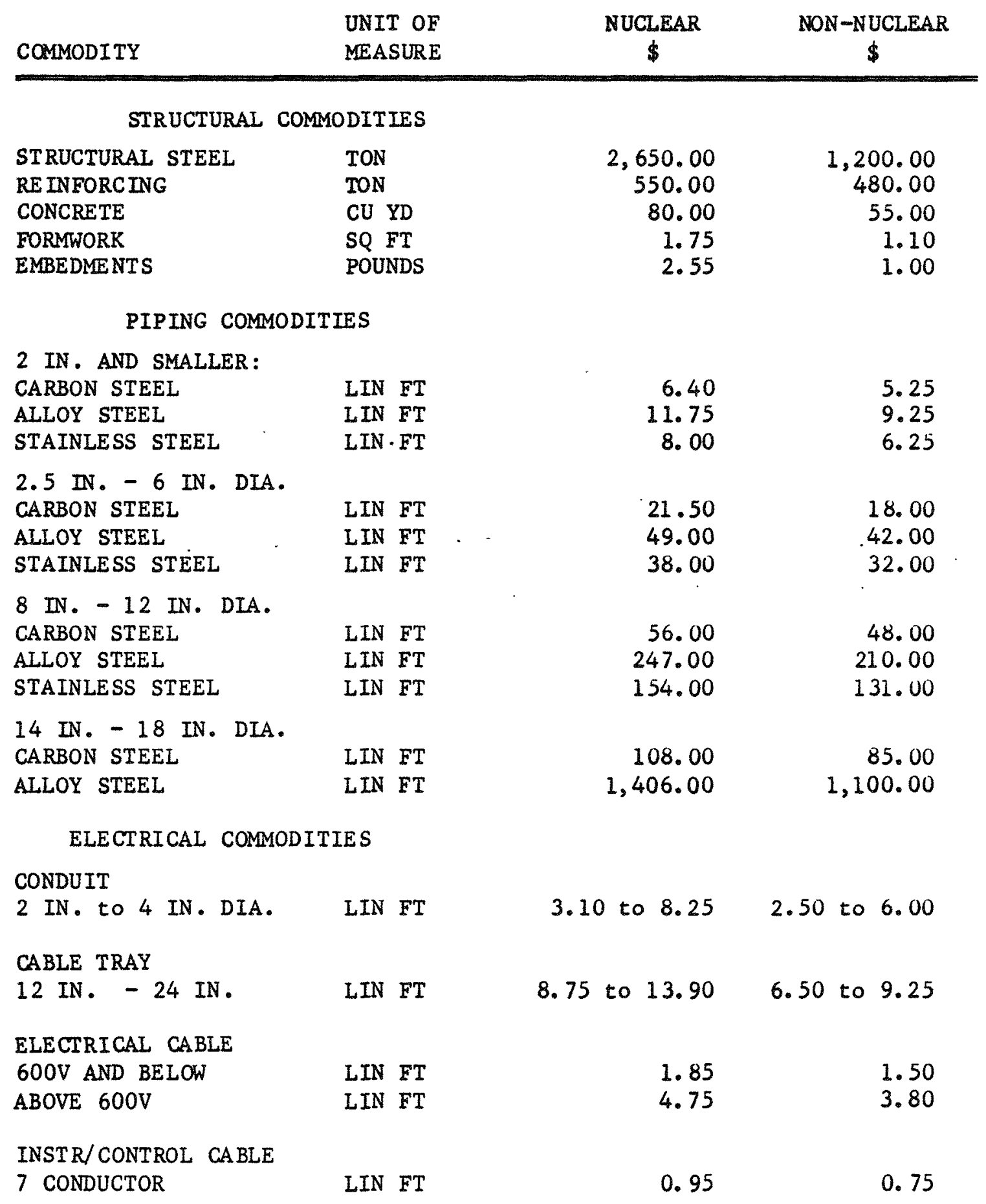


Table 5-4

UNIT MAN-HOUR INSTALLATION RATES - BULKS

\begin{tabular}{|c|c|c|c|c|c|}
\hline \multirow{2}{*}{ COMMODITY } & \multirow{2}{*}{$\begin{array}{l}\text { UNIT OF } \\
\text { MEASURE. }\end{array}$} & \multicolumn{2}{|c|}{ NUCLEAR } & \multicolumn{2}{|c|}{ NON-NUCLEAR } \\
\hline & & $\mathrm{M}$-HRS & $\mathrm{M}$-HRS & M-HRS & M-HRS \\
\hline \multicolumn{6}{|c|}{ STRUCTURAL COMMODITIES } \\
\hline STRUCTURAL STEEL & TON & 54.00 & 70.00 & 14.00 & 20.00 \\
\hline RE INFORC ING & TON & 25.00 & 40.00 & 18.00 & 24.00 \\
\hline CONCRETE & $C U$ YD & 2.20 & 3.80 & 1.20 & 2.00 \\
\hline FORMWORK & SQ FT & 0.45 & 0.75 & 0.35 & 0.45 \\
\hline EMBEDMENTS & POUNDS & 0.07 & 0.15 & 0.06 & 0.09 \\
\hline
\end{tabular}

PIPING COMMODITIES

2 IN. AND SMALLER:

$\begin{array}{llllll}\text { CARBON STEEL } & \text { LIN FT } & 4.80 & 5.40 & 1.25 & 1.50 \\ \text { ALLOY STEEL } & \text { LIN:FT } & 5.00 & 6.20 & 1.50 & 1.75 \\ \text { STAINLESS STEEL } & \text { LIN FT } & 5.00 & 6.20 & 1.50 & 1.75 \\ 2.5 \text { IN. - 6 IN. DIA. } & & & & & \\ \text { CARBON STEEL } & \text { LIN FT } & 3.50 & 3.90 & 0.75 & 1.10 \\ \text { ALLOY STEEL } & \text { LIN FT } & 5.50 & 6.50 & 0.90 & 1.30 \\ \text { STAINLESS STEEL } & \text { LIN FT } & 5.50 & 6.50 & 0.90 & 1.30 \\ 8 \text { IN. - 12 IN. DIA. } & & & & & \\ \text { CARBON STEEL } & \text { LIN FT } & 4.00 & 5.20 & 1.25 & 1.70 \\ \text { ALLOY STEEL } & \text { LIN FT } & 5.40 & 7.20 & 1.70 & 2.50 \\ \text { STAINLESS STEEL } & \text { LIN FT } & 5.40 & 7.20 & 1.70 & 2.50 \\ \text { 14 IN. - 18 IN. DIA. } & & & & & \\ \text { CARBON STEEL } & \text { LIN FT } & 5.90 & 6.50 & 1.90 & 2.20 \\ \text { ALLOY STEEL } & \text { LIN FT } & 6.30 & 10.50 & 2.50 & 3.20\end{array}$

ELECTRICAL COMMODITIES

CONDUIT

$\begin{array}{llllll}2 \text { IN. to } 4 \text { IN. DIA. } & \text { LIN FT } & 3.00 & 4.00 & 0.60 & 1.25 \\ \text { CABLE TRAY } & & & & & \\ 12 \text { IN. }-24 \text { IN. } & \text { LIN FT } & 2.70 & 4.00 & 1.50 & 1.90 \\ & & & & & \\ \text { ELECTRICAI CABLE } & \text { LIN FT } & 0.110 & 0.125 & 0.085 & 0.110 \\ \text { 60OV AND BELOW } & \text { LIN FT } & 0.125 & 0.280 & 0.100 & 0.125 \\ \text { ABOVE 600V } & & & & \end{array}$

INSTR/CONTROL CABLE

7 CONDUCTOR

LIN FT

$0.060 \quad 0.080$

0.0350 .038 . 
responsibilities. Hence, BNI prepared estimates of indirect costs relating to construction services (Account 91), field office supervision and services (Account 93), and home office engineering (Account 92), for the Nuclear Island. SWEC estimated indirect costs for the Energy Conversion Area and some minor parts of the Nuclear Island. GA estimated the cost of the reactor manufacturer's home office engineering (including Account 92) and GCRA estimated the cost which is normally incurred by the plant owner (account 94).

A/E Services (Accounts 91, 92 and 93). The Nuclear Island and Energy Conversion Area estimates are based on historical relationships between the direct costs and indirect costs. The primary cost driver for these accounts is the total value of the direct field labor. A detailed review of the nuclear and fossil power estimates had provided the relationships expressed in Table 5-5. Although these relationships are expressed differently by BNI and SWEC, they are adequately consistent in the values generated.

Owners Costs (Account 94). This account includes the costs incurred by the plant owner for activities associated with owning and managing the overall of the project. The subaccounts are management, engineering, integration and $Q A$; taxes and insurance; preoperational equipment spare parts; operating and maintenance staff preoperational training; and preoperational general and administrative expenses.

Traditionally, the Owner's Cost account has been estimated as a percentage of the sum of the direct and indirect costs. In the absence of an estimate for owner's cost, the DOE Cost Estimate Guidelines, Reference 5-1, recommend that the Owner's Cost be estimated as ten percent of the sum of the direct and indirect costs plus the cost of special coolants. This approach is used in Section 5 of Reference 5-1 for the example PWR cost estimates. For consistency with past plant estimates and for comparison with other plant alternatives, the Owner's Cost for the MHTGR plant contained herein has been based on ten percent of the direct and other indirect costs. 
I N D I R E C T R A T E S

Rate (NUS Account) Recommended by

Construction Services (91)

BN I

SWEC

Home office Engineering BNI and Services $(92)$

$\bigcup_{1}^{n}$

Field office Engineering and Services

(93)

SWEC

Owner's Expenses
$(94)$$\quad \begin{gathered}\text { DOE } \\ \text { (OKNL/TH-1 0071, } \\ \text { July } 1986)\end{gathered}$

Reactor Manufacturer Home GAT Office Engineering and

Services

Contingency

DOE

$(\underset{J u l y}{\text { ORNL }} / \mathrm{TM}-196071$
Nuclear Construction

- $\$ 2,750,000$ fixed cost

- $48 \%$ of total direct field labor cost

- \$150,000 per month for 36 months of construction.

\footnotetext{
$-\ldots-\cdots+\cdots$ - $\$ 10,500,000$ for site-specific

- Procurement costs : $16 \%$ of direct equipment and material costs exçluding NSSS

- Construction-related costs: $11 \%$ of field labor costs including Accounts 91 and 93.

- - - - - - - - - -
}

- $23 \%$ of total direct field labor cost

- $\$ 48,000$ per month for 36 months of construction.

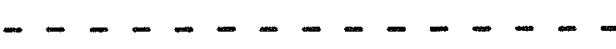

$10 \%$ of direct and other indirect costs

$$
\$ 13 \times 10^{6}
$$

Conventional Construction

- $\$ 2,100,000$ fixed cost

- $34 \%$ of total direct field labor cost

- \$100,000 per month for 36 months of construction.

$58 \%$ of direct labor cost.

- $\$ 4,000,000$ for site-specific costs

- Procurement costs : $7 \%$ of direct equipment and material costs excluding $T G$

- Construction-related costs: $2 \%$ of field labor costs including Accounts 91 and 93.

$7.4 \%$ of total field costs excluding TG.

- $15 \%$ of total direct field labor cost

- $\$ 32,500$ per month for 36 months of construction.

$20 \%$ of total direct labor costs.

$10 \%$ of direct and other indirect costs

None.

$15 \%$

$R \& D: 47375$ 
GCRA considers that a bottoms-up estimate of the indirect cost is necessary for the plant cost estimates to be prepared at the completion of conceptual design. (This consideration applies to all of the advanced nuclear power concepts under development.) Towards this end, GCRA is developing a bottomsup estimate for the MHTGR Owner's cost and is planning to have the estimate reviewed by selected utility companies and program participants. Preliminary results indicate that owner's cost will be more than the rule-of-thumb ten percent of direct and indirect cost. However, in the absence of verification by review, the results are too tentative for inclusion at this time.

Contingency. Contingency was estimated at the 3-digit account level. In the absence of specific historical data, guidance from Reference 5-2 was followed. In general, three levels of cost contingency were recognized: The safetyrelated parts of the Nuclear Island, where 20 percent was applied to shop fabricated equipment and $2 \dot{5}$ percent applied to other costs; the non-safety related parts of the Nuclear Island, where 15 percent was applied to shop fabricated equipment and 20 percent applied to other costs; and the ECA, where 10 percent was applied to shop fabricated equipment and 15 percent applied to other costs. Contingency on indirects was estimated by each contributor, based on historical data.

\subsubsection{Total Capital Cost}

The total capital cost tabulated is the all inclusive plant capital cost developed for the purpose of calculating the plant busbar electricity cost. This cost is the base construction cost plus contingency and interest-related costs. For determination of the interest during construction, also termed allowance for funds used during construction (AFUDC), the time-dependent funding requirements must be established (i.e., a cash flow curve). The cash flow curve (without AFUDC) given in Figure 5-1 was derived from the project construction schedule given in Section 4 and includes the contingency costs. The financial parameters used for determination of the interest during con- 


\section{CASH FLOW CURVE}

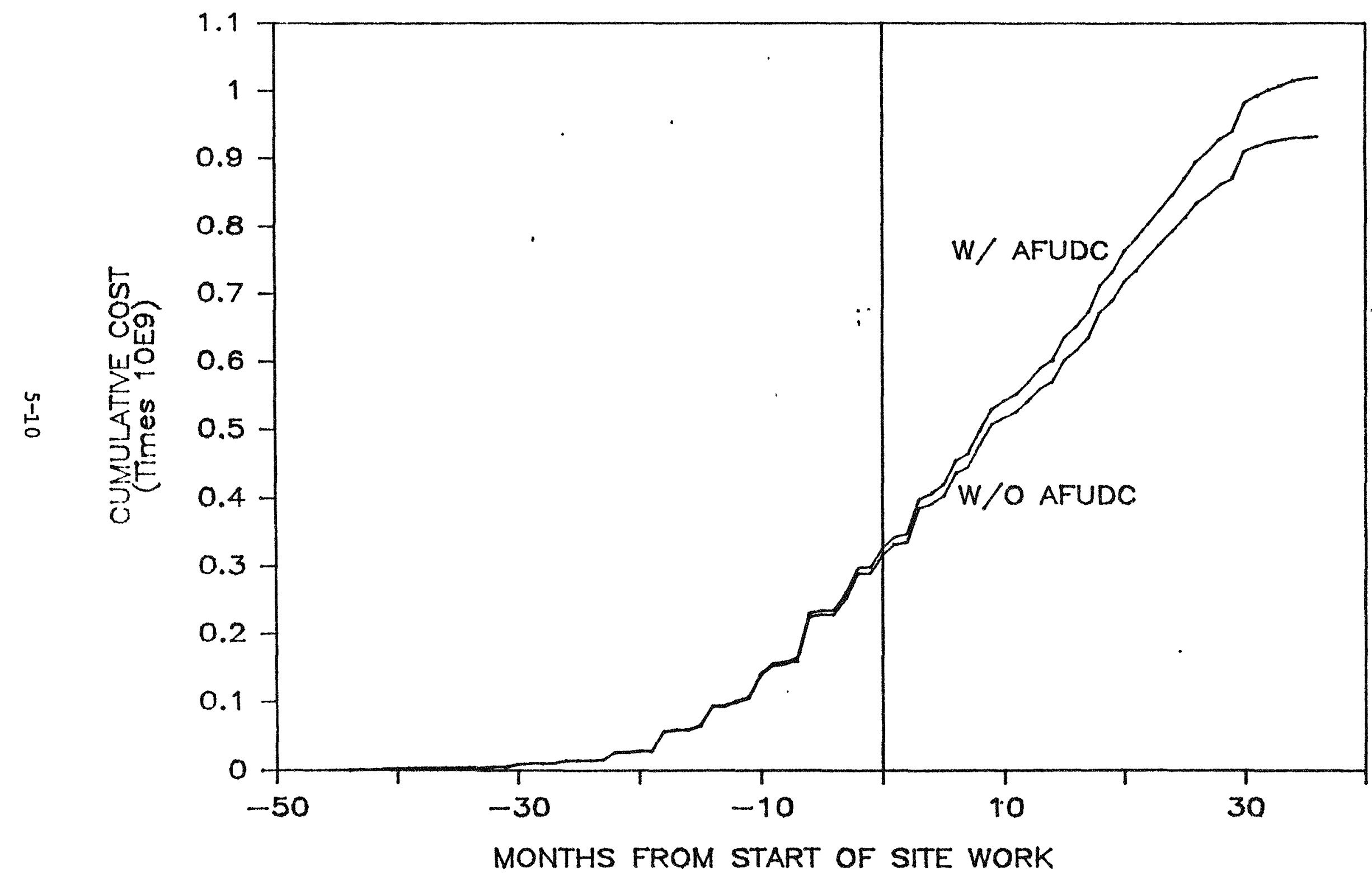

Figure 5-1 
struction were taken from the DOE Cost Estimate Guidelines, Reference 5-2, and are as tabulated in Table 5-6.

The resultant total capital cost, with contingency and AFUDC, is as given in Table 5-7 and depicted in Figure 5-1. The total capital cost estimate of $\$ 1,896 / \mathrm{kW}(\mathrm{e})$ complies with the Utility/User Requirements (Reference 1-3) that specifies a target of $\$ 2,000 / \mathrm{kW}(\mathrm{e})(1986 \$)$.

The total capital cost estimate of $\$ 1,896 / \mathrm{kW}(\mathrm{e})$ includes the cost for two turbine generators, each $269 \mathrm{MW}(e)$ net, and their auxiliary systems, as well as a turbine building sized for this equipment. Two smaller TGs were selected primarily to take advantage of higher plant availability associated with smaller TGs and to provide the flexibility to make smaller additions to generation capacity. If, however, a single 538 MWe (net) turbine generator were used, it is estimated that total capital cost would be reduced by approximately $\$ 80$ million, in which case the total per $\mathrm{kW}(\mathrm{e})$ cost for the plant would be about $\$ 1,750 / \mathrm{kW}(\mathrm{e})$.

Table 5-8 provides the total overnight plant cost at the 3-digit account level distributed between the nuclear island and energy conversion area. Additional detail of the reactor equipment costs (Account 22) are provided in Table 5-9. 
Table 5-6

F INANCIAL PARALETERS

\begin{tabular}{lc}
\hline \multicolumn{1}{c}{ Parameters } & Costs \\
\hline & \\
Capitalization, \% & 50 \\
Debt & 10 \\
Preferred Stock & 40 \\
Common Equity & \\
Return on Capitalization, \%/Year & \\
Debt Interest & \\
Preferred Dividend & \\
Common Equity Return & 9.7 \\
Federal Income Tax Rate, \% & 14.0 \\
State Income Tax Rate, \% & 46.0 \\
&
\end{tabular}


Table 5-7

PLANT TOTAL CAPITAL COST BSTIMATE

(Thousands of January 1986 Dollars)

\begin{tabular}{|c|c|c|c|c|}
\hline $\begin{array}{c}\text { EEDB } \\
\text { Account } \\
\text { No. }\end{array}$ & Account Description & & & Cost \\
\hline 20 & \multicolumn{2}{|l|}{ Land and land rights } & $\$$ & 1,400 \\
\hline 21 & \multicolumn{2}{|l|}{ Structures and improvements } & \multicolumn{2}{|r|}{111,213} \\
\hline 22 & \multicolumn{2}{|l|}{ Reactor plant equipment } & \multicolumn{2}{|r|}{245,957} \\
\hline 23 & \multicolumn{2}{|l|}{ Turbine plant equipment } & \multicolumn{2}{|r|}{119,698} \\
\hline 24 & \multicolumn{2}{|l|}{ Electric plant equipment } & \multicolumn{2}{|r|}{47,245} \\
\hline 25 & \multicolumn{2}{|l|}{ Miscellaneous plant equipment } & \multicolumn{2}{|r|}{11,290} \\
\hline \multirow[t]{2}{*}{26} & \multicolumn{2}{|c|}{ Main condenser/heat rejection system } & \multicolumn{2}{|r|}{22,045} \\
\hline & \multicolumn{2}{|l|}{ Total direct cost } & \multirow[t]{5}{*}{$\$$} & 558,848 \\
\hline 91 & \multirow{3}{*}{\multicolumn{2}{|c|}{$\begin{array}{l}\text { Construction services } \\
\text { AE home office engineering and service } \\
\text { Field office supervision and service }\end{array}$}} & & 69,042 \\
\hline 92 & & & & 56,507 \\
\hline 93 & & & & 27,374 \\
\hline \multirow[t]{11}{*}{94} & \multicolumn{2}{|c|}{$\begin{array}{l}\text { Field orilce supervision and service } \\
\text { Owner's expenses }\end{array}$} & & 71,176 \\
\hline & Total indirect costs & & $\$$ & 224,099 \\
\hline & BASE CONSTRUCTION COST & Total: & $\$$ & 782,947 \\
\hline & - & $\$ / k W(e)$ & & 1,455 \\
\hline & CONT INGENCY & & & 150,000 \\
\hline & \multirow[t]{2}{*}{ TOTAL OVERNIGHT COST } & Total: & \multirow[t]{2}{*}{$\$$} & 932,947 \\
\hline & & $\$ / k W(e)$ & & 1,734 \\
\hline & \multicolumn{2}{|l|}{ ESCALATION } & & 0 \\
\hline & \multicolumn{2}{|l|}{ INTEREST DURING CONSTRUCTION } & & 87,276 \\
\hline & TOTAL CAPITAL COST -- & Total: & & 020,223 \\
\hline & - & $\$ / k W(e)$ & & 1,896 \\
\hline
\end{tabular}


Table 5-8

- MHTGR PLANT COST ESTIMATE

Millions of January 1986 Dollars

EEDB

ACCT

NUMBER

20 LAND AND LAND RIGHTS

211 YARD WORK

212 REACTOR BUILOING

213 TURBINE BUILDING

214 OPERATIONS CENTER

215 REACTOR SERVICE BLOG

216 RADWASTE BUILOING

21 BA PERSONNEL SVC BLDG

$218 \mathrm{C}$ MAKEUP $/ \mathrm{H}_{2} \mathrm{O}$ TREAT. BLDG

2180 FIRE PUMP HOUSE

$218 E$ HELIUM STORAGE BLDG

$218 G$ HYDROGEN STOR. BLDG

$218 \mathrm{H}$ GLARD HOUSE

2181 NUC. IS. WAREHOUSE

218J ECA WAREHOUSE

$218 K$ MAINTENANCE BLDG

218U STANDBY POWER BLDG

$218 X$ NI COOL ING WATER BLDG

$218 Z$ REACTOR AUX BUILOINGS

21 TOTAL STRUCTURES

221 REACTOR SYSTEM

222 VESSEL SYSTEM

223

224

225

226

227

228

$\underline{229}$

22

231

232

234

235

236

$\frac{237}{23}$
HEAT TRANSPORT SYSTEM

RCCS

SHUTDOWN COOLING SYS

FUEL HANDLING SYSTEMS

REACTOR SERVICE SYSTEMS

PLANT CNTL DATA I\&C SYS

REACTOR PLANT MISC.

TOTAL REACTOR EQUIP

TURBINE GENERATOR

CONDENSING SYSTEM

FEED HEATING SYSTEM

OTHER T/G PLANT SYS

T/G PLANT I\&C

T/G PLANT MISC ITEMS

TOTAL T/G PLANT EQUIP
NUCLEAR ISLAND

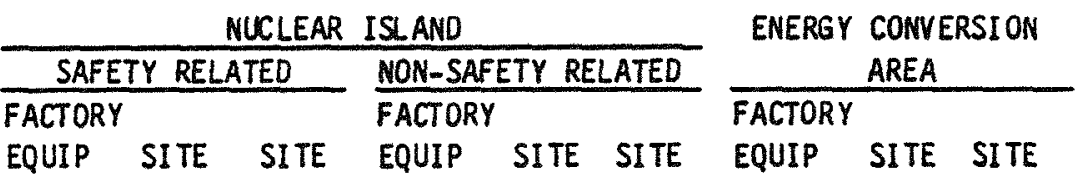

\& MAT'L MAT'L LABOR \& MAT'L MAT'L LABOR \& MAT'L MAT'L LABOR TOTAL

$\overline{0.000} \overline{0.000} \overline{0.000} \overline{0.000} \overline{0.000} \overline{0.000}$
0.22731 .22433 .494

$\overline{0.000} \frac{1.400}{1.400} \frac{1.400}{0.000} \frac{1.400}{1.400}$

$2.854 \quad 1.556 \quad 4.647 \quad 9.057$

4.6171.

$0.075 \quad 3.032 \quad 4.829$

$\begin{array}{lll}0.397 & 3.348 & 2.730\end{array}$

6.475

7.936

$\begin{array}{lll}0.775 & 0.237 & 1.241\end{array}$

2.253

$0.019 \quad 0.674 \quad 1.219$

1.912

$\begin{array}{llll}0.276 & 0.104 & 0.262 & 0.643\end{array}$

$\begin{array}{llll}0.044 & 0.009 & 0.048 & 0.101\end{array}$

$\begin{array}{lllllll}0.000 & 0.397 & 0.205 & 0.602\end{array}$

$\begin{array}{llll}0.002 & 0.011 & 0.012 & 0.025\end{array}$

$\begin{array}{llll}0.013 & 0.006 & 0.033 & 0.052\end{array}$

$\begin{array}{llll}0.144 & 0.063 & 0.182 & 0.390\end{array}$

$\begin{array}{llll}0.120 & 0.053 & 0.148 & 0.321\end{array}$

$\begin{array}{llll}0.350 & 0.136 & 0.379 & 0.865\end{array}$

$\begin{array}{llll}0.157 & 0.072 & 0.171 & 0.401\end{array}$

$\begin{array}{llll}0.000 & 0.177 & 0.075\end{array}$

0.252

$\frac{0.000}{0.302} \frac{2.067}{36.323} \frac{3.393}{41.716} \overline{0.794} \frac{}{1.485} \frac{}{2.740} \frac{}{8.974} \frac{}{6.486} \frac{5.460}{12.393}$

$\begin{array}{llll}60.100 & 0.314 & 1.520 & 61.934\end{array}$

$\begin{array}{llll}53.000 & 0.536 & 1.267 & 54.803\end{array}$

$\begin{array}{llll}36.700 & 0.124 & 0.393 & 37.217\end{array}$

$\begin{array}{llll}0.000 & 2.800 & 1.398 & 4.198\end{array}$

$\begin{array}{llllll}6.732 & 0.830 & 0.620 & 8.182\end{array}$

$\begin{array}{llll}16.300 & 0.220 & 0.793 & 17.313\end{array}$

$\begin{array}{llll}19.440 & 0.732 & 4.286 & 24.458\end{array}$

$\begin{array}{lllllll}4.249 & 0.034 & 1.158 & 16.920 & 0.136 & 4.632 & 27.129\end{array}$

$\overline{160.781} \frac{}{4.638} \frac{8.600}{6.356} \frac{0.020}{61.260} \frac{0.066}{1.108} \frac{1.154}{1.154} \frac{0.000}{0.000} \frac{0.883}{0.883} \frac{10.723}{245.957}$

$\begin{array}{llllll}59.446 & 0.886 & 3.900 & 64.231\end{array}$

$\begin{array}{llll}9.210 & 0.023 & 2.948 & 12.180\end{array}$

$\begin{array}{llll}9.336 & 0.025 & 2.743 & 12.104\end{array}$

$12.3810 .043 \quad 3.760,16.184$

$13.792 \quad 0.000 \quad 1.206 \quad 14.998$

$0.000 \quad 0.000 \quad 0.000 \quad 0.000$

$0.000 \overline{0.000} \overline{0.000} \overline{0.000} \overline{0.000} \overline{0.000} \frac{0.000}{104.165} \frac{0.000}{0.977} \frac{0.000}{14.556} \frac{0.000}{119.698}$ 
Table 5-8 (Cont'd)

MHTGR PLANT COST ESTIMATE

Millions of January 1986 Dollars

NUCLEAR ISLAND

\begin{tabular}{l} 
SAFETY RELATED \\
\hline FACTORY \\
EQUIP SITE \\
\& MITE \\
MAT'L MAT'L LABOR
\end{tabular}

ENERGY CONVERSION AREA

FACTORY FACTORY

EQUIP SITE SITE EQUIP SITE SITE

DESCRIPTION

NUMBER
SWI TCHGEAR

STATION SERVICE EQUIP

SWI TCHBOARDS

PROTECTIVE EQUIP

ELEC STR \& WIRING CNTRS

POWER \& CNTL WIRING

TOTAL ELECTRICAL PLT EQ

\subsection{4 \\ 0.088}

0.0420 .000

0.087

0.374

0.000

0.060

$\frac{0.779}{2.717} \frac{0.000}{0.010}$

1.933

0.005

0.098

0.203

0.873

$\frac{246}{24}$

251 TRANSP. \& LIFT EQUIP

252 AIR, $\mathrm{H}_{2} \mathrm{O} ;$;TEAM\&SVC SYS

253 COMMNICATION EQUIP

254 FURNISHINGS \& FIXTURES

$\frac{25}{25}$ TOTAL MISC PLANT EQUIP

261 HEAT REJ STRUCTURES

262 HEAT REJ MECH EQUIP

26 TOTAL HEAT REJ SYS

TOTAL DIRECT COSTS

\begin{tabular}{|c|c|c|c|c|c|c|c|c|c|}
\hline & & & 1.741 & 0.500 & 0.421 & 0.564 & 0.000 & 0.057 & 3.283 \\
\hline & & & 0.052 & 0.000 & 0.006 & 2.194 & 0.224 & 1.464 & 3.940 \\
\hline & & & 0.406 & 0.000 & 0.087 & $\begin{array}{l}1.370 \\
1.048\end{array}$ & $\begin{array}{l}0.000 \\
0.000\end{array}$ & $\begin{array}{l}1.006 \\
0.150\end{array}$ & $\begin{array}{l}2.376 \\
1.691\end{array}$ \\
\hline 0.000 & 0.000 & 0.000 & 2.199 & 0.500 & 0.514 & 5.176 & 0.224 & 2.677 & 11.290 \\
\hline & & & & & & 0.448 & 1.189 & 1.922 & 3.559 \\
\hline & & & & & & 12.767 & 0.758 & 4.961 & 18.486 \\
\hline 0.000 & 0.000 & 0.000 & 0.000 & 0.000 & 0.000 & 13.215 & 1.947 & 6.883 & 22.045 \\
\hline 3.800 & 0.971 & 1.074 & .530 & 3.10 & ? & $150 \Omega 80$ & 1213 & 5.142 & 558.848 \\
\hline
\end{tabular}

91 CONSTRUCTION SERVICES

10.00620 .255

$13.000 \quad 8.823 \quad 19.478$

1.75811 .202

FIELD OFC SUPVN \& SVC

94 OWNER'S EXPENSES
$3.920 \quad 7.936$

$1.489 \quad 2.822$

$0.689 \quad 4.389$
8.86118 .064

1.7349 .161

3.2356 .100

TOTAL

$\begin{array}{llll}8.746 & 0.000 & 0.413 & 9.159\end{array}$

$\begin{array}{lllll}3.876 & 0.029 & 0.586 & 10.494\end{array}$

$\begin{array}{lllll}0.970 & 0.000 & 0.089 & 1.215\end{array}$

$\begin{array}{llll}0.321 & 0.000 & 0.637 & 1.449\end{array}$

$\begin{array}{lllll}0.198 & 1.074 & 5.010 & 13.973\end{array}$

$\begin{array}{lllll}3.285 & 0.000 & 2.015 & 10.955\end{array}$

$1.396 \frac{0.000}{1.103} \frac{2.015}{8.750} \frac{10.955}{47.245}$ 
Table 5-9

REACTOR PLANT EQUIPLENT PRICE ESTIMATES

(Thousands of January 1986 dollars)

DIRECT

COSTS

ACCOUNT BASE SCOPE EQUIPMENT

222.1 STEEL VESSELS

222.1 REACTOR PRESSURE RELIEF

221.1 NEUTRON CONTROL

226. 1 CORE REFUEL ING

226. 2 SITE FUEL HANDLING

227.6 REACTOR SERVICE EQUIPMENT

221.2 REACTOR INTERNALS

221.2 REACTOR CORE W/O FUEL

223.1 MAIN HELIUM CIRCULATOR

223.2 STEAM GENERATOR

227.1

228.5

228.4

228.2

225.1

225.2

225.2

921
HELIUM PURIFICATION

MISC. CONTROL \& INSTRUMENTATION

CONTROL, DATA \& INSTRUMENTATION

SHUTDOWN CIRCULATOR

SHUTDOWN COOLING HEAT REMOVAL CONTROL

SHUTDOWN HEAT EXCHANGER

INDIRECT COSTS

TOTAL CAPITAL COST
PLANT PROTECTION \& INSTRUNENTATION

EQUILIBRIUM

PLANT

(ROUNDEU)

$4 \times 350 \mathrm{MW}(\mathrm{t})$

50,800

2,200

10,400

14,100

2,200

9,100

41,100

8,600

14,300

22,400

2,200

1,400

5,700

7,300

2,400

1,100

3,200

$\frac{13,000}{211,500}$

RELATED ITEMS IN BALANCE OF PLANT

227.6 REACTOR SEAL SERVICE EQUIPMENT

229. 1 CHECKOUT \& STARTUP EQUIPMENT

TOTAL RELATED ITEMS IN BOP

70

$\frac{500}{570}$

OPERATIONS \& MAINT. EQUIP.

229.2 STEAM GEN. MONITOR \& ISI EQUIPMENT

229.2 SHUTDOWN HX MONITOR \& ISI EQUIPMENT

O\&M EQUIP TOTALS

$\begin{array}{r}550 \\ 550 \\ \hline 1,100\end{array}$

229.3 TRANSPORTATION OF MAJOR EQUIPMENT
7,000 


\subsection{FUEL CYCLE COSTS}

\subsubsection{Economic Assumptions}

The documentation of the fuel cycle economic, resource cost, and unit handling cost assumptions and derivations are reported in Reference 5-3. The economic (money cost) assumptions, as well as the enriched uranium cost assumptions and the methodology for fuel facility costing and unit cost development are based on the recommendations contained in the Nuclear Energy Cost Data Base (NECDB), Reference 5-4. These NECDB costing parameters and methodologies have been incorporated into the cost guideline reports (References 5-5 and 5-2) issued by DOE, which contain the cost estimating guidelines for evaluating advanced nuclear power technologies, including both the Standard MATGR and the Liquid Metal Reactor (LMR).

Consistent with the above guidelines, unit costs and 30 -year levelized costs have been determined for three different MHTGR plant assumptions. These cases include:

1. "Lead Plant or First Commercial Plant or First-of-a-Kind (FOAK) Plant" with startup in 2000

2. "Replica Plant" with startup in 2005

3. "Equilibrium Commercial Plant or Nth-of-a-Kind (NOAK) Plant" with startup in 2010 .

The indicated startup dates were chosen for purposes of cost estimation.

The updated handing cost estimates for the Equilibrium NOAK plant are largely based on escalating "equilibrium" fuel facility costs determined in 1984 (Reference 5-6) to 1986 unit costs assuming a four percent escalation rate for both 1984 and 1985 .

For the Lead Commercial or Replica Plant designs, new fabrication cost estimates have been developed and reflect the much lower throughputs that would 
result from fabricating such fuel elements in a modified existing facility (the Sorrento Valley Fuel Facility).

The reference costs for $\mathrm{U}_{3} \mathrm{O}_{8}$, conversion, and enrichment are as follows:

\begin{tabular}{|c|c|c|}
\hline & 1986 Price & $\begin{array}{c}\text { Real Escalation } \\
\text { Rate (\% per year) }\end{array}$ \\
\hline $\mathrm{U}_{3} \mathrm{O}_{8}, \$ / 1 \mathrm{~b}$ & 34 & 1.2 \\
\hline Conversion, $\$ / \mathrm{kg} \mathrm{U}$ & 8 & 0 \\
\hline Enrichment, $\$ / \mathrm{kg} U$ & 115 & $\begin{array}{l}-3.4 \text { to } 2005 \\
0 \text { thereafter }\end{array}$ \\
\hline
\end{tabular}

This enrichment price schedule results in the price ( $\$ / \mathrm{kg} \mathrm{SWU}$ ) decreasing to $\$ 60 / \mathrm{sWU}$ in 2005 and then remaining constant. These $\mathrm{U}_{3} \mathrm{O}_{8}$ and enrichment prices, plotted by year, are shown in Figures $5-2$ and 5-3.

Beginning in FY86, the DOE incorporated a major change in their pricing policy for enriching services. Prior to this change, all enrichment charges were fixed for a given contract regardless of enrichment assay. In FY४6, separate charges were established for low assay and high assay enriching services in each contract. It is estimated that this new pricing policy would result in the following changes:

1. Enrichment costs for 19.8 percent enriched uranium would increase approximately three percent.

2. Fuel cycle costs would increase approximately one percent.

The waste cost is assumed to be $1.0 \mathrm{~m} / \mathrm{kWh}(\mathrm{e})$, as specified in the Nuclear Waste Policy Act of 1982.

A consistent set of economic assumptions were developed for a zero percent inflation rate. These economic assumptions define the working capital rate 


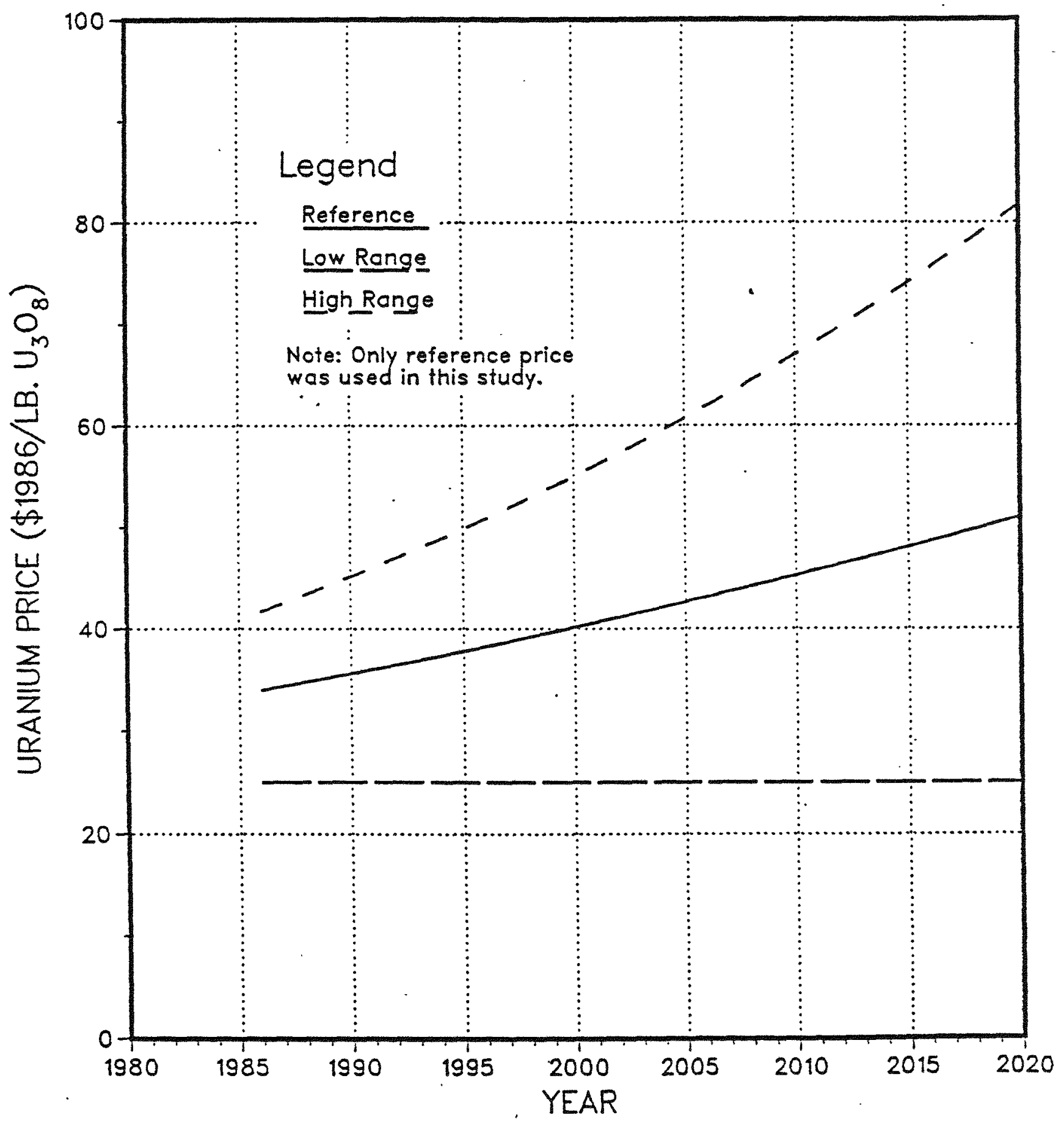

Figure 5-2 Uranium Price Projections 


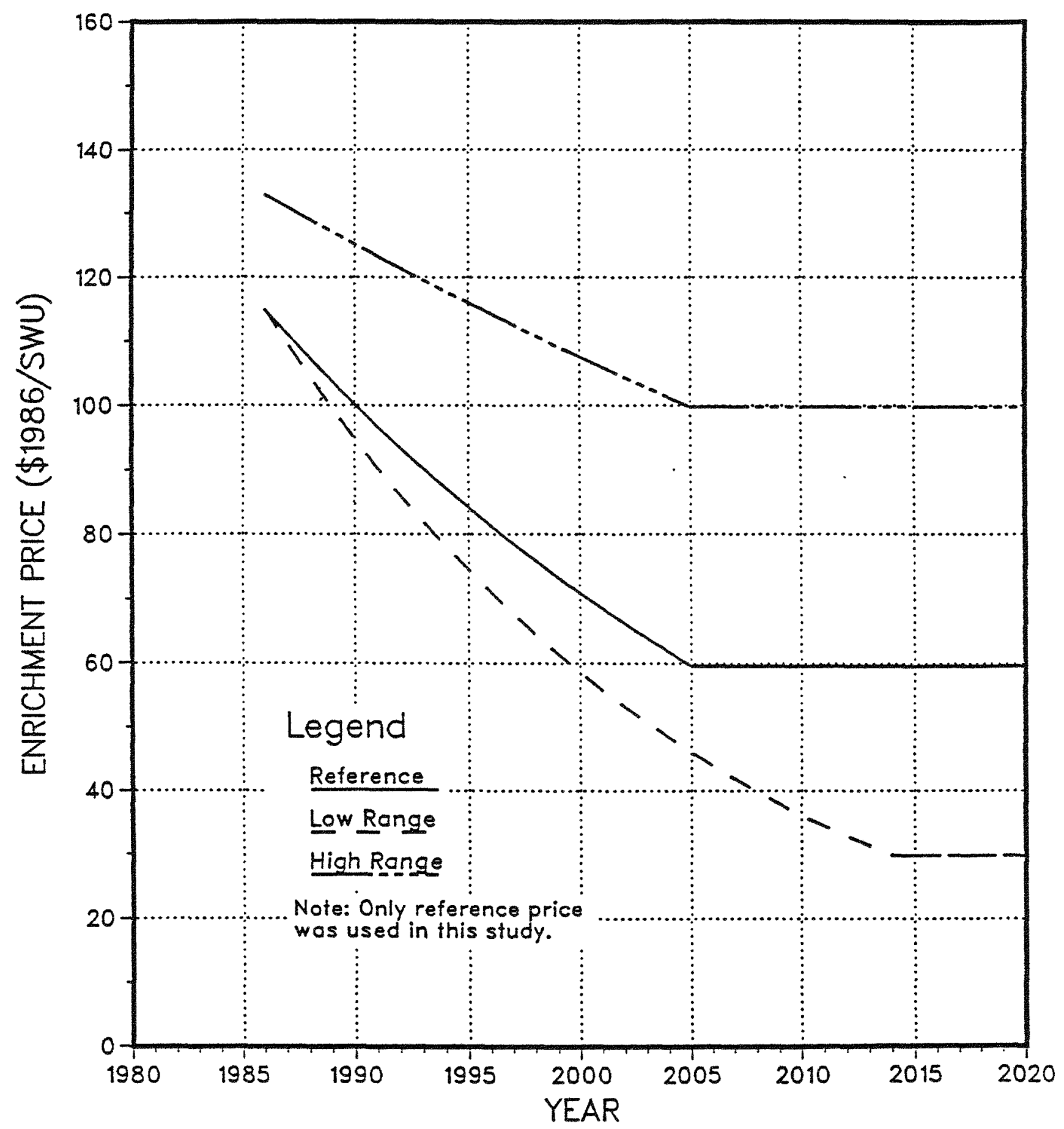

Figure 5-3 Enrichment Price Projections 
and discount rate assumptions used for determining fuel cycle costs. These and other related items are summarized in Table 5-10.

Table 5-11 summarizes the reference FY 86 unit costs used in the fuel cycle cost evaluations. The $1.0 \mathrm{~m} / \mathrm{kWh}(e)$ waste fee includes shipping costs from the reactor or a designated site to the waste repository and applies to either processed high-level waste or to other, unprocessed, fuel elements.

\subsubsection{Fue1 Cycle Cost Summary}

Thirty-year levelized fuel cycle costs, based on constant dollars, have been calculated for the following design options:

1. First Commercial (FOAK) Plant; 2000 startup

2. Replica Plant; 2005 startup

3. Equilibrium (NOAK) Plant; 2010 startup

All fuel depletion costs assume that all discharged fissile materials have zero value at discharge. The fuel depletion costs also reflect expected uranium losses of one percent for fresh fuel fabrication.

The fuel cycle costs, in $\mathrm{m} / \mathrm{kWh}(e)$, for the Standard MHTGR design are summarized in Table 5-12. The variation in the fuel depletion costs reflects only the changing enriched uranium cost components with time, since the same mass flows are assumed for three plant startup dates. It should also be noted that the fuel fabrication cost component reduces appreciably with the assumed year of startup as would be expected. However, the levelized costs for the later reloads in both the FOAK and Replica Plants is reduced by assuming fabrication in a high throughput equilibrium facility. For example, the levelized fabrication cost would be $7.43 \mathrm{~m} / \mathrm{kWh}(\mathrm{e})$ rather than $4.5 \mathrm{~m} / \mathrm{kWh}(\mathrm{e})$ for the Replica Plant if the total 30 years of fabrication were carried out in the expanded existing fabrication facility having a lower throughput. 
Table 5-10

FUEL CYCLE COST ECONOMIC ASSUMPTIONS

Plant Basis

Capacity Factor

Base Date for Costs

Levelizing Period

Plant Thermal Efficiency

Inflation Rate

Capitalization

Debt

Preferred Stock

Common Equity

Return on Capitalization

Debt Interest

Preferred Dividend

Common Equity Return

Weighted Cost of Capital

Inflation-Free cost of Money

Tax Adjusted (used as discount rate)

Working Capital Rate
FOAK (2000)

Replica (2005)

NOAK (2010)

$80 \%$

January, 1986

30 years

0.391

$0.0 \%$ (constant dollars)

$50 \%$

$10 \%$

$40 \%$

$4.5 \% / \mathrm{yr}$

$3.8 \% / \mathrm{yr}$

$8.6 \% / \mathrm{yr}$

$6.1 \% /$ y r

$3.8 \% /$ yr

$7.9 \% / y r^{(a)}$

(a) Includes 46 percent Federal Income Tax rate on equity portion of capitalization added to the weighted cost of capital. 
Table 5-11

MHTGR FRESH FUEL FABRICATION UNIT PRICES

$\$ /$ Fuel Element

\begin{tabular}{|c|c|c|c|}
\hline & FOAK & Replica & NOAK \\
\hline IC and Reloads $1-3$ & 35,700 & 30,000 & 10,900 \\
\hline Reloads 4-6 & 30,000 & 10,900 & 10,900 \\
\hline Reloads 7-end & 10,900 & 10,900 & 10,900 \\
\hline
\end{tabular}


Table 5-12

30-YEAR LEVELIZED FUEL CYCLE COSTS, 1986\$

in mills $/ \mathrm{kWh}(\mathrm{e})$ and $(\$ / \mathrm{MBtu})$

\begin{tabular}{ccccc} 
Fue1 & Fab & $\begin{array}{c}\text { NWPA } \\
\text { Waste }\end{array}$ & $\begin{array}{c}\text { Total } \\
\text { FCC }\end{array}$ & $\begin{array}{c}\text { Total } \\
\$ / M B t u\end{array}$ \\
\cline { 3 - 4 } 5.70 & 6.00 & 1.0 & 12.7 & $(1.40)$ \\
5.70 & 4.50 & 1.0 & 11.2 & $(1.29)$ \\
6.00 & 2.70 & 1.0 & 9.70 & $(1.11)$
\end{tabular}

LEU/Th (OT)

6.00

1.0

9.70

1.11) 


\subsection{OPERATIONS AND MAINTENANCE COST ESTIMATION}

This section summarizes the anticipated plant staffing requirements and associated costs for the $4 \times 350 \mathrm{MW}(t)$ MHTGR concept.

\subsubsection{Overall Staffing Estimate}

The proposed plant staffing matrix (Table 5-13) was developed to satisfy not only generic needs but also the unique requirements specific to the MHTGR design. Design and engineering inputs were used to provide staffing information for the identified unique components/systems, while the manpower factors for plant maintenance were used to generate staffing information for the generic components. A summary methodology is shown in Figure 5-4. To obtain a manpower distribution by personnel type, the maintenance and surveillance activities were broken down into mechanical, electrical, instrument, health physics, and operations.

\subsubsection{O\&M Cost Estimate}

The O\& cost estimated is patterned after the procedure developed previously by ORNL for LWR plants. The cost accounting breakdown is designed to facilitate deriving and reporting costs related to expenditures for personnel, consumable supplies and materials, and indirect costs. The direct costs -on-site staff, maintenance materials, supplies and expenses, regulatory fees, and off-site support services - encompass those expenses defined in Nuclear Power Generation Accounts 517-532 of the Federal Energy Regulatory Commission (FERC) Code of Accounts (18CFR101); the indirect costs encompass Administrative and General Accounts $920-932$ as allocated to generation. Variable costs are allocated in two subaccounts -- variable maintenance materials, and variable supplies and expenses. All other accounts are considered to be fixed expenses, although there is no rigorous definition of the allocation between fixed and variable costs. The $O \& M$ cost breakdown summary is given in Table 
Table 5-13

ESTIMATED ON-SITE STAFFING: $4 \times 350 \mathrm{MW}(t)$ MHTGR

\begin{tabular}{|c|c|c|}
\hline Description & $\begin{array}{l}\text { Ir Reactors/ } \\
10 \text { Turbine } \\
\text { ienerators }\end{array}$ & Bases \\
\hline \multicolumn{3}{|l|}{ Plant Mgr. Staff } \\
\hline Plant Manager & 1 & Given \\
\hline Assist. Manager & 1 & Given \\
\hline Training & 5 & Best Estimate \\
\hline Safety \& fire prot. & 1 & Experience \\
\hline Administrative sves. & 25 & Experience with record keeping \\
\hline $\begin{array}{l}\text { Health Services } \\
\text { Security }\end{array}$ & $\begin{array}{r}1 \\
34 \\
\end{array}$ & $\begin{array}{l}\text { On-site nurse } \\
\text { Five-person response team fxom maintenance } \\
\text { normally assigned to shifts }\end{array}$ \\
\hline Subtotal & 68 & 24 hours/day, 5 days/week \\
\hline \multicolumn{3}{|l|}{ Operation } \\
\hline Supervision & 6 & $\begin{array}{l}\text { One per shift, plus one to cover illness, } \\
\text { vacations, and training }\end{array}$ \\
\hline Shifts operations & 32 & $\begin{array}{l}\text { 28, plus four to fill in for full shift } \\
\text { coverage, seven persons/snift, } 24 \\
\text { hours/day, } 5 \text { days/week }\end{array}$ \\
\hline $\begin{array}{l}\text { Shift maint. support } \\
\text { Subtotal }\end{array}$ & $\frac{12}{50}$ & \\
\hline \multicolumn{3}{|l|}{ Maintenance } \\
\hline $\begin{array}{l}\text { Supervision } \\
\text { Crafts }\end{array}$ & $\begin{array}{r}7 \\
133\end{array}$ & $\begin{array}{l}\text { One craft plus maintenance managers } \\
\text { Based on component maintenance data base } \\
\text { for two turbines }\end{array}$ \\
\hline Annual peak maint. & 3 & $\begin{array}{l}\text { Reactor plus turbine overhaul annualized } \\
\text { to one year }\end{array}$ \\
\hline $\begin{array}{l}\text { Quality Control } \\
\text { Warehouse } \\
\text { Subtotal }\end{array}$ & $\begin{array}{r}5 \\
\frac{6}{154}\end{array}$ & $\begin{array}{l}\text { One per shift, one backup } \\
\text { Two warehouses; one nuclear island, one } \\
\text { ECA }\end{array}$ \\
\hline \multicolumn{3}{|l|}{ Technica1/Engineering } \\
\hline $\begin{array}{l}\text { Reactor engineer } \\
\text { Radiochem./water chem. } \\
\text { Engineering } \\
\text { Technicians } \\
\text { Health physics } \\
\quad \text { Subtotal }\end{array}$ & $\begin{array}{r}3 \\
8 \\
6 \\
6 \\
13 \\
36\end{array}$ & $\begin{array}{l}\text { On-call on back and weekend shifts } \\
\text { Four reactors and feedwater trains } \\
\text { Best estimate of performance testing } \\
\text { Assisting above performance testing } \\
\text { Best estimate }\end{array}$ \\
\hline
\end{tabular}




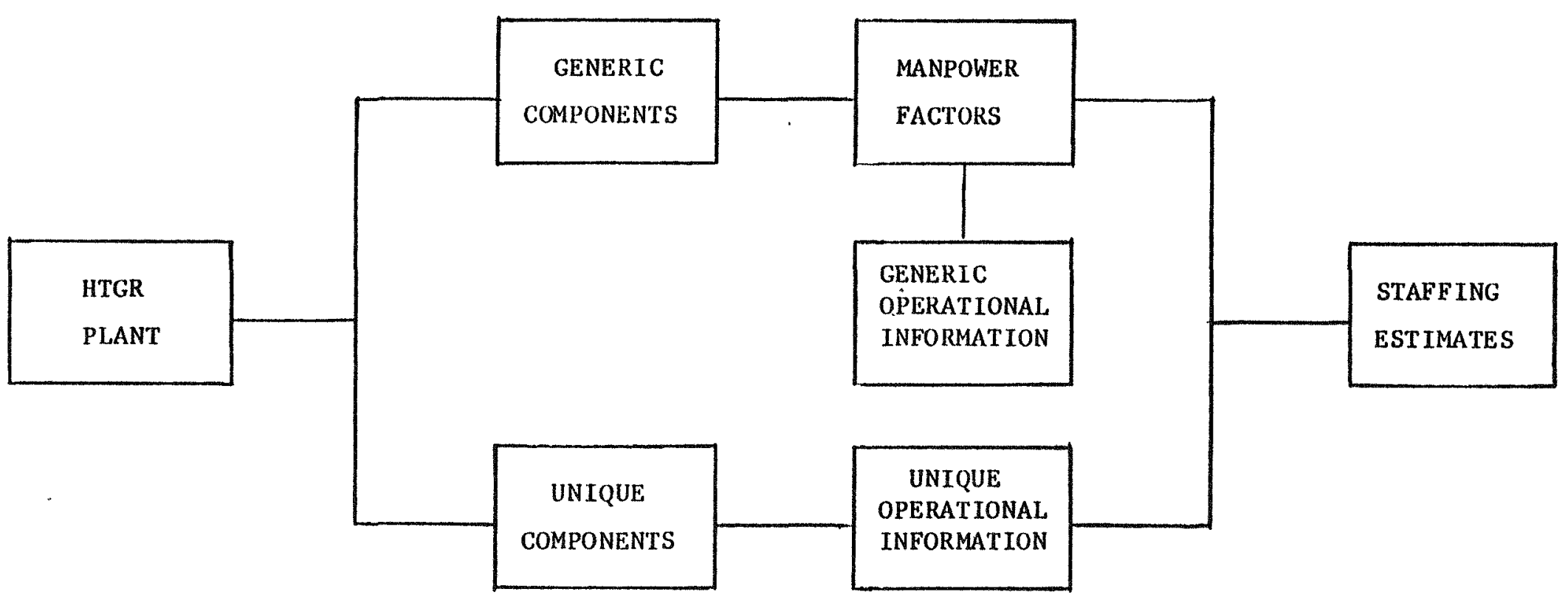

Figure 5-4 Summary Methodology Maintenance and Surveillance Staffing Matrix 
5-14, and the basis for the account estimates is given in the following paragraphs.

On-site staffing. The estimated annual salaries for on-site staff are based on a limited response to a request to Gas-Cooled Reactor Associates (GCRA) member utilities for information on nuclear power plant staffing salaries.

The fringe benefit allowance of 40 percent of direct salaries is typical for the limited response. This is double the composite of pensions and benefits for all electric utility employees as reported by the Energy Information Administration (EIA) for the year 1984, which is 20 percent of the total payrol1.

Salaries will vary regionally throughout the United States due to various socioeconomic factors such as cost of living, proximity to recreational and educational facilities, and supply of skilled labor. The salaries estimated here should be considered average for all regions. The average annual salary is $\$ 38,000 /$ year without fringe benefits and $\$ 53,000 /$ year with fringe benefits.

Maintenance Materials. The annual cost of maintenance materials is estimated to be 100 percent of the annual cost of maintenance supervision, crafts, and peak maintenance, at 80 percent capacity factor. This is separated into a fixed component, which does not vary with plant output, and a variable component, which is directly proportional to generation. The costs of maintenance materials are judged to be somewhat less than for current LWRs because of the high availability expected to be designed into advanced HTGRs and the lower level of radioactivity.

Supplies and Expenses. The supplies and expenses account includes consumable materials that are unrecoverable after use and contract services for nonmaintenance activities. The cost estimates shown in Table 5-14 are based on 
Table $5-14$

ESTIMATED TOTAL ANNUAL NON-FUEL OPERATION AND MAINTENANCE COSTS (January 1986 dollars)

\begin{tabular}{|c|c|}
\hline $\begin{array}{l}\text { Net plant output, } \mathrm{MW}(\mathrm{e}) \\
\text { Capacity Factory, } \%\end{array}$ & $\begin{array}{r}538 \\
80\end{array}$ \\
\hline $\begin{array}{l}\text { Net Generation, } 10^{6} \mathrm{MWh} \\
\text { On-site Staff }\end{array}$ & $308^{3.77}$ \\
\hline $\begin{array}{l}\text { Direct Costs }\left(10^{6} \$ / \text { year }\right) \\
\text { On-site Staff }\end{array}$ & 16.4 \\
\hline $\begin{array}{l}\text { Maintenance Materials } \\
\text { Fixed } \\
\text { Variable } \\
\quad \text { Subtotal }\end{array}$ & $\begin{array}{l}4.4 \\
1.4 \\
5.8\end{array}$ \\
\hline $\begin{array}{l}\text { Supplies and Expenses } \\
\text { Fixed } \\
\text { Variable } \\
\text { Subtotal }\end{array}$ & $\begin{array}{l}4.1 \\
0.4 \\
4.5\end{array}$ \\
\hline Off-site Support Services & 2.5 \\
\hline $\begin{array}{l}\text { Subtotal, Direct Costs } \\
\text { Fixed } \\
\text { Variable } \\
\quad \text { Subtotal, Direct Costs }\end{array}$ & $\begin{array}{r}27.4 \\
1.8 \\
29.2\end{array}$ \\
\hline $\begin{array}{l}\text { Indirect Costs }\left(10^{6} \$ \text { /year }\right) \\
\text { Nuclear Regulatory Fees } \\
\text { Administrative and General } \\
\text { Insurance } \\
\quad \text { Subtotal, Indirect Costs }\end{array}$ & $\begin{array}{l}1.0 \\
2.9 \\
3.5 \\
7.4\end{array}$ \\
\hline $\begin{array}{l}\text { Total Direct and Indirect Costs }\left(10^{6} \$ \text { /year }\right) \\
\text { Variable }\end{array}$ & $\begin{array}{r}34.8 \\
1.8 \\
\end{array}$ \\
\hline Total & 36.6 \\
\hline
\end{tabular}


judgments in comparison with LWR cost estimates. The smaller plant size, passive safety features, and lower levels of radioactivity are estimated to lead to lower costs, especially in the areas of training and radioactive waste management. For base-loaded plants with high availability, the variable component is estimated to be small.

Off-site Technical Support. The cost estimate for off-site technical support staff shown in Table 5-14 is based on the full time services of a 25-person engineering staff. This technical staff provides direct support to the nuclear power plant in areas of nuclear design, engineering, licensing, fuels, and research and development on specific problems. The size of this staff is based on the assumption of a much more stable licensing and regulatory environment and the Nth plant of a standard series. The number (25) is approximately one-half to one-third the minimum off-site staff required currently for LWR plants. The annual salary is based on the limited response to the request to GCRA member utilities for staffing and salary information for LWR plants. The 40 percent allowance for fringe benefits is the same as for on-site staff, and the 60 percent overhead allowance provides for office rent and utilities.

Nuclear Regulatory Fees. To comply with a recent Congressional mandate calling for a fee increase to cover approximately one-third of the NRC's budgeted costs, a proposed rule amending the current fee schedule has been published in the Federal Register. In this proposed rule, the NRC states that they have been unable to correlate licensing and regulation costs with reactor size. Thus they recomend a flat fee for FY 1987, calculated as follows:

$(\$ 405,000,000 \mathrm{NRC}$ budget $\times 0.33)-(\$ 1,271,000$ materials license fees $)$

$$
\begin{gathered}
\text { (103 operating licenses })+(27 \text { applications }) \\
=\$ 1,010,000 \text { per nuclear reactor }
\end{gathered}
$$


The NRC currently is analyzing public comments which they have received on the proposed rule, and there may be small reductions in the fees for nuclear reactors. The final rule is scheduled to be issued by September 1, 1986.

It is assumed in this study that the $4 \times 350 \mathrm{MW}(t)$ MHTGR can be licensed for operation as a single reactor unit. The recommended fee is $\$ 1,000,000$ per year.

Nuclear Insurance Premiums. From the time that a construction permit is issued for a nuclear power plant a utility is required to carry insurance to protect itself from public liability claims, which may arise from a nuclear accident, and to provide funds for plant cleanup and decomissioning following an accident. Amendments to the insurance policies are issued at various stages (e.g., operating permit, fuel delivery, fuel loading, and commercial operation).

The legal requirements for property damage insurance to provide funds for plant cleanup following a nuclear accident are derived from the NRC's mandate to provide for public safety. This protection is provided in two layers of commercial insurance. The minimum amounts of insurance currently required by the NRC is $\$ 500$ million primary coverage and $\$ 85$ million excess, or secondary, coverage, for a total of $\$ 585$ million, although the maximum excess coverage currently available is approximately $\$ 600$ million, for a total of $\$ 1.1$ billion. The NRC has issued a proposed rule requiring a minimum of $\$ 1.02$ billion property damage insurance, which is expected to be adopted in late 1986. The rule makes no special provisions for smaller reactors, but they can be considered through individual exemptions.

The estimated annual premium given in Table 5-14 is a typical value based on information collected by the NRC for LWR plants, adjusted downward for the smaller size of the MHTGR and assuming that the $4 \times 350$ MW( $t$ ) MHTGR can be insured as a single reactor unit. The actual premiums are subject to sitespecific risk evaluations and options relating to deductibles. 
Administrative and General (A\&G) Expenses. Other A\&G expenses were developed by analyzing electric utility operation and maintenance cost summaries published by the Energy Information Administration (EIA) for the four-year period 1981-1984. Total power production expenses as defined by the EIA include the sum of all expenses (exclusive of amortization of capital investment) incurred for operating and maintaining electric utilities and producing electric power (i.e., fossil power generation, nuclear power generation, hydraulic power generation, other power generation, other power supply, transmission, distribution, customer accounts, customer services and information, sales, and administrative and general). There are no standard cost accounting rules for allocating overhead costs to production costs other than where specific expenses can be clearly identified (e.g., benefits). It is recommended that a factor of ten percent be applied to the sum of the direct costs (i.e., on-site staff, maintenance materials, supplies and expenses, and off-site technical support). 


\subsection{BUSBAR GENERATION COSTS}

The total energy generation cost, or busbar cost, includes the plant capital cost, nonfuel operation and maintenance ( $O d M)$ costs, fuel costs and decomissioning costs and is generally expressed as cost per unit of energy generated. The busbar cost is a single decision measure which incorporates the time value and cost of money, as well as all investment and running costs and is useful for making relative economic comparisons.

The methodology as described in the DOE Cost Estimate Guidelines, Reference 5-2, has been used to determine the constant dollar levelized busbar cost. The levelized busbar cost is the equivalent uniform stream over time such that the sum of the present worths of the annual levelized values is equal to the sum of the present worths of the actual values.

The levelized values for each of the cost components contributing to the busbar cost are as follows:

Levelized Capital Cost. The methodology presented in Reference 5-2 results in the derivation of a fixed charge rate for the levelized capital cost that accounts for depreciation, interim replacements and income tax effects. For the 36 month MHTGR construction period, the fixed charge rate is derived to be 9.2 percent using the economic parameters in Table 5-15. The derivation of this fixed charge rate is based on a typical cash flow curve shape which may not exactly match the cash flow given in section 5.1. The slight differences between the assumed shape for the fixed charge rate and that in section 5.1 are not considered to be significant, particularly with the inherent uncertainties involved. The resultant levelized capital cost is as tabulated in Table 5-16.

Fuel and O\&M Costs. The 30-year levelized fuel cycle costs and the annual $O \& M$ costs are presented in Sections 5.2 and 5.3 respectively and the results are itemized in Table 5-16. The levelized fuel 


\section{Table 5-15}

\section{FIXED CHARGE RATE PARAMETERS}

\begin{tabular}{|c|c|}
\hline Parameters & Rate \\
\hline Investment Tax Credit, \% & 8.0 \\
\hline $\begin{array}{l}\text { Effective (Tax-Adjusted) Cost } \\
\text { of Money, \%/Year : }\end{array}$ & 9.0 \\
\hline Inflation Rate, \%/Year & 5.0 \\
\hline Real Cost of Money, \%/Year & 3.81 \\
\hline Combined State and Federal Income Tax Rate, \% & 48.16 \\
\hline Property Tax Rate, \% of Capital Investment/Year & 2.0 \\
\hline $\begin{array}{c}\text { Interim Replacement Rate, } \% \\
\text { of Investment/Year }\end{array}$ & 0.05 \\
\hline Book Life, Year & 30.0 \\
\hline Tax Depreciation Duration, Years, TEFRA & 10.0 \\
\hline $\begin{array}{l}\text { Tax Depreciation Component, \% } \\
\text { of Investment }\end{array}$ & 83.74 \\
\hline Accounting Method & Normalized \\
\hline
\end{tabular}


Table 5-16

LEVELIZED BUSBAR GENERATION COST

January $1986 \$$

\begin{tabular}{|c|c|}
\hline Thermal Rating, $M W(t)$ & 1400 \\
\hline Net Electric Rating, $M W(e)$ & 537.6 \\
\hline Capacity Factor, \% & 80 \\
\hline Construction Schedule, Months & 36 \\
\hline Total Capital Cost, \$/million Btu & 1020.2 \\
\hline Fixed Charge Rate & 0.092 \\
\hline Levelized Annual Capital Cost, M\$/Year & 93.9 \\
\hline Levelized Fuel.Cycle cost, \$/million Btu & 1.11 \\
\hline Levelized Fuel Cycle Cost, M\$/Year & 37.2 \\
\hline Fixed O\&M Costs, M\$/Yeax & 34.8 \\
\hline Variable O\&M Costs, M\$/Year & 1.8 \\
\hline Decommissioning Cost Rate, $\$ / \mathrm{kW}(\mathrm{e})$ & 127.27 \\
\hline Total Decommissioning Cost, $M \$$ & 68.42 \\
\hline Levelized Decommissioning Cost, M\$/Year & 1.38 \\
\hline Total Revenue Requirements $M /$ Year & 169.08 \\
\hline Busbar Cost, Mills/kWh (e) & 45.0 \\
\hline Busbar Cost Components, mills/kwh(e) & \\
\hline Capital & 25.0 \\
\hline Fue1 & 9.9 \\
\hline O\&M & 9.7 \\
\hline Decommissioning & 0.4 \\
\hline
\end{tabular}


cycle cost given in Table 5-16 in terms of $\mathrm{M} \$$ /year is based on a net electric generation capability of $537.6 \mathrm{MW}(\mathrm{e})$ (i.e., an efficiency of 38.4 percent). This is the efficiency given in section 2.0 but is slightly different than the efficiency assumed in section 5.2 for calculating the fuel cycle mill/kWh(e) costs tabulated in Table 5-12. for the NOAK plant.

Decommissioning Costs. The decommissioning costs were determined using the default value of $\$ 127 / \mathrm{kW}(\mathrm{e})$ prescribed for use in Reference 5-2 when a specific decommissioning cost estimate is not available. It has been assumed that an external sinking fund of U.S. government securities earning 8.5 percent/year would be established over the operating life of the plant to accumulate the funds necessary for decomissioning. Here the operating life was assumed to be 30 years. The present worth of the decomissioning fund and the constant dollar levelized cost of decommissioning was determined using the formulations provided in Reference 5-2. The results are tabulated in Table 5-16.

The total annual revenue requirements is the sum of each one of the above components and the busbar generation cost is the revenue requirement sum divided by the annual electricity generation. The results are as given in Table 5-16. 


\subsection{COMPARISON WITH ALTERNATIVES}

Cost data for alternative power plants are presented in "Specific Guidelines for LMR and HTGR Cost Estimates", Reference.5-5. Of primary interest for comparison with the reference MHTGR NOAK costs are cost data determined using equivalent economic parameters for a comparably sized coal plant. Equivalent cost data for such a plant, a 560MW(e) single unit coal plant, are presented in the referenced Specific Guidelines. The coal plant data are based on the plant using mechanical draft wet cooling towers and having precipitators and wet limestone scrubbers. Other relevant plant characteristics and cost data are given in Table 5-17.

A comparison of the MHTGR reference plant busbar cost data with those for the reference 560MW(e) coal plant is given in Table 5-18. As can be seen, the MHTGR NOAK busbar costs compare very favorably with the coal plant costs. The conclusion can be reached that the MHTGR reference plant has a 15 to 18 percent economic advantage over a comparably sized coal plant alternative. This result complies with GCRA's Utility/User Requirements that the MHTGR have at least a ten percent economic advantage over a comparable coal plant alternative.

The coal plant busbar generation costs were developed in Reference 5-5 using a 70 percent capacity factor based on historical coal plant capacity factor data. Since the MHTGR busbar costs are based on an 80 percent capacity factor, the coal plant busbar costs assuming an 80 percent capacity factor are also given in Table 5-18. 
Table 5-17

\section{MW(e) COAL PLANT \\ (Costs in 1986\$)}

Plant Heat Rate

Plant Life

Total Plant Capital Cost

Annual O\&M Cost

Coal Cost
$9684 \mathrm{Btu} / \mathrm{kWh}$

30 yr

$1557 \$ / \mathrm{kW}(\mathrm{e})$

$24.6 \mathrm{M} \$ / \mathrm{yr}$

$\$ 1.75 /$ million Btu 
Table 5-18

MHTGR PLANT v8. COAL PLANT

Levelized Busbar Costs, mills/kWh(e)

January, $1986 \$$

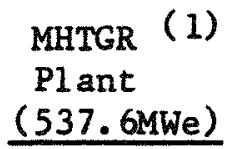

Capital Cost

O\&M Cost

Fue1

Decommissioning
25.0

9. 9

9.7

0.4

TOTAL
45.0
Coal (2)

Plant (560MWe)

23.8

7.2

7.2

24.2

0.0

0.0

24.4
Coal (3)

Plant (560MWe)

20.8 
SECTION 6

PLANT MAINTAINABILITY AND AVAILABILITY ASSESSMENT

\section{1 PLANT SCHEDULED OUTAGE ASSESSMENT}

Scheduled outages are a combination of maintenance outages, planned deratings, and planned outages. A planned outage is the removal of the plant from service for inspection and/or general overhaul of one or more major equipment groups. This work is usually scheduled well in advance (e.g., refueling, annual reactor system maintenance, 50,000 hour turbine overhaul). A maintenance outage is the removal of the plant from service to perform work on specific components which could have been deferred beyond the very next weekend but require that the unit be removed from service before the next planned outage. This is done to prevent a potential forced (unplanned) outage. The philosophy of derating a plant is to implement extended maintenance outage tasks which are intended to minimize or eliminate as many maintenance and forced outages and forced deratings as possible.

The scheduled outage frequency and durations for the $4 \times 350 \mathrm{MW}(t) \operatorname{MHTGR}$ concept can be used in combination with the forced outage study results to assess the overall plant equivalent availability factor.

Specific objectives of the scheduled outage assessment include:

- Identification of the optimum scheme for accomplishing the plant refueling (i.e., maintaining maximum availability)

- Determination of the historical duration and frequency of plant maintenance. outages

- Identification of typical types of maintenance and inspection activities that can be performed during the same outage 
- Integration of planned maintenance and inspection activities into an optimized overall plant outage schedule

- Identification of those areas of plant design which warrant close attention to design, operation, and maintenance in order to achieve maximum plant availability

The scheduled outage assessment indicates that the plant in the reference configuration described in this report will have a scheduled outage rate of 13.4 percent. This exceeds the unavailability goal of 10 percent for scheduled outages. Additional capital investment may be required to improve the scheduled outage. For example, the scheduled outage rate can be reduced to 12 percent by the addition of two fuel storage pools. These additional pools could probably be located between modules 2 and 3 . 


\subsection{PLANT FORCED OUTAGE ASSESSMENT}

Forced outages are due to an unplanned component failure or other condition which requires a module or the plant to be removed from service immediately, or up to and including the next weekend.

The current plant design has been assessed to have a forced outage rate of 8.9 percent per-year. All investment risk events (those causing outages of six months or greater) have not been evaluated at this time, but their total is expected to be less than one percent per-year, which is a plant goal. Therefore, the total unavailability due to plant forced outage and investment risk meets the ten percent per-year goal.

The plant forced outage assessment is based on individiual estimates of forced outage for each of the plants systems, by the cognizant participant. GA Technologies estimated the forced outage for the reactor system, Stone \& Webster for the turbine plant, and Bechtel National,. Inc. for the Nuclear Is land.

The major contributors to forced outage are the turbine generator, feedwater and condensate, heat transport and reactor systems. These systems contribute a total of 4.9 percent per-year, or about one-half the goal. 
The present plant layout has been reviewed from a constructability point of view and for fabricability and preassembly of the Nuclear Island (NI) components and systems to assure that the overall plant configuration is consistent with cost effective fabrication and construction.

Modular construction techniques have been used extensively in process plants and other industries to take advantage of the cost and efficiency of shop labor. The MHTGR which uses multiple identical subunits, and which is proposed as a standard design, represents an ideal application for extension of this techniques. The simplicity of MHTGR and the potential to largely shop fabricate it in standard modules for installation in a power plant provides unique opportunities to simplify site construction and improve cost and schedule.

Table 7-1 shows the manufacturing approach for the major systems and components. The approach is keyed to producing the required volume of hardware in the most cost and time effective manner consistent with nuclear quality. Table 7-2 shows the construction approach keyed to this manufacturing approach and based on the assumption that shop preassembly and modularization will result in sufficiently lower installation and construction costs at the site to overcome increased shop and manufacturing costs. A cost comparison study (Reference 7-1) for the shop fabrication of NI Cooling System modules showed that the offsite preassembly could result in 5 to 10 percent overall cost saving over the "stick built" approach used in the field. The study showed that some parts of the current MHTGR design are more suitable than others. Further, from a review of unrelated modular construction projects, the use of offsite preassembly introduced very early in the design and the utilization of specific design features was found to enhance the benefits from this construction approach. 
During the optimization phase of the conceptual design, the detailed approach should be developed for identifying each preassembled module, its contents, and a system developed for specification of the portions of systems contained in each module. 
Table 7-1

REFERENCE MANUFACTURING APPROACH

Area/System/Component

$\operatorname{Vesse1}(a)$

Steam generator

Shutdown cooling heat exchanger

Reactor internals : Metallic components
Manufacturing Approach

State-of-the-art welded pressure vessel fabrication utilizing formed plate stock for shell segments; ring forgings for large diameter flanges; and integrally reinforced (full penetration welded through the vessel wall) nozzles. Maximum automation of equipment to perform the forming, machining, welding, and nondestructive testing operations.

State-of-the-art helical coil bunde fabrication utilizing drilled radial tube support plates; full penetration tube-to-tube and tube-to-tubesheet welds; flow shrouds, flow distribution devices, etc. made from formed plate stock; and tubesheets made from machined forgings. Maximum automation of equipment to perform the tube coiling and bending, tube-to-tube and tube-to-tubesheet welding, tube installation, tube wear protection device installation, and nondestructive testing. Maximum automation of equipment- to perform the forming, machining and welding of shrouds, flow baffles, plena, etc. Installation of tube bundle in vessel prior to shipment.

Same as steam generator

Metal core support plate is fabricated from stainless steel segments supported by a steel built-up beam structure. Core exit plenum skirt is a weldment made from rolled plates attached to the core support plate as a shop preassembly.

The top cap, consisting of an upper core plenum skirt and a support plate, is fabricated from stainless steel in a manner similar to the core support plate and exit plenum skirt and is a shop preassembly.

Core lateral restraint is composed of 240 assemblies consisting of springs and keys, preassembled and attached by means of welded studs and pads to the reactor vessel inner surface in the shop.

(a) Inclusive of the Reactor Vessel and Closure Head; the Reactor Vesselto-Steam Generator Crossduct; the Steam Generator Vessel and Closure Head; and the Shutdown Cooling System Heat Exchanger Vessel and Connecting Duct. 
Table 7-1 (Cont'd)

Area/System/Component

Reactor internals:

Graphite components

Main hot gas duct components

Main helium circulator system

Plant protection and inst rumentation system

Helium purification and moisture

monitoring

systems

Core refueling and site fuel handling
Manufacturing Approach

Factory-machined and delivered to the reactor site in ready-to-assemble configuration. Manufacture of the graphite components is conventional machining of billets.

Two components shipped to site:

- Main duct with thermal barrier and expansion joints

- Flow distribution elbows

These systems will be fully preassembled. Each rod drive, motor, and reserve shutdown hopper will be shipped as an individual assembly and installed in penetrations in the reactor vessel head. Components will undergo acceptance testing prior to shipping as well as field checkout.

The synchronous variable speed electric motor, which operates in helium, is considered to be an advanced state-of-the-art design, and manufacturing technology will be developed accordingly. Mechanical components of the circulator will utilize conventional manufacturing technology. The impeller and drive motor will be shipped as a unit. The circulator and its auxiliaries will undergo acceptance testing prior to shipping as well as field checkout.

PPIS electronics components will be fully preassembled and will be "plug" compatible with any field wiring. Components will undergo acceptance testing prior to shipping as well as field checkout.

System components will be supplied as shop assembled modules.

At the time of this study, the design of this system was not sufficiently defined to consider fabrication or construction methods. Components will undergo acceptance testing prior to shipping as well as field checkout. 
Table 7-2

REFERENCE CONSTROCTION APPROACH

Area/System/Component

Site preparation

Silo st ructures

Other NI structures

Reactor Cavity Cooling System

Reactor module vessels and heat exchangers (including SCS) and reactor internals

Main hot gas duct components

Neut ron control system and reserve shutdown system
Construction Approach

Follow industry practice. For the reference site, excavate by auger with freeze wall groundwater barriers.

Install a light structural frame to which all rebar and embeds will be tied. Concrete placement to be by a single slipformed operation up to an elevation of -35 feet.

Use zone outfitted modules, where possible, to construct the NI.

. .

Install prefabricated cooling panels prior tó vessel installation.

For each module, installation of the reactor and steam generator components will occur in the sequence. A heavy-lift crane will be required for site handling of the major components.

After the steam generator has been set and welded to the outer crossduct, two components (horizontal duct assembly and flow distributor) will be received at the site and installed through the steam generator access opening).

These systems will be received fully preassembled and installed in penetrations in the reactor vessel head after the vessel is installed in the silo. Components will undergo acceptance testing prior to shipping and field checkout prior to and after installation. 
Table 7-2 (Cont'd)

Area/System/Component

Main helium circulator system

Plant protection, instrumentation, and other inst rumentation and control systems

Helium purification and moisture monitoring systems

Fuel handling, storage, shipping systems

Other NI Support Systems
Construction Approach

The main helium circulator system will be received on site in fully preassembled condition. The impeller and drive motor will be shipped as an individual assembly and installed in the steam generator vessel head at the site after the steam generator has been installed in the silo. The circulator and its auxiliaries will undergo acceptance testing prior to shipping and field checkout prior to and after installation.

Systems will be received on site as fully modularized, plug-in equipment. Modules will undergo acceptance testing prior to shipping, and field testing upon receipt and after installation.

Install and interconnect prefabricated modules, using minimal field labor. Install precast or prefabricated formwork for shielding, where required.

Received in field as ready to use components or shop assembled modules ready for installation.

Received in field as shop fabricated, pretested component assemblies, incorporated into zone modules. Hookup in field at zone interfaces, with minimum field labor. 
SECTION 8

SAFETY APPROACH AND ASSESSMENT

\section{1 OVERALL APPROACH TO SAFETY AND LICENSING}

\subsubsection{Philosophy}

The overall philosophy guiding the design of the Standard MHTGR is similar to that which has guided and continues to guide all reactor designs. This philosophy may be stated, in its simplest terms, as follows:

Produce a safe, economical plant design which meets NRC and user requirements by providing defense-in-depth through the pursuit of four goals:

1. Maintain Safe Plant Operation

Reliably maintain the functions necessary for normal plant operation, including the plant states of energy production, shutdown, refueling, and startup/shutdown operations.

2. Maintain Plant Protection

Assume that despite the care taken to maintain safe plant operation, failures will occur and proviae additional design features or systems to prevent plant damage.

3. Maintain Control of Radionuclide Release

Provide additional design features or systems to ensure containment of radionuclides in the event that normal operating conditions cannot be maintained and/or plant protection is not assured.

4. Maintain Emergency Preparedness

Maintain adequate emergency preparedness to protect the health and safety of the public in the event that control of radionuclide releases is not assured. 
With regard to the achievement of NRC criteria for the accomplishment of Goal 1 and 2 functions, measures are taken in the design of the Standard MHTGR, as they are in other reactor concepts, to minimize defects in the fuel and to purify the primary circuit of any radionuclides which do escape the fuel so that normal operational releases or any accidental releases of primary activity are low and worker exposures are minimized. These techniques have been proven to be effective in other gas-cooled reactors as has been demonstrated by measuring releases and work exposures from operating plants.

The unique aspect of the Standard MHTGR, however, is the approach which has been taken to achieve the functions of Goal 3. To accomplish this goal with high assurance, the design of the Standard MHTGR has been guided by the additional philosophy that control of radionuclide releases be accomplished by retention of radionuclides within the fuel particles with minimal reliance on active design features or operator actions. The overall intent here is to provide a simple safety case: that will provide high confidence that the Goal 3 safety criteria are met. There are two key elements to this philosophy which have had a profound impact on the design of the Standard MHTGR, especially in the selection of core size and geometry, power density, and vessel type; the basis for each element is described below.

First, the philosophy requires that control of radionuclides be accomplished with minimal reliance on active systems or operator actions. By eliminating the need to rely on active systems or operator actions, the safety case centers on the behavior of the laws of physics and on the integrity of passive design features. Arguments need not center on an assessment of the reliability of pumps, valves and their associated services or on the probability of an operator taking various actions, given the associated uncertainties involved in such assessments.

Second, the philosophy requires control of releases by the retention of radionuclides within the fuel particle coating rather than reliance on secondary barriers (such as the primary coolant boundary or Reactor Building). The judgment made here is that the proof of containment is dramatically simplified 
if arguments can center on issues associated with fuel particle coating integrity alone, without having to make a case for additional barriers after core integrity is lost.

The following sections describe the method which has been employed to ensure the consistent incorporation of this safety philosophy into the design.

\section{1.2 Licensing Approach}

The approach to safety for the Standard MHTGR has been applied in a "topdown" fashion as illustrated in Figure 8-1. The process begins with the quantification of top-level criteria pertaining to how well each of the four Goals defined in the previous section is to be achieved. Next, an integrated systems engineering approach is systematically applied to develop the functions, requirements, and specific design selections necessary to achieve, in a balanced fashion, all of the Top-Level Regulatory Criteria (Reference 1-5) and user requirements. The product of this Integrated Approach is the plant design described in this document.

As an adjunct to this process, a set of specific licensing bases for the Standard MHTGR has been derived as represented in Figure 8-1 by the box labeled "bridge". The bridge is the method by which those regulatory bases for the design as implemented in the Integrated Approach design process are cast in a framework and format similar to the traditional licensing bases applied to current generator LWRs. The licensing bases include the licensing basis events which demonstrate the design's compliance with the Top-Level Regulatory Criteria, the principal design criteria, which specify how the Standard MHTGR will meet the Top-Level Regulatory Criteria, and the classification of equipment that can be assured to respond to the events in the manner specified to meet the Top-Level Regulatory Criteria. The method employed to derive this licensing basis is described in section 3.2 of the PSID (Reference 1-4). 


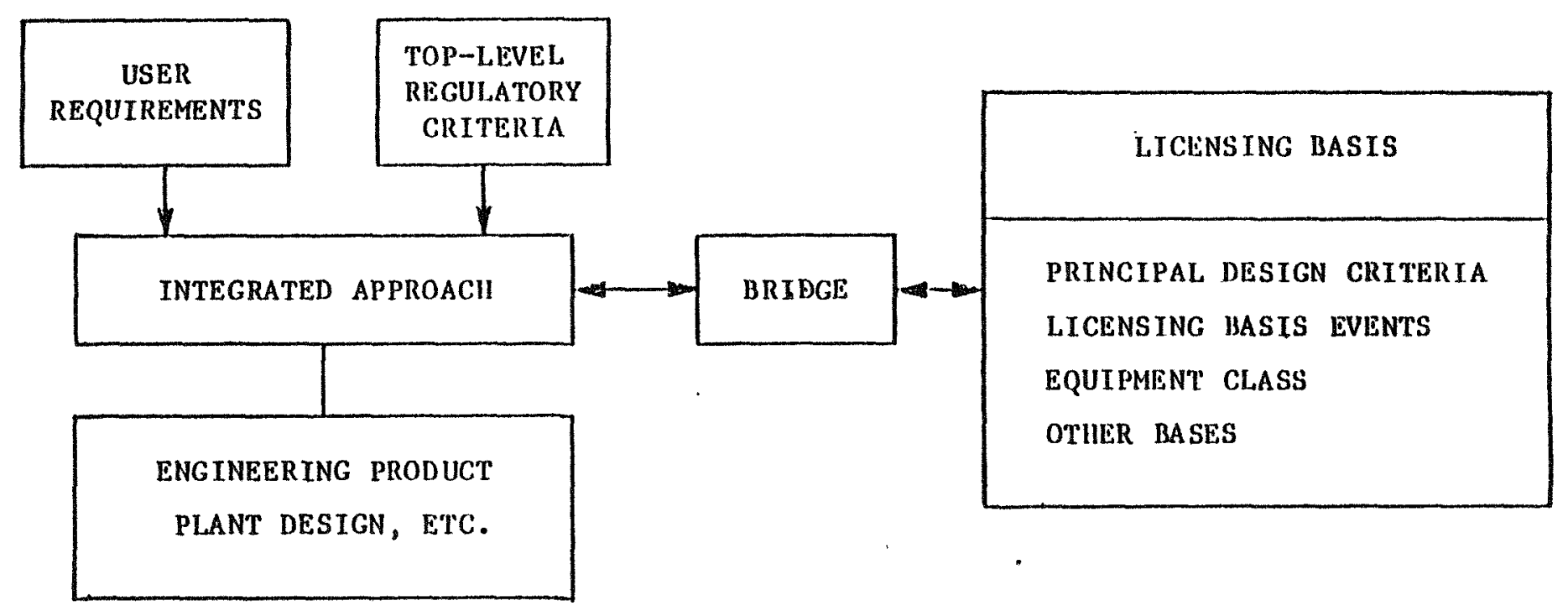

Figure 8-1 Standard MHTGR Design and Licensing Approach 


\subsection{SEISMIC ASSE SSMENT}

The Standard MHTGR has been seismically analyzed for an OBE of $0.15 \mathrm{~g}$, and an SSE of $0.3 g$, considering a range of soils with shear wave velocities $\left(V_{s}\right.$ ) ranging from 305 to $2,438 \mathrm{~m} / \mathrm{s}(1,000$ to $8,000 \mathrm{ft} / \mathrm{sec})$. A parameter screening study (Reference 8-1) was first performed with the CLASSI computer code to ascertain the subsurface conditions which would produce the largest seismic response in selected reactor module components. On the bases of this study, the following subsurface conditions were selected for further study with the SASSI computer code:

1. A uniform rock site with $V_{s}=2,438 \mathrm{~m} / \mathrm{s}(8,000 \mathrm{ft} / \mathrm{sec})$, as it controls the design in the rigid range of the spectrum (frequencies $33 \mathrm{~Hz}$ )

2. A linearly varying soil profile from $V_{s}=335 \mathrm{~m} / \mathrm{s}(1,100 \mathrm{ft} /$ $\mathrm{sec})$ at grade to $\mathrm{V}_{\mathrm{s}}=762 \mathrm{~m} / \mathrm{s}(2,500 \mathrm{ft} / \mathrm{sec})$ at a depth of $47.5 \mathrm{~m}$ ( $156 \mathrm{ft})$ and then constant below, since this case represents the maximum linear rate variation of soil properties over the silo length based upon available site data for. the ten representative sites considered. Furthermore, this soil profile controls the spectrum responses for certain NSSS components in the range of 4 to $11 \mathrm{~Hz}$.

3. A saft soil with $v_{s}=335 \mathrm{~m} / \mathrm{s}(1,100 \mathrm{ft} / \mathrm{sec})$ down to $22.9 \mathrm{~m}$ $(75 \mathrm{ft})$ below grade overlaying rock with $\mathrm{V}_{\mathrm{S}}=2,438 \mathrm{~m} / \mathrm{s}$ $(8,000 \mathrm{ft} / \mathrm{sec})$, as it may produce the limiting conditions for silo design and for its potential for causing rocking effects.

The above selected cases are, to a large degree, specific to the current design of the reactor vessel and steam generator support system. It is likely that, by changing the stiffness of these components and their supports, the controlling subsurface conditions may change somewhat. However, the three cases selected should provide a sound basis for developing the enveloping floor response spectra required for the design of reactor module components. For the OBE loading, a single spectrum is developed at each node for several damping values which envelope the range of soil cases considered. This is done to simplify the analysis and qualifications of systems and components which must fulfill, with a high degree of confidence, 10CFR100-related radio-. 
nuclide control functions under design basis conditions. Based on initial seismic analyses performed for a reactor silo, the vessel system (including supports) and the reactor core with core supports, the following conclusions can be drawn:

A $0.9 \mathrm{~m}$ ( $3 \mathrm{ft}$ ) thick concrete silo is structurally adequate with reasonable reinforcing steel. However, the results of the response spectrum analysis indicate that the reactor vessel peak horizontal acceleration at the controlling core restraint point exceeds the stated allowable (Reference $8-2$ ). This result is corroborated by a concurrent time history analysis of the core (Reference 8-3) which shows unacceptably high core loads with the present reactor module vessel design. In addition, even though the general stresses in the vessels are quite low and should present no problems, some local stresses at the vessel attachment interfaces are very high. These excessive responses appéar to be caused by insufficient vessel and attachment stiffness at the vessel restraint locations. It is expected that increasing the vessel wall thickness at these locations and strengthening the attachments will reduce the seismic responses to acceptable levels.

Evaluation of the core and reactor internal components indicates that, after slight modifications to the reactor vessel, the seismic loads at the OBE or SSE level will not cause damage to prevent either safe operations or safe shutdown of the reactor. The plant seismic analysis gives SSE response spectrum design loads of approximately $1.0 \mathrm{~g}$ horizontally and $0.5 \mathrm{~g}$ vertically for the reactor core and core support structures. Preliminary analyses show that these load levels do not induce excessive stresses in the fuel or replaceable reflector elements which, when combined with thermal and irradiation stresses, must satisfy limits for preventing excessive cracking or separation fracture of these elements. Similarly, the permanent reflector blocks and core support blocks and posts satisfy the design limits with generally larger margins compared to 
the core elements. Stresses due to SSE loads accomodated by the metallic core support structures, including the core barrel/key restraints and the core support plant structure, are shown to be well below material strength limits for providing excessive core deflections and core collapses. Consequently, the core and reactor internal design gives assurance that a coolable core geometry is maintained at all times and control rods and reserve shutdown materials can be inserted into the core when required.

Thus, with minor modifications to the present design of the reactor vessel, it is anticipated that the Standard MHTGR can be demonstrated to perform its intended functions during seismic events up to and including the SSE.

When a specific site is identified, a site-specific seismic analysis would most likely be performed, culminating in preparation of floor response spectra (FRS). These will be compared with the Standard MHTGR FRS to assure that the site-specific FRS are-bounded by the standard FRS. Tnis is discussed in greater detail Reference 8-4. 


\section{3 SAFETY ASSE SSMENT}

The MHTGR design has been analyzed to demonstrate its compliance with the TopLevel Regulatory Criteria and Utility/User Requirements for events occurring in the design basis region. Specifically addressed is the adequacy of the design to perform the functions necessary to control accidental radioactivity releases to within the offsite dose limits of 10CFR100 (Regulatory Criteria) and within the EPA's Protective Action Guide (PAG) limits (Utility/User Requirements). To accomplish this, a set of "bounding" design basis events (DBEs) is evaluated considering the mechanistic response of the entire plant. These events encompass the important physical phenomenon which are not expected to occur in the lifetime of a single MHTGR plant, but would be expected to occur at least once in the lifetime of several hundred MHTGR plants. Also analyzed are the non-mechanistic limiting design conditions which are labeled safety-related design conditions (SRDCs). The SRDCs are established by analyzing the DBEs without taking credit for the mitigating effect of any system not designated as safety-related.

As discussed in Section 8.1, the safety approach taken in the design of the Standard MHTGR relies on the coated fuel particles for fission product containment. Thus, assuring that the safety criteria are met is the same as assuring that the retention capability of the coated fuel particles is not compromised. Three functions have been identified which, when accomplished, assure that radionuclide retention within the fuel remains acceptable:

1. Control Heat Generation

2. Remove Core Heat

3. Control Chemical Attack

While all these functions must be performed at all times, the DBEs and SRDCs can be thought of as representing limiting challenges to these functions. The limiting events analyzed in the PSID for each function and the resulting consequence is summarized in the following sections. 


\subsubsection{Control Heat Generation Events}

Two key events are considered in the PSID with regard to the ability to control heat generation. The first involves a loss of the normal cooling path using the Heat Transport System (HTS) without a control rod trip (such an event is commonly referred to as an anticipated transient without scram or ATWS) and the second involves a control rod withd rawal.

The function of controlling core heat is challenged in the first event when, with the reactor initially at 100 percent power, the HTS experiences a transient which causes it to trip. Outer control rod insertion, which normally results automatically from a loss of the HTS, fails. Additionally, as the limiting SRDC, the shutdown cooling system is assumed to fail. Thus the reactor is postulated to undergo a complete loss of forced circulation without scram. The loss of forced circulation while the reactor remains at full power results in a core temperature rise which, in turn, causes the reactor to become subcritical owing to its negative temperature coefficient. At 56 seconds after the initiating event, the $\mathrm{Plant}$ Protection and Instrumentation System (PPIS) releases the reserve shutdown control material into the reactor core as a result of core power-to-circulator speed ratio being above its trip point for more than fifty seconds. At that time, core power has already been reduced to 33 percent by the inherent negative temperature feedback. Following insertion of the reserve poison material, reactor power falls rapidly to decay heat levels.

The gradual heatup of the core in this event produces a peak maximum core temperature of $1,296^{\circ} \mathrm{C}\left(2,364^{\circ} \mathrm{F}\right)$ after some 95 hours. The rapid initial heatup causes the system pressure to peak at 1,009 psia which is below the relief setting of 1,041 psia. Since the Reactor System remains pressurized with the primary coolant boundary intact and temperatures stay well below the threshold for fuel particle failure, no radioactivity is released from the vessel, and no offsite dose occurs. 
The function of controlling core heat is also challenged by the second event. For this event, the spurious uninhibited withdrawal of an outer reflector control rod group (consisting of three rods) at their maximum withdrawal speed without reactor power setback results in a reactivity transient producing excess power above normal levels and increased core temperatures. As core temperatures increase, the reactivity defect due to temperature becomes more negative and thus mitigates the reactivity increase caused by the rod group withdrawal. Heat generation is brought under full control when at 99 seconds the reactor trips on high core power ratio of 1.5 . The peak power level reaches only 147 percent at about 100 seconds as shown in Figure 8-2.

The heatup of the core in this event leads to a peak temperature of only $1,394^{\circ} \mathrm{C}\left(2,541^{\circ} \mathrm{F}\right)$, well below the threshold for fuel particle failure. Additionally, the primary system integrity is maintained and thus there is no offsite dose.

\subsubsection{Remove Core Heat Events}

The limiting event analyzed in terms of challenging the remove core heat function is a depressurization accident with failure of all forced cooling systems. For this event, a 12.7 square inch leak is assumed located in the pressure relief train depressurizing the primary system in some minutes. At 20 seconds, the reactor trips on a low-pressure signal. Although the Shutdown Cooling system is designed to cool the core following this event, it is assumed to fail. Thus, heat is removed from the core in this event only by radiation and conduction to the reactor vessel. In turn, heat is removed from the vessel by the passive Reactor Cavity Cooling System.

The thermal transient experienced by the core is shown in Figure 8-3. The core temperature reaches a peak of slightly over $1,600^{\circ} \mathrm{C}\left(2,912^{\circ} \cdot \mathrm{F}\right)$ in approximately 80 hours after the loss of forced circulation. Beyond this point, the core heat removal rate exceeds the afterheat-generation rate resulting in a slow cooldown of the core. 


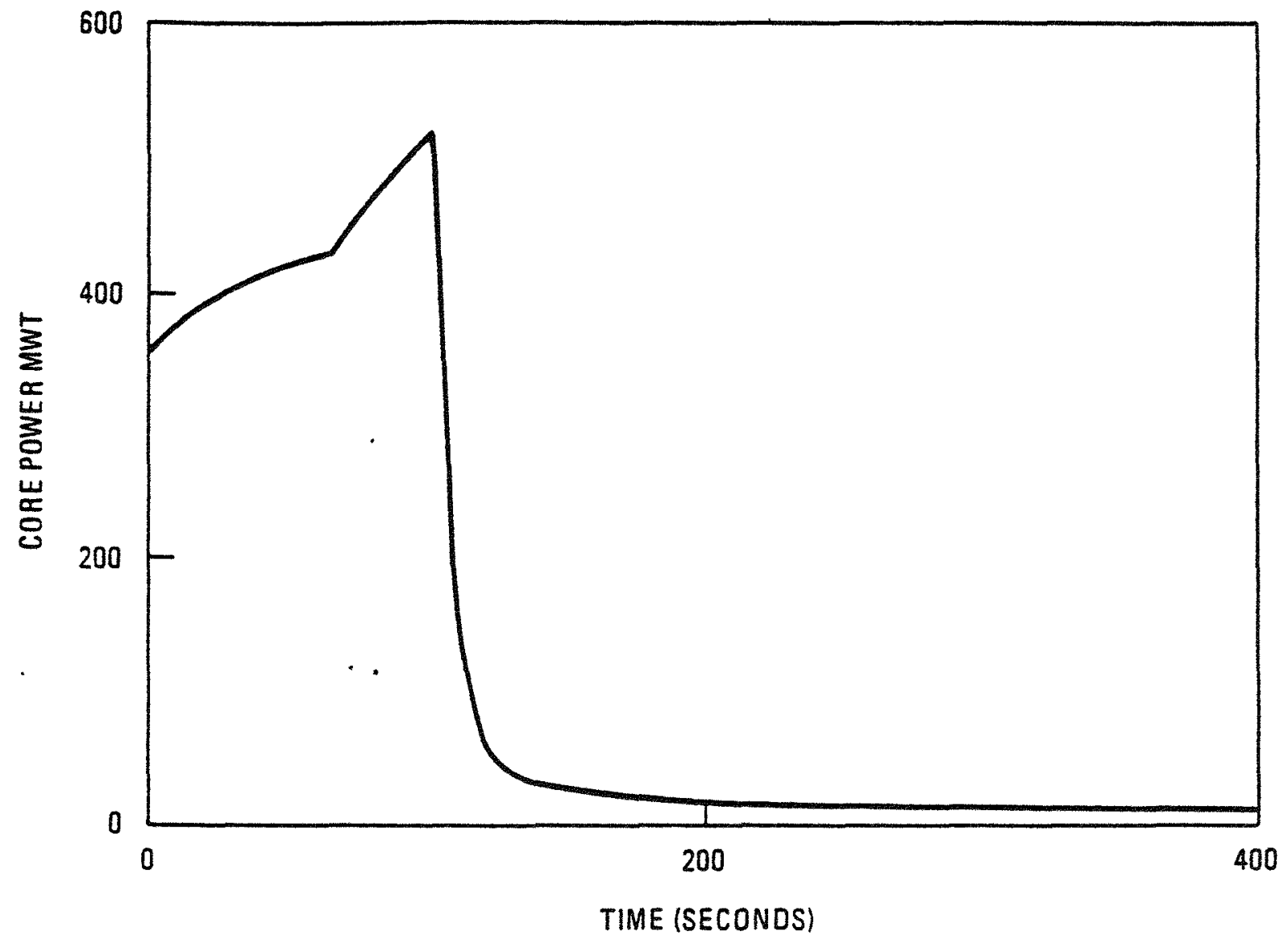

Figure 8-2 Core power during control rod withdrawal without HTS and SCS cooling 
TIME (DAYS)

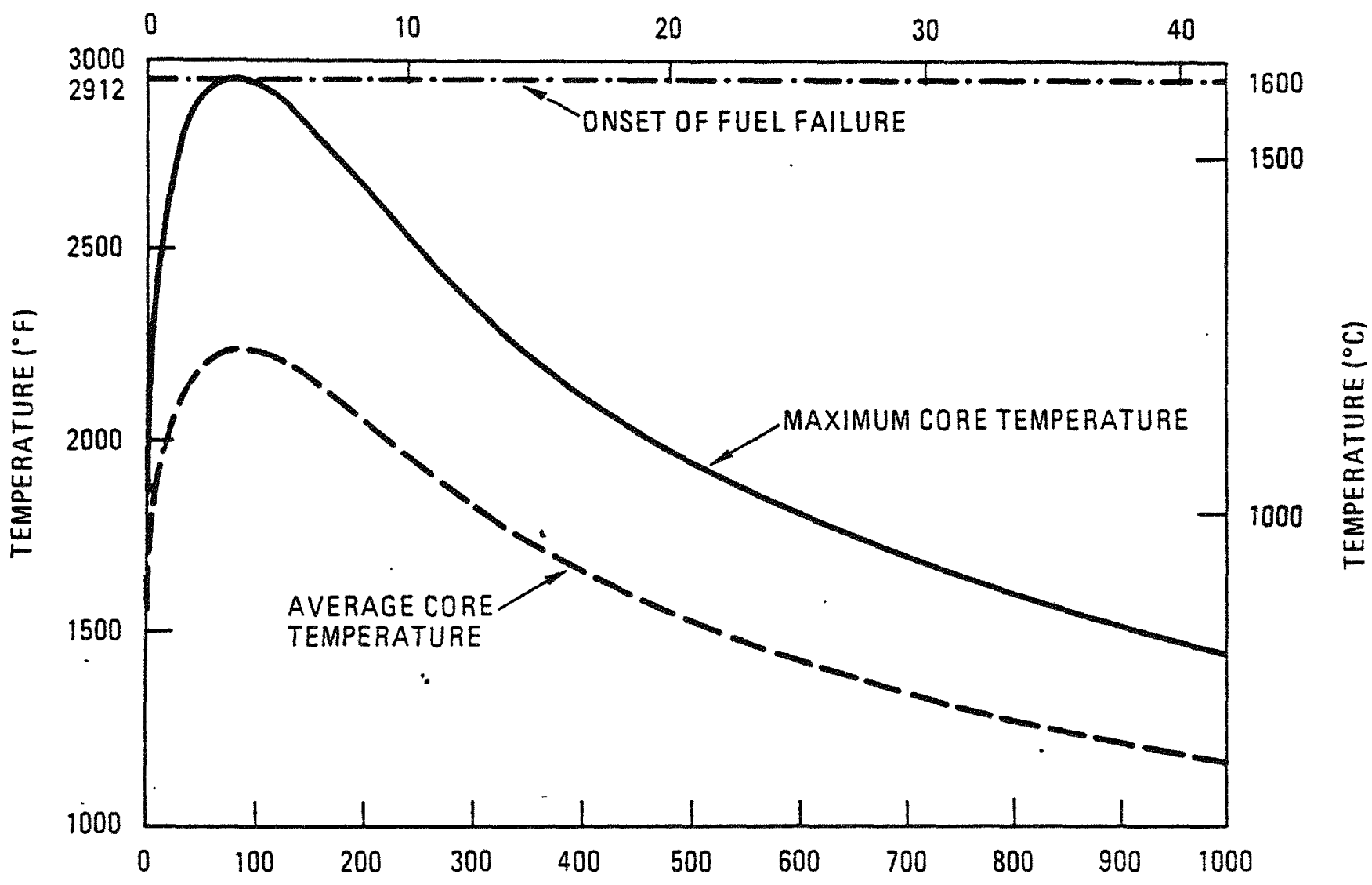

TIME PAST LOSS OF FORCED CIRCULATION (HOURS)

Figure 8-3 Maximum and average core temperatures during a depressurized conduction cooldown with primary coolant leak 
For this event the core does heat up to a point at which some incremental fuel particles fail and the event initiator causes a loss of primary boundary integrity, so that there is a small release of fission products to the Reactor Building and to the environment. The limiting radionuclide in this release is calculated to be Iodine-131; approximately 150 curies of I-131 are assessed to be released from the core and approximately 25 curies of this are assessed to be released from the vessel to the environment. The resulting offsite dose to the thy roid is conservatively assessed to be $.36 \mathrm{rem}$, we 11 within the $10 \mathrm{CFR} 100$ limit of 300 rem and within the PAG limit of 5 rem.

\subsubsection{Control Chemical Attack Events}

The limiting event analyzed in the PSID with regard to controlling chemical attack is a depressurized conduction cooldown with a moisture ingress. This event is postulated to be initiated by a break in a single steam generator tube resulting in a water ingress to the primary system. Reactor trip is provided by high power-to-flow ratio as a result of power increase due to the positive reactivity effect of the moisture. The detection of the moisture inleakage by the moisture monitor system is ignored, because it is not a safety related system. As the water ingress continues, primary system pressure increases until the reserve shutdown control material is inserted due to a high pressure signal. At the same time, the main loop and steam generator are automatically isolated on high pressure. However, the steam generator dump system is assumed to fail to empty the remaining contents of the steam generator and further the Shutdown Cooling System is assumed to fail to start (neither system is classified as safety-related). Thus even after steam generator isolation, steam continues to enter the primary system until the pressure in the steam generator equilibrates with primary system pressure. As a result, some $9,000 \mathrm{lbm}$ of steam enters the primary system.

Because of the overpressure condition, the primary relief valves open some 370 seconds into the accident. The relief valve is assumed to cycle open and close several more times maintaining primary pressure below the relief set- 
point of 1,041 psia, until finally the relief valve fails open, depressurizing the primary system. At this point the system enters into a depressurized conduction cooldown such as was described in the previous section.

The moisture in the primary system in this case, however, is available to chemically attack both the graphite and the fuel. Reaction of the graphite occurs mainly in the hotter bottom half of the core; however, not enough oxidation occurs to result in any structural concerns. Additionally, a fraction of the fuel particles which have defective fuel coatings, and thus fuel kernels exposed to the steam environment, undergo fuel hydrolysis and liberation of fission products.

For this event the core heats up to a point at which some incremental fuel particles fail; additionally fission product release occurs due to fuel hydrolysis, and since the event initiator involved a loss of primary boundary integrity, there is a release of fission products to the Reactor Building and to the environment. The limiting radionuclide in this release is calculated to be Iodine-131; some 50 curies of this are assessed to be released from the vessel to the environment. The resulting offsite dose to the thyroid is conservatively assessed to be $3.8 \mathrm{rem}$, well within the 10 CFR 100 limit of 300 rem and within the PAG limit of 5 rem.

\subsubsection{Assessment Summary}

In sumnary, the PSID accident assessment considers a wide range of events threatening the successful accomplishment of the key safety functions necessary to maintain the integrity of the fuel particles. Based upon reliance only on fail safe, self-powered components (control rods, relief valves, steam generator isolation valves) and inherent features (radiation, conduction, natural circulation, negative temperature reactivity feedback), the assessments show that these accidents can be accommodated by the MHTGR design without exceeding the accident limits of $10 C F R 100$ or the evacuation/sheltering limits of the Protective Action Guidelines. 


\subsection{PROBABALIST IC RISK ASSESSMENT}

A Probabalistic Risk Assessment (PRA) of the Standard MHTGR has been performed. The results of this safety assessment show the MHTGR to behave in an extraordinarily benign manner with only limited offsite releases predicted during even extremely unlikely accidents. The concept is shown to comply with the risk limits of the NRC Safety Goals (Reference 8-5) and to do so with a substantial margin. The MHTGR is even shown to satisfy the very stringent user-imposed requirement of no need for public sheltering or evacuation based on the Protective Action Guideline (PAG) doses for emergency planning (Reference 8-6).

The basis of this safety assessment is the preconceptual design as presented in the PSID. The assessment scope included frequency and consequences for a wide spectrum of events with frequencies greater than once in ten million years. The assessment considered both events in which the system failure probabilities are not strongly coupled (e.g, loss of main loop cooling) and two of the-most important external events (loss of offsite power and earthquakes) in which the initiating event can simultaneously threaten multiple plant systems.

The methodology employed included the standard features of a PRA: initiating event selection, event tree construction, fault tree, common mode failure, and uncertainty analyses leading to sequence probability quantification; and transient, radionuclide transport, dose, and uncertainty analyses leading to sequence consequence quantification. An important element of the initiating event selection is the use of a master logic diagram that utilizes inductive logic to assure completeness. The data bank employed draws upon LWR and nonnuclear power plant as well as gas-cooled reactor experience. The Beta Factor method utilized for the assessment of common mode failures compensates for the lack of sufficient design detail to explicitly model system interactions. The event tree quantification appropriately utilizes the fault tree probabilities by accounting for conditional probabilities. The transient radionuclide transport analyses considers the physical phenomenon and the timing specific 
to the MHTGR. For both the sequence frequency and consequence quantification Monte Carlo uncertainty propagation techniques are employed.

The principle objectives of the PRA were as follows:

1. Provide a means of characterizing the safety of the MHTGR such such that the concept design can be evaluated in a logical fashion.

2. Provide the basis from which to select the MHTGR licensing basis events ( $L B E^{\prime} s$ ) evaluated in the PSID.

3. Evaluate the MHTGR risk to the public to show compliance with the NRC safety goals.

4. Evaluate a wide spectrum of events with offsite consequence to show compliance with PAGs at the site boundary.

The assessment of plant safety documented in the PRA, in considering a broad range of accidents covering both a cross section of initiating events and an extreme frequency spectrum, shows the MHTGR to display an exceptionally high level of safety. By virtue of its high reliance on passive features inherent in this small HTGR, the overall safety of the concept is shown to be relative$1 y$ insensitive to failures in active systems or errors in operator actions.

Furthermore, the assessment supports the underlying approach to safety that has been taken with the MHTGR. This approach focuses on assuring retention within the high temperature ceramic HTGR fuel to prevent the gross release of fission products. Throughout the assessment, no accident scenarios of meaningful probability were identified that could compromise the fuel and lead to such a release. Rather, the accident scenarios identified all relate to releasing only some portion of the fission product inventory associated with the very small fraction of fuel that is defective in its fabrication. As a 
result, despite the range of frequencies considered in the assessment, none of the releases identified would be sufficient to cause any measurable health effect in the population surrounding the plant.

A review of the dominant accident sequences leads to the notable observation that the risk attributable to the MHTGR, small as it is, largely results from the failure of passive components rather than failures in active or powered systems. For example, the assessment shows the highest risk scenarios to result from leakage of primary coolant as a result of failures in the primary pressure boundary. In contrast, accident scenarios initiated by loss of forced cooling or loss of offsite power contribute essentially nothing to plant risk. This characterization of the dominant risk contributors is a direct result of the high reliance placed on passive features in the MHTGR design. Thus, by eliminating or reducing the number of active systems whose failure can lead to fission product release, accident frequency is reduced, plant risk is reduced and the remaining release scenarios tend to involve failures in passive equipments.

The operators contribution to risk is also seen to be reduced in the MHTGR. In general, no operator actions are required in response to accidents. The various features of the plant are sufficient to assure that no or only small releases will occur. Where operator actions can help further mitigate accident consequences, the passive safety and longer thermal response time in the MHTGR design provide the operator considerable time, resulting in a high likelihood of successful action.

Two design goals against which the adequacy of the MHTGR safety, as quantified here, is measured are: the calculated dose limits at which the Protective Action Guides (PAG) recommend public sheltering and, the NRC Safety Goal limits on public risk due to nuclear power plant operation. The ability of the MHTGR to meet these goals is discussed below. 


\subsubsection{Quantification of Risk}

The safety risk for the MHTGR is a function of the frequency of occurrence and the consequence to the public of various accidents examined in this assessment. Quantification of that risk is performed by combining the accident frequencies and their uncertainties with the consequences and their uncertainties.

Mean risk is defined as the product of mean frequency and consequence. One method of interpreting the risk assessment results is to find this product for each of the different accident categories considered, sum the individual risks, and view the result as a single expectation value for plant risk. This approach, while having certain limitations, is simple and is necessary if the plant is to be compared against risk limits such as are included in the NRC Safety Goals. Such a treatment of mean risk has been done for the MHTGR and shows that, measured at the exclusion area boundary (EAB), the total mean risk is $4.7 \times 10^{-4}$ rem. per year whole body and $1.7 \times 10^{-3}$ rem per. year thy roid.

The complementary cumulative distribution curve of frequency versus consequence (typically called a risk curve or envelope) is a second method used to display risk assessment results. At at a glance, it shows the likelihood of having an accident with a consequence beyond some severity of interest. Because of this, it is a useful tool for showing how the plant compares when measured against a frequency dependent consequence (dose) design goal. Furthermore, while total plant risk is not explicitly plotted, the curve can be used to quickly identify the major contributors to that total risk. This differs from the approach described above because mean risk signifies what is expected to occur when considered on an annualized average basis. This average, though, does not necessarily correspond to any real accident scenario. In contrast, here doses that would result from specific accident scenarios, despite their being unlikely, can be seen.

Complementary cumulative frequency curves represent a combination of the mean 
frequency, based on probability distributions obtained from the frequency assessment, and the complementary cumulative consequence distribution obtained from the consequence uncertainty analysis. These curves display the frequency per plant year of exceeding a specified level of accident consequence.

Figures 8-4 and 8-5 are two such dose curves showing the total probability of exceeding specified doses considering all release categories evaluated in the assessment. The two curves depict whole body gamma and thyroid dose consequences, respectively. In addition, these first figures also show how the sum of the release categories, grouped into four major accident types, make up the total envelope.

\subsubsection{Comparison with PAG Dose Limits}

A design requirement imposed by the user on the MHTGR is to ensure that potential accidental releases are below regulatory criteria without taking credit for public sheltering or evacuation. Hence, the MHTGR is designed so that emergency planning will not be required beyond the 425 meter site exclusion area boundary (EAB) (Reference 1-3). As a part of meeting this requirement, the PRA is used to demonstrate that the frequency of a release that would result in a dose (measured at the EAB) in excess of the PAG that would trigger shelter of the surrounding is less than $5 \times 10^{-7}$ per year of plant operation. The PAG for sheltering is specified as being 1 rem whole body and 5 rem thy roid.

Referring to Figures $8-4$ and $8-5$, the MHTGR's compliance with the user-imposed MHTGR requirement can be readily verified. Viewing Figure $8-4$, it can be seen that an accidental release which would result in a calculated whole body gamma dose at the EAB in excess of the 1 rem PAG limit is not predicted to occur even as rarely as $5 \times 10^{-7}$ per year. Likewise, Figure 8-5 shows calculated thyroid doses to also fall within allowable limits for any release predicted to occur within the range of the probabilities of interest. 


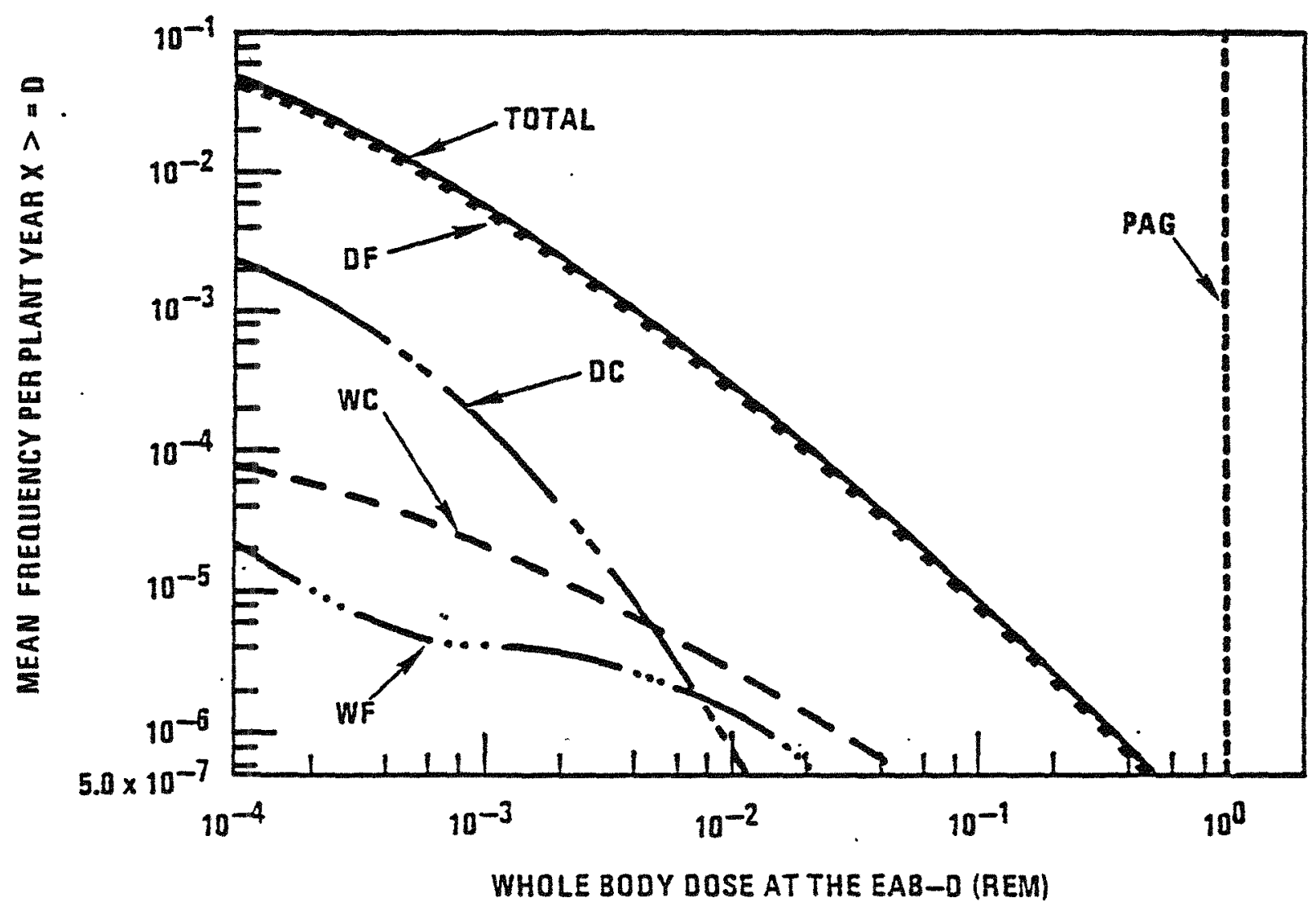

Figure 8-4 Cummulative frequency for whole body dose from all release catagories 


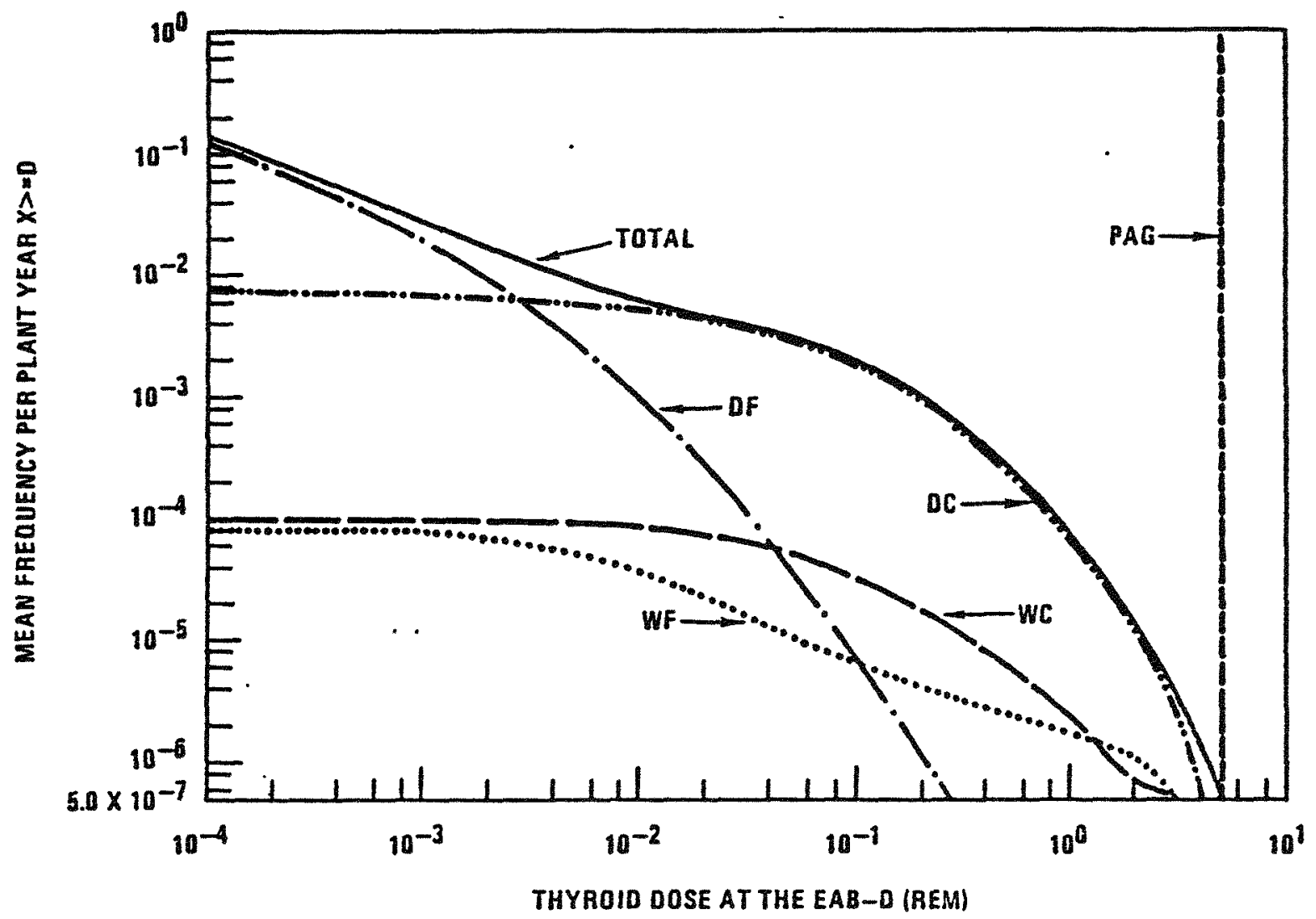

Figure 8-5 Cummulative frequency for thyroid dose from all release catagories 


\subsubsection{Comparison with Safety Goals for the Operations of Nuclear Power Plants}

The NRC has established Safety Goals with the objective to define an acceptable level of radiological risk from nuclear power plants that was not a significant increase over other societal risks. Two quantitative health effect objectives are stated that can be used to determine whether the NRC qualitative safety goals are met:

- The risk to an average individual in the vicinity of a nuclear power plant of prompt fatalities that might result from reactor accidents should not exceed one-tenth of one percent $(0.1$ percent) of the sum of prompt fatality risks resulting from other accidents to which members of the U.S. population are generally exposed.

- The risk to the population in the area near a nuclear power plant of cancer fatalities that might result from nuclear power plant operation should not exceed one-tenth of one percent $(0.1$ percent) of the sum of cancer fatality risks resulting from all other causes. Based upon Reference 8-11, this limit corresponds to a latent fatality risk of $1.9 \times 10^{-6}$ per year.

An "average individual" is defined in Reference 8-8 as the "average individual biologically (in terms of age and other risk factors) and locationally who resides within a mile from the plant boundary." In Reference 8-5, it is suggested this risk be calculated by accumulating the individual risks to persons residing in the vicinity of the plant and dividing by the number of individuals residing in the vicinity of the plant. For evaluation of the prompt fatality risk criterion, the NRC suggests that since individuals within a mile of the plant boundary would be subject to the greatest risk, if there are no individuals within a mile of the plant, an individual should be assumed to reside one mile from the boundary. In applying the latent fatality criterion, the Comnission suggests that the population within 10 miles of the 
site be considered.

Instead of averaging the latent cancer fatality risk over a number of individuals exposed in a region near the plant boundary, this assessment has conservatively evaluated the total plant risk as the exposure to a theoretical individual who remains at the EAB throughout the accident. Although the exposure to an individual at the EAB is obviously higher than the exposure to an "average individual" within a one to ten mile radius (the suggested method to illustrate compliance with the Safety Goals in Reference 8-5) or even to the individual most at risk at one mile from the site boundary (as suggested by Commissioner Gilinsky as a more appropriate Safety Goal in Reference 8-11), the fact that the MHTGR risk to an individual at the site boundary satisfies the Safety Goals guarantees compliance with these limits.

Illustrating compliance with this goal, the risk due to whole body gamma exposure in rem was converted to fatality risk by applying a linear, low dose response model conversion factor of 1.2 rem per 10,000 man-rem exposure (Reference 8-8). The thyroid exposure risk in rem was converted to a latent fatality risk by applying another linear, low dose response model conversion factor of 1.34 thyroid cancers per 10,000 man-rem exposure in conjunction with a 0.1 factor corresponding to the assumption that ten percent of all cancerous thyroid nodules will result in a fatality (Reference 8-8). The latent cancer fatality risk corresponding to operation an MHTGR plant was then computed to be as follows:

- From whole body exposure the incremental additional risk to an individual is $5.6 \times 10^{-8}$ fatality risk/year and,

- From thyroid exposure the incremental addition to individual risk is $2.2 \times 10^{-8}$ fatality risk/year

These risks were then summed to obtain a latent fatality risk of $7.8 \times 10^{-8}$ per year. This risk is over twenty times smaller than the NRC Safety Goal for 
latent fatality risk $\left(1.9 \times 10^{-6}\right.$ fatality per risk year). Hence, it is expected that the risk to an "average individual" within a one to ten mile radius would be well within the latent fatality limit suggested in the Safety Goals.

No acute fatality risk is predicted for the MHTGR because the doses for any given accident are well below doses (around 300 rem, assuming supportive treatment is provided) where acute fatalities are observed (Reference 8-8).

The results from this risk assessment have been applied to illustrate that the MHTGR will easily comply with the quantitative limits suggested in the NRC Safety Goals. By satisfying these criteria, it is expected that the MHTGR would not provide any significant increase to the public over other societal risks, which in the objective of the NRC Safety Goals. 
ferinces $1-2,1-4,1-8,8-1,8-4,8-7$ himoved.

\title{
REFERENCES
}

\author{
Reference \\ Number \\ 1-1 "Concept Description Report, 4 × $350 \mathrm{MW}(t)$ Side-by-Side, Steel \\ Vesse1, Prismatic Core Concept", HTGR-85-142, Bechtel Group, \\ Inc., October 1985. \\ 1-3 "Utility/User Design Requirements for Modular High Temperature \\ Gas-Cooled Reactor Plants", GCRA-86-002 (Revision 2), Gas-Cooled \\ Reactor Associates, September 1986. \\ 1-5 "Top-Level Regulatory Criteria for the Standard HTGR", HTGR-85- \\ 002 (Revision 1); GA Technologies, Inc., June 1985. \\ 1-6 "An Integrated Approach to Economica1, Reliable, Safe Nuclear \\ Power Production", Alo-1011, Combustion Engineering, Inc., June \\ 1982. \\ 1-7 "Functional Analysis Report, Standard Modular HTGR Plant", HTGR- \\ 86-002 (Revision 1), GA Technologies, Inc., September 1986. \\ 4-1 "Constructibility/Fabricability/Preassembly Assessment", HTGR-85- . \\ 141, Bechtel Group, Inc., September 1985. \\ 5-1 Letter, W. R. Sheridan (SWEC) to L. D. Mears (GCRA), SWEC/GCRA- \\ 0391, "Cost Estimating Plan", dated June 19, 1986. \\ 5-2 Hudson II, C. R., "Cost Estimate Guidelines for Advanced Nuclear \\ Power Technologies", ORNL/TM-10071, July 1986. \\ 5-3 "FY86 Fuel Cycle Economic and Unit Cost Assumptions for Standard \\ MHTGR Alternative Cycle Designs", HTGR-86-092 (Document No. \\ 908991), August 1986.
}


REFERENCES (Cont'd)

Reference

Number

5-4 "Nuclear Energy Cost Data Base - 1986, A Reference Data Base for Nuclear and Coal-Fired Power Plant Generation Cost Analysis", DOE/NE-0044/4, U.S. Department of Energy, December 1985 (draft).

5-5 "Specific Guidelines for the LMR and HTGR Cost Estimates", ORNL Letter Report submitted for review with Reference 3 above.

5-6 "FY-84 Unit Handling and Resource Cost Assumptions for Fuel Cycle Evaluations", Document 907521, June 1984.

5-7 Bowers, H. I., "Cost Estimating Methods for Modular HTGR Operation and Maintenance", ORNL Letter Report, Ju1y 31, 1986.

7-1 Letter Report, T. M. Sweeney (BNI) to H. Gotschall (GCRA), "Construction, Fabrication and Preassembly Report for the Standard MHTGR", september 30, 1986.

8-2 "Seismic Design Criteria for the Reactor Core", Letter GEN-GA/ C-E:008:SJB:86, S. J. Brown (GA Technologies, Inc.) to S.A. Caspersson (Combustion Engineering, Inc.), dated January 21, 1986.

8-3 "Recommendations for Modified Reactor Vessel Design to Reduce Core Seismic Loads", Letter GA/M-050-86, G. C. Bramblett (GA Technologies, Inc.) to F. G. Small (Combustion Engineering, Inc.) and T. M. Sweeney (Bechtel National, Inc.), dated June 9, 1986.

8-5 "Safety Goals for the Operation of Nuclear Power P1ants", U.S. NRC (Policy Statement for 10CFR50; Federal Register, Volume 51, No. 149), August 4, 1986.

8-6 "Manual of Protective Action Guides and Protective Actions for Nuclear Incidents", EPA-510/1-75-001, United States Environmental Protection Agency, September, 1975. 


\section{REFERENCES (Cont'd)}

Reference

Number

8-8 "Reactor Safety Study", WASH 1400, Appendix VI, pages 8-33, 8-34, and 8-37.

8-9 "Safety Goals for Nuclear Power Plants: A Discussion Paper", NUREG-0880, U.S. NRC, February 1982.

8-10 "Planning Basis for Development of State and Local Government Radiological Emergency Response Plans in Support of Light Water Nuclear Power Plants", NUREG-0396, NRC-APE Task Force on Emergency Planning, November 1978.

8-11 "Safety Goals for Nuclear Power Plant Operation", NUREG-0880 (Revision 1), U.S., NRC, May 1983. 